UNIVERSIDAD DE GRANADA

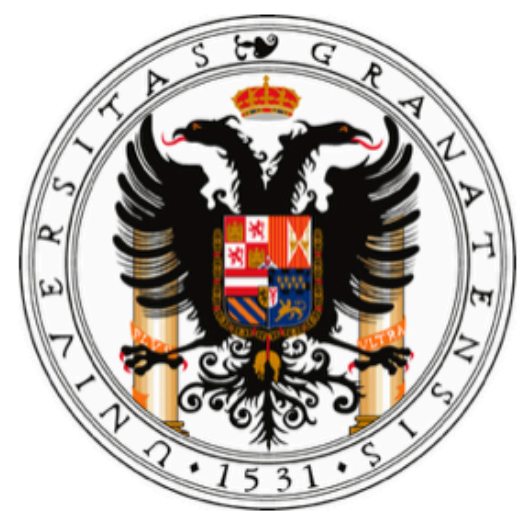

MÁSTER DE ENTRENAMIENTO PERSONAL

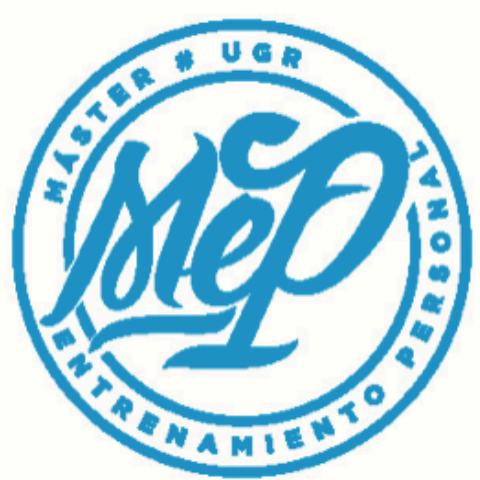

Trabajo Fin de Máster

\title{
PLAN DE ENTRENAMIENTO ORIENTADO A LA PREVENCIÓN DELESIONESEN FÚTBOL
}

Autor: Fidel Muñoz Molina

Tutor: Carlos Vallés Ortega 

No te rindas, por favor no cedas, aunque el frío queme, aunque el miedo muerda, aunque el sol se esconda, y se calle el viento, aún hay fuego en tu alma, aún hay vida en tus sueños, porque la vida es tuya y tuyo también el deseo, porque cada día es un comienzo nuevo, porque esta es la hora y el mejor momento, porque no estás sola, ¡Porque yo te quiero!

Mario Benedetti

A mis hijas Elena y Paula, que en este momento no entenderán mis palabras. Os dedico más de un año de esfuerzo y trabajo duro. Aunque sé que mi trabajo más importante es con vosotras y espero estar a la altura.

Os aseguro que pondré todo mi empeño en inculcaros el valor del esfuerzo, la superación, el respeto, el cuidado de las cosas, el orden, la tolerancia, la empatía, el amor a los demás y a vosotras mismas,... Y que intentaré que siempre seáis felices, como lo sois ahora.

A Cristi... mi mujer, mi compañera, mi amiga, mi apoyo, mi fuerza,... mi TODO. 


\section{AGRADECIMIENTOS}

Me gustaría dejar constancia de mi agradecimiento a aquéllas personas que han contribuido a que este trabajo sea una realidad. En especial:

A mi tutor Carlos Vallés, por sus revisiones, sus aportaciones, sus palabras de ánimo cada vez que ha surgido un problema y por implicarse más de lo que se le pedía.

A Fernando García, fisioterapeuta, por ayudarme en las evaluaciones en su tiempo libre, por mantenerme al tanto del estado del jugador y por soportar mi insistencia en algunos momentos.

A Dioni González, responsable de los servicios médicos, por la confianza que ha tenido en mí y en mi trabajo antes siquiera de empezar y por abrirme las puertas del Club.

A Francisco Javier Fernández Navarro, por ayudarme con el uso del gestor bibliográfico y por su disponibilidad cuando he necesitado su ayuda.

A Antonio López, compañero de promoción del Máster y Entrenador Personal, por sus desinteresados y valiosos consejos y orientaciones sobre la disquinesia escapular.

A mi hermano Jose, mi referencia en cuanto a rigor, orden y perfección en lo académico, por las charlas y consejos sobre formato y por resolverme cualquier duda o problema que le he planteado con premura y eficacia.

A mi hermano David, un ejemplo de constancia, por sus cariñosos consejos que no siempre he sabido entender pero que nunca he dejado de apreciar.

A mis padres, Pepe y Dori, por la educación que me han dado, por inculcarme el valor del respeto, el esfuerzo y la responsabilidad, por permitirme crecer en un entorno sano y lleno de amor. A mi padre por ser exigente conmigo y no permitir que me acomodase nunca. A mi madre por renunciar a sus sueños por darnos la mejor educación que ha sabido a mis hermanos y a mí. Es inútil tratar de expresar mi agradecimiento porque no existen palabras tan grandes.

A mi mujer, Cristi, por darme su tiempo libre para que yo pudiese leer y escribir, por hacer todo aquello que no he hecho yo mientras estaba estudiando, por su infinita paciencia cuando yo perdía la mía o estaba cansado, por aguantar con una sonrisa mis monotemáticas conversaciones, por ser mi modelo de vida, por hacerme mejor persona, por haberme dado lo más maravilloso que tengo en la vida, por cuidar de mi y de nuestras pequeñas y porque, sin ella, no habría sido capaz ni tan siquiera de empezar este trabajo. 


\section{ÍNDICE DE CONTENIDOS}

1. CONTEXTUALIZACIÓN

1.1 Descripción, situación y propósito del cliente: Resultados de la Entrevista Inicial.........

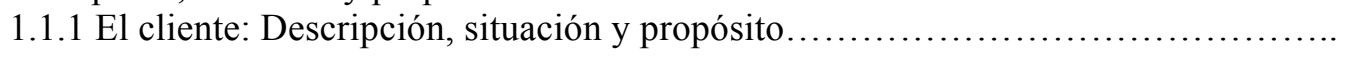

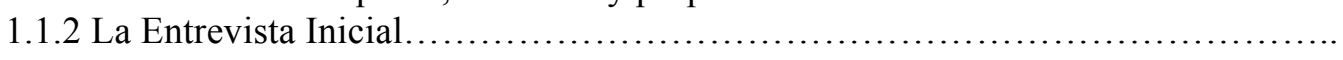

1.1.2.1 Objetivos.

1.1.2.2 Resultados.

1.2 Recursos Materiales, Espaciales, Temporales y Humanos................................ 2

1.2.1 Recursos Temporales..................................................... 2

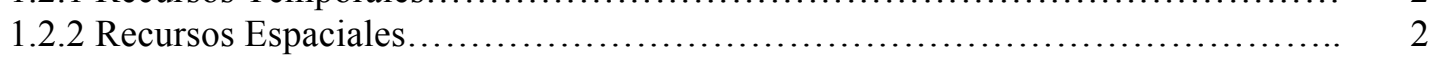

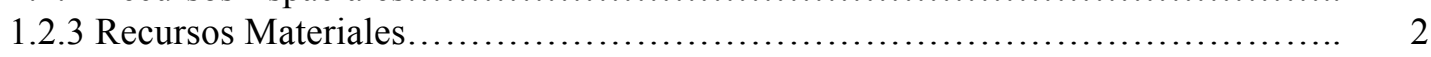

1.2.4 Recursos Humanos..................................................... 3

1.3 Aspectos Éticos, Legales y Jurídicos.......................................... 3

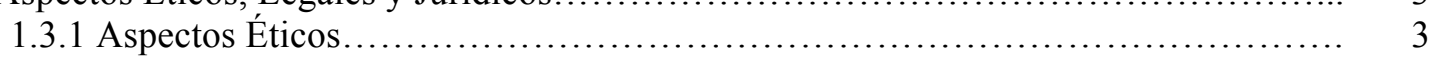

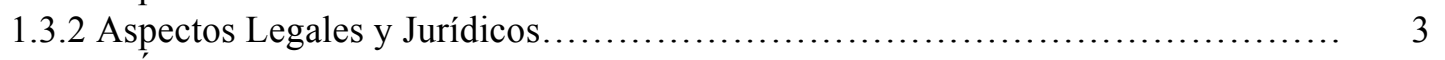

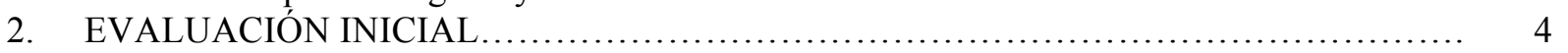

2.1 ¿Qué evalúo? Justificación de los contenidos a evaluar................................ 4

2.2 ¿Cómo evalúo? Herramientas de evaluación....................................... 7

2.3 ¿Qué datos he obtenido? Resultados de la evaluación................................ 20

2.3.1 Resultados de los Tests de Flexibilidad y ROM..................................... 20

2.3.2 Resultados de los Tests de Fuerza Analíticos.................................... 21

2.3.3 Resultados del SEBT Modificado ...................................................... 21

2.3.4 Resultados de la Valoración Postural Estática.......................................... 21

2.3.5 Resultados de los Tests de Valoración Dinámica................................ 22

2.3.6 Resultados del Cuestionario de Dolor Lumbar.................................... 22

2.3.7 Resultados de los Tests de Control Motor del Complejo Coxolumbopélvico........ 22

2.3.8 Resultados del Cuestionario de Perfil Psicológico.................................. 23

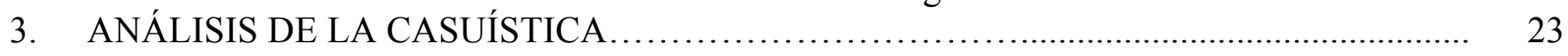

3.1 Marco Teórico: Información Necesaria para la Interpretación de la Evaluación Inicial.... 23

3.1.1 Introducción................................................................................. 23

3.1.1.1 Características generales del fútbol y consecuencias de las lesiones......... 23

3.1.1.2 Justificación de la estructura del Marco Teórico......................... 24

3.1.1.3 Conceptos básicos de Epidemiología................................... 24

3.1.1.3.1 A nivel general...................................................... 24

3.1.1.3.2 Referidos a Lesiones Musculares.................................... 26

3.1.1.3.3 Referidos a Lesiones en la zona Inguinal........................ 26

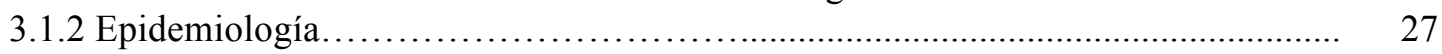

3.1.2.1 Tipos de Lesiones................................................................. 27

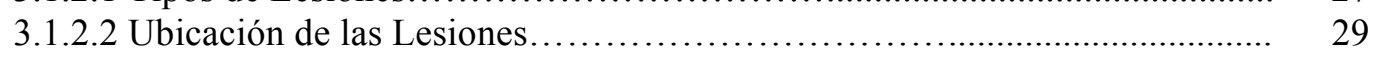

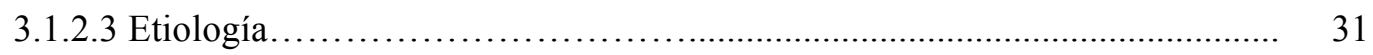

3.1.2.4 Gravedad de las Lesiones..................................................... 31

3.1.2.5 Actividad realizada y momento en el que se producen....................... 32

3.1.2.6 Lesiones Recurrentes............................................................ 33

3.1.2.7 Lesiones y Posiciones de Juego............................................. 33

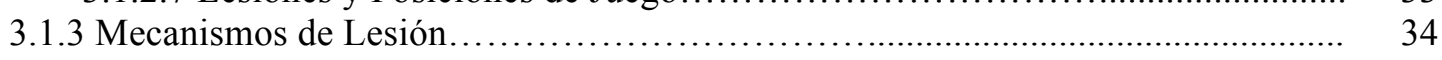

3.1.3.1 Esguinces de Tobillo............................................................ 35

3.1.3.2 Ligamento Cruzado Anterior................................................ 35

3.1.3.3 Desgarros en Cuádriceps....................................................... 37

3.1.3.4 Desgarros en Isquiosurales..................................................... 38

3.1.3.5 Desgarros en Aductor........................................................ 38

3.1.4 Factores de Riesgo........................................................................ 38

3.1.4.1 Lesión Previa como Factor de Riesgo........................................... $\quad 40$

3.1.4.2 La Fatiga como Factor de Riesgo......................................... 40

3.1.4.3 El Desequilibrio Muscular como Factor de Riesgo...................... 41 
3.1.4.4 La Carga de Entrenamiento como Factor de Riesgo........................

3.1.4.5 Las Variables Psicológicas como Factor de Riesgo..........................

3.1.4.6 Factores de Riesgo para las lesiones abordadas en el trabajo................. 3.1.4.6.1 Factores de Riesgo en Esguinces de Tobillo............................. 3.1.4.6.2 Factores de Riesgo en Esguinces de Rodilla y LCA...................

3.1.4.6.3 Factores de Riesgo en Lesiones de Cuádriceps.......................

3.1.4.6.4 Factores de Riesgo en Lesiones de Isquiosurales.....................

3.1.4.6.5 Factores de Riesgo en Lesiones de Aductor........................

3.1.5 Dolor Lumbar.

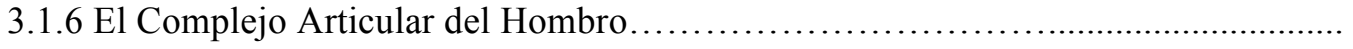

3.1.7 Lesión de Recto Anterior................................................................ 47

3.2 Interpretación de los Datos obtenidos en la Evaluación Inicial........................ 48

3.2.1 Interpretación de los Datos de los Tests de Flexibilidad y ROM.................. 48

3.2.2 Interpretación de los Datos de los Tests de Fuerza Analítica...................... 49

3.2.3 Interpretación de los Datos del SEBT Modificado.............................. 50

3.2.4 Interpretación de la Valoración Postural Estática............................ 50

3.2.5 Interpretación de la Valoración Postural Dinámica............................. 51

3.2.6 Interpretación de los Datos del Cuestionario de Dolor Lumbar................... 51

3.2.7 Interpretación de los Tests de Control Motor del Complejo Coxolumbopélvico.... 51

3.2.8 Interpretación de los Datos del Cuestionario de Perfil Psicológico................ 52

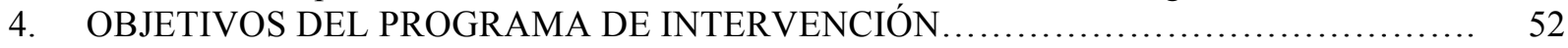

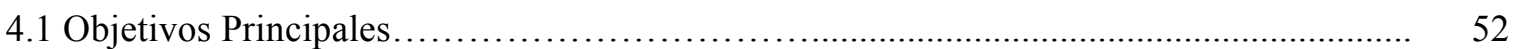

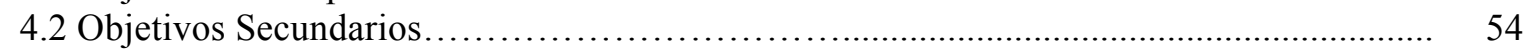

4.3 Informe Personalizado para el Jugador...................................................... 54

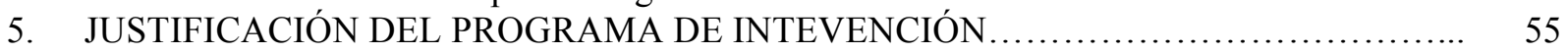

5.1 Justificación del Trabajo Excéntrico.......................................................... 58

5.2 Justificación del Trabajo de Fuerza.......................................................... $\quad 60$

5.3 Justificación del Trabajo de CORE o de Estabilización Coxolumbopélvica............... 60

5.4 Justificación del Trabajo Propioceptivo........................................................... 62

5.5 Justificación del Trabajo para la Mejora del ROM................................. 63

5.6 Justificación del Trabajo del Complejo Articular del Hombro.......................... 65

5.7 Justificación del Control de la Carga de Entrenamiento............................... 65

5.8 Justificación de la utilización de Medios de Recuperación............................ 66

5.9 Justificación de la Liberación Miofascial........................................... 68

5.10 Justificación del Control del dolor y otras variables subjetivas...................... 69

5.11 Justificación de la Readaptación de la Lesión de Recto Anterior....................... 69

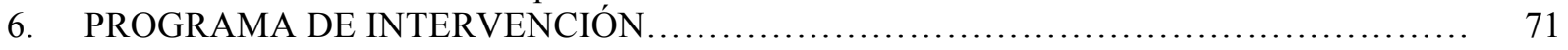

6.1 Secuenciación de las Fases de Entrenamiento del programa de intervención.............. 71

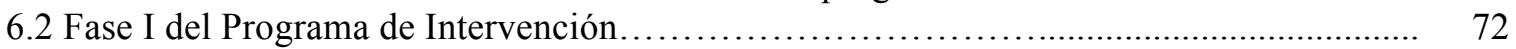

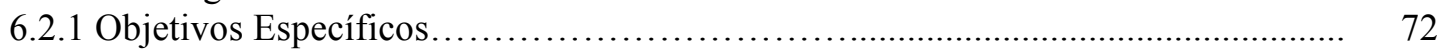

6.2.2 Metodología............................................................................... $\quad 73$

6.2.2.1 Metodología empleada en los Calentamientos y la Vuelta a la Calma........ 73

6.2.2.2 Estructura e Intensidad de la Sesión.................................... 73

6.2.2.3 Metodología del Entrenamiento para la reeducación del patrón de $\quad 74$

activación de la musculatura periescapular....................................

6.2.2.4 Metodología del Entrenamiento Propioceptivo............................ 75

6.2.2.5 Metodología del Trabajo de la Región Coxolumbopélvica.................. 76

6.2.2.6 Metodología del Trabajo de Flexibilidad y ROM......................... 77

6.2.2.7 Metodología para el Trabajo Miofascial............................. 78

6.2.2.8 Metodología para el Aprendizaje de los Patrones Básicos de Movimiento... 78

6.2.3 Secuenciación de Contenidos........................................................ $\quad 79$

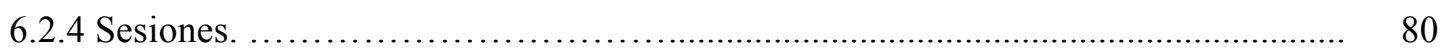

6.2.5 Control / Monitorización del Entrenamiento...................................... 85

6.2.5.1 Control de la Carga de Entrenamiento...................................... 85

6.2.5.2 Control del Volumen de Entrenamiento........................................ 86

6.2.5.3 Control de la Escala de Bienestar................................................ 86 
6.2.5.4 Control del Dolor Lumbar.

6.2.5.5 Reflexión sobre lo planificado en la Fase I............................... 87

6.2.6 Evaluación del Progreso............................................................... 88

6.3 Fase II del Programa de Intervención.................................................... 89

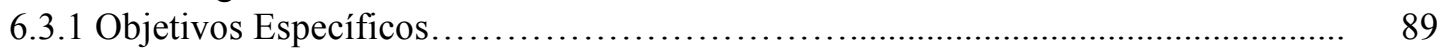

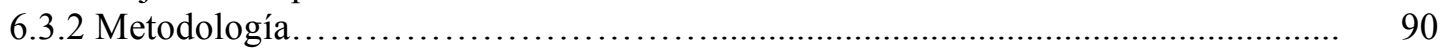

6.3.2.1 Estructura e Intensidad de la Sesión........................................ 90

6.3.2.2 Metodología empleada en los Calentamientos y la Vuelta a la Calma....... 91

6.3.2.3 Metodología del Entrenamiento para la reeducación del patrón de $\quad 91$

activación de la musculatura periescapular....................................

6.3.2.4 Metodología del Entrenamiento Propioceptivo.......................... 91

6.3.2.5 Metodología del Trabajo de la Región Coxolumbopélvica................. 92

6.3.2.6 Metodología del Trabajo de Flexibilidad y ROM........................ 92

6.3.2.7 Metodología para el Trabajo Miofascial. .................................. 93

6.3.2.8 Metodología para el Trabajo Excéntrico................................... 93

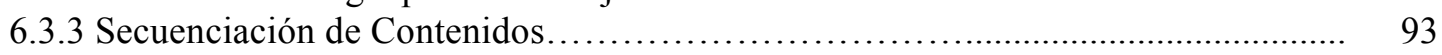

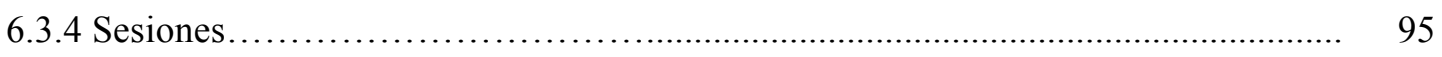

6.3.5 Control / Monitorización del Entrenamiento........................................... 99

6.3.5.1 Control de la Carga de Entrenamiento........................................ 99

6.3.5.2 Control del Volumen de Entrenamiento..................................... 99

6.3.5.3 Control de la Escala de Bienestar............................................. 99

6.3.5.4 Control del Dolor Lumbar...................................................... 100

6.3.5.5 Reflexión sobre lo planificado en la Fase II.............................. 100

6.3.6 Evaluación del Progreso................................................................. 100

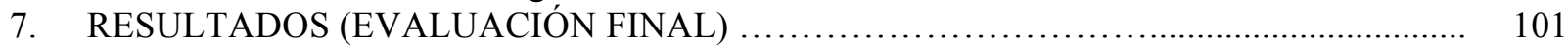

7.1 Resultados de los Tests de Flexibilidad y ROM.......................................... 101

7.2 Resultados de los Tests de Fuerza Analíticos................................................ 102

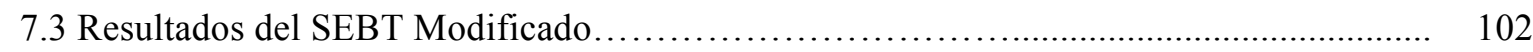

7.4 Resultados de la Valoración Postural Estática.................................................. 102

7.5 Resultados de los Tests de Valoración Dinámica................................... 103

7.6 Resultados del Cuestionario de Dolor Lumbar....................................... 103

7.7 Resultados de los Tests de Control Motor del Complejo Coxolubopélvico................ 103

7.8 Resultados del Cuestionario de Perfil Psicológico..................................... 103

7.9 Informe Personalizado para el Jugador........................................... 104

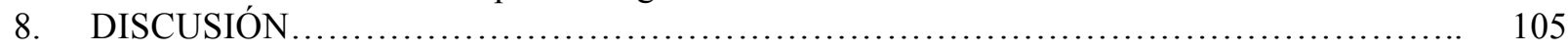

8.1 Discusión del grado de consecución de los Objetivos planteados y posibles causas........ 105

8.1.1 Discusión de los Resultados de los Tests de Flexibilidad y ROM................. 105

8.1.2 Discusión de los Resultados de los Tests de Fuerza Analítica..................... 106

8.1.3 Discusión de los Resultados del SEBT Modificado............................... 106

8.1.4 Discusión de los Resultados de la Valoración Postural Estática.................... 106

8.1.5 Discusión de los Resultados de los Tests de Valoración Dinámica................. 107

8.1.6 Discusión sobre los Resultados de los Patrones de Movimiento.................... 107

8.1.7 Discusión de los Resultados del Cuestionario de Dolor Lumbar................... 107

8.1.8 Discusión de los Resultados de los Tests de Control Motor del Complejo 107

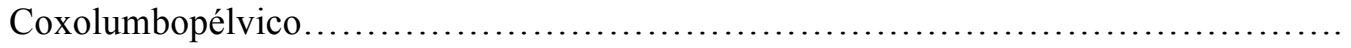

8.1.9 Discusión de los Resultados del Cuestionario de Perfil Psicológico.................. 108

8.1.10 Discusión sobre los Resultados de Dolor de Hombro........................... 108

8.2 Puntos Fuertes y Débiles del Programa de Intervención.............................. 108

8.3 Limitaciones y Dificultades......................................................... 109

8.4 Posibles Soluciones y Alternativas............................................... 110

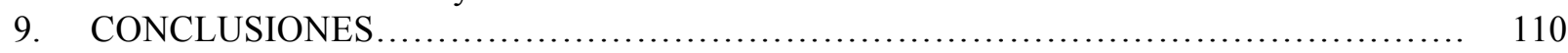

9.1 Grado de Consecución de los Objetivos planteados y causas más importantes............ 110

9.2 Conclusiones personales sobre el trabajo y aspectos a mejorar en futuras intervenciones.. 111

10. LÍNEAS FUTURAS DE INTERVENCIÓN ................................................ 111

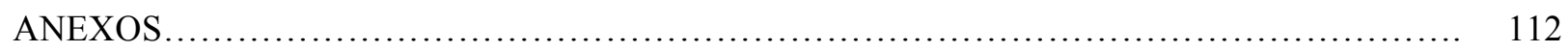

ANEXO I: Datos Personales y Deportivos. Historial de Lesiones........................ 113 
ANEXO II: Contrato de Prestación de Servicios de Entrenamiento Personal................. 115

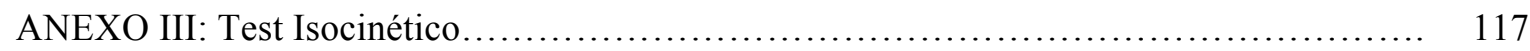

ANEXO IV: Valoración de la Disquinesia Escapular.................................. 118

ANEXO V: Valoración del Landing Error Scoring System (LESS) ...................... 119

ANEXO VI: Valoración del Tuck Jump Test....................................... 121

ANEXO VII: Índice de Discapacidad de Oswestry.................................... 122

ANEXO VIII: Cuestionario de "Características Psicológicas relacionadas con el 124

Rendimiento Deportivo en Fútbol" $\ldots \ldots \ldots \ldots \ldots \ldots \ldots \ldots \ldots \ldots \ldots \ldots \ldots \ldots \ldots \ldots \ldots \ldots \ldots \ldots \ldots \ldots \ldots \ldots \ldots \ldots \ldots \ldots \ldots \ldots \ldots \ldots \ldots \ldots \ldots \ldots \ldots$
ANEXO IX: Entidades Clínicas para el Dolor Inguinal $\ldots \ldots \ldots \ldots \ldots \ldots \ldots \ldots$

ANEXO X: Pautas Metodológicas para el Entrenamiento de la Fuerza.................... 128

BIBLIOGRAFÍA............................................................ 129 


\section{ÍNDICE DE FIGURAS}

Figura 1. Imagen de algunos materiales.............................................. 2

Figura 2. Montaje de las 3 cámaras para la evaluación.................................................. 6

Figura 3. Deficiencias iniciales observadas en el Single Leg Squat. Visión Anterior............. 22

Figura 4. Deficiencias iniciales observadas en el Single Leg Squat. Visión Anterior............... 22

Figura 5. Deficiencias iniciales observadas en el Single Leg Squat. Visión Lateral................ 22

Figura 6. Deficiencias iniciales observadas en el Single Leg Squat. Visión Posterior............. 22

Figura 7. Deficiencias iniciales observadas en el Single Leg Squat. Visión Posterior............ 22

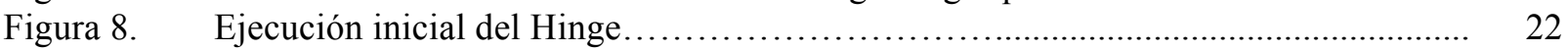

Figura 9. Ejecución inicial del Forward Bending.............................................................. 23

Figura 10. Ejecución inicial del Sitting Knee Extension...................................................... 23

Figura 11. Ejecución inicial del One Leg Stance.................................................................. 23

Figura 12. Ejecución inicial del Prone Lying Active Knee Flexion........................... 23

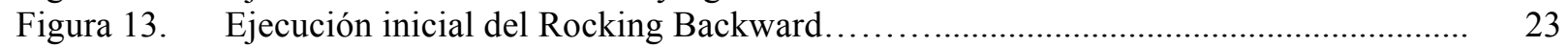

Figura 14. Entidades clínicas definidas para el dolor inguinal................................................... 26

Figura 15. Matriz de riesgo de la Liga de Campeones en la que se ilustra la gravedad / 27

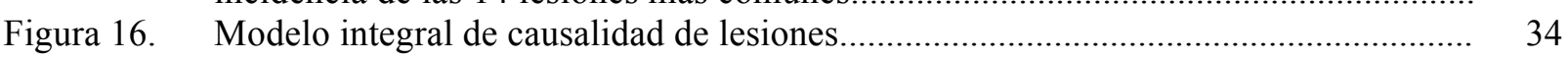

Figura 17. Golpe medial que provoca inversión de tobillo y posible esguince.................. 35

Figura 18. Posible esguince de tobillo por flexión plantar forzada.......................... 35

Figura 19. Mecanismos de lesión de LCA: Acoso al poseedor de balón..................... 36

Figura 20. Mecanismos de lesión de LCA: Despeje................................................................. 36

Figura 21. Mecanismos de lesión de LCA: Recepción de salto................................................. 36

Figura 22. Mecanismos de lesión de LCA: Tackle por detrás.................................................. 36

Figura 23. Fases del Swing durante el golpeo de balón............................................................. 37

Figura 24. Relación entre los factores extrínsecos y la asociación o no con la aparición de una 39

Figura 25. Relación entre los factores intrínsecos y la asociación o no con la aparición de una lesión.

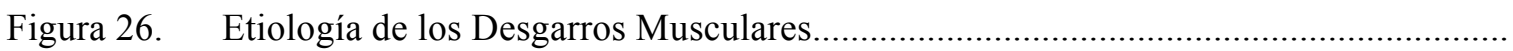

Figura 27.

Figura 28.

Figura 29.

Figura 30.

Figura 31.

Figura 32.

Figura 33.

Figura 34 .

Aleteo y elevación de escápula izquierda....

(1)

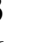

Ejecución del Biering Sorensen Modificado........................................... $\quad 50$

Ejecución del Side Bridge............................................................................. 50

Ejecución del Trunk Flexor Endurance Test............................................................ $\quad 50$

Realización del SEBT Modificado........................................................................... 50

Recepción del salto (sin valgo) en LESS, previo a salto vertical..................... 51

Salto en Tuck Jump Test .............................................................................. 51

Recepción (sin valgo) en Tuck Jump Test.............................................................. 51

Figura 35. Modelo Causa - Efecto para la lesión de Isquiosurales................................................. 56

Figura 36. Nuevo Modelo Conceptual para la lesión de Isquiosurales......................................... 56

Figura 37. Percepción de los Fisioterapeutas de la importancia de la conformidad del 56

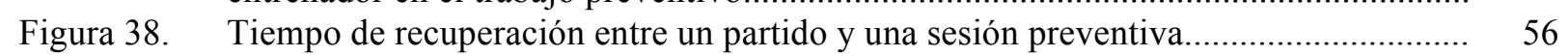

Figura 39. Tiempo de recuperación entre 2 sesiones preventivas.................................................. 56

Figura 40. Tiempo de recuperación entre 1 sesión de fuerza de tren inferior y 1 preventiva...... 56

Figura 41. Ejercicios con los que los entrenadores pueden estar más conformes para 57

Figura 42. 5 tipos de ejercicios más utilizados para prevenir lesiones por los equipos de primer nivel.

Figura 43. Herramientas de monitorización más utilizadas por las selecciones nacionales.......... 57

Figura 44. Frecuencia de sesiones preventivas en equipos de primer nivel..................... 57

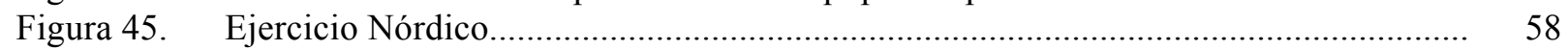

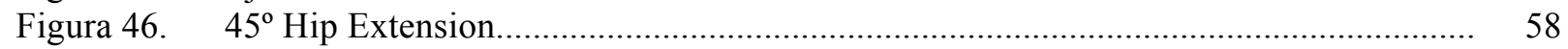

Figura 47. Medios para el trabajo propioceptivo: 1) BOSU; 2) Plataforma de Equilibrio; 3) 62 
Disco; 4) Trampolín.

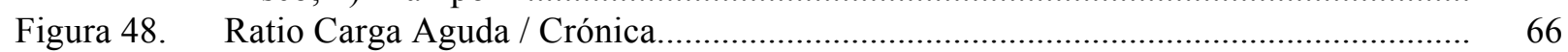

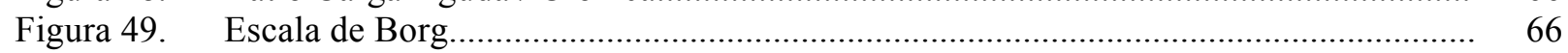

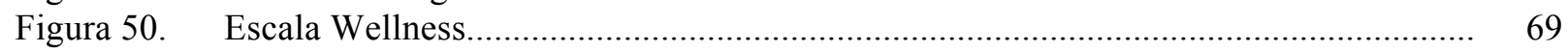

Figura 51. Calendario de Entrenamientos del Jugador.................................................................. 72

Figura 52. Carga de Entrenamiento Aguda:Crónica durante la Fase I......................... 86

Figura 53. Carga de Entrenamiento en mis sesiones de Entrenamiento Personal de la Fase I..... 86

Figura 54. Valores de la Escala Wellness durante la Fase I.................................................... 87

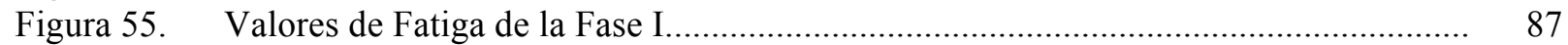

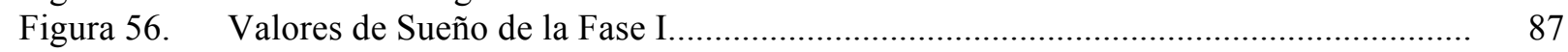

Figura 57. Valores de Dolor Muscular de la Fase I.................................................................. 87

Figura 58. Valores de Estrés de la Fase I.................................................................................... 87

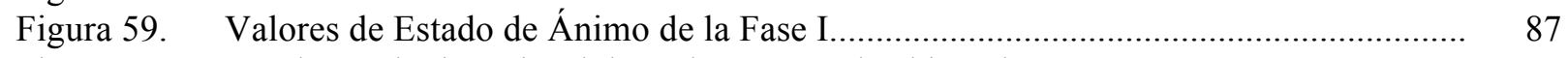

Figura 60. Escala Analógica Visual de Dolor entregada al jugador.......................... 87

Figura 61. Percepción de Dolor Lumbar durante la Fase I...................................................... 87

Figura 62. Carga de Entrenamiento Aguda:Crónica durante la Fase II....................... 99

Figura 63. Carga de Entrenamiento en mis sesiones de Entrenamiento Personal de la Fase II... 99

Figura 64. Valores de la Escala Wellness durante la Fase II...................................................... 100

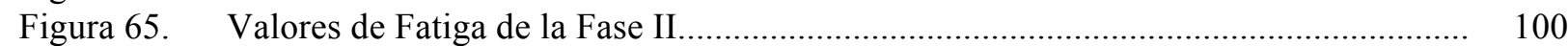

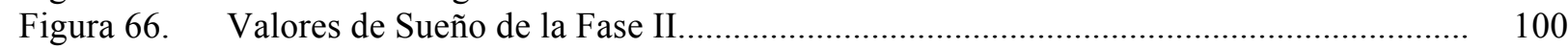

Figura 67. Valores de Dolor Muscular de la Fase II............................................................... 100

Figura 68. Valores de Estrés de la Fase II................................................................................ 100

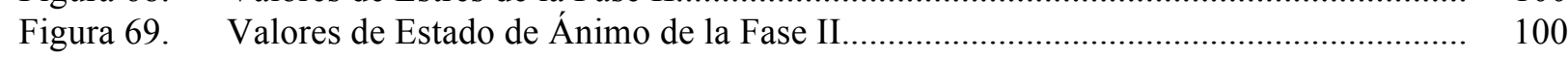

Figura 70. Percepción de Dolor Lumbar durante la Fase II......................................................... 100

Figura 71. Comparación de la Evaluación Inicial y Final del Single Leg Squat. Visión Frontal.. 103

Figura 72. Comparación de la Evaluación Inicial y Final del Single Leg Squat. Visión Frontal.. 103

Figura 73. Comparación de la Evaluación Inicial y Final del Single Leg Squat. Visión Lateral... 103

Figura 74. Evaluación Final Disquinesia Escapular...................................... 106 


\section{ÍNDICE DE TABLAS}

Tabla 1. Materiales utilizados en el Plan de Intervención.................................... 2

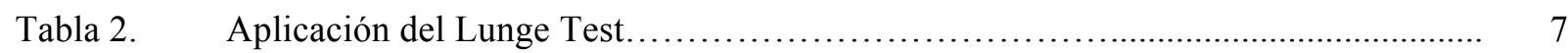

Tabla 3.

Tabla 4.

Tabla 5.

Tabla 6.

Tabla 7.

Tabla 8.

Tabla 9.

Tabla 10.

Tabla 11.

Tabla 12.

Tabla 13.

Tabla 14.

Tabla 15.

Tabla 16.

Tabla 17.

Tabla 18.

Tabla 19.

Tabla 20.

Tabla 21.

Tabla 22.

Tabla 23.

Tabla 24.

Tabla 25.

Tabla 26.

Tabla 27.

Tabla 28.

Tabla 29.

Aplicación del KEA Test.

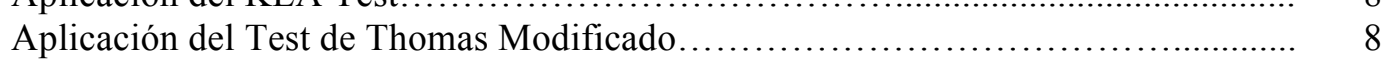

Aplicación del Test de Ober Modificado .............................................. 8

Aplicación del Hip Internal Rotation................................................... 9

Aplicación del Hip External Rotation................................................. 9

Aplicación del Passive Hip Flexion Test................................................ 10

Aplicación del Passive Hip Extension Test........................................... 10

Aplicación del Passive Hip Abduction Test.......................................... 10

Aplicación del Passive Hip Adduction Test......................................... $\quad 10$

Aplicación del Shoulder Flexion............................................................. 11

Aplicación del Shoulder Internal Rotation Range of Motion........................ 11

Aplicación del Shoulder External Rotation Range of Motion...................... 12

Aplicación del Posterior Shoulder Flexibility Test............................... 12

Aplicación del Test de Longitud del Pectoral Menor............................... 12

Aplicación del Eccentric Hip Adduction............................................. 13

Aplicación del Eccentric Hip Abduction......................................... 13

Aplicación del Squeeze Test.............................................................. 14

Aplicación del Biering Sorensen Modificado.......................................... 14

Aplicación del Side Bridge Test....................................................... 14

Aplicación del Trunk Flexor Endurance Test......................................... 15

Aplicación del Scapular Dyskinesis Test.............................................. 15

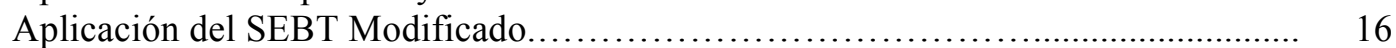

Aplicación del Single Leg Squat....................................................... 17

Aplicación del Landing Error Scoring System (LESS)........................... 17

Aplicación del Tuck Jump Test........................................................ 18

Aplicación del Índice de Discapacidad de Oswestry.............................. 19

Aplicación del Cuestionario CPRD adaptado al Fútbol........................... 20

Tabla 30. Datos de referencia, resultados iniciales y persona que realiza y propone los tests de

Flexibilidad y ROM.

Datos de referencia, resultados iniciales y persona que realiza y propone los tests de

Tabla 31.

Fuerza Analíticos

Datos de referencia, resultados iniciales y persona que realiza y propone el Test

Tabla 32.

SEBT Modificado.

Tabla 33.

Resultados iniciales de la Valoración Postural Estática...

Datos de referencia, resultados iniciales y persona que realiza y propone los Test de

Tabla 34. Valoración Dinámica.

Tabla 35. Resultados iniciales del Cuestionario de Discapacidad de Oswestry..................

Tabla 36.

Tabla 37.

Tabla 38.

Tabla 39.

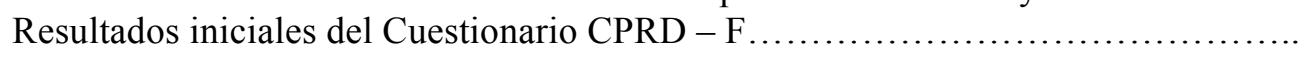

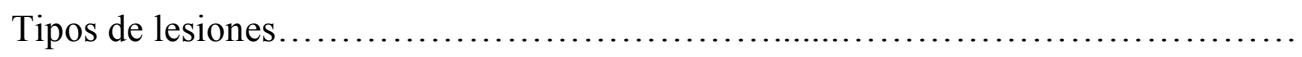

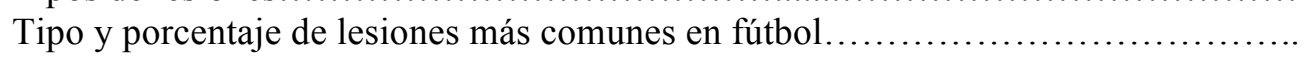

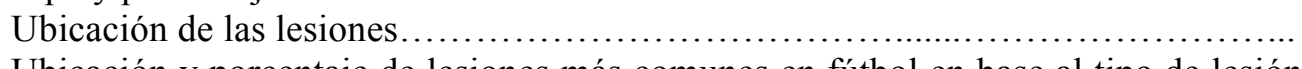

Tabla 40.

Ubicación y porcentaje de lesiones más comunes en fútbol en base al tipo de lesión descrita.

Tabla 41.

Gravedad de lesiones más comunes en fútbol en base al tipo de lesión descrita.........

Tabla 42.

Actividad realizada y momento en el que se producen las lesiones más comunes en fútbol en base al tipo de lesión descrita.

Principales Factores de Riesgo reflejados por servicios médicos de Equipos de

Tabla 43. Máximo Nivel....

Tabla 44.

Factores de Riesgo en Esguinces de Tobillo. 
Factors

Factores de Riesgo en Lesiones en Aductor.

Tabla 53.

Secuenciación de los Contenidos de la Fase 1 del Programa de Intervención y relación con Objetivos.

Tabla 54. Sesión de Entrenamiento n ${ }^{\circ} 1$

Secuenciación de Contenidos de las 3 primeras semanas de la Fase 1I del Programa

Tabla 63. de Intervención y relación con Objetivos.

Secuenciación de Contenidos de las 3 últimas semanas de la Fase 1I del Programa

Tabla 64. de Intervención y relación con Objetivos.

Tabla 65. Sesión de Entrenamiento n ${ }^{\circ} 13$.

Tabla 66.

Sesión de Entrenamiento $\mathrm{n}^{\mathrm{o}} 19$.

Tabla 67.

Sesión de Entrenamiento $n^{\circ} 21$

Tabla 68.

Tabla 69.

Sesión de Entrenamiento $n^{\circ} 23$.

Grado de consecución de los Objeti.................................................

Tabla 70.

Tabla 71.

Tabla 72.

Comparación entre la Evaluación Inicial y Final en los tests de Flexibilidad y ROM.

Comparación entre la Evaluación Inicial y Final en los tests de Fuerza Analíticos....

Comparación entre la Evaluación Inicial y Final en el Test SEBT Modificado..........

Tabla 73.

Resultados Finales de la Valoración Postural Estática...

Tabla 74. Dinámica. Informe Personalizado. Comparación de los Resultados de la Evaluación Inicial y

Tabla 78. Final. 


\section{1-. CONTEXTUALIZACIÓN}

“El principio es la mitad del todo"

Pitágoras de Samos, filósofo griego (570 AC - 469 AC)

\subsection{Descripción, situación y propósito del cliente: Resultados de la entrevista inicial.}

\subsubsection{El cliente: Descripción, situación y propósito}

El presente trabajo se llevará a cabo con un jugador profesional de fútbol, que ocupa la demarcación de Portero. Es importante señalar que ha habido un cambio de sujeto. A finales de 2018 los responsables médicos del club me asignaron un portero con años de contrato. La intención era que fuese un sujeto "estable", con ciertas garantías de continuar durante varias temporadas. Pero a principios de Julio el propio jugador me informó que era probable una salida del club y me pidió discreción para hablar con cualquier miembro del cuerpo técnico, y así lo hice. 3 semanas después se confirma la salida y, a primeros de Agosto el club me asigna otro sujeto.

En el fútbol la competencia es muy alta y llegar a la élite no es fácil. La suerte es un factor a tener en cuenta, pero además hay aspectos que están en la mano del jugador (llevar una vida sana, entrenar con plena conciencia y máxima concentración e intensidad,...) y otros que no, como son las lesiones. Actualmente se encuentra "activo", no padeciendo ninguna lesión que le impida competir o entrenar. Sin embargo, dada la gran cantidad de lesiones que se producen en el fútbol (1-4), su intención es mantener ese estado durante el mayor tiempo posible. Su propósito es sumar el mayor número de minutos y mejorar todo lo posible esta temporada, siempre con vistas a convertirse en un jugador de máximo nivel, para lo cual es necesario estar en condiciones de entrenar y competir. Por confidencialidad de datos (Ley Orgánica $3 / 2018^{1}$ ) no se indicará su nombre ni ningún dato que pueda identificarlo.

Es un jugador joven, que ha competido al máximo nivel en categoría juvenil y ahora forma parte de un equipo profesional. No es granadino pero este es su tercer año en el club. Actualmente vive solo en Granada. En el momento de empezar a trabajar con el jugador acaba de terminar su pretemporada, realizando 4-5 sesiones matinales y 2-4 por la tarde cada semana. Por lo que nos encontramos un sujeto muy activo a nivel de actividad física y en plena forma a nivel condicional. Durante todo el trabajo no me referiré a él como "cliente" sino como "futbolista" o "jugador", para huir de una concepción monetaria y porque la relación entre un entrenador personal y un jugador de fútbol debe ser cercana y estrecha.

\subsubsection{La Entrevista Inicial}

\subsubsection{Objetivos}

Nuestro principal objetivo, como entrenadores personales, es adaptarnos lo máximo posible a la persona con la que estamos trabajando, dando solución a cada uno de los imprevistos que surjan durante el proceso de entrenamiento. Para ello es necesario, e incluso obligado, realizar una entrevista inicial o anamnesis que vamos a utilizar para alcanzar los siguientes objetivos:

- Presentarnos al jugador. Transmitirle confianza y seguridad, que vea que va a trabajar con una persona con experiencia y que puede ayudarle a alcanzar sus objetivos.

- Conocer al jugador:

- Datos personales y deportivos.

- Historial de Lesiones.

- Resultados de valoraciones previas, si las hubiese.

- Definir los objetivos que guiarán el proceso de entrenamiento y conocer su disponibilidad.

- Informar al jugador sobre nuestra actuación:

- Estructura del Trabajo Fin de Máster (TFM).

- Periodo de trabajo (Agosto - Noviembre).

\footnotetext{
${ }^{1}$ Ley Orgánica 3/2018, de 5 de Diciembre, de Protección de Datos Personales y Garantía de los Derechos Digitales)
} 
- Aspectos legales (confidencialidad de datos y fotos).

- Contrato Entrenador - Jugador.

\subsubsection{Resultados}

Debido al cambio precipitado de sujeto, y que justo cuando supe con quién iba a trabajar el jugador se marchó una semana de concentración con su equipo y no había mucho margen de tiempo para realizar las 12 semanas, la entrevista se envió por correo al jugador (ver Anexo I) y se completó con cuestiones por teléfono. De todo ello podemos concluir:

- El jugador tiene disponibilidad e interés para entrenar cualquier tarde que creamos oportuno (obviamente en base a la planificación de su equipo).

- El único objetivo que quiere alcanzar con este programa es reducir el riesgo de lesión.

- Tiene molestias en zona lumbar al finalizar partidos y entrenamientos desde hace tres años y en hombro derecho (dominante) al realizar algunos movimientos.

- Tuvo una tendinosis en el tendón rotuliano hace 3 años de la que está totalmente recuperado y no refiere ni molestia ni sintomatología alguna.

- Fuera del entrenamiento su vida es sedentaria, no realiza otro tipo de actividad.

- Lleva una alimentación sana. Él mismo se prepara la comida, salvo el desayuno que lo hace en la Ciudad Deportiva, en base a una dieta de un nutricionista. Evita los fritos y procura tener una ingesta variada. También le da importancia a verduras y fruta.

En esa charla telefónica también establecimos los objetivos del plan de intervención. De manera prioritaria el jugador pretendía disminuir el riesgo de lesión, pero además buscamos reducir o eliminar el dolor lumbar que sufre en partidos y entrenamientos desde hace 3 años así como el dolor de hombro.

\subsection{Recursos Materiales, Espaciales, Temporales y Humanos}

\subsubsection{Recursos Temporales}

La fase de intervención tendrá lugar entre los meses de Agosto y Noviembre, con una duración de 12 semanas y 24 sesiones (excluyendo la valoración). De nuevo el cambio de sujeto nos obligó a adaptarnos, por lo que la evaluación se realizó mientras estuvo de concentración (por un fisioterapeuta) y se completó la semana antes de comenzar (por mí). En este punto es necesario comentar que el sujeto realiza 5 sesiones de entrenamiento más un partido cada semana, aspecto al que nos deberemos adaptar.

Durante estas 12 semanas mantendremos un contacto periódico con el preparador físico, readaptador y fisioterapeutas del equipo para saber de antemano el trabajo que va a realizar el jugador y su estado, y poder determinar los días más adecuados para ubicar nuestras sesiones de entrenamiento.

\subsection{2 $\quad$ Recursos Espaciales}

Las sesiones tendrán lugar en las Instalaciones Deportivas del Club al que pertenece el jugador. Las ventajas de entrenar en esta instalación son enormes, puesto que se trata de un lugar al que el futbolista ya está acostumbrado, disponemos de material totalmente específico para este deporte y de tecnologías que no podríamos encontrar en un gimnasio convencional. Sólo podemos disponer del gimnasio para nuestras sesiones, pero en las instalaciones también hay piscina y campos de entrenamiento de césped natural, además de sala médica, sala de prensa, cocina y oficinas.

\subsubsection{Recursos Materiales}

Durante el plan de intervención utilizaremos los siguientes materiales:

\begin{tabular}{|c|c|c|c|}
\hline Gomas Elásticas & Slastix & TRX & Stabilizer \\
\hline $\begin{array}{c}\text { Escalera de } \\
\text { Coordinación }\end{array}$ & $\begin{array}{c}\text { Bandas de } \\
\text { Flossing }\end{array}$ & Bosu & Kine Dynamic \\
\hline Cama Elástica & Dyn-air & Slide Discs & Kettlebell \\
\hline Picas & Barra & Discos & Foam Roller \\
\hline Swissball & Balón Medicinal & Versapulley & Battle Rope \\
\hline
\end{tabular}

Tabla 1: Materiales utilizados en el Plan de Intervención

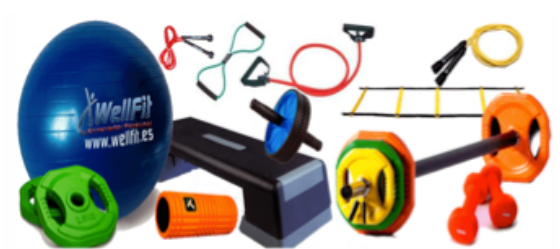

Figura 1: Imagen de algunos materiales 


\subsubsection{Recursos Humanos}

Dentro del cuerpo técnico del jugador hay distintos profesionales. Como entrenador personal no puedo plantear un trabajo para el sujeto sin tener en cuenta lo planificado por ellos. Además como mi objetivo principal, y uno de los del cuerpo técnico, es reducir el riesgo de lesión del jugador, un trabajo sinérgico, esto es, multidisciplinar, nos ayudaría a todos a conseguirlo. De este modo, a lo largo de este trabajo he tenido contacto con:

- Entrenador del Jugador: Le he comunicado verbalmente que voy a trabajar con uno de sus jugadores. No ha puesto ninguna pega, todo lo contrario, se ha ofrecido a buscar un sujeto si los responsables médicos tenían problemas para encontrar uno.

- Médico del Club: Me ha ofrecido su ayuda en todo lo que esté en su mano.

- Preparador Físico y Readaptador del equipo: Han realizado la valoración postural estática y el single leg squat y me ha facilitado los videos para su análisis (yo realicé mi propio análisis). Además me daban diariamente la duración de cada entrenamiento del jugador.

- 2 Fisioterapeutas: Han buscado el sujeto que creían que más se iba a beneficiar de este programa. Han realizado la mayoría de los tests (ver apartado 2.3), tanto los que coincidían con los planteados en su equipo como los reflejados por mí y que ellos no contemplaban. Han realizado tratamiento fisioterápico cuando el jugador lo ha solicitado, unas veces antes de su entrenamiento normal y la mayoría después o cuando se lesionó.

Durante la fase de intervención han ocurrido 2 situaciones imprevistas que han requerido una participación extra del cuerpo técnico con el jugador:

- Compresión del Compartimento Externo de la Rodilla derecha: En la sesión 5 el jugador me informó que había tenido un gesto "feo" en su entrenamiento específico y, por precaución, dejó de entrenar. Esa sesión estuvo condicionada por las molestias que presentaba el jugador (yo no tenía ningún diagnóstico) en las planchas o el trabajo propioceptivo. El servicio médico del club decidió no parar al jugador porque había poca sintomatología. Desde el día siguiente continuó entrenando con normalidad y recibió tratamiento fisioterápico para eliminar el dolor.

- Elongación con pequeña rotura de fibras (grado I) en Recto Anterior del Cuádriceps de la pierna derecha. Los fisios realizaron una ecografía y vieron que no era una lesión grave. El médico estimó 10 días de baja y fisios y readaptador trabajaron para recuperar esa lesión. Al final el jugador estuvo de baja desde el 5 hasta el 23 de Octubre. Durante esos días intenté tener un contacto continuo con su cuerpo técnico al tiempo que realizaba un trabajo para conseguir los objetivos propuestos sin interferir en su proceso de recuperación.

\subsection{Aspectos Éticos, Legales y Jurídicos}

\subsubsection{Aspectos Éticos}

Es imposible prevenir todas las lesiones, incluso en los mejores equipos, con grandes medios, ocurren. Es importante que el jugador entienda que reducir la probabilidad de tener una lesión es distinto a eliminar esa posibilidad, lo cual no está en nuestras manos, y menos en el fútbol donde el mero hecho de entrenar o competir expone al futbolista a un cierto riesgo.

Sin embargo, como entrenador personal, y especialmente en un programa orientado a la prevención de lesiones, debo saber que mi actuación va a tener un impacto sobre la salud del jugador. Voy a entrenar con una persona cuyo trabajo depende de estar "sano" para entrenar y competir, por lo que mi responsabilidad es grande. En este sentido se informa al jugador que llevaré a cabo mis funciones con la mayor profesionalidad y no me excederé en ellas, guardando un contacto continuo con su cuerpo técnico.

\subsubsection{Aspectos Legales y Jurídicos}

En primer lugar destacar la necesidad de estar colegiado por nuestra comunidad autónoma. Además, tal y como se recoge en el Manual de la NSCA (5), antes de comenzar con la aplicación de cualquier entrenamiento personal, es necesario disponer de una serie de documentos de protección legal. 
Del mismo modo, el cliente (en este caso el jugador) debe ser informado de ello, para evitar posibles malentendidos. Esos documentos son, según el Manual de la NSCA (5):

- Consentimiento Informado: "En los pleitos causados por lesiones inherentes (aquéllas que se deben a accidentes y no son culpa de nadie), un consentimiento informado o acuerdo de colaboración son la mejor protección legal por lo que se denomina defensa por asunción de riesgos" (p. 745).

- Exoneración de responsabilidad o renuncia: En pleitos por negligencia "suponen la mejor protección" (p. 746). Quedará reflejado explícitamente que el cliente exculpa al entrenador de cualquier responsabilidad asociada por negligencia. La negligencia se define como "la incapacidad de mostrar una conducta aceptable, o la incapacidad de actuar como lo haría una persona razonablemente prudente en similares circunstancias" (p. 732).

- Confidencialidad: Como entrenador personal no recabaré más información del jugador que la estrictamente profesional y necesaria para llevar a cabo mi actuación. Del mismo modo, tampoco compartiré con él más información de la necesaria. Además, no se publicará ningún dato que pueda identificar al sujeto de estudio de este TFM. Esto queda recogido en la Ley Orgánica 3/2018. En caso de ser necesario, previamente se deberá "firmar un consentimiento informado en presencia de testigos" (p. 744).

A esto podríamos añadir un seguro de responsabilidad civil tal y como indica la Ley del Deporte de Andalucía en el artículo 45. En la entrevista inicial nos aseguraremos de que el jugador entienda la importancia de estos documentos. Además, para tener una evidencia por escrito, se presenta un "Contrato de Prestación de Servicios de Entrenamiento Personal" (6) (Ver Anexo II) que recoge estos tres documentos anteriormente mencionados, y que deberá ser firmado por el jugador.

\section{2-. EVALUACIÓN INICIAL}

\begin{tabular}{c}
\hline "Lo que no se define no se puede medir. Lo que no se mide, no se puede mejorar. \\
Lo que no se mejora, se degrada siempre.” \\
William Thomson, físico y matemático británico (1824 - 1907)
\end{tabular}

\section{1 ¿Qué evalúo? Justificación de los contenidos a evaluar.}

En primer lugar hay que comentar que en la literatura encontramos dudas sobre si la valoración puede ayudarnos a identificar sujetos (jugadores en nuestro caso) en riesgo de sufrir una lesión y se señala que no existe una prueba que sea capaz de predecir lesiones (7), aunque sí sería interesante realizarlo porque permite detectar una serie de problemas (musculoesqueléticos, cardiovasculares, médicos,...) que pueden tener relación con la salud (8).

La evaluación inicial que realice con el jugador debe servirme, según las normas del TFM (y como no podía ser de otra manera) para:

- Establecer un punto de partida de modo que los estímulos que aplique al jugador sean lo más individualizados posibles.

- Detectar déficits que deban ser corregidos en el plan de entrenamiento.

- Establecer unos objetivos en base a los que diseñar el programa de intervención.

- Comprobar, al final del programa de intervención, si se han producido cambios que indiquen que hay un menor riesgo de lesión, es decir, si hemos alcanzado los objetivos propuestos.

Además, debo añadir que es importante utilizar herramientas válidas y confiables para realizar una valoración útil (de la que obtenga información relevante para el posterior programa de intervención) y práctica (que conlleve poco tiempo y no permita al jugador pensar que está perdiendo el tiempo). Indicar que los test serán grabados para analizarlos con mayor minuciosidad (el jugador aceptó este aspecto en la cláusula sexta del contrato presentado en el $A$ nexo II) y se ordenarán buscando economizar el tiempo. 
Debido al cambio de sujeto, y para cumplir con las 12 semanas de intervención, me resultó imposible estar presente en la primera valoración. Mientras se resolvía si mi primer sujeto permanecía en el club, el equipo realizó la evaluación inicial. Después se confirmó la salida de ese jugador y se me asignó uno nuevo, fue a principios de Agosto y el futbolista se marchaba de concentración con su equipo. Algunos tests realizados por ellos coincidían con los planteados por mí (lunge, movilidad de cadera, dinamometría de cadera, valoración postural y single leg squat), pero otros no y era importante para mí realizarlos. La prevención de lesiones debe tener un enfoque multidisciplinar $(3,9,10)$ y queda fuera de mis competencias manipular a un cliente. así que hablé con uno de los fisioterapeutas para que realizara, durante la concentración, los tests que implicaban manipulación. La evaluación se completó por mí la semana previa a comenzar el plan. En las tablas 30 - 32 y 34 puede verse quién realizó cada test.

En la entrevista inicial (telefónica) acordamos que los objetivos a cumplir serían, con carácter prioritario, reducir el riesgo de lesión, para ello, por un lado, debemos tener en cuenta su historial de lesiones, ya que la lesión previa es un factor de riesgo ampliamente reflejado en la literatura (9,11-14), y, por otro, tendremos en cuenta los principales factores de riesgo de las lesiones más prevalentes en fútbol (analizados en profundidad en el punto 3.1.4); disminuir el dolor lumbar que padece en partidos y entrenamientos, para lo cual valoraremos el control motor lumbopélvico, ya que podría estar alterado (15); y disminuir el dolor de hombro, para ello valoraremos la movilidad del hombro y una posible disquinesia escapular. Y, de forma secundaria, ejecutar correctamente los patrones de movimiento y asesorar sobre la importancia de llevar una vida sana.

En el caso de este sujeto, su actividad laboral coincide con su actividad física y, al tratarse de un deportista profesional, es sedentario fuera de ese ámbito, por lo que no tendría demasiado sentido analizar las necesidades motrices de su vida diaria. Sin embargo, sí es interesante pensar en aquéllos movimientos repetidos que realiza mientras entrena o compite (su entorno laboral) y que puedan generar una lesión destacando la realización de movimientos overhead, en especial los saques largos con la mano, que podrían generar una disminución de la rotación interna de esta articulación (GIRD), para lo cual se evaluará el ROM de la articulación glenohumeral. También atenderemos las recepciones de los saltos, que grabaremos en video para observar el valgo dinámico de rodilla, la inclinación del tronco y el comportamiento de estructuras como la cadera; o el volumen de acciones que crea necesario conocer para cuantificar la carga en caso de aparecer una lesión (despejes y saques de puerta con el pie y caídas).

En la entrevista inicial también se pregunta al sujeto por hábitos de su vida diaria, tales como horas y calidad de sueño o diversos aspectos sobre su alimentación. Se trata de un sujeto que no tiene problemas de insomnio e intenta llevar una alimentación sana y equilibrada. Además se recogen los siguientes datos:

- Edad: Existen un gran cantidad de artículos que analizan la edad como factor de riesgo de lesión en esguinces de tobillo (16-18), lesiones de rodilla (19), lesiones de isquiosurales (20,21) o de aductor (22-24), aunque la mayoría concluyen que no hay tal asociación, ya que depende de la lesión previa, que es el principal factor de riesgo, de modo que un jugador con más edad puede haber tenido más lesiones, aumentando así su riesgo de lesión.

- Altura: Aunque no hay una fuerte evidencia, existen referencias que estudian la altura como un aspecto que puede predisponer al jugador a un mayor número de lesiones en esguinces de tobillo $(16,25)$, lesiones de rodilla (19), de isquiosurales $(21,26)$ o de aductor $(24)$. Los porteros suelen ser los jugadores más altos del equipo. Es un factor no modificable pero la mayoría de esos estudios concluyen que no hay asociación entre la altura y el riesgo de lesión.

A lo largo de la valoración se realizarán pruebas de:

\section{A) Flexibilidad o ROM}

Estos tests nos indicarán si la longitud muscular es normal o no, bien por estar limitada o ser excesiva (27), lo que podría provocar alteraciones en el movimiento (por insuficiencia pasiva) o incluso lesiones. Además, uno de los principales motivos de las recidivas es la disminución del ROM (28) que se produce como consecuencia de una alteración del tejido cicatricial tras la lesión (29). Me centraré en las estructuras que ya hayan sufrido lesión y aquéllas en las que un déficit pueda provocar una lesión, tal y como ha sido fundamentado en el apartado 3.1.4, además del complejo del hombro, ya que su posición le obliga a realizar acciones de brazos por encima de la cabeza. 


\section{B) Tests de Fuerza Analíticos}

La excesiva rigidez muscular (30,31) o la debilidad (20,22-24,32-34) van a provocar compensaciones que pueden llevar a producir dolor, sobrecarga o incluso lesión, limitando de esta forma el rendimiento deportivo. Este tipo de pruebas son una parte fundamental dentro de la exploración física (27) tanto en deportistas principiantes como en profesionales. Por un lado, se medirán ratios de musculatura agonista/antagonista (Abductores / Aductores de cadera (34)), así como la comparación entre una pierna y la contralateral (35) y, por otro, se buscará una posible debilidad en aquélla musculatura (Core y Tren Inferior) que pueda suponer un factor de riesgo, tal y como ha sido fundamentado en el apartado 3.1.4.

\section{C) Déficit Propioceptivo}

Un déficit propioceptivo disminuye la estabilidad articular y aumenta el riesgo de lesión, tal y como se ha explicado en profundidad en el apartado 5.4, ya que puede crear una actividad neuromuscular anormal y un déficit de equilibrio.

\section{D) Valoración Postural Estática}

"Adoptar una postura correcta representa un buen hábito que contribuye al bienestar del individuo... Los fallos posturales tienen su origen en la mala utilización de las capacidades del cuerpo y no en su estructura y función normal... Si esos fallos posturales persisten, pueden originar malestar, dolor y discapacidad... Además, el efecto acumulativo de una serie de tensiones poco intensas, las cuales actúan de forma constante o repetida durante un largo período, dan lugar a un problema de gravedad similar al originado por una tensión brusca de gran intensidad" (27).

Dentro de los principios básicos del alineamiento, articulaciones y músculos destacamos (27):

- El alineamiento defectuoso es consecuencia de una tensión excesiva en huesos, articulaciones, ligamentos y músculos.

- Las posiciones de las articulaciones indican qué músculos parecen estar estirados o acortados.

- El acortamiento muscular provoca que origen e inserción del músculo se acorten aún más, al contrario de lo que ocurre con la atrofia muscular.

Para el análisis postural el jugador se colocará en posición anatómica y se utilizará la aplicación "ACPP Core2 Posture Measurement", que nos permite realizar una fotografía con la cuadrícula superpuesta y ofrece un "nivel" que indica la línea de plomada. Se realizará un análisis con visión frontal, lateral y posterior.

E) Valoración Dinámica

Las acciones que realiza cualquier jugador de fútbol (y, evidentemente, las que conllevan lesión) se producen en movimiento, por lo que no tendría sentido realizar únicamente la valoración estática y pretender extrapolar los resultados a la función. Es importante observar cómo se mueve el jugador. Así, analizaremos patrones generales de movimiento buscando detectar posibles susceptibilidades de movimiento que indiquen una debilidad muscular o un déficit en el control motor que requiera ser corregido en el programa de intervención.

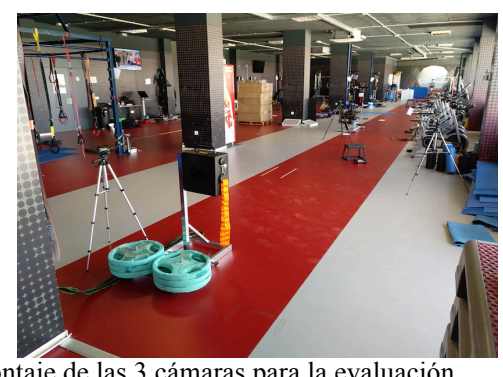

Figura 2: Montaje de las 3 cámaras para la evaluación

En este sentido, se prestará especial atención al comportamiento de la rodilla en la flexión unipodal y bipodal y en la recepción de un salto y a la flexión de cadera en apoyo monopodal y bipodal y las posibles compensaciones lumbares o de abducción que aparezcan. Además, se analizarán patrones de movimiento como el Hinge, el Hip Thrust, o los "presses" y "pulles", que pueden ser la base de ejercicios que se realizarán durante el plan de intervención. Es importante señalar que estos test serán grabados en vídeo con 3 cámaras (visión frontal, lateral y posterior) y analizados con el software Kinovea. 


\section{F) Cuestionario de Dolor Lumbar}

El dolor lumbar es una sintomatología muy común y que puede disminuir la calidad de vida de las personas. Mi función como entrenador personal no se limita, de forma exclusiva, al ámbito deportivo o de la prevención de lesiones. El dolor lumbar que refiere el jugador, en principio, aparece únicamente en partidos y entrenamientos pero es interesante analizar si tiene algún efecto en su vida diaria. Para ello la herramienta más utilizada en la literatura son cuestionarios validados como el que se presenta en el apartado correspondiente.

\section{G) Control Motor del Complejo Coxolumbopélvico}

Nuestro sujeto padece dolor lumbar desde hace 3 años, aunque sólo ocurre en partidos y algunos entrenamientos. Como se explica más detalladamente en el apartado 3.1.5, el dolor lumbar puede llevar asociado un déficit en el control motor del complejo lumbopélvico $(15,36,37)$, es más, se ha demostrado la existencia de diferencias en el control del movimiento lumbar en sujetos sanos y con dolor en espalda baja (38). Por tanto, es importante valorar si existe disociación segmentaria entre la región lumbopélvica así como posibles alteraciones del movimiento en esta región que puedan ocasionar molestia a largo plazo o influir en la sensación percibida por el jugador.

Hay evidencia de una mejor confiabilidad en las pruebas de control motor lumbopélvico cuando se realizan de forma activa en comparación con movimientos pasivos (39), por lo que las pruebas propuestas cumplirán esta premisa. Estos tests también se grabarán con cámara.

\section{H) Aspectos Psicológicos}

Tal y como se explica en el apartado 3.1.4.5, las variables psicológicas tienen una gran importancia en la producción de lesiones en el deporte en general (40,41), y en fútbol en particular (42-44), especialmente el estrés y la ansiedad, que además están asociados con el dolor lumbar (45) que sufre nuestro futbolista en partidos (situación más estresante que un entrenamiento). Por ello, es recomendable que los servicios médicos de los clubes observen la aparición de eventos negativos importantes en la vida de los jugadores, debido a las graves consecuencias que pueden suponer al disminuir la concentración y elevar la ansiedad, lo que conduce a un aumento de la tensión muscular y del riesgo de lesión (42).

Cabe destacar que, una vez realizada la evaluación inicial se decidió realizar un test para medir la longitud del pectoral menor. El motivo es que es lógico pensar que la protracción de hombros y la separación del borde inferior de la escápula, observados en el análisis postural estático, junto con la disquinesia escapular, detectada en el test correspondiente, estuviesen indicando un acortamiento de esta musculatura como así se comprobó tras la medición.

\section{2 ¿Cómo evalúo? Herramientas de evaluación.}

\section{A) Pruebas de Flexibilidad y ROM}

\section{A1. Lunge Test.}

El Lunge Test es un test fiable y validado (46). En un estudio se comprobó la fiabilidad de 3 métodos distintos de medida de la dorsiflexión de tobillo (goniómetro, inclinómetro y cinta métrica) y se concluyó que un evaluador inexperto puede obtener resultados fiables utilizando cualquiera de estas técnicas (47). Lo más cómodo es utilizar la cinta métrica aunque los estudios suelen medir grados.

\begin{tabular}{|c|l|c|c|}
\hline TEST & \multicolumn{1}{|c|}{ LUNGE TEST } & OBJETIVO & \multicolumn{1}{c|}{ VALORAR LA DORSIFLEXÓN DE TOBILLO } \\
\hline $\begin{array}{c}\text { Motivo de su } \\
\text { elección }\end{array}$ & $\begin{array}{l}\text { Como se comenta en el apartado 3.1.4.6.2 la dorsiflexión limitada de tobillo es un factor de riesgo } \\
\text { para lesiones de rodilla }(19,48) \text {, además de estar relacionado con lesiones de LCA (49), síndrome de } \\
\text { dolor patelofemoral (50) o tendinopatía rotuliana (51). }\end{array}$ \\
\hline Descripción & $\begin{array}{l}\text { Colocaremos al jugador de cara a la pared, con el talón en contacto con el suelo, la rodilla en línea con } \\
\text { el segundo dedo del pie y el dedo gordo a } 10 \mathrm{~cm} \text {. de la pared (se permite el contacto con la pared con } \\
\text { dos dedos de cada mano). Se debe dirigir la rodilla hacia la pared hasta llegar a tocarla. Si el jugador } \\
\text { consigue tocar, se alejará } 1 \mathrm{~cm} \text { (y si no se acercará otro cm). En cuanto el jugador no consiga tocar, se } \\
\text { irá acercando milímetro a milímetro hasta hallar la medida exacta (47). }\end{array}$ \\
\hline
\end{tabular}


Aspectos a $\quad$ - Durante el movimiento, la rodilla permanece en línea con el segundo dedo del pie.

Observar / - Evitar que se levante el talón del pie a valorar.

Controlar - Evitar la rotación interna de cadera y la excesiva pronación del pie.

Tabla 2: Aplicación del Lunge Test

A2. Test de KEA.

El Test de KEA es el "Gold Standard" para valorar la longitud de los isquiosurales (52) y muestra una excelente fiabilidad en la medición intra e inter evaluadores (53).

\begin{tabular}{|c|c|c|}
\hline TEST & OBJETIVO & VALORAR LA LONGITUD DE ISQUIOSURALES \\
\hline $\begin{array}{l}\text { Motivo de su } \\
\text { elección }\end{array}$ & \multicolumn{2}{|c|}{$\begin{array}{l}\text { La mayoría de los estudios no encuentran asociación entre la longitud muscular de los isquiosurales y } \\
\text { la aparición de una lesión }(20,21,26,30) \text {, aunque hay otros que sí (54). Sin embargo, el principal factor } \\
\text { de riesgo para una nueva lesión en isquiosurales es tener una previa }(9,11-14) \text { y, entre los distintos } \\
\text { motivos por los que la lesión anterior puede provocar una nueva lesión encontramos una limitada } \\
\text { flexibilidad (28) debido a las modificaciones que se producen en el tejido cicatricial (55), por lo que } \\
\text { puede resultar adecuado comprobar la rigidez de este grupo muscular y comparar un miembro con el } \\
\text { contralateral. }\end{array}$} \\
\hline Descripción & \multicolumn{2}{|c|}{$\begin{array}{l}\text { El jugador se coloca en decúbito supino sobre la camilla, con una flexión de } 90^{\circ} \text { de la cadera y rodilla } \\
\text { a evaluar. Desde esa posición se realiza una extensión activa de rodilla hasta conseguir la máxima } \\
\text { extensión posible, momento en el cual se medirá el ángulo entre la vertical y la tibia (56). }\end{array}$} \\
\hline $\begin{array}{l}\text { Aspectos a } \\
\text { Observar / } \\
\text { Controlar }\end{array}$ & \multicolumn{2}{|c|}{$\begin{array}{l}\text { - Mantener los } 90^{\circ} \text { de flexión de cadera durante todo el recorrido. } \\
\text { - Evitar la báscula pélvica. } \\
\text { - } \text { Mantener la flexión plantar de tobillo. }\end{array}$} \\
\hline
\end{tabular}
Tabla 3: Aplicación del KEA Test

A3. Thomas Test.

El Test de Thomas Modificado es una prueba que permite obtener valores objetivos de la flexibilidad de recto anterior del cuádriceps, psoas iliaco y tensor de la fascia lata (TFL) (57), además ofrece una gran fiabilidad en la medición entre distintos observadores (56) y tanto la medida con goniómetro como con inclinómetro son fiables (58).

\begin{tabular}{|c|l|c|c|}
\hline TEST & $\begin{array}{c}\text { THOMAS TEST } \\
\text { MODIFICADO }\end{array}$ & OBJETIVO & \multicolumn{1}{c|}{$\begin{array}{c}\text { VALORAR LA LONGITUD DE LOS FLEXORES DE } \\
\text { CADERA }\end{array}$} \\
\hline $\begin{array}{c}\text { Motivo de su } \\
\text { elección }\end{array}$ & $\begin{array}{l}\text { Un déficit en los flexores de cadera puede ocasionar una hipermovilidad de columna lumbar en } \\
\text { extensión, una anteversión pélvica o una inhibición glútea que provoque una dominancia de } \\
\text { isquiosurales y aductores (59). Además, un déficit en la longitud de la musculatura del cuádriceps } \\
\text { puede ser un factor de riesgo de lesión en este mismo grupo muscular (54). }\end{array}$ \\
\hline Descripción & $\begin{array}{l}\text { El jugador se sienta en un extremo de la camilla y, posteriormente se tumba. Luego lleva ambas rodillas } \\
\text { al pecho para asegurar que la columna lumbar está plana y se produce una rotación posterior de la } \\
\text { pelvis. Una rodilla permanecerá pegada al pecho mientras la otra, la que se mide, se extenderá hacia la } \\
\text { camilla (56). }\end{array}$ \\
\hline $\begin{array}{c}\text { Aspectos a } \\
\text { Observar / } \\
\text { Controlar }\end{array}$ & $\begin{array}{l}\text { Asegurar una flexión máxima de la pierna contralateral para evitar una rotación anterior de la pelvis } \\
\text { que provoque un descenso del fémur, falseando el test (56). } \\
\text { Evitar la extensión de la columna lumbar, para ello se puede colocar un stabilizer o un tensiómetro a } \\
\text { 60mmHg bajo la columna lumbar (60). }\end{array}$ \\
\hline
\end{tabular}

A4. Test Ober Modificado.

Este test fue propuesto por Ober en 1937 y modificado por los Kendall posteriormente, ya que permite "una menor fuerza aplicada medialmente en el área de la articulación de la rodilla, menor tensión sobre la rótula y menor interferencia por contractura del recto anterior del muslo" (27).

\begin{tabular}{|c|c|c|c|}
\hline TEST & $\begin{array}{c}\text { TEST DE OBER } \\
\text { MODIFICADO }\end{array}$ & OBJETIVO & VALORAR LA TENSIÓN DE LA CINTILLA ILIOTIBIAL \\
\hline $\begin{array}{c}\text { Motivo de su } \\
\text { elección }\end{array}$ & $\begin{array}{l}\text { Una excesiva rigidez de la cintilla iliotibial puede provocar una limitación en los movimientos de } \\
\text { aducción de cadera, lo que puede relacionarse con patologías en rodilla o cadera. }\end{array}$ \\
\hline Descripción & $\begin{array}{l}\text { Se coloca al jugador en decúbito lateral con la pierna interior flexionada por la cadera y la rodilla para } \\
\text { mantener recta la región dorsal baja y estabilizar la pelvis. En el lado examinado, el fisioterapeuta } \\
\text { colocará la mano lateralmente sobre la pelvis del jugador, justo bajo la cresta ilíaca y empuja hacia }\end{array}$ \\
\hline
\end{tabular}




\begin{tabular}{|c|c|}
\hline & $\begin{array}{l}\text { arriba lo suficiente para estabilizar la pelvis y mantener la porción lateral del tronco en contacto con la } \\
\text { mesa. La pierna debe mantenerse extendida, alineada con el tronco (en el plano coronal) (27). } \\
\text { Colocando un stabilizer bajo la pelvis podemos controlar los movimientos en el plano frontal (61). }\end{array}$ \\
\hline $\begin{array}{l}\text { Aspectos a } \\
\text { Observar / } \\
\text { Controlar }\end{array}$ & $\begin{array}{l}\text { - La pelvis debe permanecer estabilizada, evitando el balanceo anterior y la inclinación lateral hacia } \\
\text { abajo sobre el lado que va a ser explorado }(27) \text {. } \\
\text { - Evitar rotar externamente el muslo y también la rotación interna. }\end{array}$ \\
\hline
\end{tabular}
Tabla 5: Aplicación del Test de Ober Modificado

\section{A5. Rotación Interna de Cadera.}

Este aspecto se medirá de dos formas distintas: 1) con la cadera neutra y 2) con la cadera en flexión de $90^{\circ}$, ya que existen músculos que son rotadores externos con una flexión de cadera de $90^{\circ}$ y rotadores internos con cadera neutra. La rotación interna con la cadera flexionada a $90^{\circ}$ podemos medirla con el sujeto en decúbito supino o sentado, sin embargo se obtienen valores significativamente distintos en una y otra medición (62). En este caso, la medición en supino tiene una mayor fiabilidad (excelente) que sentado (62), por lo que será la que utilicemos. Además, es necesario indicar que, para la medición del ROM de cadera y otros test, se utilizarán goniómetros que, aunque pueden dar una medida sobreestimada del ROM real de cadera, es la principal herramienta para su medición (63), además de ser simple y económico.

\begin{tabular}{|c|c|c|c|}
\hline TEST & $\begin{array}{l}\text { HIP INTERNAL } \\
\text { ROTATION }\end{array}$ & OBJETIVO & $\begin{array}{l}\text { VALORAR LA MOVILIDAD DE LA ROTACION } \\
\text { INTERNA DE CADERA }\end{array}$ \\
\hline eleccion & \multicolumn{3}{|c|}{$\begin{array}{l}\text { Una limitación en el ROM de cadera puede estar relacionado con osteoartritis de cadera o dolor } \\
\text { lumbar (62). }\end{array}$} \\
\hline Descripción & \multicolumn{3}{|c|}{$\begin{array}{l}\text { 1) El jugador se coloca en decúbito prono con la rodilla a valorar flexionada a } 90^{\circ} \text { y la cadera neutra, } \\
\text { la otra pierna descansa sobre la camilla. A partir de ahí el pie cae hacia fuera (rotación interna de } \\
\text { cadera). Se mide el ángulo entre la cara lateral de la pierna inferior y el eje vertical (64). Este test tiene } \\
\text { una alta fiabilidad intra e interobservador (64). } \\
\text { 2) El jugador se coloca en decúbito supino y flexiona } 90^{\circ} \text { la cadera y rodilla de la pierna a valorar. Se } \\
\text { fija la rodilla y se produce de forma pasiva la rotación interna de cadera. Este test presenta una } \\
\text { excelente fiabilidad intra e interobservadores (65). }\end{array}$} \\
\hline $\begin{array}{l}\text { Aspectos a } \\
\text { Observar / } \\
\text { Controlar }\end{array}$ & \multicolumn{3}{|c|}{$\begin{array}{l}\text { - Evitar la rotación no deseada de la pelvis mientras se produce la rotación interna (64), para ello se } \\
\text { coloca un nivel sobre el punto más alto de ambos glúteos con el sujeto en decúbito prono. }\end{array}$} \\
\hline
\end{tabular}

Tabla 6: Aplicación del Hip Internal Rotation

A6. Rotación Externa de Cadera.

Al igual que ocurría en el test anterior, este aspecto se medirá de dos formas distintas: 1) con la cadera neutra y 2) con la cadera en flexión de $90^{\circ}$, ya que existen músculos que son rotadores externos con una flexión de cadera de $90^{\circ}$ y rotadores internos con cadera neutra. La rotación externa con la cadera flexionada a $90^{\circ}$ podemos medirla con el sujeto en decúbito supino o sentado, sin embargo se obtienen valores significativamente distintos en una y otra medición (62). La medición en supino tiene una mayor fiabilidad (excelente) que sentado (62), por lo que será la que utilicemos.

\begin{tabular}{|c|c|c|c|}
\hline TEST & $\begin{array}{l}\text { HIP EXTERNAL } \\
\text { ROTATION }\end{array}$ & OBJETIVO & $\begin{array}{l}\text { VALORAR LA MOVILIDAD DE LA ROTACIÓN } \\
\text { EXTERNA DE CADERA }\end{array}$ \\
\hline $\begin{array}{l}\text { Motivo de su } \\
\text { elección }\end{array}$ & \multicolumn{3}{|c|}{$\begin{array}{l}\text { La Rotación Externa de Cadera se encuadra dentro del ROM de cadera, por lo que el motivo por el } \\
\text { que se elige este test coincide con el expuesto en la tabla de Rotación Interna de Cadera (A5). }\end{array}$} \\
\hline Descripción & \multicolumn{3}{|c|}{$\begin{array}{l}\text { 1) El jugador se coloca en decúbito supino. La pierna que no se mide se flexiona y se apoya el pie en } \\
\text { la camilla, la que se evalúa se deja caer delante de la camilla. A partir de ahí se mueve pasivamente la } \\
\text { parte inferior de la pierna hacia la rotación externa de cadera hasta que se nota el final del rango o hay } \\
\text { movimiento de la pelvis (64). Este test tiene una alta fiabilidad intra e interobservador (64). } \\
\text { 2) El jugador se coloca en decúbito supino y flexiona } 90^{\circ} \text { la cadera y rodilla de la pierna a valorar, la } \\
\text { otra descansa extendida sobre la camilla. A partir de ahí se fija la rodilla y se busca, de forma pasiva, } \\
\text { la rotación externa de cadera. Este test presenta una excelente fiabilidad intra e interobservadores (65). }\end{array}$} \\
\hline $\begin{array}{l}\text { Aspectos a } \\
\text { Observar / } \\
\text { Controlar }\end{array}$ & \multicolumn{3}{|c|}{ - Evitar la rotación no deseada de la pelvis mientras se produce la rotación interna (64). } \\
\hline
\end{tabular}

Tabla 7: Aplicación del Hip External Rotation 


\section{A7. Flexión de Cadera.}

Este test tiene una buena fiabilidad en sujetos con osteoartritis (66), en jugadores de fútbol sala y balonmano (67) y excelente en sujetos asintomáticos (65).

\begin{tabular}{|c|c|c|c|}
\hline TEST & $\begin{array}{l}\text { PASSIVE HIP } \\
\text { FLEXION TEST }\end{array}$ & OBJETIVO & VALORAR EL ROM DE FLEXIÓN DE CADERA \\
\hline $\begin{array}{l}\text { Motivo de su } \\
\text { elección }\end{array}$ & \multicolumn{3}{|c|}{$\begin{array}{l}\text { La Flexión de Cadera se encuadra dentro del ROM de cadera, por lo que el motivo por el que se elige } \\
\text { este test coincide con el expuesto en la tabla de Rotación Interna de Cadera (A5). }\end{array}$} \\
\hline Descripción & \multicolumn{3}{|c|}{$\begin{array}{l}\text { El jugador se coloca en decúbito supino. La extremidad que no se valora permanece extendida sobre la } \\
\text { camilla. El fisioterapeuta flexiona la cadera a valorar lo máximo posible. Se utiliza un goniómetro para } \\
\text { medir los grados de flexión (66). }\end{array}$} \\
\hline $\begin{array}{l}\text { Aspectos a } \\
\text { Observar / } \\
\text { Controlar }\end{array}$ & \multicolumn{3}{|c|}{ - Evitar compensaciones en el movimiento. } \\
\hline
\end{tabular}

Tabla 8: Aplicación del Passive Hip Flexion Test

A8. Extensión de Cadera.

Este test tiene una buena fiabilidad en jugadores de fútbol sala y balonmano (67).

\begin{tabular}{|c|c|c|c|}
\hline TEST & $\begin{array}{c}\text { PASSIVE HIP } \\
\text { EXTENSION TEST }\end{array}$ & OBJETIVO & VALORAR EL ROM DE EXTENSIÓN DE CADERA \\
\hline $\begin{array}{l}\text { Motivo de su } \\
\text { elección }\end{array}$ & \multicolumn{3}{|c|}{$\begin{array}{l}\text { La Extensión de Cadera se encuadra dentro del ROM de cadera, por lo que el motivo por el que se } \\
\text { elige este test coincide con el expuesto en la tabla de Rotación Interna de Cadera (A5). }\end{array}$} \\
\hline Descripción & \multicolumn{3}{|c|}{$\begin{array}{l}\text { El jugador se coloca en decúbito supino sobre la camilla, con muslo y piernas "colgando". La pierna a } \\
\text { valorar es extendida por el fisioterapeuta mientras que la contralateral se flexiona. Se mide con } \\
\text { goniómetro los grados de extensión (67). }\end{array}$} \\
\hline $\begin{array}{l}\text { Aspectos a } \\
\text { Observar / } \\
\text { Controlar }\end{array}$ & \multicolumn{3}{|c|}{ - Evitar elevar zona lumbar para compensar movimiento. } \\
\hline
\end{tabular}

Tabla 9: Aplicación del Passive Hip Extension Test

A9. Abducción de Cadera.

Este test tiene una buena fiabilidad en sujetos con osteoartritis (66) y también en jugadores de fútbol sala y balonmano (67).

\begin{tabular}{|c|c|c|c|}
\hline TEST & $\begin{array}{c}\text { PASSIVE HIP } \\
\text { ABDUCTION TEST }\end{array}$ & OBJETIVO & VALORAR EL ROM ABDUCCIÓN DE CADERA \\
\hline $\begin{array}{l}\text { Motivo de su } \\
\text { elección }\end{array}$ & \multicolumn{3}{|c|}{$\begin{array}{l}\text { Aunque podemos encontrar estudios que concluyen que una limitación en la abducción de cadera no } \\
\text { se asocia con la aparición de lesiones }(24,64) \text {, también existen otros que sí encuentran dicha } \\
\text { asociación (23). A pesar de no existir consenso, podemos relacionar el déficit de movilidad de cadera } \\
\text { con el dolor y posterior lesión inguinal }(68) \text {, por lo que hay evidencias suficientes para realizar este } \\
\text { test. Además, la Abducción de Cadera se encuadra dentro del ROM de cadera, por lo que el motivo } \\
\text { por el que se elige este test coincide con el expuesto en la tabla de Rotación Interna de Cadera (A5). }\end{array}$} \\
\hline Descripción & \multicolumn{3}{|c|}{$\begin{array}{l}\text { El jugador se coloca en decúbito supino con las piernas extendidas. Tras colocar el goniómetro, el } \\
\text { fisioterapeuta abduce la pierna a valorar hasta determinar el ROM final de la articulación y mide los } \\
\text { grados de abducción (66). }\end{array}$} \\
\hline $\begin{array}{l}\text { Aspectos a } \\
\text { Observar / } \\
\text { Controlar }\end{array}$ & \multicolumn{3}{|c|}{ - Evitar la inclinación pélvica. } \\
\hline
\end{tabular}

Tabla 10: Aplicación del Passive Hip Abduction Test

\section{A10. Aducción de Cadera.}

Este test tiene una buena fiabilidad en sujetos con osteoartritis (66), aunque no se ha encontrado en la literatura nada referente a sujetos asintomáticos o deportistas.

\begin{tabular}{|c|c|c|c|}
\hline TEST & $\begin{array}{c}\text { PASSIVE HIP } \\
\text { ADDUCTION TEST }\end{array}$ & OBJETIVO & VALORAR EL ROM DE ADUCCIÓN DE CADERA \\
\hline $\begin{array}{l}\text { Motivo de su } \\
\text { elección }\end{array}$ & $\begin{array}{l}\text { La Aducción de Cader } \\
\text { elige este test coincide }\end{array}$ & encuadra & $\begin{array}{l}\text { del ROM de cadera, por lo que el motivo por el que se } \\
\text { tabla de Rotación Interna de Cadera (A5). }\end{array}$ \\
\hline
\end{tabular}




\begin{tabular}{|c|l|}
\hline Descripción & $\begin{array}{l}\text { El jugador se coloca en decúbito supino sobre la camilla, con las piernas extendidas. Tras colocar el } \\
\text { goniómetro, el fisioterapeuta aduce la pierna a valorar hasta determinar el ROM final de la articulación } \\
\text { y mide los grados de aducción (66). }\end{array}$ \\
\hline $\begin{array}{c}\text { Aspectos a } \\
\text { Observar / } \\
\text { Controlar }\end{array}$ & - Evitar la inclinación pélvica. \\
\hline
\end{tabular}

Tabla 11: Aplicación del Passive Hip Adduction Test

El contacto entre las superficies óseas de la articulación glenohumeral es muy reducido para toda la movilidad que ofrece esta articulación, por ello es importante controlar su estabilidad y control motor, especialmente en deportistas "overhead", como puede ser nuestro portero de fútbol que, aunque no con la frecuencia de un jugador de voleibol, tenis, beisbol o un nadador, debe realizar acciones específicas (saques, despejes, blocajes o estiradas) por encima de la cabeza. Por tanto, derivado de las necesidades motrices de su actividad laboral, se incluye en nuestra valoración el complejo articular del hombro.

\section{A11. Test de Flexión de Hombros.}

Tras una amplia revisión bibliográfica no se ha encontrado un test adecuado (válido y fiable) para medir la flexión de hombro. Por lo que realizaré uno bastante extendido en la práctica.

\begin{tabular}{|c|c|c|c|}
\hline TEST & $\begin{array}{l}\text { SHOULDER } \\
\text { FLEXION }\end{array}$ & OBJETIVO & VALORAR LA FLEXIÓN DE HOMBRO \\
\hline $\begin{array}{l}\text { Motivo de su } \\
\text { elección }\end{array}$ & \multicolumn{3}{|c|}{$\begin{array}{l}\text { Una limitada flexión conllevará compensaciones para poder realizar movimientos con normalidad, una } \\
\text { mayor limitación para los movimientos por encima de la cabeza y una mayor probabilidad de sufrir } \\
\text { lesiones en el complejo articular del hombro. }\end{array}$} \\
\hline Descripción & \multicolumn{3}{|c|}{$\begin{array}{l}\text { El jugador se coloca en decúbito supino sobre la camilla. Las rodillas y caderas se flexionan y se } \\
\text { apoyan los pies en la camilla. Los brazos rotan externamente lo justo como para levantar el pulgar de } \\
\text { cada mano de forma totalmente vertical. } \\
\text { A partir de ahí, el jugador realiza una flexión completa de hombros e intenta tocar con el pulgar la } \\
\text { camilla, por la parte superior de la cabeza. }\end{array}$} \\
\hline $\begin{array}{l}\text { Aspectos a } \\
\text { Observar / } \\
\text { Controlar }\end{array}$ & \multicolumn{3}{|c|}{$\begin{array}{l}\text { - Evitar compensaciones en la realización del movimiento. } \\
\text { - } \text { Evitar flexionar codos. }\end{array}$} \\
\hline
\end{tabular}

Tabla 12: Aplicación del Shoulder Flexion

\section{A12. Test de Rotación Interna de Hombro.}

Este test tiene una mayor fiabilidad en decúbito lateral que en decúbito supino, por lo que será así como se realice, además, presenta una alta fiabilidad intra e interobservador (69).

\begin{tabular}{|c|c|c|c|}
\hline TEST & $\begin{array}{c}\text { SHOULDER INTERNAL } \\
\text { ROTATION RANGE OF MOTION }\end{array}$ & OBJETIVO & $\begin{array}{c}\text { VALORAR LA ROTACIÓN INTERNA } \\
\text { DEL HOMBRO }\end{array}$ \\
\hline & \multicolumn{3}{|c|}{$\begin{array}{l}\text { Un déficit de Rotacion Interna Glenohumeral (GIRD) es definido como una pérdida de } 15^{\circ} \text { (o más) de } \\
\text { Rotación Interna combinados con una pérdida de } 10^{\circ} \text { (o más) en el arco total del movimiento en } \\
\text { comparación con el hombro contralateral (70). Nuestro jugador es portero, y suele realizar } \\
\text { lanzamientos con la mano por encima de la cabeza. Se ha demostrado que en deportes en los que esto } \\
\text { sucede continuamente, se puede producir una adaptación crónica que implica un exceso de rotación } \\
\text { externa y una limitación en la rotación interna }(71,72) \text {, favoreciendo el GIRD, que puede conllevar } \\
\text { dolor inespecífico de hombro (73) y un aumento en la incidencia de lesiones (74), por lo que sería } \\
\text { interesante comprobar el estado de los hombros de nuestro jugador. }\end{array}$} \\
\hline Descripción & \multicolumn{3}{|c|}{$\begin{array}{l}\text { El jugador se coloca en decúbito lateral con el brazo a valorar a } 90^{\circ} \text { de flexión de codo y } \\
\text { glenohumeral. La pierna del lado contralateral se lleva a } 90^{\circ} \text { de flexión de cadera y se apoya en la } \\
\text { camilla. La escápula se colocará en aducción y retracción máximas, para evitar su movimiento. A } \\
\text { partir de ahí se rota el brazo hasta la sensación de final capsular o dolor en el jugador (69). }\end{array}$} \\
\hline $\begin{array}{l}\text { Aspectos a } \\
\text { Observar / } \\
\text { Controlar }\end{array}$ & \multicolumn{3}{|c|}{$\begin{array}{l}\text { - Evitar la anteriorización compensatoria de la cabeza del húmero. } \\
\text { - Evitar movimiento escapular. }\end{array}$} \\
\hline
\end{tabular}




\section{A13. Test de Rotación Externa de Hombro.}

Este test tiene una alta fiabilidad intra e interobservador en posición supina sin sobrepresión, no así en decúbito lateral, donde sólo muestra fiabilidad alta intraobservador (69).

\begin{tabular}{|c|c|c|c|}
\hline TEST & $\begin{array}{c}\text { SHOULDER EXTERNAL } \\
\text { ROTATION RANGE OF MOTION }\end{array}$ & OBJETIVO & $\begin{array}{c}\text { VALORAR LA ROTACIÓN EXTERNA } \\
\text { DEL HOMBRO }\end{array}$ \\
\hline $\begin{array}{l}\text { Motivo de su } \\
\text { elección }\end{array}$ & \multicolumn{3}{|c|}{ Ya se ha comentado en el test de rotación interna de hombro. } \\
\hline Descripción & \multicolumn{3}{|c|}{$\begin{array}{l}\text { El jugador se coloca en decúbito supino con el brazo a valorar en } 90^{\circ} \text { de abducción y } 90^{\circ} \text { de flexión de } \\
\text { codo con rotación glenohumeral neutra. El jugador debe relajar el brazo hacia atrás. Cuando se detiene } \\
\text { el movimiento asistido por la gravedad, se miden los grados de extensión. Si se produce una rotación } \\
\text { activa se detiene la prueba (69). }\end{array}$} \\
\hline $\begin{array}{l}\text { Aspectos a } \\
\text { Observar / } \\
\text { Controlar }\end{array}$ & \multicolumn{3}{|c|}{$\begin{array}{l}\text { - Vigilar que no se produce rotación activa por parte del jugador, sólo debe actuar la gravedad (69). } \\
\text { - Evitar movimiento escapular. }\end{array}$} \\
\hline
\end{tabular}

Tabla 14: Aplicación del Shoulder External Rotation Range of Motion

\section{A14. Test de Aducción de Hombro.}

Esta medición suele obtenerse con el sujeto en decúbito supino, sin embargo, esta medición no tiene en cuenta la rotación glenohumeral. Se propone un test que corrige ese matiz y muestra una alta fiabilidad intraobservador y una buena fiabilidad interobservador (75).

\begin{tabular}{|c|c|c|c|}
\hline TEST & $\begin{array}{c}\text { POSTERIOR SHOULDER } \\
\text { FLEXIBILITY TEST }\end{array}$ & OBJETIVO & \multicolumn{1}{c|}{$\begin{array}{c}\text { VALORAR LA RIGIDEZ POSTERIOR DEL } \\
\text { HOMBRO }\end{array}$} \\
\hline $\begin{array}{c}\text { Motivo de su su } \\
\text { elección }\end{array}$ & $\begin{array}{l}\text { Los rotadores externos del hombro deben frenar excéntricamente el movimiento de saque con la mano } \\
\text { o despeje de puños de nuestro portero. Una de las consecuencias del GIRD que nombrábamos } \\
\text { anteriormente, y que es muy frecuente en deportistas overhead, es una mayor rigidez de esos rotadores } \\
\text { externos (72). Este test nos permite valorar una posible rigidez posterior del hombro. }\end{array}$ \\
\hline Descripción & $\begin{array}{l}\text { El jugador de coloca en decúbito lateral, con caderas y rodillas flexionadas a } 90^{\circ} \text { y descansando sobre } \\
\text { la camilla. El brazo que no se testea se coloca debajo de la cabeza. La columna se mantiene en flexión, } \\
\text { extensión y rotación neutras. El fisioterapeuta cogerá el brazo del jugador distal a los epicóndilos del } \\
\text { codo y lo moverá a 90 } 90^{\circ} \text { de abducción con el húmero en } 0^{\circ} \text { de rotación interna y externa. A partir de ahí } \\
\text { se fija la escápula y se produce la adución del húmero (75). }\end{array}$ \\
\hline $\begin{array}{c}\text { Aspectos a } \\
\text { Observar/ } \\
\text { Controlar }\end{array}$ & - La escápula debe estabilizarse de manera efectiva. \\
\hline
\end{tabular}

Tabla 15: Aplicación del Posterior Shoulder Flexibility Test

\section{A.15 Longitud del Pectoral Menor.}

Como se ha comentado anteriormente, el análisis de la evaluación inicial nos indicó que cabía la posibilidad de encontrarnos un pectoral menor acortado, por lo que, justo antes de comenzar nuestra primera sesión de entrenamiento, se procedió a realizar este test.

\begin{tabular}{|c|c|c|c|}
\hline TEST & $\begin{array}{l}\text { LONGITUD DEL } \\
\text { PECTORAL MENOR }\end{array}$ & OBJETIVO & VALORAR LA LONGITUD DEL PECTORAL MENOR \\
\hline $\begin{array}{l}\text { Motivo de su } \\
\text { elección }\end{array}$ & \multicolumn{3}{|c|}{$\begin{array}{l}\text { Un acortamiento del pectoral menor impedirá que la escápula se oriente correctamente al levantar el } \\
\text { brazo (76) ya que produce una inclinación anterior de la misma y, si esto se mantiene en el tiempo, } \\
\text { puede estar relacionado con dolor en hombro o cuello. }\end{array}$} \\
\hline Descripción & \multicolumn{3}{|c|}{$\begin{array}{l}\text { Es importante que la musculatura a medir esté relajada. El sujeto se colocará de pie en posición } \\
\text { anatómica y utilizaremos una cinta métrica para medir la distancia desde la apófisis coracoides hasta } \\
\text { la cuarta costilla, cerca del esternón (77). A partir de ahí se calcula el Índice de Pectoral Menor (IPM) } \\
\text { con la siguiente fórmula }(78) \text { : } \\
\qquad I P M=\text { Resultado test A.15 (cm) / altura jugador }(\mathrm{cm}) \times 100 .\end{array}$} \\
\hline $\begin{array}{l}\text { Aspectos a } \\
\text { Observar / } \\
\text { Controlar }\end{array}$ & \multicolumn{3}{|c|}{ - Evitar movimiento el hombro que pueda falsear el test. } \\
\hline
\end{tabular}




\section{B) Test de Fuerza Analíticos.}

En este punto creo necesario señalar que un test isocinético es muy útil para detectar desequilibrios musculares en flexores y extensores de rodilla (20,30,79-81), ya que puede ser un factor de riesgo de lesiones en isquiosurales. Se trata de una prueba costosa pero que puede realizarse en el club (por el médico) si se cree necesario. El primer sujeto que me asignaron había tenido 2 lesiones en la musculatura isquiosural la temporada anterior, motivo suficiente para realizar esta valoración. Sin embargo, este sujeto no ha tenido nunca esa lesión, y no se trata de una prueba que se realice rutinariamente en el club, por lo que no ha sido posible realizarla. Aún así, en el Anexo III se presenta toda la información que se recogió para la realización de este test cuando se realizó la valoración para el sujeto anterior.

\section{B1. Aducción Excéntrica de Cadera.}

La mayoría de las acciones que se realizan en fútbol (cambios de dirección, golpeos,...) están relacionadas con la fuerza excéntrica de la musculatura de la cadera (82). Además, para detectar a los jugadores con dolor de cadera o ingle es mejor medir la fuerza de aductores en excéntrico que en isométrico (83). El ratio ADD:ABD se considera un posible factor de riesgo de lesión (34) y para calcularlo es necesario medir la fuerza de aducción y de abducción de cadera.

Es necesario indicar que los siguientes test (ADD; ABD; SQUEEZE) se realizarán con dinamometría manual, que es una herramienta válida comparada con el gold standard para medir la fuerza muscular (84) y los resultados obtenidos se normalizarán para el peso corporal, como se recomienda en este tipo de tests. Para ello se utilizará la fórmula: $\mathrm{S}_{\mathrm{n}}=\mathrm{S} / \mathrm{m}^{\mathrm{b}} \quad$ (donde $\mathrm{S}_{\mathrm{n}} \rightarrow$ Fuerza Normalizada; $\mathrm{S} \rightarrow$ Fuerza medida con dinamómetría; $m \rightarrow$ Peso del jugador; $b \rightarrow$ Constante $=0,67)(85)$.

\begin{tabular}{|c|l|c|c|}
\hline TEST & $\begin{array}{c}\text { ECCENTRIC HIP } \\
\text { ADDUCTION }\end{array}$ & OBJETIVO & \multicolumn{1}{c|}{$\begin{array}{c}\text { VALORAR LA ADUCCIÓN DE CADERA Y PODER } \\
\text { DETERMINAR EL RATIO ADD:ABD }\end{array}$} \\
\hline $\begin{array}{c}\text { Motivo de su } \\
\text { elección }\end{array}$ & $\begin{array}{l}\text { Una debilidad en los aductores de cadera es un factor de riesgo de lesiones }(22-24,83,86) \text {, que puede } \\
\text { multiplicar por 4 la probabilidad de tener una lesión de ingle (87). }\end{array}$ \\
\hline & $\begin{array}{l}\text { El jugador se coloca en decúbito lateral sobre la pierna a evaluar, que permanecerá extendida y } \\
\text { sobresaldrá de la camilla. La pierna que no se valora se coloca en flexión de } 90^{\circ} \text { de cadera y rodilla } \\
\text { sobre una superficie firme que facilite una rotación pélvica neutra. Podrá agarrarse al borde de la } \\
\text { camilla con la mano. Luego se realiza una aducción completa y se coloca el dinamómetro sobre la } \\
\text { marca tibial medial. Para estandarizar la prueba se colocará } 8 \mathrm{~cm} \text {. por encima del maléolo medial. } \\
\text { Partiendo de esa posición, el jugador deberá realizar una contracción voluntaria máxima isométrica } \\
\text { durante 5 segundos contra la resistencia del fisioterapeuta. } \\
\text { La medida se normaliza al peso corporal y se registra en Newton-metros por } \mathrm{kg}(\mathrm{Nm} / \mathrm{kg})(83) .\end{array}$ \\
\hline $\begin{array}{c}\text { Aspectos a } \\
\text { Observar / } \\
\text { Controlar }\end{array}$ & $\begin{array}{l}\text { - Controlar que no se produce compensación. } \\
\text { Evitar movimiento en zona pélvica. }\end{array}$ \\
\hline
\end{tabular}

Tabla 17: Aplicación del Eccentric Hip Adduction

B2. Abducción Excéntrica de Cadera.

Esta prueba muestra una buena confiabilidad para su medida (64).

\begin{tabular}{|c|l|l|l|}
\hline TEST & \multicolumn{1}{|c|}{$\begin{array}{c}\text { ECCENTRIC HIP } \\
\text { ABDUCTION }\end{array}$} & OBJETIVO & \multicolumn{1}{c|}{$\begin{array}{c}\text { VALORAR LA ABDUCCIÓN DE CADERA Y PODER } \\
\text { DETERMINAR EL RATIO ADD:ABD }\end{array}$} \\
\hline $\begin{array}{c}\text { Motivo de su } \\
\text { elección }\end{array}$ & $\begin{array}{l}\text { Un déficit en esta musculatura puede estar relacionado con lesiones en tobillo (32) o en rodilla (33). } \\
\text { Además, es necesario medirlo para calcular el ratio ADD:ABD, considerado también como factor de } \\
\text { riesgo de lesión en aductores (34). }\end{array}$ \\
\hline & $\begin{array}{l}\text { El jugador se coloca en decúbito lateral sobre la pierna que no se evalúa, que se colocará en flexión de } \\
90^{\circ} \text { de cadera y rodilla. Podrá agarrarse al borde de la camilla con la mano. La pierna a valorar se } \\
\text { extiende y se abduce hasta colocarse al nivel del cuerpo, entonces se coloca el dinamómetro en la } \\
\text { marca tibial lateral. Para estandarizar la prueba se colocará } 8 \mathrm{~cm} \text {. por encima del maléolo lateral. } \\
\text { Partiendo de esa posición, el jugador deberá realizar una contracción voluntaria máxima isométrica } \\
\text { durante } 5 \text { segundos contra la resistencia del fisioterapeuta. } \\
\text { La medida se normaliza al peso corporal y se registra en Newton-metros por } \mathrm{kg}(\mathrm{Nm} / \mathrm{kg})(83) .\end{array}$ \\
\hline $\begin{array}{c}\text { Aspectos a } \\
\text { Observar / } \\
\text { Controlar }\end{array}$ & $\begin{array}{l}\text { - Controlar que no se produce compensación. } \\
- \text { Evitar movimiento en zona pélvica. }\end{array}$ \\
\hline
\end{tabular}

Tabla 18: Aplicación del Eccentric Hip Abduction 


\section{B3. Squeeze Test.}

Este test se puede realizar de varias formas y, en función de dónde se coloque la resistencia, la producción de fuerza variará. Se ha demostrado una alta fiabilidad para realizar el Squeeze Test con palanca corta (resistencia entre las rodillas), en palanca corta junto con leve rotación externa de cadera (resistencia más ancha, por ejemplo brazo, sobre rodillas) o con palanca larga (resistencia entre los tobillos). Sin embargo, esta última opción parece ser más precisa y tiene una mayor activación de la musculatura aductora (87).

Dentro de las distintas opciones de realizar el Squeeze Test encontramos que el "Copenhaguen Five Seconds" es una medida válida. Se coloca el brazo entre los tobillos del sujeto y se le pide la contracción máxima. El dolor se indica en una escala de $0-10 \mathrm{y}$, en base a eso, se establecen 3 colores (como en un semáforo). Verde $\rightarrow 0-2$ que indica práctica normal; Amarillo $\rightarrow 3-5$ que indica atención, es decir, que el jugador debe ser valorado; Rojo $\rightarrow 6-10$ que indica que el jugador debe parar su actividad (88). Esta opción es útil para identificar dolor pero no debilidad. Comentar que los jugadores de fútbol $(64,83)$ o fútbol gaélico (89) con dolor inguinal suelen tener un rendimiento más bajo en esta prueba.

Se ha demostrado que un esfingomanómetro inflado a $10 \mathrm{~mm} \mathrm{Hg}$ es una herramienta confiable (y más económica que un dinamómetro) para realizar esta prueba con $45^{\circ}$ de flexión de cadera (90).

\begin{tabular}{|c|c|c|c|}
\hline TEST & SQUEEZE TEST & OBJETIVO & VALORAR LA DEBILIDAD DE LOS ADUCTORES \\
\hline $\begin{array}{l}\text { Motivo de su } \\
\text { elección }\end{array}$ & \multicolumn{3}{|c|}{$\begin{array}{l}\text { Como se ha argumentado en el test de aducción de cadera, es necesario medir la fuerza de esta } \\
\text { musculatura ya que su debilidad es un factor de riesgo. }\end{array}$} \\
\hline Descripción & \multicolumn{3}{|c|}{$\begin{array}{l}\text { El jugador se colocará en decúbito supino, con las piernas extendidas. Entre sus tobillos, se colocará } \\
\text { un dinamómetro y se le pedirá que realice una aducción máxima bilateral (87). }\end{array}$} \\
\hline $\begin{array}{l}\text { Aspectos a } \\
\text { Observar / } \\
\text { Controlar }\end{array}$ & \multicolumn{3}{|c|}{$\begin{array}{l}\text { - Controlar que no se produce compensación. } \\
\text { - Evitar movimiento en zona pélvica. }\end{array}$} \\
\hline
\end{tabular}

Tabla 19: Aplicación del Squeeze Test

El desarrollo del CORE es fundamental para el rendimiento deportivo y para la prevención de lesiones (91), además, un déficit en el control neuromuscular de la estabilidad central está relacionado tanto con el síndrome de dolor lumbar como con lesiones en los miembros inferiores (92), especialmente en rodilla (93) y tobillo (94). Por este motivo, es necesario incluirlo en la valoración de nuestro jugador.

Para llevar a cabo la valoración de la estabilidad central me voy a basar en la propuesta de McGill, en la que se realizan 3 test en los cuales el jugador deberá mantener una posición durante el mayor tiempo posible $(95)$. Estos tests gozan de una excelente fiabilidad $(95,96)$ y son los siguientes:

B4. Biering - Sorensen Modificado.

\begin{tabular}{|c|l|l|c|}
\hline TEST & $\begin{array}{c}\text { BIERING SORENSEN } \\
\text { MODIFICADO }\end{array}$ & OBJETIVO & \multicolumn{1}{c|}{$\begin{array}{c}\text { VALORAR LA FUERZA DE LOS ERECTORES } \\
\text { TORACOLUMBARES }\end{array}$} \\
\hline $\begin{array}{c}\text { Motivo de su } \\
\text { elección }\end{array}$ & Se acaba de comentar la relación entre CORE y rendimiento deportivo y lesiones. \\
\hline Descripción & $\begin{array}{l}\text { El jugador se coloca en decúbito prono con tobillos, rodilla y cadera fijados sobre la camilla. El resto } \\
\text { del cuerpo sobresale de la camilla. Los brazos irán cruzados y con cada mano sobre el hombro } \\
\text { contrario. Se colocará una toalla bajo las espinas ilíacas anterosuperiores para evitar molestias. } \\
\text { A partir de esa posición, el jugador deberá elevar el tronco y mantenerlo en posición completamente } \\
\text { paralelo al suelo el mayor tiempo posible. Se anotará el tiempo que transcurre hasta que pierde la } \\
\text { horizontalidad (95). }\end{array}$ \\
\hline $\begin{array}{c}\text { Aspectos a } \\
\text { Observar / } \\
\text { Controlar }\end{array}$ & - Pedir una contracción de glúteo al tiempo que se eleva el tronco. \\
\hline
\end{tabular}

Tabla 20: Aplicación del Biering Sorensen Modificado

B5. Side Bridge.

\begin{tabular}{|c|l|c|c|}
\hline $\begin{array}{c}\text { Nombre del } \\
\text { Test: }\end{array}$ & SIDE BRIDGE TEST & Objetivo: & $\begin{array}{c}\text { VALORAR LA FUERZA DE LA MUSCULATURA } \\
\text { LATERAL DEL CORE }\end{array}$ \\
\hline $\begin{array}{c}\text { Motivo de su } \\
\text { elección }\end{array}$ & \multicolumn{2}{|l|}{ Se acaba de comentar la relación entre CORE y rendimiento deportivo y lesiones. } \\
\hline
\end{tabular}




\begin{tabular}{|c|l|}
\hline \multirow{2}{*}{ Descripción } & $\begin{array}{l}\text { El jugador se coloca en decúbito lateral y realiza una plancha lateral, por lo que estará apoyado sobre } \\
\text { un codo y los pies del lado ipsilateral. Deberá mantener la posición de plancha el mayor tiempo } \\
\text { posible. El test finaliza cuando la cadera descienda. Se realizará por lado izquierdo y derecho (95). }\end{array}$ \\
\hline Aspectos a & - Evitar la flexión / extensión de cadera. \\
Observar / & - Controlar el descenso de la cadera. \\
Controlar & - Mantener completamente alineada la columna. \\
\hline
\end{tabular}
Tabla 21: Aplicación del Side Bridge Test

B6. Trunk Flexor Endurance Test.

\begin{tabular}{|c|l|l|l|}
\hline TEST & $\begin{array}{c}\text { TRUNK FLEXOR } \\
\text { ENDURANCE TEST }\end{array}$ & OBJETIVO & $\begin{array}{c}\text { VALORAR LA FUERZA ISOMÉTRICA DE } \\
\text { LA REGIÓN ABDOMINAL }\end{array}$ \\
\hline $\begin{array}{c}\text { Motivo de } \\
\text { su elección }\end{array}$ & \multicolumn{2}{|c|}{ Se acaba de comentar la relación entre CORE y rendimiento deportivo y lesiones. } \\
\hline Descripción & $\begin{array}{l}\text { El jugador se sienta en la camilla, flexiona rodillas y cadera a } 90^{\circ} \text {, cruza los brazos por } \\
\text { delante del pecho y le sujetamos los pies. Además apoya la espalda en un respaldo con una } \\
\text { inclinación de } 60^{\circ} \text { con respecto a la horizontal. } \\
\text { Partiendo de esa posición se retira el respaldo y debe mantener dicha posición durante el } \\
\text { mayor tiempo posible hasta tocar con el tronco un tope colocado } 10 \mathrm{~cm} \text { por detrás del } \\
\text { jugador (95). }\end{array}$ \\
\hline $\begin{array}{c}\text { Aspectos a } \\
\text { Observar } / \\
\text { Controlar }\end{array}$ & - Evitar flexión lumbar. \\
\hline
\end{tabular}

\section{B7. Test de Disquinesia Escapular.}

Existe una prueba que está validada, en la que se realizan 3 repeticiones y se colocan sensores electromagnéticos en tórax, escápula y húmero (97). Por falta de material se utiliza una prueba muy similar (con 5 repeticiones) con una fiabilidad satisfactoria en deportistas "Overhead" y que está a nuestro alcance (98).

\begin{tabular}{|c|l|c|c|}
\hline TEST & $\begin{array}{c}\text { SCAPULAR } \\
\text { DYSKINESIS TEST }\end{array}$ & OBJETIVO & \multicolumn{1}{c|}{$\begin{array}{c}\text { DETECTAR UNA POSIBLE DISQUINESIA } \\
\text { ESCAPULAR }\end{array}$} \\
\hline $\begin{array}{c}\text { Motivo de su } \\
\text { elección }\end{array}$ & $\begin{array}{l}\text { Como se ha justificado en el apartado 3.1.6, la disquinesia escapular suele aparecer asociada a varias } \\
\text { lesiones de hombro, por lo que es interesante su valoración. }\end{array}$ \\
\hline Descripción & $\begin{array}{l}\text { El jugador se coloca a 2 }-3 \text { metros de una cámara que grabará la visión posterior. Sin camiseta para } \\
\text { observar el movimiento escapular. La posición de partida será con los brazos al lado del cuerpo, los } \\
\text { codos rectos y los hombros en rotación neutral. A partir de ahí el jugador realiza 5 flexo-extensiones } \\
\text { de hombro a una velocidad de 3 segundos por movimiento. Posteriormente realiza una abducción - } \\
\text { aducción. El jugador sujeta una pesa de 2,5 Kg en cada mano y llevará el pulgar hacia arriba. Se } \\
\text { evaluará cada escápula por separado y se catalogará como disquinesia normal, leve u obvia en base al } \\
\text { movimiento que se observa (ver tabla en Anexo } \mathrm{IV} \text { ) (98). }\end{array}$ \\
\hline
\end{tabular}

C) Déficit Propioceptivo.

\section{C1. Test de Equilibrio Dinámico.}

En primera instancia se utilizó el Test de la Estrella (Star Excursion Balance Test) para medir el equilibrio dinámico monopodal de un sujeto mientras alcanzaba 8 direcciones. Éste es un test que tiene una alta fiabilidad inter e intraobservador (99) y requiere de un pequeño aprendizaje, por lo que se recomiendan 6 repeticiones en cada dirección antes de realizar el test (99). Poco después de su aparición, y debido a la redundancia, se limitaron las direcciones a 3 (anterior, medial posterior y lateral posterior) y se redujeron las repeticiones a 3 (SEBT modificado) (100), además ahorra bastante tiempo y tiene validez como prueba dinámica para predecir el riesgo de lesión (101).

Posteriormente, a partir de la modificación del SEBT aparece el Y Balance Test (YBT), que mide equilibrio dinámico monopodal en las mismas 3 direcciones pero sobre una plataforma de PVC y también tiene una alta fiabilidad (102), incluso algo mayor que el SEBT modificado (103). La diferencia entre ambos test es que el YBT permite apoyar el pie durante el alcance dinámico, por lo que se obtienen valores distintos en las mediciones $(104,105)$. 


\begin{tabular}{|c|c|c|c|}
\hline & SEBT MOD & OBJETIVO & DETECTAR POSIBLES DEFICIT PRO \\
\hline & \multicolumn{3}{|c|}{$\begin{array}{l}\text { Debido a que no dispongo de la estructura para realizar el YBT pero sí puedo poner cinta sobre el } \\
\text { suelo para dibujar las líneas del SEBT elijo el SEBT MODIFICADO para su realización, ya que } \\
\text { también presenta una alta fiabilidad inter e intra observadores (99) y es una herramienta sencilla y } \\
\text { económica. Recientemente, un estudio señala que se puede realizar el test únicamente con las } \\
\text { direcciones Medial Posterior y Lateral Posterior (106), no obstante, como el test que planteo incluye } \\
\text { esas dos direcciones más la anterior y ha sido utilizado para detectar jugadores con mayor riesgo de } \\
\text { lesión en estudios científicos (107), me inclino por realizarlo con } 3 \text { direcciones. }\end{array}$} \\
\hline Descr & \multicolumn{3}{|c|}{$\begin{array}{l}\text { El jugador se coloca en el centro de las líneas que hayamos dibujado en el suelo, descalzo sobre el pie } \\
\text { que se va a valorar y con las manos en la cintura. A partir de ahí debe tocar, con la punta del dedo del } \\
\text { pie, el punto más lejano posible en cada una de las direcciones. Se mide la distancia que alcanza en } \\
\text { cada una de las } 3 \text { repeticiones y se calcula la media de todos los intentos en cada dirección (100). } \\
\text { Además, se ha encontrado que la longitud de la pierna está muy relacionada con la distancia que se } \\
\text { alcanza (108) (obviamente), por lo que, para normalizar los resultados, dividiremos cada distancia por } \\
\text { la longitud de la pierna (desde la espina ilíaca anterosuperior hasta el maléolo medial) y } \\
\text { multiplicaremos el número obtenido por } 100 \text { (108). Además se suma la distancia de cada dirección y } \\
\text { se divide por } 3 \text { veces la longitud de la extremidad para obtener el rendimiento general del test (107). }\end{array}$} \\
\hline & \multicolumn{3}{|c|}{$\begin{array}{l}\text { - El contacto con la línea dibujada debe ser limpio, sin apoyar el peso del cuerpo (108). } \\
\text { - Evitar el desequilibrio postural durante el alcance (108). } \\
\text { - } \quad \text { No mover el pie de apoyo del centro de la cuadrícula (108). }\end{array}$} \\
\hline
\end{tabular}
Tabla 24: Aplicación del SEBT Modificado

\section{D) Valoración Postural Estática.}

Para el análisis postural estático seguiré las indicaciones de Kendall (27) que me permitirá obtener una visión general del jugador e identificar anomalías estructurales o funcionales (causadas por desequilibrios musculares).

Para su realización tomaremos 4 fotografías del jugador (Plano Sagital Izquierdo y Derecho, Plano Frontal Anterior y Posterior). Es importante fijarse que, en las imágenes del plano frontal, los talones deben estar juntos y cada pie rotado externamente $15^{\circ}$. Esto nos permitirá partir de una posición estándar y simétrica, ya que es un error muy común no atender a la posición de los pies antes de capturar la imagen. En las visiones sagitales, los pies deben permanecer paralelos a la anchura de los hombros mirando al frente, cuidando que no haya uno más adelantado que otro. La línea de plomada debe pasar por delante del maléolo tibial.

\section{E) Valoración Dinámica.}

El Gold Standard para la valoración del movimiento es el análisis cinemático tridimensional (3D) (109), pero su inaccesibilidad me impide utilizarlo. En lugar de ello se grabarán los tests con 3 cámaras.

Antes de indicar los tests que hay en este apartado es necesario señalar que la batería de test de la Functional Movement Screen (FMS) es la prueba más utilizada por varios clubes de élite de fútbol para detectar el riesgo de lesión (110). En 2016 se publicó una revisión sistemática (111) y una revisión sistemática con meta-análisis (112) para valorar la fiabilidad de esta batería de test. Ambos estudios concluyeron que la fiabilidad era "moderada" tanto intra como entre observadores. Sin embargo, en 2017, otra revisión sistemática con meta-análisis refirió una excelente fiabilidad intra e interobservador, llegando a indicar, aunque con evidencia limitada, que sujetos con una puntuación menor a 14 tendrían un riesgo mayor de lesión que sujetos con puntuaciones altas. No obstante, no pudieron demostrar que fuese una prueba válida, debido a la gran heterogeneidad de los datos existentes y que no se puede comparar con un gold standard (113). En base a esto no incluyo ningún test de la FMS en mi valoración porque considero que tengo suficiente información con los tests propuestos para plantear un trabajo riguroso en el programa de intervención. Creo que estos tests no me aportarían información nueva y, en ningún caso, busco plantear algo que pueda hacer perder el tiempo a mi sujeto por el mero hecho de hacer más cosas.

\section{E1. Single Leg Squat.}

Este test muestra una fiabilidad aceptable cuando se discriminan las repeticiones aceptables realizadas, pero la fiabilidad es deficiente cuando se intenta establecer el principal factor limitante en una ejecución no perfecta (109). Ante los ojos de un examinador inexperto la fiabilidad es baja pero aceptable 
para un fisioterapeuta experimentado (114). Finalmente, una revisión sistemática con metaanálisis de 2019 señala que la mayoría de los estudios encuentran una fiabilidad "moderada" entre observadores y "sustancial" a nivel interno, no obstante concluye que es una prueba aceptable para su uso (115), coincidiendo con otros estudios (116). Esta prueba se grabará en video, ya que el análisis de video en 2D es una forma consistente y válida para medir el valgo de rodilla (117).

\begin{tabular}{|c|c|c|c|}
\hline TEST & $\begin{array}{l}\text { SINGLE LEG } \\
\text { SQUAT }\end{array}$ & OBJETIVO & $\begin{array}{l}\text { VALORAR EL VALGO DINÁMICO DE RODILLA Y LA } \\
\text { INCLINACIÓN LATERAL DE TRONCO }\end{array}$ \\
\hline $\begin{array}{l}\text { Motivo de su } \\
\text { elección }\end{array}$ & \multicolumn{3}{|c|}{$\begin{array}{l}\text { Este test permite reproducir situaciones comunes en el deporte en las que se requiere un control del } \\
\text { tronco en un apoyo monopodal (109), como suele ocurrir en el fútbol, en el que la mayoría de las } \\
\text { acciones (carrera, saltos, golpeos de balón,...) se realizan en apoyo monopodal, permitiéndonos } \\
\text { observar el comportamiento de la rodilla y del tronco que, como veremos en el siguiente test, son } \\
\text { claves en la prevención de lesiones. }\end{array}$} \\
\hline Descripción & \multicolumn{3}{|c|}{$\begin{array}{l}\text { El jugador permanece en apoyo monopodal y se coloca una referencia a la altura de la rodilla (para } \\
\text { estandarizar el test). Se pide al jugador que realice } 5 \text { sentadillas unipodales hasta llegar a tocar con las } \\
\text { nalgas la referencia que habíamos establecido (109). Se le pide que cruce los brazos sobre el pecho } \\
\text { para evitar compensaciones de los brazos y poder observar mejor el movimiento del tronco (118). } \\
\text { En este artículo flexiona } 75^{\circ} \text {, con lo que pondría la marca de referencia por encima de la rodilla (118). }\end{array}$} \\
\hline $\begin{array}{l}\text { Aspectos a } \\
\text { Observar / } \\
\text { Controlar }\end{array}$ & \multicolumn{3}{|c|}{$\begin{array}{l}\text { El test se detiene cuando (109): } \\
\text { - Hay una pérdida de equilibrio que impide realizar la sentadilla. } \\
\text { - No se alcanza la profundidad establecida (tocar la referencia con las nalgas). } \\
\text { - } \quad \text { El jugador tarda más de } 6 \text { segundos en realizar una repetición (119). }\end{array}$} \\
\hline
\end{tabular}

\section{E2. Landing Error Scoring System (LESS).}

El aumento del valgo de rodilla es un factor de riesgo en esguinces de rodilla y LCA $(33,48,93)$, especialmente en recepciones de salto (120). Sin embargo este mecanismo aislado no es suficiente para provocar una lesión en el LCA sin lesionar antes el Ligamento Colateral Medial (121), pero sí cuando aparece con una falta de estabilidad del resto del cuerpo (118). En este sentido, un déficit en el control del tronco puede aumentar el riesgo de lesiones de rodilla (122).

Otros tests muy utilizados en la literatura, especialmente en la recuperación tras una lesión de LCA, son los Single Hop Test (123). Estos test buscan conocer si existe un índice de simetría menor al 80\% entre la pierna lesionada por LCA y la contralateral (123), presentan una buena fiabilidad intra observador en sujetos sanos (124) y constituyen una herramienta válida para valorar el rendimiento a partir del $4^{\circ}$ mes de rehabilitación de una rotura del LCA (concretamente el Single Hop Test, Triple Hop Test, Cross-Over Hop Test y Timed Hop Test) (125). El jugador con el que trabajamos no ha sufrido una rotura de LCA, además un estudio reciente demuestra que se puede obtener un rendimiento "satisfactorio" en el Timed Hop Test (índice de simetría superior al 80 - $85 \%$ ) sin haber ganado la fuerza requerida durante la recuperación de una lesión de cruzado (126), por lo que no incluiremos estos tests en nuestra valoración.

Un test que presenta una excelente fiabilidad intra e interobservador para medir el valgo de rodilla es el Single Leg Drop Vertical Jump (SLDVJ) (118). Sin embargo, la lesión de LCA tiene un origen multifactorial y, posiblemente implique distintos factores de riesgo biomecánicos en distintos planos (121). Existe un test que evalúa esos aspectos biomecánicos multiplanares de una forma más exhaustiva que el SLDVJ, que es el Landing Error Scoring System (LESS), además es un test validado y confiable para identificar patrones de movimiento potencialmente lesivos en recepciones de salto en comparación con el gold standard que es el análisis del movimiento 3D en laboratorio (121) y es una buena herramienta para ser utilizada con futbolistas juveniles de élite (127). El LESS se realiza con 2 cámaras que graban la ejecución del test y se analiza en base a 17 items. Para hacer la medición más rápida, se comparó el LESS con un test medido en tiempo real (LESS-RT) y se encontró que es una medida confiable para ser utilizada (128). El LESS-RT reduce los ítems a analizar a 10.

\begin{tabular}{|c|c|c|c|}
\hline TEST & $\begin{array}{c}\text { LANDING ERROR } \\
\text { SCORING SYSTEM }\end{array}$ & OBJETIVO & $\begin{array}{c}\text { VALORAR EL RIESGO POTENCIAL DE LESIÓN } \\
\text { DE LCA }\end{array}$ \\
\hline $\begin{array}{c}\text { Motivo de su } \\
\text { elección }\end{array}$ & $\begin{array}{l}\text { Recordemos que la posición que ocupa el jugador implica frecuentes saltos para blocar o despejar } \\
\text { balones, normalmente con perturbaciones, por lo que será necesario valorar aspectos biomecánicos } \\
\text { multiplanares de su recepción de salto para detectar un riesgo de lesión. Utilizaré el LESS-RT porque }\end{array}$ \\
\hline
\end{tabular}




\begin{tabular}{|c|l|}
\hline & $\begin{array}{l}\text { tiene unos ítems sencillos pero no estoy suficientemente familiarizado con el test como para evaluarlo } \\
\text { correctamente en tiempo real, por lo que utilizaré las dos cámaras para comparar resultados } \\
\text { posteriormente (además estarán montadas por la grabación de otros tests). No obstante, cuando mi } \\
\text { grado de experiencia lo permita, podré utilizar el LESS-RT sin grabación de video. }\end{array}$ \\
\hline Descripción & $\begin{array}{l}\text { El jugador se coloca de pie sobre una caja de } 30 \mathrm{~cm} \text { de altura, con las piernas separadas a la altura de } \\
\text { los hombros y pies hacia delante. Frente a él, a una distancia de la mitad de su altura, se pinta una } \\
\text { línea en el suelo. El jugador debe saltar con ambos pies, caer justo detrás de la línea con ambos pies a } \\
\text { la vez e, inmediatamente, realizar un salto vertical lo más alto que pueda. Se realizan } 2 \text { repeticiones } \\
\text { (en lugar de las } 4 \text { que requiere el test) que se graban con dos cámaras, una frontal y otra sagital } \\
(121,128) . \text { La ejecución en puntúa en base a 10 ítems que se recogen en el Anexo V. }\end{array}$ \\
\hline $\begin{array}{l}\text { Aspectos a } \\
\text { Observar/ } \\
\text { Controlar }\end{array}$ & - El salto de la caja debe ser hacia delante, no hacia arriba. \\
\hline
\end{tabular}

Tabla 26: Aplicación del Landing Error Scoring System (LESS)

\section{E3. Tuck Jump Test.}

Este test mostró una excelente fiabilidad intra y entre observadores en un estudio realizado a 5 hombres y 5 mujeres (129) y también en 25 futbolistas juveniles de élite, aunque recomiendan tomar los resultados con cautela salvo para el valgo dinámico de rodilla, donde existe mayor fiabilidad (130).

\begin{tabular}{|c|c|c|c|}
\hline TEST & TUCK JUMP TEST & OBJETIVO & IDENTIFICAR DÉFICITS NEUROMUSCULARES \\
\hline $\begin{array}{l}\text { Motivo de su } \\
\text { elección }\end{array}$ & \multicolumn{3}{|c|}{$\begin{array}{l}\text { Un control neuromuscular insuficiente en los miembros inferiores, especialmente en rodilla, puede ser } \\
\text { un factor de riesgo de lesión (131). De todos los factores de riesgo que subyacen en la lesión de LCA, } \\
\text { el déficit neuromuscular es el más importante y modificable (132). Además, este test permite ejecutar } \\
\text { saltos y recepciones con una cierta fatiga acumulada, tal y como podría suceder en los minutos finales } \\
\text { de un partido. Es importante ver cómo responde el jugador en ese contexto. }\end{array}$} \\
\hline Descripción & \multicolumn{3}{|c|}{$\begin{array}{l}\text { El jugador permanece de pie, con los pies separados } 35 \mathrm{~cm} \text { (dos trozos de cinta que se pegan en el } \\
\text { suelo). Durante } 10 \text { segundos debe realizar saltos verticales lo más alto que pueda, flexionando las } \\
\text { rodillas. El test se grabará con visión frontal y sagital y se analiza retrospectivamente en base a } 10 \\
\text { criterios. Si un déficit está presente en algún criterio en } 2 \text { o más repeticiones se marca, por lo que, a } \\
\text { mayor puntuación, menor rendimiento (132). Los criterios del test se pueden ver en el Anexo VI. }\end{array}$} \\
\hline $\begin{array}{l}\text { Aspectos a } \\
\text { Observar / } \\
\text { Controlar }\end{array}$ & \multicolumn{3}{|c|}{$\begin{array}{l}\text { - El contacto con el suelo debe ser mínimo al aterrizar. } \\
\text { - } \quad \text { El apoyo debe realizarse sobre las líneas marcadas en el suelo. }\end{array}$} \\
\hline
\end{tabular}

Tabla 27: Aplicación del Tuck Jump Test

\section{E4. Patrones de Movimiento.}

\section{E4.1 Hinge.}

Es un movimiento dominante de cadera que es base de muchos ejercicios y, además, tiene relación con actividades de la vida diaria como coger objetos. Para realizar la valoración el jugador cogerá una pica y la colocará en su espalda (una mano a la altura de la zona lumbar y la otra a la altura de la nuca). A partir de ahí, realizará la flexión de cadera sin separar una mano ni otra de la espalda (manteniendo la neutralidad de la columna) y sin desplazar las tibias.

\section{E4.2 Hip Thrust.}

Es un movimiento que potencia la cadena posterior y, en particular el glúteo mayor. Ya se ha comentado la importancia de esta musculatura para, entre otras cosas, el control de la rodilla. La valoración se realiza partiendo de decúbito supino con rodillas flexionadas, se realiza una extensión de cadera y se termina apoyado sobre cintura escapular y pies. Es importante que durante el movimiento se active el glúteo. No se realizará en valoración inicial sino que se observará durante las primeras sesiones.

\section{E4.3 Presses y Pulles.}

Observaremos la ejecución en ejercicios de empuje y tracción vertical y horizontal, para asegurarnos que la técnica es correcta en todo momento. No se realizará en valoración inicial sino que se observará durante las primeras sesiones. 
F) Cuestionario de Dolor Lumbar.

F1. Índice de Discapacidad de Oswestry.

Haciendo una revisión de la literatura podemos comprobar que los cuestionarios más utilizados son el "Cuestionario de Discapacidad Roland - Morris" (CDR) y el "Índice de Discapacidad de Oswestry" (IDO). Ambos están validados y presentan una alta confiabilidad $(133,134)$.

\begin{tabular}{|c|c|c|c|}
\hline TEST & $\begin{array}{l}\text { INDICE DE DISCAPACIDAD } \\
\text { DE OSWESTRY }\end{array}$ & OBJETIVO & VALORAR EL DOLOR DE ESPALDA \\
\hline $\begin{array}{l}\text { Motivo de su } \\
\text { elección }\end{array}$ & \multicolumn{3}{|c|}{$\begin{array}{l}\text { Aunque no hay grandes diferencias entre un cuestionario y otro, los autores recomiendan utilizar IDO } \\
\text { con sujetos "con probabilidad de discapacidad severa persistente" y el CDR con sujetos "con } \\
\text { probabilidad de tener relativamente poca discapacidad". Sin embargo, aunque nuestro jugador no } \\
\text { presenta una discapacidad severa, tras analizar ambos cuestionarios creo que el IDO se adapta mejor a } \\
\text { su casuística, por lo que se pedirá al jugador que lo rellene pensando en la "semana anterior", no sólo } \\
\text { en el "día de hoy" como indica el cuestionario original } \\
\text { Además es muy rápido de rellenar (menos de } 5 \text { minutos) y de corregir (menos de } 1 \text { minuto) y ha sido } \\
\text { diseñado específicamente para sujetos con dolor lumbar. }\end{array}$} \\
\hline Descripción & \multicolumn{3}{|c|}{ 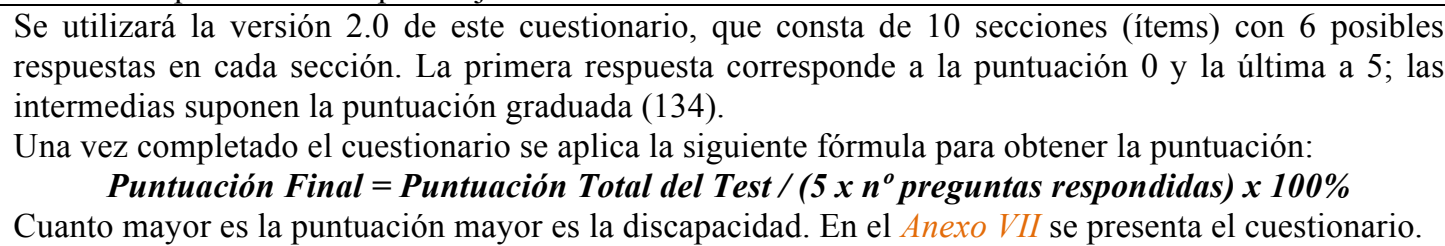 } \\
\hline
\end{tabular}

\section{G) Control Motor del Complejo Coxolumbopélvico.}

A continuación se presentan una serie de tests que nos permiten valorar el control del movimiento de la columna lumbar en flexión, extensión y rotación. Todos los tests que se proponen tienen una fiabilidad de buena a "sustancial" (39). En condiciones normales, estos tests se podrían realizar durante las primeras sesiones como parte de la sesión, eso permitiría aligerar la evaluación inicial. Sin embargo, debido a las circunstancias que han envuelto este trabajo (cambio de sujeto, viaje de concentración con el equipo,...) se llevaron a cabo junto con otros en un solo día, dado que el tiempo necesario para realizarlos no es muy alto y los otros tests se habían hecho durante la concentración por un fisioterapeuta.

\section{G1. Forward Bending.}

La inclinación anterior en bipedestación es una de las acciones más realizadas en la vida diaria de cualquier persona. El jugador se coloca de pie, con las piernas ligeramente separadas. A partir de ahí realiza una flexión anterior de cadera tratando de llegar con las manos al suelo (135).

\section{G2. Sitting Knee Extension.}

El jugador se sienta en el borde de la camilla, con la columna neutra y las piernas colgando. Desde esa posición realizará una extensión de rodilla sin perder la neutralidad, llegando hasta $30-50^{\circ}(38)$.

\section{G3. One Leg Stance.}

Desde posición bípeda, el jugador se apoya sobre uno de sus pies y levanta la pierna contralateral. Después hará lo mismo con la otra extremidad. Prestaremos atención al desplazamiento lateral. Hasta 10 $\mathrm{cm}$ de desplazamiento en un lado y menos de $2 \mathrm{~cm}$ entre un lado y otro se considera normal $(38,39)$.

G4. Prone lying active knee Flexion.

El jugador se coloca en decúbito prono y flexiona una rodilla intentando llevar el talón al glúteo. Deberá flexionar, al menos, $90^{\circ}$ sin perder la neutralidad de la columna (38). Observaremos si hay movimiento en la zona lumbopélvica. Se puede colocar un stabilizer bajo la cadera del jugador.

\section{G5. Rocking Backwards.}

En posición de cuadrupedia, con $90^{\circ}$ de flexión de cadera, se realiza un "balanceo" de la pelvis hacia atrás sin perder la neutralidad de la columna. Se debe llegar hasta $120^{\circ}$ de flexión sin que aparezca la flexión lumbar (38). 


\section{H) Aspectos Psicológicos.}

H1. Cuestionario de Perfil Psicológico.

Como se explica en el apartado 3.1.4.5, el estrés y la ansiedad pueden aumentar el riesgo de lesión y el dolor lumbar (136). Trabajamos con un jugador joven, profesional y que aspira a llegar a lo más alto en este deporte. Las situaciones que se viven en entrenamientos y competición, el nivel de exigencia y autoexigencia,... pueden afectar al jugador, por lo que debemos obtener información en este sentido, no para actuar si se encuentra algún dato llamativo, sino para que lo comente con su psicólogo deportivo.

Si revisamos la literatura comprobamos que los cuestionarios más utilizados para valorar aspectos psicológicos son: "Sport Competition Anxiety Test" (SCAT) (137), "Life Events Survey for Collegiate Athletes" (LESCA) (138), "Swedish universities Scales of Personality" (SSP) (139), "The Athletic Coping Skills Inventory - 28" (ACSI-28) (140) o "Brief COPE" (141).

Para este trabajo utilizaré el "Cuestionario de Características Psicológicas relacionadas con el Rendimiento Deportivo en jugadores de Fútbol” (CPRD-F) (142), que es una adaptación del Cuestionario original que ha sido validado en su versión española (143).

\begin{tabular}{|c|c|c|c|}
\hline TEST & $\begin{array}{l}\text { Características Psicológicas relacionadas con el } \\
\text { endimiento Deportivo adaptado al Fútbol (CPRD - F) }\end{array}$ & OBJETIVO & PSICOLOGICO \\
\hline & \multicolumn{3}{|c|}{$\begin{array}{l}\text { He escogido el CPRF - F porque es una versión adaptada al fútbol (el deporte que nos ocupa) de un } \\
\text { cuestionario que ha sido validado, además, uno de los autores de esa adaptación ha sido jugador de } \\
\text { fútbol profesional, por lo que sabe en primera instancia qué puede estar viviendo o sintiendo el } \\
\text { jugador con el que trabajo en todo momento. }\end{array}$} \\
\hline Descripción & \multicolumn{3}{|c|}{$\begin{array}{l}\text { Este cuestionario modifica las escalas del estudio original distinguiendo: 1) Autoconfianza, 2) } \\
\text { Preparación Mental, 3) Concentración, } 4) \text { Control de Estrés y Ansiedad y 5) Motivación; y reduce el } \\
\text { número de ítems de } 55 \text { a } 40(9,8,11,7 \text { y } 5 \text { respectivamente para cada escala). Para cada ítem hay } 5 \\
\text { posibles respuestas, desde "totalmente de acuerdo" hasta "totalmente en desacuerdo" más la opción de } \\
\text { "no entiendo el ítem". } \\
\text { En base a la respuesta marcada en cada ítem, se da una puntuación de } 1 \text { a } 5 \text { y se suman para conocer la } \\
\text { puntuación total del test, que será de } 200 \text { puntos ( } 45 \text { en Autoconfianza, } 40 \text { en Preparación Mental, } 35 \\
\text { en Concentración, } 55 \text { en Control del Estrés y Ansiedad y } 25 \text { en Motivación). En el Anexo VIII se } \\
\text { presenta el cuestionario completo (144). }\end{array}$} \\
\hline
\end{tabular}

Tabla 29: Aplicación del Cuestionario CPRD adaptado al Fútbol

\section{3 ¿Qué datos he obtenido? Resultados de la evaluación.}

\subsubsection{Resultados de los Tests de Flexibilidad y ROM.}

\begin{tabular}{|c|c|c|c|c|c|c|c|c|c|c|}
\hline \multicolumn{11}{|c|}{ RESULTADOS DE LA EVALUACIÓN INICIAL } \\
\hline \multirow{6}{*}{ 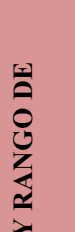 } & \multirow{2}{*}{\multicolumn{2}{|c|}{ TEST }} & \multirow{2}{*}{\multicolumn{2}{|c|}{$\begin{array}{c}\text { DATOS DE } \\
\text { REFERENCIA }\end{array}$}} & \multicolumn{2}{|c|}{ RESULTADOS } & \multicolumn{2}{|c|}{$\begin{array}{c}\text { REALIZADO } \\
\text { POR }\end{array}$} & \multicolumn{2}{|c|}{$\begin{array}{c}\text { EVALUACIÓN } \\
\text { PROPUESTA POR }\end{array}$} \\
\hline & & & & & IZQ & DER & FISIO & MÍ & EL CLUB & MÍ \\
\hline & \multicolumn{2}{|l|}{ 1. Lunge Test } & $36,5^{\circ}$ & $(145)$ & $35^{\circ}$ & $34^{\circ}$ & $\mathrm{X}$ & & $\mathrm{X}$ & $\mathrm{X}$ \\
\hline & \multicolumn{2}{|l|}{ 2. Test de Kea } & $15^{\circ}$ & $(146)$ & $35^{\circ}$ & $40^{\circ}$ & $\mathrm{X}$ & & & $\mathrm{X}$ \\
\hline & \multicolumn{2}{|l|}{ 3. Thomas Test } & Negativo & $(27)$ & \multicolumn{2}{|c|}{ Psoas derecho acortado } & $\mathrm{X}$ & & $\mathrm{X}$ & $\mathrm{X}$ \\
\hline & \multicolumn{2}{|l|}{ 4. Test de Ober Modificado } & Negativo & $(27)$ & \multicolumn{2}{|c|}{ Negativo } & $\mathrm{X}$ & & & $\mathrm{X}$ \\
\hline \multirow{8}{*}{ 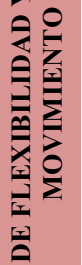 } & \multirow{2}{*}{ 5. Hip Internal Rotation Test } & C. $0^{\circ}$ & $35^{\circ}-40^{\circ}$ & $(147)$ & $40^{\circ}$ & $38^{\circ}$ & $\mathrm{X}$ & & $\mathrm{X}$ & $\mathrm{X}$ \\
\hline & & C. $90^{\circ}$ & $35^{\circ}-45^{\circ}$ & (147) & $30^{\circ}$ & $25^{\circ}$ & $\mathrm{X}$ & & & $\mathrm{X}$ \\
\hline & \multirow{2}{*}{ 6. Hip External Rotation Test } & C. $0^{\circ}$ & $45^{\circ}$ & $(147)$ & $20^{\circ}$ & $30^{\circ}$ & $\mathrm{X}$ & & $\mathrm{X}$ & $\mathrm{X}$ \\
\hline & & C. $90^{\circ}$ & $45^{\circ}$ & $(147)$ & $25^{\circ}$ & $30^{\circ}$ & $\mathrm{X}$ & & & $\mathrm{X}$ \\
\hline & \multicolumn{2}{|l|}{ 7. Passive Hip Flexion Test } & $125^{\circ}$ & $(27)$ & $145^{\circ}$ & $140^{\circ}$ & $\mathrm{X}$ & & & $\mathrm{X}$ \\
\hline & \multicolumn{2}{|l|}{ 8. Passive Hip Extension Test } & $10^{\circ}$ & $(27)$ & $10^{\circ}$ & $15^{\circ}$ & $\mathrm{X}$ & & & $\mathrm{X}$ \\
\hline & \multicolumn{2}{|l|}{ 9. Passive Hip Abduction Test } & $45^{\circ}$ & $(27)$ & $40^{\circ}$ & $35^{\circ}$ & $\mathrm{X}$ & & $\mathrm{X}$ & $\mathrm{X}$ \\
\hline & \multicolumn{2}{|l|}{ 10. Passive Hip Adduction Test } & $10^{\circ}$ & (27) & $10^{\circ}$ & $10^{\circ}$ & $\mathrm{X}$ & & $\mathrm{X}$ & $\mathrm{X}$ \\
\hline 勻 & \multicolumn{2}{|c|}{ 11. Shoulder Flexion } & $180^{\circ}$ & $(27)$ & $180^{\circ}$ & $180^{\circ}$ & $\mathrm{X}$ & & & $\mathrm{X}$ \\
\hline 寻 & \multicolumn{2}{|c|}{ 12. Shoulder Internal Rotation ROM } & $70^{\circ}$ & $(27)$ & $50^{\circ}$ & $40^{\circ}$ & $\mathrm{X}$ & & & $\mathrm{X}$ \\
\hline 2 & \multicolumn{2}{|c|}{ 13. Shoulder External Rotation ROM } & $90^{\circ}$ & $(27)$ & $90^{\circ}$ & $95^{\circ}$ & $\mathrm{X}$ & & & $\mathrm{X}$ \\
\hline & \multicolumn{2}{|c|}{ 14. Posterior Shoulder Flexibility Test } & $30^{\circ}$ & $(27)$ & $25^{\circ}$ & $25^{\circ}$ & $\mathrm{X}$ & & & $\mathrm{X}$ \\
\hline & \multicolumn{2}{|c|}{ 15. Longitud del Pectoral Menor } & IPM $>7,44$ & $(77)$ & 7,14 & 6,5 & & $\mathrm{X}$ & & $\mathrm{X}$ \\
\hline
\end{tabular}

Tabla 30: Datos de referencia, resultados iniciales y persona que realiza y propone los tests de Flexibilidad y ROM 


\subsubsection{Resultados de los Tests de Fuerza Analíticos.}

\begin{tabular}{|c|c|c|c|c|c|c|c|c|c|}
\hline \multicolumn{10}{|c|}{ RESULTADOS DE LA EVALUACIÓN INICIAL } \\
\hline \multirow{9}{*}{ 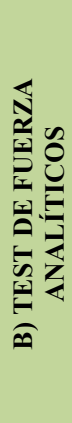 } & \multirow{2}{*}{ TEST } & \multirow{2}{*}{\multicolumn{2}{|c|}{$\begin{array}{c}\text { DATOS DE } \\
\text { REFERENCIA }\end{array}$}} & \multicolumn{2}{|c|}{ RESULTADOS } & \multicolumn{2}{|c|}{$\begin{array}{c}\text { REALIZADO } \\
\text { POR }\end{array}$} & \multicolumn{2}{|c|}{$\begin{array}{c}\text { EVALUACIÓN } \\
\text { PROPUESTA POR }\end{array}$} \\
\hline & & & & IZQ & DER & FISIO & MÍ & EL CLUB & MÍ \\
\hline & 1. Eccentric Hip Adduction & $2,2-3,0$ & (83) & 2,48 & 2,51 & $\mathrm{X}$ & & $\mathrm{X}$ & $\mathrm{X}$ \\
\hline & 2. Eccentric Hip Abduction & $2,4-3,6$ & $(83)$ & 2,48 & 2,75 & $\mathrm{X}$ & & $\mathrm{X}$ & $\mathrm{X}$ \\
\hline & 3. Squeeze Test & $2,8-4,4$ & $(83)$ & \multicolumn{2}{|c|}{3,01} & $\mathrm{X}$ & & $\mathrm{X}$ & $\mathrm{X}$ \\
\hline & 4. Biering Sorensen Modificado & $146^{\prime \prime}$ & (95) & \multicolumn{2}{|c|}{$38^{\prime \prime}$} & & $\mathrm{X}$ & & $\mathrm{X}$ \\
\hline & 5. Side Bridge & $\begin{array}{l}\text { Izq: 97"' } \\
\text { Der: } 94^{\prime}\end{array}$ & (95) & $71^{\prime \prime}$ & $61^{\prime \prime}$ & & $\mathrm{X}$ & & $\mathrm{X}$ \\
\hline & 6. Trunk Flexor Endurance Test & $144^{\prime \prime}$ & $(95)$ & \multicolumn{2}{|c|}{$56^{\prime \prime}$} & & $\mathrm{X}$ & & $\mathrm{X}$ \\
\hline & 7. Scapular Dyskinesis Test & $\begin{array}{c}\text { Normal / } \\
\text { Anomalía sutil } \\
\text { / Obvia }\end{array}$ & (98) & $\begin{array}{c}\text { Fx: } 2 \\
\text { Abd: } 2 \\
\text { Anom. Sutil }\end{array}$ & $\begin{array}{c}\text { Fx: } 2 \\
\text { Abd: } 1 \\
\text { Normal }\end{array}$ & & $\mathrm{X}$ & & $\mathrm{X}$ \\
\hline
\end{tabular}

Tabla 31: Datos de referencia, resultados iniciales y persona que realiza y propone los tests de Fuerza Analíticos

\subsubsection{Resultados del SEBT Modificado.}

\begin{tabular}{|c|c|c|c|c|c|c|c|c|}
\hline \multicolumn{9}{|c|}{ RESULTADOS DE LA EVALUACIÓN INICIAL } \\
\hline \multicolumn{9}{|c|}{ C) DÉFICIT PROPIOCEPTIVO } \\
\hline \multirow[t]{2}{*}{ TEST } & \multirow{2}{*}{\multicolumn{2}{|c|}{$\begin{array}{c}\text { DATOS DE } \\
\text { REFERENCIA }\end{array}$}} & \multicolumn{2}{|c|}{ RESULTADOS } & \multicolumn{2}{|c|}{$\begin{array}{c}\text { REALIZADO } \\
\text { POR }\end{array}$} & \multicolumn{2}{|c|}{$\begin{array}{l}\text { EVALUACIÓN } \\
\text { PROPUESTA POR }\end{array}$} \\
\hline & & & IZQ & DER & FISIO & MÍ & EL CLUB & Mí \\
\hline 1. SEBT Modificado & $<4 \mathrm{~cm}$ ANT & (107) & $\begin{array}{c}\text { A: } 74 \\
\text { PM: } 81 \\
\text { PL: } 72\end{array}$ & $\begin{array}{c}\text { A: } 67 \\
\text { PM: } 84 \\
\text { PL: } 84\end{array}$ & $\mathrm{X}$ & & & $\mathrm{X}$ \\
\hline
\end{tabular}

Tabla 32: Datos de referencia, resultados iniciales y persona que realiza y propone el Test SEBT Modificado

\subsubsection{Resultados de la Valoración Postural Estática.}

\begin{tabular}{|c|c|c|c|}
\hline ESTRUCTURA & VISIÓN FRONTAL & VISIÓN LATERAL & VISIÓN POSTERIOR \\
\hline Cabeza & Ni inclinada ni rotada & Adelantada & Ni inclinada ni rotada \\
\hline Columna Cervical & - & Hiperextendida & - \\
\hline Hombros & A la misma altura & Anteriorizados & - \\
\hline Escápulas & 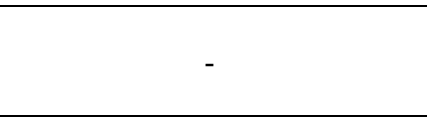 & 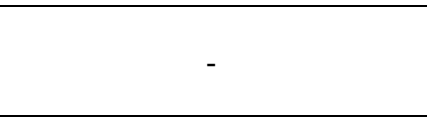 & $\begin{array}{l}\text { Derecha ligeramente alada. } \\
\text { Ambas separadas de la línea } \\
\text { media. Báscula axilar. }\end{array}$ \\
\hline Columna Dorsal & - & Levemente Cifótica & - \\
\hline Brazos & $\begin{array}{l}\text { Relajados con palmas mirando } \\
\text { al cuerpo. }\end{array}$ & 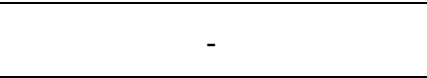 & - \\
\hline Columna Lumbar & - & Hiperlordosis & - \\
\hline Pelvis & Linealidad entre EIAS y EIPS & Desplazada hacia delante & - \\
\hline Cadera & A la misma altura & $\begin{array}{l}\text { Adelantadas pero ambas por } \\
\text { igual. }\end{array}$ & - \\
\hline Rodilla y Piernas & $\begin{array}{l}\text { Las piernas están rectas. Las } \\
\text { rótulas miran hacia delante. No } \\
\text { genu valgo ni varo. }\end{array}$ & $\begin{array}{l}\text { Ni flexionadas ni } \\
\text { hiperextendidas }\end{array}$ & No genu valgo ni varo \\
\hline Tobillo y pie & $\begin{array}{l}\text { Dedos ligeramente hacia fuera } \\
\text { (descalzo). Peso repartido de } \\
\text { forma equilibrada. }\end{array}$ & $\begin{array}{l}\text { Pierna vertical y en ángulo } \\
\text { recto con el pie. }\end{array}$ & - \\
\hline
\end{tabular}




\subsubsection{Resultados de los Tests de Valoración Dinámica.}

\begin{tabular}{|c|c|c|c|c|c|c|c|c|}
\hline \multicolumn{9}{|c|}{ RESULTADOS DE LA EVALUACIÓN INICIAL } \\
\hline \multirow{4}{*}{ 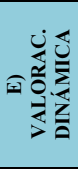 } & \multirow[b]{3}{*}{ 2. Landing Error Scoring System (LESS) } & \multirow{2}{*}{\multicolumn{2}{|c|}{$\begin{array}{c}\text { DATOS DE } \\
\text { REFERENCIA }\end{array}$}} & \multirow{2}{*}{ RESULTADOS } & \multicolumn{2}{|c|}{$\begin{array}{c}\text { REALIZADO } \\
\text { POR }\end{array}$} & \multicolumn{2}{|c|}{$\begin{array}{c}\text { EVALUACIÓN } \\
\text { PROPUESTA POR }\end{array}$} \\
\hline & & & & & FISIO & Mí & EL CLUB & Mí \\
\hline & & 0 Puntos & $(128)$ & 0 puntos & & $\mathrm{X}$ & & $\mathrm{X}$ \\
\hline & 3. Tuck Jump Test & 0 Puntos & (132) & 1 punto & & $\mathrm{X}$ & & $\mathrm{X}$ \\
\hline
\end{tabular}

Tabla 34: Datos de referencia, resultados iniciales y persona que realiza y propone los Test de Valoración Dinámica

- Single Leg Squat: En visión frontal se observa una gran inestabilidad de la rodilla, que pasa continuamente de valgo a varo. También se observa un valgo pronunciado en ambas rodillas (ver figuras 3 y 4). Además, el jugador no llega a tocar la marca que se le pone (cajón) sino que se deja caer antes de contactar. En visión lateral se aprecia que es incapaz de mantener los brazos pegados al tronco, ayudándose de ellos para estabilizarse (ver figura 5). En visión posterior se observa una inclinación del cuerpo hacia la pierna de apoyo cuando se realiza sobre el pie izquierdo, mientras que, cuando se mantiene sobre la derecha, se produce una caída de la cadera hacia el lado izquierdo (ver figuras 6 y 7 ).
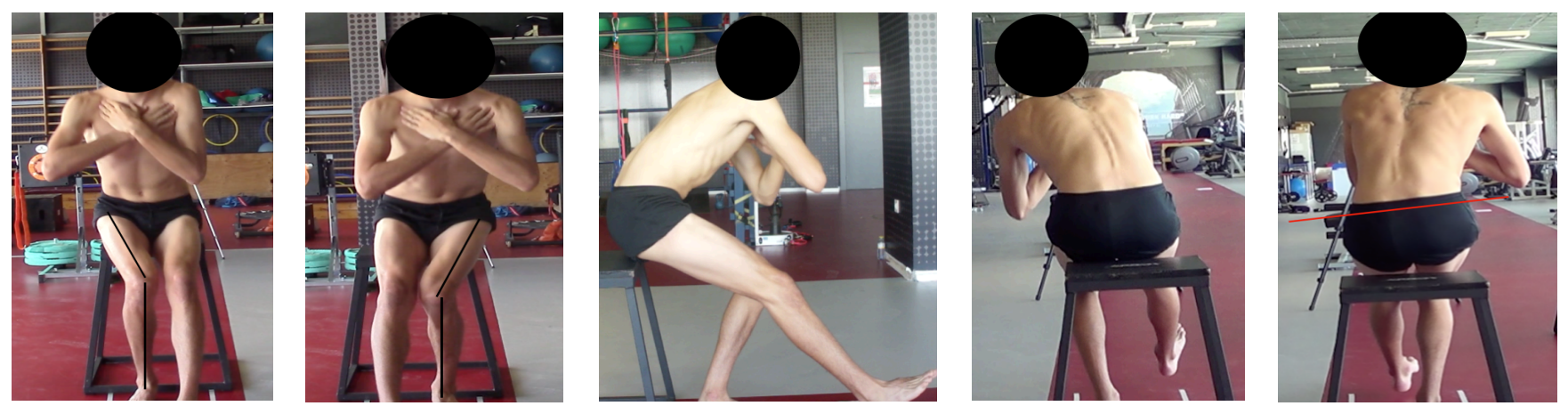

Figuras 3 - 7: Deficiencias iniciales observadas en el Single Leg Squat

- Hinge: El movimiento se realiza correctamente aunque aparece una flexión de rodilla y la cadera se desplaza posteriormente. Se mantiene la neutralidad de la columna (aunque en la figura 8 se puede apreciar que la pica está separada a nivel lumbar, es por el agarre que realiza con la mano caudal, pero esa distancia se mantiene constante durante todo el movimiento), la ejecución es dominante de cadera, no de rodilla, y las tibias no se anteriorizan.

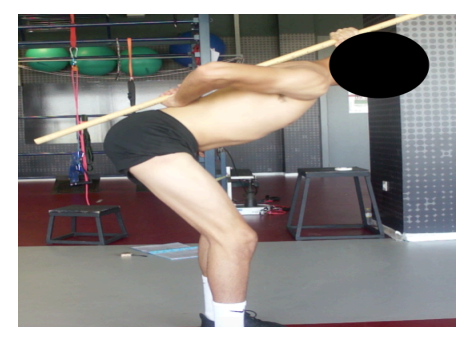

Figura 8: Ejecución inicial del Hinge

- Patrones de Movimiento: En este punto es necesario destacar que, dada la escasez de tiempo con la que cuento por el inesperado cambio de sujeto, la valoración del Hip Thrust y los Presses y Pulles se realizó durante las sesiones de entrenamiento.

\subsubsection{Resultados del Cuestionario de Dolor Lumbar.}

\begin{tabular}{|l|c|l|c|}
\hline Sección 1: Intensidad del Dolor & 2 & Sección 6: Estar de Pie & 1 \\
\hline Sección 2: Cuidado Personal & 0 & Sección 7: Dormir & 0 \\
\hline Sección 3: Levantar y/o cargar objetos & 0 & Sección 8: Vida Sexual & 0 \\
\hline Sección 4: Caminar & 0 & Sección 9: Vida Social & 0 \\
\hline Sección 5: Estar sentado & 0 & Sección 10: Viajar & 0 \\
\hline \multicolumn{2}{|c|}{ Puntuación Final = Puntuación Total del Test / (5 $\mathrm{x} \mathrm{n}^{\mathbf{0}}$ Secciones respondidas) x 100\% } & $\mathbf{6 \%}$ \\
\hline
\end{tabular}

2.3.7 Resultados de los Test de Control Motor del Complejo Coxolumbopélvico.

- Forward Bending: La amplitud de flexión de la cadera está ligeramente limitada. Además se produce una rectificación de columna lumbar y una flexión torácica excesiva.

- Sitting Knee Extensión: Durante los primeros grados y en ambas piernas, el jugador realiza una pequeña flexión lumbar que se mantiene hasta llegar a la amplitud de movimiento que se pide. 
- One Leg Stance: El desplazamiento lateral cuando está apoyado sobre el pie izquierdo es de 15 $\mathrm{cm}$., mientras que cuando apoya sobre el derecho es de $13 \mathrm{~cm}$.

- Prone Lying Active Knee Flexion: Esta prueba se realizó con un stabilizer. Cuando solamente yo podía ver la presión que realizaba, el jugador no llegaba a $90^{\circ}$ de flexión de rodilla. Sin embargo, cuando tenía ese feedback sí (aunque la presión no era constante, aumentaba y disminuía continuamente).

- Rocking Backward: Cuando el jugador se balancea hacia atrás pierde la neutralidad de la columna en $110^{\circ}$. Al final del movimiento, ambas caderas se flexionan por igual, sin que exista rotación lumbopélvica compensatoria.

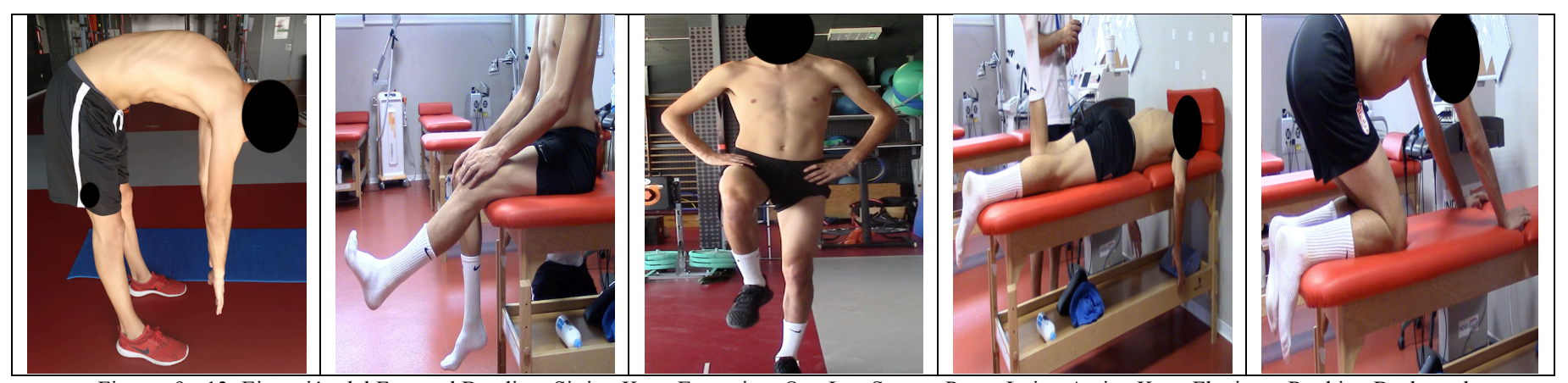

Figuras 9 - 13: Ejecución del Forward Bending, Sitting Knee Extension, One Leg Stance, Prone Lying Active Knee Flexion y Rocking Backward

\subsubsection{Resultados del Cuestionario de Perfil Psicológico}

\begin{tabular}{|l|c|l|c|}
\hline Autoconfianza & $42 / 45$ & Concentración & $31 / 35$ \\
\hline Actitud y Preparación Mental & $35 / 40$ & Motivación & $20 / 25$ \\
\hline Control de Estrés y Ansiedad & $44 / 55$ & & \\
\hline \multicolumn{2}{|r|}{ PUNTUACIÓN TOTAL } & $\mathbf{1 7 2} / \mathbf{2 0 0}$ \\
\hline
\end{tabular}

\section{3-. ANÁLISIS DE LA CASUÍSTICA}

“Lo que sabemos es una gota de agua; lo que ignoramos es el océano”

Isaac Newton, matemático y físico británico $(1642-1727)$

\subsection{Marco Teórico: Información necesaria para la interpretación de la Evaluación Inicial.}

\subsubsection{Introducción.}

\subsubsection{Características generales del fútbol y consecuencias de las lesiones.}

El fútbol es el deporte más practicado en todo el mundo $(1,148)$ con aproximadamente 200.000 jugadores profesionales y 240 millones de aficionados (149). Es un deporte de contacto, intermitente y de alta intensidad en el que se realizan carreras a distintas velocidades con cambios rápidos de dirección, arrancadas, paradas, saltos y patadas $(150,151)$ exponiendo a los jugadores de élite a continuas demandas físicas, técnicas, tácticas, psicológicas y fisiológicas $(152,153)$.

El hecho de jugar a fútbol puede mejorar la salud (154) pero también genera una elevada tasa de lesiones (1-4), ya que los futbolistas juegan con mayor intensidad y agresividad que antes (155), realizando continuas acciones de alta intensidad en los entrenamientos para alcanzar un mayor nivel de aptitud física, además de que se disputan un mayor número de partidos (156).

En el fútbol actual, el resultado prima por encima de cualquier otro aspecto. Para poder rendir al máximo nivel, los jugadores deben tener talento, un nivel óptimo de condición física y estar en condiciones de jugar (157). Una lesión disminuirá el rendimiento, ya que la lesión es el principal factor que reduce la disponibilidad del jugador (157). Por ello, cuando aparece la lesión se intenta que el futbolista esté disponible lo antes posible (158), ya que la inactividad impide que alcance su nivel de habilidad máximo $(4,159)$, e incluso reduce las posibilidades de éxito del equipo $(160,161)$, existiendo 
una relación entre la tasa de lesiones y la clasificación al final del campeonato (162), tanto en equipos que, por falta de recursos, no pueden sustituir a jugadores importantes (152) como en equipos "top", donde la ausencia de un jugador clave puede decidir el resultado de un partido importante, con grandes consecuencias económicas $(151,163)$. En este sentido, se estima que 1 mes de lesión para un jugador de un primer equipo de élite conlleva un gasto medio de alrededor de $500.000 €(164)$.

Por ello, con jugadores profesionales, donde las decisiones sobre el retorno al juego y la disponibilidad para los partidos tienen consecuencias financieras o estratégicas significativas para jugador y equipo, hay un gran interés en optimizar el diagnóstico, el tratamiento terapéutico y el proceso de rehabilitación tras las lesiones, de modo que se minimice la presencia de recurrencias (165).

En concreto, para la posición que ocupa nuestro sujeto, la de portero, la distribución de las lesiones parece estar asociada con características específicas de desempeño relacionadas con esa posición (166). (ver 3.1.2.7).

\subsubsection{Justificación de la estructura del Marco Teórico.}

Como acabamos de evidenciar, es necesario prevenir lesiones en cualquier equipo, independientemente de la edad de los jugadores y el nivel de rendimiento (156). En este sentido, existe una "secuencia de prevención de lesiones deportivas" (167) con 4 sencillos pasos que serán los que utilizaremos para fundamentar una parte del marco teórico de este TFM:

1. Establecer la extensión del problema en cuanto a incidencia y severidad. Una profunda comprensión de la epidemiología de las lesiones es, de hecho, el primer paso necesario para diseñar un plan preventivo exitoso $(1,151,160,168)$, respondiendo a preguntas como ¿qué lesiones podemos esperar? o ¿cuáles son las más graves? (169). (ver punto 3.1.2).

2. Establecer la etiología y el mecanismo de lesión. Otro factor clave, y el siguiente paso en la investigación de prevención de lesiones, es comprender cómo ocurren las lesiones (170). Además de los mecanismos lesionales, los factores de riesgo de las lesiones más comunes deben estudiarse con más detalle para generar ideas para medidas preventivas (160). (ver punto 3.1.3).

3. Diseñar e introducir las medidas preventivas. Es aconsejable diseñar programas preventivos individualizados, sobre los datos obtenidos en los pasos 1 y 2 (151). Además, para tener éxito es necesario que tanto los miembros del cuerpo técnico como los jugadores estén comprometidos y crean en este tipo de trabajo (171). En esta línea, para actuar con el jugador se seguirá la siguiente clasificación (172):

- Medidas Primarias: Basadas en la epidemiología de lesiones en fútbol.

- Medidas Secundarias: Programa individualizado basado en la aparición de molestias o indicadores de riesgo tras la realización de la evaluación inicial.

- Medidas Terciarias: Programa individualizado orientado a las lesiones previas que haya tenido el jugador.

4. Evaluar la eficacia de estas medidas repitiendo el paso 1.

\subsubsection{Conceptos básicos de epidemiología.}

\subsection{A nivel general.}

El diagnóstico es clave para una correcta recuperación. Sin embargo, como no hay definiciones estandarizadas, a veces resulta complicado definir una lesión, lo cual perjudicará la rehabilitación y aumentará las recidivas $(165,173)$. Por ello, antes de abordar la epidemiología es necesario definir una serie de conceptos en base a distintos consensos aceptados por la comunidad científica.

Con el objetivo de establecer definiciones y una metodología estandarizada se estableció un Grupo de Consenso de Lesiones bajo los auspicios del Centro de Investigación y Evaluación Médica de la Federación Internacional de Fútbol, y se propusieron las siguientes definiciones (174). 
- Lesión: "Cualquier molestia fisica sostenida por un jugador que resulte de un partido o entrenamiento de fútbol. (...) Si la lesión implica atención médica se conoce como 'lesión de atención médica' y si impide la participación del jugador en el próximo entrenamiento o partido se conoce como 'lesión por pérdida de tiempo'”, (174). Un jugador permanecerá lesionado hasta que reciba el alta por parte de los servicios médicos y pueda participar con total normalidad en entrenamientos o estar disponible para partidos $(2,160,175)$.

- Atención Médica: "Se refiere a una evaluación de la condición médica de un jugador por parte de un profesional médico cualificado" (174).

- Lesión Recurrente: "Una lesión del mismo tipo y en el mismo sitio que una lesión inicial, y que ocurre después del regreso a la participación total de la lesión inicial" (174). "Si la recidiva se produce dentro de los dos meses posteriores a la plena participación se conoce como 'recurrencia temprana', si se produce entre los 2 y los 12 meses se denomina 'recurrencia tardía' y si tiene lugar después de los 12 meses se define como 'recurrencia retrasada', (174).

- Gravedad de la Lesión: "La cantidad de días que han transcurrido desde la fecha de la lesión hasta la fecha de regreso a la participación completa en el entrenamiento del equipo y la disponibilidad para la selección para partidos" (174). El día en el que se produce la lesión es el "día 0" y no se cuenta al determinar la gravedad de la lesión (174). Dentro de la gravedad podemos distinguir (2):

- Lesión Mínima: 1 - 3 días de ausencia.

- Lesión Leve: 4 - 7 días de ausencia.

- Lesión Moderada: 8 - 28 días de ausencia.

- Lesión Grave: $>28$ días de ausencia.

- Exposición de Partidos: "Partidos realizados entre equipos de diferentes clubes" (174). Los partidos entre equipos del mismo club deben considerarse como exposición de entrenamiento. Cualquier partido que forme parte de la rehabilitación de un jugador por una lesión no debe registrarse como exposición de partido (174).

- Exposición de Entrenamiento: "Actividades fisicas individuales y en equipo bajo el control u orientación del cuerpo técnico, que tienen como objetivo mantener o mejorar la condición física de los jugadores o sus habilidades especificas del fútbol" (174). Las sesiones de calentamiento antes y después del partido se deben registrar como exposición de entrenamiento. Las actividades de entrenamiento personal llevadas a cabo por jugadores que están fuera de su equipo y que no están planeadas por el entrenador o el equipo de acondicionamiento físico del equipo no deben registrarse como exposición al entrenamiento. Cualquier actividad de entrenamiento que forme parte de la rehabilitación de una lesión de un jugador no debe registrarse como una exposición de entrenamiento (174).

- Clasificación de Lesiones: Las lesiones deben clasificarse por ubicación, tipo, lado del cuerpo y mecanismo de lesión (traumático o por uso excesivo) y si la lesión fue una recurrencia (174). En este contexto, una lesión por sobreuso se refiere a "una causada por micro traumas repetidos sin un solo evento identificable responsable de la lesión"; y una lesión traumática (o aguda) a "una lesión que resulta de un evento específico e identificable" (174). Dentro de las lesiones traumáticas podemos distinguir (176):

- Esguince: Lesión aguda de ligamentos o cápsula articular.

- Lesión Articular: Lesión condral o de menisco aislada.

- Desgarro (sustituye a distensión): Lesión aguda de músculos y tendones.

- Contusión: Lesión o daño causado al golpear o comprimir una parte del cuerpo sin producir herida exterior.

- Fractura: Rotura traumática de un hueso.

- Luxación: Desplazamiento parcial o completo de la parte ósea o de una articulación.

- Otros: Lesiones no clasificadas en otra parte, por ejemplo heridas, contusiones cerebrales, ...

- Lesión por juego sucio: Es "aquella que se produce durante el partido como consecuencia de la violación de las leyes del juego, según el criterio del árbitro" (175).

- Incidencia (o tasa) de Lesiones: Número de lesiones por 1000 horas de exposición de jugador $((\Sigma$ lesiones $/ \Sigma$ horas de exposición $) \times 1000)(156)$.

- Carga de Lesiones: Se define como "el producto cruzado de la gravedad y la incidencia de lesiones" $(2,169)$. 
- Porcentaje de Lesiones: Se define como "el número de jugadores lesionados dividido por el número total de jugadores" (172). Se utiliza menos que la incidencia de lesiones ya que puede llevar a engaño porque la cantidad de partidos y sesiones de entrenamiento cambia de un equipo a otro, y además no todos los jugadores participan en cada sesión de partido o de entrenamiento (151).

- Prevalencia de Lesiones: Se refiere a "la proporción de jugadores lesionados por al menos una lesión durante una temporada" (177).

\subsection{Referidos a Lesiones Musculares.}

Los músculos tienen tamaños y estructuras muy diversas, además de una complicada anatomía (178), por lo que disponer de una clasificación y definiciones estandarizadas debe ser algo obligado (165). Para ello se realizó una reunión de consenso en Munich con el objetivo de definir y establecer términos prácticos y sistemáticos relacionados con las lesiones musculares (165).

La distensión muscular se utiliza con mucha frecuenta, tanto para referirse a lesiones anatómicas como funcionales, sin embargo, aún no está clara su definición (165). La distensión muscular se define como "lesión aguda por pequeñas roturas de músculos y tendones" (179), sin embargo "tensión" es un término biomecánico, por lo que no deberíamos emplearlo y se debería sustituir por "desgarro" para lesiones estructurales de fibras/haces musculares que llevan a la pérdida de continuidad y propiedades contráctiles (165).

\subsection{Referidos a Lesiones en la zona Inguinal.}

La taxonomía de las lesiones de ingle es compleja ya que la lesión puede aparecer en multitud de estructuras e incluso en sujetos asintomáticos (180). Para subsanar esta problemática, se realizó una reunión de consenso en Doha en la que, en base a la historia y al examen físico, se alcanzó un acuerdo sobre taxonomía utilizando tres categorías principales (180):

1) Entidades clínicas definidas para el dolor en la ingle relacionadas con (la ubicación de estas entidades se muestra en la figura 14):
a) El aductor.
b) El psoas ilíaco.
c) La zona inguinal.
d) El pubis.

2) Dolor en la ingle relacionado con la cadera.

3) Otras causas de dolor inguinal en deportistas.

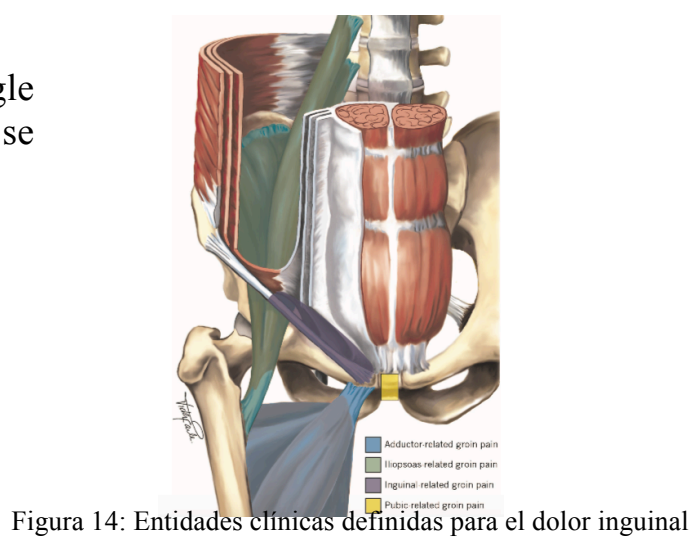

El término "sensibilidad" se define como "malestar o dolor cuando se palpa el área, y el atleta reconoce que ese es el dolor de su lesión específica" (180). Durante la reunión en Doha se indicó que una palpación precisa (ya que hay estructuras muy cercanas que pueden referir dolor a otras zonas) es necesaria para encontrar el origen del dolor (180).

El término "entidad clínica" fue elegido "para reflejar el patrón de síntomas y signos reconocibles exhibidos por el deportista" (180). Un sujeto puede tener más de una entidad. En el Anexo IX se incluye una tabla que muestra las distintas entidades clínicas con los síntomas y pruebas encontradas para su diagnóstico (181).

Como conclusión de la reunión, se decidió no recomendar los siguientes términos porque se consideraron inespecíficos, incorrectos o generaban confusión sobre la patología subyacente (180).

- Tendinitis o tendinopatía de aductor y psoas ilíaco.

- Dolor en la ingle.

- Pubalgia.

- Sobrecarga biomecánica de la ingle.

- Hernia del deportista. 


\subsubsection{Epidemiología.}

Como veremos en el apartado 3.1.4, la aparición de lesiones está influenciada por factores internos y externos (167), como los cambios en el reglamento, cambios organizativos o el aumento de los parámetros de rendimiento físico y técnico, por lo que los resultados podrían variar si recopilamos bibliografía demasiado lejana en el tiempo (156). Por este motivo se ha procurado seleccionar los estudios más relevantes y relativamente recientes.

En términos generales, podríamos decir que un jugador sufre entre $1(148,149)$ y $2(2,166)$ lesiones por temporada, lo que supone una media de 37 días de ausencia por jugador (2). La mayoría de los estudios reflejan la incidencia de lesiones, que puede variar, en futbolistas profesionales, desde 2,49 a 9,4 lesiones por 1.000 horas de exposición $(2,4,159,176,182-186)$. Aunque no están claros los aspectos implicados, parece ser que las diferencias regionales $(176)$ o en cuanto a la categoría $(4,156,187,188)$ y el nivel de juego (176,189-191) pueden influir en la epidemiología de las lesiones y la traumatología. No existen referencias para la categoría de nuestro sujeto, por lo que, basándonos en la bibliografía consultada, se establecerá un marco teórico que pueda ser aplicable a dicho contexto (Jugador senior, que milita en una categoría semiprofesional del fútbol español).

Sin embargo, otros estudios argumentan que atender únicamente a la incidencia de lesiones puede dar una visión incompleta o falseada (169). Así, en lugar de evaluar la incidencia (tasa) de lesiones y la gravedad (duración de la pérdida de tiempo) de forma aislada, se deben combinar ambos conceptos en la "carga de lesión". Este término no es nuevo (192), pero si queremos realizar una evaluación exhaustiva de los riesgos de lesión, hay que tenerlo en cuenta (169). Para ello se utiliza una "matriz de riesgos", aplicada por primera vez a las lesiones deportivas por Drawer y Fuller en 2002 (192) y se muestra la incidencia y severidad de cada uno de los tipos más comunes de lesiones con pérdida de tiempo. Cuanto más oscuro es el color, mayor será la carga de lesión y, por tanto, la prioridad de prevención. Así, la baja incidencia de lesiones muy severas y la alta incidencia de lesiones de baja gravedad pueden generar la misma carga de lesiones (169).

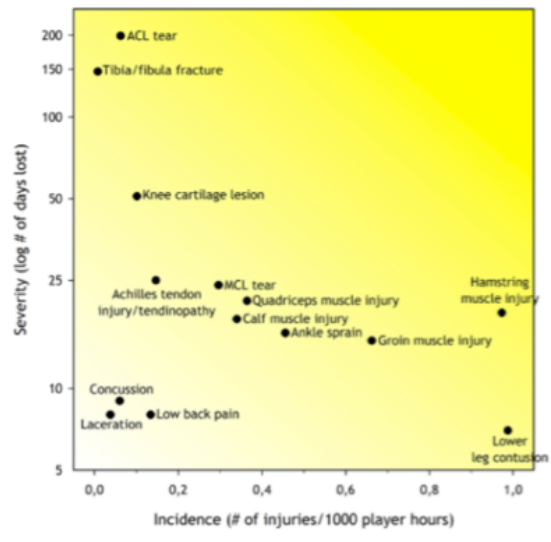

Figura 15: Matriz de riesgo de la Liga de Campeones en la que se ilustra la gravedad / incidencia de las 14 lesiones más comunes (169).

\subsubsection{Tipos de Lesiones.}

Cuando clasifiquemos los tipos de lesiones debemos tener en cuenta las siguientes categorías (174):

\begin{tabular}{|c|l|}
\hline TIPO DE LESIÓN & \multicolumn{1}{|c|}{ CATEGORÍA } \\
\hline \multirow{2}{*}{ Fracturas y estrés óseo } & Fracturas \\
\cline { 2 - 2 } & Otras lesiones óseas \\
\hline \multirow{2}{*}{ Articulación y Ligamento } & Luxación / Subluxación \\
\cline { 2 - 2 } & Esguince \\
\hline \multirow{2}{*}{ Músculos y Tendones } & Lesión de Menisco o Cartílago \\
\cline { 2 - 2 } & Rotura Muscular / Desgarro / Calambre \\
\hline Contusiones & Hematoma / Contusión \\
\hline Laceración y Heridas de la piel & Laceración / Abrasión \\
\hline Sistema Nervioso Central / Periférico & Conmoción cerebral / Lesión Nerviosa \\
\hline \multirow{2}{*}{ Otras } & Lesiones Dentales \\
\cline { 2 - 2 } & Otras lesiones \\
\hline \multicolumn{2}{|c}{ Tabla 37: Tipos de lesiones (174) } \\
\hline
\end{tabular}

Un estudio prospectivo en el que se siguió a 14 equipos Noruegos de máximo nivel durante 6 temporadas reflejó que los tipos de lesión más común son lesión muscular (46\%), seguido de lesiones articulares (27\%) y contusiones (14\%) (193). Otros trabajos obtienen las mismas conclusiones, señalando que las lesiones musculares en muslo y cadera, los esguinces (lesión articular) y las contusiones son los tipos de lesión más frecuentes tanto en jugadores profesionales $(149,182)$ como en sujetos jóvenes $(4)$. 
Varios estudios coinciden al señalar que las lesiones musculares son el tipo de lesión más frecuente y constituyen un grave problema para los futbolistas profesionales, ya que representan del 20 al $37 \%$ de todas las lesiones que suceden en una temporada $(160,168,194,195)$, causando más de un $25 \%$ de la ausencia total $(160,177,195)$. Esto supone alrededor de 15 lesiones musculares en una temporada para un equipo de 25 jugadores con una media de 2 semanas de ausencia por lesión (160).

En cuanto a las lesiones en las extremidades superiores debemos decir que no son muy comunes en el fútbol, sin embargo, pueden alcanzar hasta el $18 \%$ de todas las lesiones en porteros profesionales (196) (posición de nuestro sujeto). Las lesiones más comunes en miembros superiores son (196):

- Lesión de la articulación acromioclavicular (AC). Es la lesión más común en el hombro $(18 \%)(197)$ y la gran mayoría de ellas son esguinces (72\%) (198).

- Luxación de hombro (12\%).

- Fractura metacarpiana de la mano (8\%) .

- Tendinopatía del manguito rotador del hombro (6\%).

- Luxación de la AC del hombro (5\%).

Por último, en la tabla 38 se refleja el tipo y el porcentaje de lesión más común en el fútbol según la literatura revisada.

\begin{tabular}{|c|c|c|c|c|c|c|c|c|}
\hline Estudio & $\begin{array}{c}\text { Año de } \\
\text { Publicación }\end{array}$ & País & Categoría & Temporadas & Equipos & $\begin{array}{l}\text { Total de } \\
\text { Lesiones }\end{array}$ & Tipo de Lesión & $\mathrm{N}(\%)$ \\
\hline Ekstrand et al (2) & 2011 & Europa & $\begin{array}{c}\text { Máximo } \\
\text { Nivel }\end{array}$ & $\begin{array}{c}7 \\
(2001-2008)\end{array}$ & 23 & 4483 & $\begin{array}{c}\text { Fractura } \\
\text { Luxación } \\
\text { Esguince } \\
\text { Menisco/ } \\
\text { Cartílago } \\
\text { Desgarro } \\
\text { muscular } \\
\text { Lesión en } \\
\text { tendón } \\
\text { Contusión } \\
\text { Otros }\end{array}$ & $\begin{array}{c}160(4) \\
50(1) \\
\mathbf{8 2 8}(\mathbf{1 8}) \\
124(3) \\
\\
\mathbf{1 5 8 1 ( 3 5 )} \\
\\
327(7) \\
\\
\mathbf{7 4 4}(\mathbf{1 7 )} \\
661(15)\end{array}$ \\
\hline Owen et al (152) & 2015 & - & $\begin{array}{l}\text { Champions } \\
\text { League }\end{array}$ & $\begin{array}{c}2 \\
\text { Desconocidas }\end{array}$ & 1 & 119 & $\begin{array}{c}\text { Luxación } \\
\text { Esguince } \\
\text { Músculos y } \\
\text { Tendones } \\
\text { Contusión } \\
\text { Otros }\end{array}$ & $\begin{array}{c}1\left(0^{\prime} 84\right) \\
\mathbf{2 4}\left(20^{\prime} 16\right) \\
55\left(46^{\prime} 21\right) \\
\\
37(31,09) \\
2\left(1^{\prime} 68\right)\end{array}$ \\
\hline Eirale et al (168) & 2012 & Qatar & $\begin{array}{l}\text { Selección } \\
\text { Nacional } \\
\text { Masculina }\end{array}$ & $\begin{array}{c}1 \\
(2007-2008)\end{array}$ & 1 & 78 & $\begin{array}{c}\text { Fractura } \\
\text { Luxación } \\
\text { Esguince } \\
\text { Desgarro } \\
\text { muscular } \\
\text { Lesión en } \\
\text { tendón } \\
\text { Contusión } \\
\text { Otros }\end{array}$ & $\begin{array}{c}4\left(5^{\prime} 1\right) \\
3\left(3^{\prime} 8\right) \\
\mathbf{1 0}\left(\mathbf{1 2}^{\prime} \mathbf{8}\right) \\
\mathbf{2 4}\left(\mathbf{3 0}^{\prime} 8\right) \\
\\
10\left(12^{\prime} 8\right) \\
\\
\mathbf{1 2}\left(\mathbf{1 5}^{\prime} \mathbf{4}\right) \\
15\left(19^{\prime} 2\right)\end{array}$ \\
\hline Walden et al (176) & 2005 & Europa & $\begin{array}{l}\text { Champions } \\
\text { League }\end{array}$ & $\begin{array}{c}1 \\
(2001-2002)\end{array}$ & 11 & 658 & $\begin{array}{c}\text { Fractura } \\
\text { Luxación } \\
\text { Esguince } \\
\text { Desgarro } \\
\text { muscular } \\
\text { Contusión } \\
\text { Otros }\end{array}$ & $\begin{array}{c}16(2) \\
6(1) \\
\mathbf{1 5 2 ( 2 3 )} \\
\mathbf{1 6 9}(\mathbf{2 6}) \\
\\
\mathbf{1 0 5 ( 1 6 )} \\
210(32)\end{array}$ \\
\hline $\begin{array}{l}\text { Noya Salces et al } \\
\qquad(182)\end{array}$ & 2014 & España & $\begin{array}{l}\text { Primera } \\
\text { División }\end{array}$ & $\begin{array}{c}1 \\
(2008-2009)\end{array}$ & 16 & 1293 & $\begin{array}{c}\text { Esguinces } \\
\text { Músculos y } \\
\text { Tendones } \\
\text { Contusiones } \\
\text { Otros }\end{array}$ & $\begin{array}{c}315\left(24^{\prime} 4\right) \\
696\left(53^{\prime} 8\right) \\
\\
184\left(14^{\prime} 2\right) \\
98\left(7^{\prime} 6\right)\end{array}$ \\
\hline Hawkins et al (186) & 1999 & Inglaterra & $\begin{array}{c}\text { Profesional } \\
\text { es y } \\
\text { juveniles }\end{array}$ & $\begin{array}{c}3 \\
(1994-1997)\end{array}$ & 4 & 744 & $\begin{array}{c}\text { Fractura } \\
\text { Esguince } \\
\text { Músculos y } \\
\text { Tendones } \\
\text { Contusión } \\
\text { Otros } \\
\end{array}$ & $\begin{array}{c}29(4) \\
149(20) \\
305(41) \\
\\
148(20) \\
113(15)\end{array}$ \\
\hline Bjørneboe et al (193) & 2014 & Noruega & $\begin{array}{l}\text { Primera } \\
\text { División }\end{array}$ & $\begin{array}{c}6 \\
(2002-2007)\end{array}$ & $11-14$ & 2325 & $\begin{array}{c}\text { Fractura } \\
\text { Esguince } \\
\text { Músculos y } \\
\text { Tendones } \\
\text { Contusión } \\
\text { Otros }\end{array}$ & 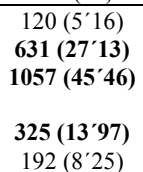 \\
\hline Hawkins et al (199) & 2001 & Inglaterra & $\begin{array}{c}4 \text { ligas } \\
\text { profesional } \\
\text { es }\end{array}$ & $\begin{array}{c}2 \\
(1997-1999)\end{array}$ & 91 & 6030 & $\begin{array}{l}\text { Fractura } \\
\text { Esguince } \\
\text { Músculos y } \\
\text { Tendones } \\
\text { Contusión } \\
\text { Otros }\end{array}$ & $\begin{array}{c}253(4) \\
1153(19) \\
2603(43) \\
\\
767(13) \\
1254(21)\end{array}$ \\
\hline
\end{tabular}




\subsubsection{Ubicación de las Lesiones.}

Entre las ubicaciones donde se puede producir una lesión debemos distinguir (174):

\begin{tabular}{|c|l|}
\hline UBICACIÓN & \multicolumn{1}{|c|}{ CATEGORIA } \\
\hline \multirow{2}{*}{ Cabeza y Cuello } & Cabeza / Cara \\
\cline { 2 - 2 } & Cuello / Cervicales \\
\hline \multirow{3}{*}{ Miembros Superiores } & Hombro / Clavícula \\
\cline { 2 - 2 } & Brazo / Codo / Antebrazo / Muñeca \\
\cline { 2 - 2 } & Mano / Dedos / Pulgar \\
\hline \multirow{2}{*}{ Tronco } & Esternón / Costillas / Dorsal \\
\cline { 2 - 2 } & Abdomen \\
\cline { 2 - 2 } & Lumbar / Pelvis / Sacro \\
\hline \multirow{3}{*}{ Miembros Inferiores } & Cadera / Ingle \\
\cline { 2 - 2 } & Muslo / Rodilla / Pierna / Tendón Aquiles \\
\cline { 2 - 2 } & Tobillo / Pie \\
\hline
\end{tabular}

Tabla 39: Ubicación de las lesiones (174)

Cerca del $90 \%$ de las lesiones ocurren en los miembros inferiores $(2,151,176,182,200)$, especialmente en los músculos del muslo $(22 \%(193)$ - 33'3\% (168)) y la pantorrilla (10\%) y las articulaciones de tobillo (18\%) y rodilla $\left(16^{\prime} 7 \%\right)$ (168), siendo un grave problema en ambos sexos, grupos de edad y niveles de rendimiento $(156,201)$ que ha aumentado, pasando de una incidencia de 1.09 por 1000 h. de exposición en 1995 - 1996 a 2.3 en 2009 - 2010 (159). Estas ubicaciones son las que se lesionan con más frecuencia y las que reportan mayor gravedad (156).

Esto parece, incluso, ser más pronunciado cuando se trata de lesiones musculares, donde la gran mayoría (92\%) afecta a los principales grupos musculares de las extremidades inferiores: Isquiosurales (37\%), Aductores (23\%), Cuádriceps (19\%) y músculos de la pantorrilla (13\%) (160).

El desgarro muscular en el muslo es la categoría de lesión más común en el fútbol de élite $(11,183,184,186,199)$, ocurriendo en la parte posterior significativamente más veces que en la anterior $(67 \%$ vs $36 \%)(176)$. Por tanto, el desgarro de los isquiosurales es la lesión más común en el fútbol de élite $(2,159,160,176,194)$, representando entre el $12 \%(2,160,202)$ y el $25^{\prime} 4 \%(195)$ de todas las lesiones, lo que supone, para un equipo de 25 jugadores, entre 5 (194) y 7 (2) lesiones de este tipo cada temporada y una media de entre $80(177,194)$ y 90 días $(202)$ de ausencia en partidos o entrenamientos. Dentro de este grupo muscular, el $84 \%$ de las lesiones afecta al bíceps femoral, el 11\% al semimembranoso y el 5\% al semitendinoso (194). Apenas hay diferencia entre pierna dominante y no dominante (202). Esta alta incidencia de lesiones puede deberse, en parte, a que es biarticular (199) y que posee una mayor proporción de fibras de contracción rápida, por lo que un desequilibrio puede predisponer al músculo a lesionarse en acciones de contracción rápida y alta velocidad (202).

Los desgarros en cuádriceps suponen el 5\% de todas las lesiones (2) y, aunque tienen una incidencia significativamente menor que los que se producen en los isquiosurales ( $0.3 \mathrm{vs} 1.5 / 1000 \mathrm{~h}$.), el tiempo de ausencia que conllevan es el mismo (168) o incluso mayor (160). Para un equipo de 25 jugadores esto supone una media de 3 lesiones de este tipo cada temporada (2).

La incidencia de lesiones en tobillo es del $21{ }^{\prime} 2 \%$ siendo el esguince la categoría más común en esta zona y pudiendo representar entre el $80 \%$ y el $100 \%$ de todas las lesiones de tobillo registradas (163) Entre el $12^{\prime} 8 \%$ y el $27^{\prime} 13 \%$ de las lesiones que ocurren en fútbol son esguinces $(2,152,168,176,182)$. De todos ellos, 9 de cada 10 se localizan en el tobillo (51\%) o en la rodilla (39\%) (194).

En el caso de la rodilla, el ligamento colateral medial (LCM) es la lesión más frecuente en fútbol (175), supone un 5\% de todas las lesiones que se producen en una temporada (2) y más de la mitad de los esguinces de esta ubicación (176). De media un equipo de 25 jugadores puede tener 2 lesiones de este tipo cada temporada y alrededor del 65\% ocurren en la pierna dominante (175). Sin embargo, parece que la tasa de este tipo de lesión está disminuyendo; esto puede ser debido a que hay menos contacto entre jugadores por un fútbol más técnico, porque los árbitros son más estrictos al pitar (recordemos que se producían lesiones por "juego sucio") o por la implantación de entrenamientos preventivos (175). Las lesiones de menisco representan el $15 \%$ de todas las lesiones de rodilla (203), siendo los desgarros de 
menisco medial más frecuentes que los de menisco lateral, posiblemente porque éste último es más móvil (204). Además, las lesiones de menisco son concomitantes a lesiones de Ligamento Cruzado Anterior (LCA) $(204,205)$ y, en menor medida, de Ligamento Colateral Medial (203).

Las lesiones de cadera / ingle representan un 12\% - 16\% del total de lesiones que se producen en fútbol (206). El dolor en la ingle es común en el fútbol $(148,206)$ y es el doble de prevalente en hombres que en mujeres (148). Los aductores (68\%) (181) son la entidad lesionada con mayor frecuencia tanto a nivel subélite (188) como élite (206), seguidos de psoas ilíaco (12\%) y dolor en la ingle relacionado con el pubis (9\%) (181). Parece ser que los jugadores de nivel subélite sufren menos lesiones en la ingle que los profesionales $(11,22,207)$. A lo largo de una temporada, un equipo de 25 jugadores sufre aproximadamente 5 lesiones en la ingle con una ausencia media de 15 días por lesión (181), ubicándose en la pierna dominante entre un $58 \%(188,206)$ y un $68 \%$ de los casos $(181)$.

Las lesiones en los miembros superiores no son muy frecuentes en fútbol, ya que suponen sólo el $3 \%$ de todas las lesiones con pérdida de tiempo (208), pero pueden alcanzar el $18 \%$ en el caso de los porteros (196). Las ubicaciones de lesiones más comunes en el miembro superior son hombro/clavícula (56\%), mano/dedo/pulgar (24\%), codo (10\%), muñeca (5\%), antebrazo (4\%) y brazo (1\%) (196).

Por último, en la tabla 40 se refleja la ubicación más común de lesiones en fútbol y el porcentaje de las mismas, en función del tipo de lesión descrito en cada referencia.

\begin{tabular}{|c|c|c|c|c|c|c|c|c|c|}
\hline Estudio & $\begin{array}{c}\text { Año de } \\
\text { Publicación }\end{array}$ & País & Categoría & Temporadas & Equipos & $\begin{array}{l}\text { Total de } \\
\text { Lesiones }\end{array}$ & $\begin{array}{l}\text { Tipo de } \\
\text { Lesiones } \\
\end{array}$ & Ubicación & $\mathrm{N}(\%)$ \\
\hline Ekstrand et al (2) & 2011 & Europa & $\begin{array}{l}\text { Máximo } \\
\text { Nivel }\end{array}$ & $\begin{array}{c}7 \\
(2001-2008)\end{array}$ & 23 & 4483 & Cualquiera & $\begin{array}{c}\text { Cabeza y Cuello } \\
\text { MMSS } \\
\text { Tronco } \\
\text { Cadera / Ingle } \\
\text { Muslo } \\
\text { Rodilla } \\
\text { Tobillo } \\
\end{array}$ & $\begin{array}{c}100(2) \\
158(4) \\
315(7) \\
\mathbf{6 1 6 ( 1 4 )} \\
\mathbf{1 0 6 4 ( 2 4 )} \\
\mathbf{8 1 8 ( 1 8 )} \\
\mathbf{6 2 5 ( 1 4 )} \\
\end{array}$ \\
\hline $\begin{array}{l}\text { Ekstrand et al } \\
\qquad(160)\end{array}$ & 2011 & Europa & $\begin{array}{l}\text { Máximo } \\
\text { Nivel }\end{array}$ & $\begin{array}{c}8 \\
(2001-2009)\end{array}$ & 51 & 2908 & Musculares & $\begin{array}{c}\text { Cabeza y Cuello } \\
\text { MMSS } \\
\text { Tronco } \\
\text { Cadera / Ingle } \\
\text { Muslo }\end{array}$ & $\begin{array}{c}10(0) \\
3(0) \\
60(2) \\
\mathbf{8 5 3 ( 3 0 )} \\
\mathbf{1 5 6 9 ( 5 4 )}\end{array}$ \\
\hline $\begin{array}{l}\text { Walden et al } \\
\qquad(176)\end{array}$ & 2005 & Europa & $\begin{array}{l}\text { Champions } \\
\text { League }\end{array}$ & $\begin{array}{c}1 \\
(2001-2002)\end{array}$ & 11 & 658 & Cualquiera & $\begin{array}{c}\text { Cabeza y Cuello } \\
\text { MMSS } \\
\text { Tronco } \\
\text { Cadera / Ingle } \\
\text { Muslo } \\
\text { Rodilla } \\
\text { Tobillo } \\
\end{array}$ & $\begin{array}{c}22(3) \\
- \\
41(6) \\
79(12) \\
152(23) \\
131(20) \\
81(14) \\
\end{array}$ \\
\hline $\begin{array}{c}\text { Noya Salces et } \\
\text { al (182) }\end{array}$ & 2014 & España & $\begin{array}{l}\text { Primera } \\
\text { División }\end{array}$ & $\begin{array}{c}1 \\
(2008-2009)\end{array}$ & 16 & 1293 & Cualquiera & $\begin{array}{c}\text { Cabeza y Cuello } \\
\text { MMSS } \\
\text { Tronco } \\
\text { Cadera / Ingle } \\
\text { Muslo } \\
\text { Rodilla } \\
\text { Tobillo } \\
\end{array}$ & $\begin{array}{c}35(3) \\
30(2) \\
69(6) \\
175(14) \\
473(37) \\
147(11) \\
185(14) \\
\end{array}$ \\
\hline $\begin{array}{l}\text { Hawkins et al } \\
\text { (186) }\end{array}$ & 1999 & Inglaterra & $\begin{array}{c}\text { Profesionales } \\
\text { y juveniles }\end{array}$ & $\begin{array}{c}3 \\
(1994-1997)\end{array}$ & 4 & 744 & Cualquiera & $\begin{array}{c}\text { Cabeza y Cuello } \\
\text { MMSS } \\
\text { Tronco } \\
\text { Cadera / Ingle } \\
\text { Muslo } \\
\text { Rodilla } \\
\text { Tobillo }\end{array}$ & $\begin{array}{c}28(4) \\
22(3) \\
52(7) \\
103(14) \\
171(23) \\
103(14) \\
125(17)\end{array}$ \\
\hline $\begin{array}{c}\text { Bjørneboe et al } \\
\text { (193) }\end{array}$ & 2014 & Noruega & $\begin{array}{l}\text { Primera } \\
\text { División }\end{array}$ & $\begin{array}{c}6 \\
(2002-2007)\end{array}$ & $11-14$ & 2325 & Cualquiera & $\begin{array}{c}\text { Cabeza y Cuello } \\
\text { MMSS } \\
\text { Tronco } \\
\text { Cadera / Ingle } \\
\text { Muslo } \\
\text { Rodilla } \\
\text { Tobillo }\end{array}$ & $\begin{array}{c}123(5) \\
67(3) \\
184(8) \\
\mathbf{3 0 2 ( 1 3 )} \\
\mathbf{5 0 6 ( 2 2 )} \\
\mathbf{3 7 9 ( 1 6 )} \\
\mathbf{4 1 2 ( 1 8 )}\end{array}$ \\
\hline $\begin{array}{l}\text { Hawkins et al } \\
\text { (199) }\end{array}$ & 2001 & Inglaterra & $\begin{array}{c}4 \text { ligas } \\
\text { profesionales }\end{array}$ & $\begin{array}{c}2 \\
(1997-1999)\end{array}$ & 91 & 6030 & Cualquiera & $\begin{array}{c}\text { Cabeza y Cuello } \\
\text { MMSS } \\
\text { Tronco } \\
\text { Cadera / Ingle } \\
\text { Muslo } \\
\text { Rodilla } \\
\text { Tobillo } \\
\end{array}$ & $\begin{array}{c}153(3) \\
- \\
\mathbf{7 3 1 ( 1 2 )} \\
\mathbf{1 3 8 8 ( 2 3 )} \\
\mathbf{1 0 1 4 ( 1 7 )} \\
\mathbf{1 0 1 1 ( 1 7 )} \\
\end{array}$ \\
\hline
\end{tabular}




\subsubsection{Etiología.}

La mayor parte de la literatura refleja que las lesiones por uso excesivo representan entre el $9 \%$ y el $35 \%$ de todas las lesiones $(2,156,168,186,193,209)$, aunque también podemos encontrar datos bastante más prevalentes $(65,7 \%$ (182) o $63 \%$ (4), éste último referido a jóvenes futbolistas). A veces los jugadores siguen entrenando y compitiendo incluso estando limitados por el dolor, lo que hace que las lesiones por sobreuso se subestimen en muchos estudios (210).

Una causa importante en las lesiones en fútbol es el contacto con otro jugador (149), siendo el principal mecanismo de lesión por contacto (entre el $12 \%$ y el $31 \%$ de todas las lesiones se atribuyen a juego sucio $(2,176,186,211)$ ), seguido del contacto con la pelota y con un compañero (156). Las lesiones sin contacto suelen producirse en la carrera y el giro $(186,199)$ y las acciones realizadas en el momento de la lesión son saltar/aterrizar (212) o correr/sprintar (213).

En el caso de lesiones musculares prácticamente todas (95\%) ocurren en situaciones sin contacto y sólo un 5\% se deben a juego sucio (160) y, concretamente en los isquiosurales, el $70 \%$ tiene lugar mientras se esprinta o corre a alta velocidad (194).

En la cadera / ingle las lesiones por sobreuso son más comunes que en el resto de músculos de las extremidades inferiores (160). Las lesiones traumáticas constituyen el 39\% de las lesiones de ingle y sólo el $20 \%$ de ellas son lesiones de contacto.

Si atendemos a las extremidades superiores, el $90 \%$ de las lesiones son traumáticas y sólo el 10\% se deben a sobreuso (208) y la mayoría se produce por contacto (196).

\subsubsection{Gravedad de las Lesiones.}

Las lesiones mínimas (1 a 3 días de ausencia (2)) suponen entre el 21\% (2) y el 35,7\% (182) del total de lesiones y ocurren con menor frecuencia en partidos $(9,2 \%)$ que en entrenamientos $(28,1 \%)(152)$. Sólo un $10 \%$ de las lesiones de isquiosurales (177) y un 16\% de las de ingle se consideran mínimas (181).

Las lesiones leves (4 a 7 días de ausencia (2)) constituyen el 26\% del total de lesiones $(2,182)$ y, junto con las lesiones mínimas, representan la mayor parte de lesiones en jóvenes futbolistas (214). Aproximadamente la mitad de las lesiones agudas de entrenamiento (51\%), de partido $(49 \%)$ y de las lesiones por uso excesivo (55\%) son leves (193), así como el $21 \%$ de las que se producen en los isquiosurales (177) y el $25 \%$ de las que tienen lugar en la ingle (181).

Las lesiones moderadas (8 a 28 días de ausencia (2)) ocurren entre el 29,2\% (182) y el 37\% (2) del total de lesiones. Si hablamos de lesiones musculares, el 58\% de ellas son moderadas (160), de las cuales el $54 \%$ se localiza en los isquiosurales (177), mientras que en el caso de lesiones de ingle y cadera, entre el $41 \%(181,206)$ y el $43 \%(188)$ son moderadas. Además, el $75 \%$ de todas las lesiones de ligamento colateral medial de rodilla son moderadas o graves (175).

Las lesiones graves (más de 28 días de ausencia (2)) representan entre el $15 \%$ y el $21 \%$ de las lesiones totales $(2,176,193,215)$, aunque en la liga española se han encontrado resultados más bajos ( $8 \%)$ debido, probablemente, a las diferencias en la forma de entrenar y los estilos de juego entre países (182). Además ocurren en partidos con mayor frecuencia que en entrenamientos $(168,182,215)$, posiblemente porque durante los partidos, a menos que se los sustituya, los jugadores no dejan de jugar y, en consecuencia, las lesiones pueden empeorar con un impacto (168). No se aprecian diferencias en la gravedad de lesiones por contacto o sin contacto (168). Más de un cuarto de las lesiones que ocurren en los miembros superiores (28\%) son graves (2), siendo la luxación de hombro la lesión más severa, con una media de 41 días de ausencia (196). Un 10\% de todas las lesiones de las extremidades superiores afectan al codo, un $5 \%$ a la muñeca y un $25 \%$ a mano, dedos y pulgar (208) considerándose graves el $19 \%$, el $2 \%$ y el $25 \%$ de ellas respectivamente (196).

Si hablamos de lesiones musculares, el $11 \%$ son graves $(160) \mathrm{y}$, de todas las lesiones graves, el $12 \%$ (2) - 15\% (177) se localizan en isquiosurales, el 9\% en cuádriceps y el $6 \%$ en aductores (2). En cuanto a las lesiones de ingle / cadera, entre el 12\% (206) y el 18\% (181) de ellas fueron graves. 
Por último, en la tabla 41 se refleja la gravedad de las lesiones en fútbol y el porcentaje de las mismas, en función del tipo de lesión descrito en cada referencia.

\begin{tabular}{|c|c|c|c|c|c|c|c|c|c|}
\hline Estudio & $\begin{array}{c}\text { Año de } \\
\text { Publicación }\end{array}$ & País & Categoría & Temporadas & Equipos & $\begin{array}{l}\text { Total de } \\
\text { Lesiones }\end{array}$ & $\begin{array}{l}\text { Tipo de } \\
\text { Lesiones }\end{array}$ & Gravedad & $\mathbf{N}(\%)$ \\
\hline Ekstrand et al (2) & 2011 & Europa & $\begin{array}{l}\text { Máximo } \\
\text { Nivel }\end{array}$ & $\begin{array}{c}7 \\
(2001-2008)\end{array}$ & 23 & 4483 & Cualquiera & $\begin{array}{c}\text { Mínimas }(1-3) \\
\text { Leves }(4-7) \\
\text { Moderadas }(8-28) \\
\text { Graves }(+ \text { de } 28)\end{array}$ & $\begin{array}{l}971(22) \\
1164(26) \\
1651(37) \\
697(15)\end{array}$ \\
\hline $\begin{array}{l}\text { Ekstrand et al } \\
\quad(160)\end{array}$ & 2011 & Europa & $\begin{array}{l}\text { Máximo } \\
\text { Nivel }\end{array}$ & $\begin{array}{c}8 \\
(2001-2009)\end{array}$ & 51 & 2908 & Musculares & $\begin{array}{c}\text { Mínimas }(1-3) \\
\text { Leves }(4-7) \\
\text { Moderadas }(8-28) \\
\text { Graves }(+ \text { de } 28)\end{array}$ & $\begin{array}{c}369(13) \\
695(24) \\
1241(43) \\
304(11)\end{array}$ \\
\hline $\begin{array}{l}\text { Noya Salces et } \\
\text { al (182) }\end{array}$ & 2014 & España & $\begin{array}{l}\text { Primera } \\
\text { División }\end{array}$ & $\begin{array}{c}1 \\
(2008-2009)\end{array}$ & 16 & 1293 & Cualquiera & $\begin{array}{c}\text { Mínimas }(1-3) \\
\text { Leves }(4-7) \\
\text { Moderadas }(8-28) \\
\text { Graves }(+ \text { de } 28\end{array}$ & $\begin{array}{c}462(36) \\
346(27) \\
377(29) \\
108(8)\end{array}$ \\
\hline $\begin{array}{l}\text { Hawkins et al } \\
\text { (186) }\end{array}$ & 1999 & Inglaterra & $\begin{array}{l}\text { Profesionales } \\
\text { y juveniles }\end{array}$ & $\begin{array}{c}3 \\
(1994-1997)\end{array}$ & 4 & 744 & Cualquiera & $\begin{array}{c}\text { Mínimas }(1-3) \\
\text { Leves }(4-7) \\
\text { Moderadas }(8-28) \\
\text { Graves }(+ \text { de } 28\end{array}$ & $\begin{array}{c}119(16) \\
260(35) \\
283(38) \\
82(11)\end{array}$ \\
\hline $\begin{array}{l}\text { Bjørneboe et al } \\
\text { (193) }\end{array}$ & 2014 & Noruega & $\begin{array}{l}\text { Primera } \\
\text { División }\end{array}$ & $\begin{array}{c}6 \\
(2002-2007)\end{array}$ & $11-14$ & 2325 & Cualquiera & $\begin{array}{c}\text { Leves }(1-7) \\
\text { Moderadas }(8-21) \\
\text { Graves }(+ \text { de } 21) \\
\end{array}$ & $\begin{array}{l}1191(51) \\
650(28) \\
484(21) \\
\end{array}$ \\
\hline $\begin{array}{l}\text { Hawkins et al } \\
\text { (199) }\end{array}$ & 2001 & Inglaterra & $\begin{array}{c}4 \text { ligas } \\
\text { profesionales }\end{array}$ & $\begin{array}{c}2 \\
(1997-1999)\end{array}$ & 91 & 6030 & Cualquiera & $\begin{array}{c}\text { Mínimas }(1-3) \\
\text { Leves }(4-7) \\
\text { Moderadas }(8-28) \\
\text { Graves }(+ \text { de } 28 \\
\end{array}$ & $\begin{array}{c}588(10) \\
1385(23) \\
2698(45) \\
1359(23) \\
\end{array}$ \\
\hline
\end{tabular}

Tabla 41: Gravedad de lesiones más comunes en fútbol en base al tipo de lesión descrita. Elaboración Propia

\subsubsection{Actividad realizada y momento en el que se producen.}

El riesgo de lesión es mayor durante la competición que durante el entrenamiento $(1,2,155,156,168,176)$ posiblemente porque la intensidad es mayor en un partido (182). Como consecuencia, la incidencia de lesiones también es mayor en partidos que en entrenamientos, variando entre 15,9 y 54,1 por 1000 horas de exposición en partido y entre 3,4 y 5,9 por 1000 horas de exposición en entrenamiento $(2,152,182,184,186,193)$, lo que supone una tasa entre 3,3 y 15,3 veces mayor $(2,4,149,152,176,182,183,215,216)$. Esto puede explicarse porque cuanto mayor es la velocidad de juego y la intensidad los jugadores tienden a tener más contacto con el cuerpo, aumentando así la tasa de lesiones (151).

Lo mismo ocurre en las lesiones musculares, encontrándose tasas de lesión 6 veces mayores en partidos en comparación con los entrenamientos (160). En el caso de la rodilla encontramos la misma situación, una incidencia 9 veces mayor en partido que en entrenamiento ( 1.31 vs 0.14 por 1000 horas de exposición) para el esguince de Ligamento Colateral Medial (175) y 5 veces mayor para las lesiones de menisco (11.9 vs 2.7) (203). Esto también ocurre en lesiones de ingle, registrando una tasa de lesiones 5 veces mayor en partido (3.5 por 1000 horas) que en entrenamiento $(0.5$ por 1000 horas) $(181,206)$.

Aunque hay estudios que no encontraron diferencias en la incidencia de lesiones entre la pretemporada y la temporada competitiva $(176,193)$ otros señalan que la tasa de lesiones en el entrenamiento es mayor durante la pretemporada y disminuye a medida que avanza la temporada (182), debido a que los jugadores no recuperan completamente en el periodo transitorio, a errores en la planificación de la pretemporada o a que, para algunos jugadores, la tensión y mayor intensidad que requiere buscar un hueco entre los jugadores que formarán la plantilla podría estar asociado a un mayor riesgo de lesión (215); mientras que la incidencia en competición aumenta durante todo el año (182), debido a la pérdida de condición física y/o a una intensidad más alta en los partidos ya que la proximidad de la finalización de los campeonatos hace que los resultados tengan más trascendencia (215).

En pretemporada las lesiones por uso excesivo son más comunes $(199,217)$, debido a que hay más entrenamientos y una alta intensidad que genera una fatiga residual (152) y a que hay menos partidos, y las lesiones traumáticas ocurren fundamentalmente en partidos, por lo que éstas ocurrieron más frecuentemente durante el periodo competitivo $(2,186)$ y cada vez con un mayor riesgo en partidos y menor en entrenamientos conforme avanza la temporada (193). 
Si analizamos las lesiones que ocurren en partido, se podría asegurar que la gravedad y la incidencia aumentan en los últimos 15 minutos de cada parte (186). En este sentido, el $47 \%$ de las lesiones en isquiosurales (202), el 43\% de los esguinces de ligamento colateral medial (175) o la mayoría de las lesiones traumáticas que ocurren en partido tienen lugar en esa última franja de cada mitad de partido (195). El motivo podría ser la mayor fatiga, que impide reaccionar a los jugadores y ejecutar con la misma precisión que lo hacen en los primeros compases del partido $(160,175,186)$, o que hay un aumento en la intensidad por parte de los jugadores, conscientes del final del partido y la necesidad de cambiar el resultado $(175,195)$.

Por último, en la tabla 42 se refleja la actividad realizada cuando se produce la lesión y en qué momento de la temporada ocurren, así como la incidencia de las mismas, en función del tipo de lesión descrito en cada referencia.

\begin{tabular}{|c|c|c|c|c|c|c|c|c|c|}
\hline Estudio & $\begin{array}{c}\text { Año } \\
\text { Publicación } \\
\end{array}$ & País & Categoría & Temporadas & Equipos & $\begin{array}{c}\text { Total } \\
\text { Lesiones } \\
\end{array}$ & $\begin{array}{c}\text { Tipo } \\
\text { Lesiones } \\
\end{array}$ & $\begin{array}{c}\text { Actividad / } \\
\text { Momento lesivo }\end{array}$ & Incidencia \\
\hline \multirow{2}{*}{ Ekstrand et al (2) } & \multirow{2}{*}{2011} & \multirow{2}{*}{ Europa } & \multirow{2}{*}{$\begin{array}{l}\text { Máximo } \\
\text { Nivel }\end{array}$} & \multirow{2}{*}{$\begin{array}{c}7 \\
(2001-2008)\end{array}$} & \multirow{2}{*}{23} & \multirow{2}{*}{4483} & \multirow{2}{*}{ Cualquiera } & $\begin{array}{c}\text { Entrenamiento } \\
\text { Partido }\end{array}$ & $\begin{array}{l}1,37 \\
8,70\end{array}$ \\
\hline & & & & & & & & $\begin{array}{c}\text { Pretemporada } \\
\text { Temporada Compet. }\end{array}$ & - \\
\hline \multirow{2}{*}{ Walden et al (176) } & \multirow{2}{*}{2005} & \multirow{2}{*}{ Europa } & \multirow{2}{*}{$\begin{array}{l}\text { Champions } \\
\text { League }\end{array}$} & \multirow{2}{*}{$\begin{array}{c}1 \\
(2001-2002)\end{array}$} & \multirow{2}{*}{11} & \multirow{2}{*}{658} & \multirow{2}{*}{ Cualquiera } & $\begin{array}{c}\text { Entrenamiento } \\
\text { Partido } \\
\end{array}$ & $\begin{array}{c}5,8 \\
30,5 \\
\end{array}$ \\
\hline & & & & & & & & $\begin{array}{c}\text { Pretemporada } \\
\text { Temporada Compet. }\end{array}$ & $\begin{array}{l}8,2 \\
9,7\end{array}$ \\
\hline \multirow{2}{*}{$\begin{array}{l}\text { Noya Salces et al } \\
\text { (182) }\end{array}$} & \multirow{2}{*}{2014} & \multirow{2}{*}{ España } & \multirow{2}{*}{$\begin{array}{l}\text { Primera } \\
\text { División }\end{array}$} & \multirow{2}{*}{$\begin{array}{c}1 \\
(2008-2009)\end{array}$} & \multirow{2}{*}{16} & \multirow{2}{*}{1293} & \multirow{2}{*}{ Cualquiera } & $\begin{array}{c}\text { Entrenamiento } \\
\text { Partido } \\
\end{array}$ & $\begin{array}{c}3,5 \\
43,5 \\
\end{array}$ \\
\hline & & & & & & & & $\begin{array}{c}\text { Pretemporada } \\
\text { Temporada Compet. }\end{array}$ & - \\
\hline \multirow{2}{*}{$\begin{array}{c}\text { Bjørneboe et al } \\
\text { (193) }\end{array}$} & \multirow{2}{*}{2014} & \multirow{2}{*}{ Noruega } & \multirow{2}{*}{$\begin{array}{l}\text { Primera } \\
\text { División }\end{array}$} & \multirow{2}{*}{$\begin{array}{c}6 \\
(2002-2007)\end{array}$} & \multirow{2}{*}{$11-14$} & \multirow{2}{*}{2325} & \multirow{2}{*}{ Cualquiera } & $\begin{array}{l}\text { Entrenamiento } \\
\text { Partido }\end{array}$ & $\begin{array}{c}1,86 \\
16\end{array}$ \\
\hline & & & & & & & & $\begin{array}{c}\text { Pretemporada } \\
\text { Temporada Compet. }\end{array}$ & - \\
\hline
\end{tabular}

Tabla 42: Actividad realizada y momento en el que se producen las lesiones más comunes en fútbol en base al tipo de lesión descrita. Elaboración Propia

\subsubsection{Lesiones Recurrentes.}

Las lesiones recurrentes constituyen entre el 11\% y el 30\% de todas las lesiones que ocurren durante una temporada $(2,12,168,176,182-184,186,193,195,218)$ y casi dos tercios de ellas $(61 \%)$ ocurre por uso excesivo (176). La diferencia entre unos valores y otros puede deberse a que los equipos europeos de máximo nivel tienen más apoyo médico y pueden realizar una rehabilitación individualizada $(2,160)$. En cualquier caso, la alta tasa de lesiones recurrentes indica la necesidad de planes de rehabilitación más eficaces y de criterios para el retorno al juego mejorados para disminuir el riesgo de este tipo de lesiones (219).

La mayoría de las recaídas (hasta un 76\%) son desgarros en la parte inferior de la pierna, el muslo y la ingle, y esguinces en tobillo y rodilla $(2,186)$, y los isquiosurales son la ubicación con la mayor frecuencia de lesiones recurrentes $(156,168)$. Al igual que ocurría en las lesiones originales, la tasa de recidivas y la gravedad de las mismas es mayor en competición que en entrenamientos $(168,182)$.

En cuanto al tiempo de ausencia de las recidivas, podemos encontrar referencias en las que no hay diferencia entre la lesión original y la recurrente $(176,194)$, aunque la mayoría indica que las recaídas causan bajas más largas que las lesiones originales $(2,160,184)$.

Hay muchos factores que pueden provocar esta elevada tasa de lesiones recurrentes: una mala ejecución técnica continuada, una incorrecta organización del entrenamiento o una intensidad excesiva, un fallo en la prescripción de la lesión o subestimarla, un retorno al juego prematuro o una rehabilitación ineficaz (202), además de la lesión previa $(9,11,149)$, que puede elevar el riesgo de una recaída de 4 a 7 veces (11), aumentando la probabilidad de que ocurran lesiones a lo largo de la carrera de un jugador (4).

\subsubsection{Lesiones y Posiciones de Juego.}

En cuanto a las posiciones de juego, parecen no ser un factor de riesgo de lesión en el fútbol de élite, aunque sí pueden tener diferentes índices de lesiones y mecanismos de lesión debido a diferentes cargas y patrones de movimiento (1). Al analizar la epidemiología de lesiones en función de la posición de los jugadores nos encontramos que, por un lado, nos hay muchos estudios que realicen un análisis prospectivo de esta temática y, por otro, los que existen no son concluyentes. 
Algunos estudios indican que la incidencia de lesiones en los porteros era inferior a la del resto de jugadores durante los partidos $(220,221)$, debido a que recorren menos distancia y tienen menos contactos directos con los oponentes (1); mientras que otros no encuentran diferencias (215). No obstante, los resultados más consistentes señalaron que los porteros pueden tener un menor riesgo de lesiones que el resto de jugadores (1). Por ejemplo, en el caso de los isquiosurales, se encuentran menos desgarros en porteros que en el resto de jugadores de campo (202).

Lo mismo ocurre con el resto de posiciones. Podríamos decir que los delanteros tienen un mayor riesgo de lesión $(157,221)$ debido a las aceleraciones y desaceleraciones muy frecuentes y que actúan en una zona en la que se producen más tackles y choques con otros jugadores (1); o que son los mediocentros los que sufren ese mayor riesgo debido a que recorren más distancia y también realizan un gran volumen de acciones de aceleración y desaceleración (218). En cuanto a los defensores, parece ser que están más predispuestos a lesiones en el Ligamento Cruzado Anterior (LCA) (1), ya que la mayor parte de estas lesiones ocurre en situación de defensa $(222,223)$.

\subsubsection{Mecanismos de Lesión.}

Detallar las situaciones en las que se produce una lesión es el siguiente paso en la estructura de nuestro marco teórico (167). Analizar los mecanismos en los que suceden las lesiones es fundamental para el diseño de programas preventivos $(170,224-226)$ y el uso de vídeo puede ser una herramienta muy útil para ello $(227,228)$, sin embargo, como sólo se describen los mecanismos de lesión en competición, no se puede afirmar que las lesiones en distintas categorías o en entrenamientos, donde hay menos tackles y menos juego sucio (227) ocurran de la misma forma (222).

Los mecanismos de lesión se han descrito tradicionalmente en términos puramente biomecánicos, es decir, la cinemática y la cinética de la estructura dañada en el momento de la lesión (224). En esta línea, el daño resulta de una transferencia de energía al tejido. Los tejidos tienen unas propiedades mecánicas (rigidez, fuerza máxima y estrés) que marcan la manera de responder ante cargas físicas. La lesión se produce cuando un evento provoca una carga mayor de la que puede soportar el tejido o disminuye su tolerancia, de modo que otro estímulo podría dañarlo. (229).

Pero como nuestro objetivo es prevenir lesiones, es necesario ampliar ese enfoque tradicional para analizar el evento que provoca la lesión y utilizar un enfoque multifactorial o integral, que incluya los factores de riesgo internos y externos y en el que el mecanismo de lesión describa (170):

a) Aspectos vitales de la situación de juego, es decir, la situación descrita desde un punto de vista deportivo específico.

b) Comportamiento del jugador y del rival y su interacción.

c) Características biomecánicas generales (del cuerpo entero).

d) Características biomecánicas detalladas (de las articulaciones y tejidos).

e) Factores conductuales (psicológicos, sociológicos y organizativos) (229).

Basándose en el modelo biomecánico tradicional y el epidemiológico, se ha planteado un enfoque más completo (ver figura 16) para explicar la causa de la lesión y que puede ser utilizado para diseñar métodos de prevención específicos (170).

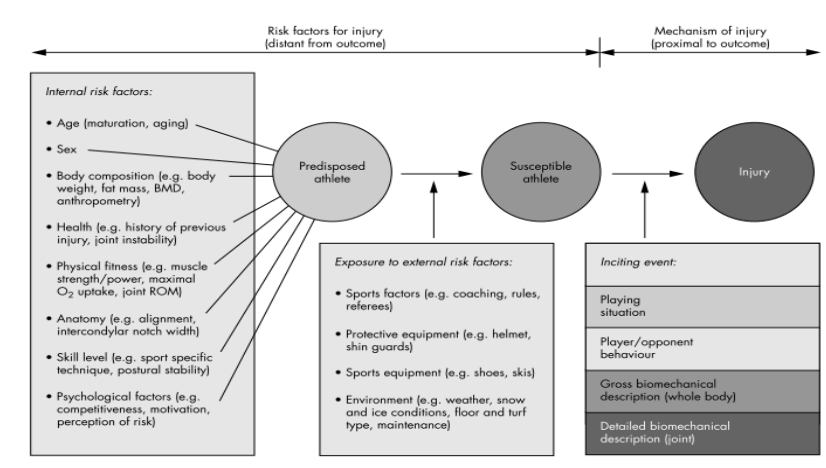

Figura 16: Modelo integral de causalidad de lesiones (170).

Además, es necesario tener en cuenta que, en el caso de lesiones por uso excesivo, la causa que provoca la lesión no coincide temporalmente con el momento en el que se produce, por lo que es necesario obtener la mayor información sobre los aspectos que la han podido provocar para ver sobre cuáles actuar (170). 


\subsubsection{Esguinces de Tobillo.}

La mayoría de las lesiones que se producen en el tobillo ocurren por contacto con otro jugador $(227,230)$, en concreto el contacto medial con la parte inferior de la pierna o tobillo (227). En la mayoría de los casos la pierna lesionada soporta peso (231) y la posición de lesión es la inversión de tobillo $(13,170,227,230)$.

Gran parte de los esguinces de tobillo ocurren en la pierna dominante, ya que está expuesta a una inversión forzada durante los saltos y los golpeos de balón (13). Los ligamentos laterales son los que más se lesionan en los esguinces de tobillo $(199,232,233)$.

Dos son los mecanismos específicos de esguinces de tobillo en fútbol (227):

1) Contacto con otro jugador que realiza un tackle lateral e impacta en la parte medial de la pierna (figura 17), esto puede provocar un movimiento de inversión o eversión del tobillo $(227,231)$. Es difícil que el trabajo propioceptivo o un vendaje evite esta lesión (170). Sin embargo, puede ser que el contacto directo no sea la causa la lesión, sino que solamente ponga el tobillo en una posición vulnerable, especialmente en jugadores con un reducido control neuromuscular $(170,227)$. En ese caso, un trabajo propioceptivo mejoraría el control neuromuscular y permitiría reposicionar el pie antes de que ocurriese la lesión (170).

2) Flexión plantar forzada debido a un contacto con el pie del rival en un intento de despeje o tiro (figura 18).

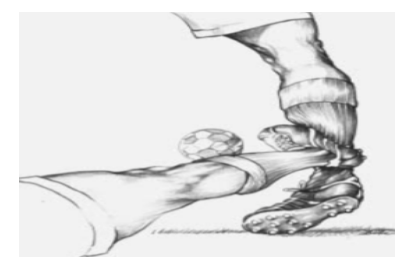

Figura 17: Golpe medial que provoca inversión de tobillo y posible esguince (227)

Figura 18: Posible esguince de tobillo por flexión plantar forzada (227)

Aunque podemos encontrar otros mecanismos que ocurren con menor frecuencia que son:

- Lesiones al golpear la pelota: Este tipo de lesiones aparecen cuando un jugador contacta con la pierna del rival mientras intenta despejar o tirar, lo que provoca una flexión plantar forzada. Normalmente el jugador lesionado se desplaza a gran velocidad antes de la lesión (227).

- Lesiones al correr: Pueden ocurrir mientras el jugador está en contacto con un rival o estando solo. Normalmente el jugador lesionado se desplaza a alta intensidad y entra en contacto con el suelo mientras tiene el pie en inversión (227).

- Otros mecanismos de lesión que podemos encontrar con menor frecuencia son aterrizar tras un salto con un oponente, contacto con un compañero o tropezar tras haber realizado un control (227).

\subsubsection{Ligamento Cruzado Anterior.}

La lesión de LCA es bastante común en los deportes en los que hay deceleraciones, saltos, cambios de dirección y giros repentinos, como el fútbol, y tiene un efecto muy grande sobre la actividad del jugador cuando aparece (234). Parece ser que es más probable que ocurra en clima seco, debido a un menor deslizamiento del pie (235).

La lesión de LCA ocurre cuando se aplica una fuerza o carga excesiva sobre el LCA (234). La anteriorización de la cabeza de la tibia aumenta la carga en el LCA, especialmente si va unida a un momento de valgo, varo o rotación interna de rodilla y a ángulos de flexión de rodilla bajos (236). Además, una fuerte contracción del cuádriceps también puede aumentar la carga sobre el LCA (234).

La musculatura del cuádriceps es el principal factor que genera esa anteriorización de la tibia (236), especialmente desde la extensión total hasta los $30^{\circ}$ de flexión de rodilla, momento a partir del cual se reduce (237), por lo que el apoyo con la rodilla relativamente extendida tras la recepción de un salto puede ser un factor de riesgo para las lesiones de LCA (234) (vienen a la mente lesiones de Víctor Valdés 
o Sergio Asenjo). Cuando se produce una fuerza de reacción con el suelo (por ejemplo en la recepción unipodal de un salto), se produce un momento de flexión de rodilla que debe ser contrarrestado con un momento de extensión de rodilla, provocado por el cuádriceps (238). Como la contracción del cuádriceps aumenta la carga (234), cuanto mayor es la fuerza de reacción contra el suelo, mayor debe ser la fuerza ejercida por el cuádriceps y, por tanto, la carga sobre el LCA (238), aumentando así el riesgo de lesión.

Existe la idea de que una co-contracción de la musculatura posterior del muslo (isquiosurales) favorece la posteriorización de la cabeza de la tibia, protegiendo así de una lesión de LCA (234). Sin embargo esto no es del todo cierto, ya que sólo ocurre cuando el ángulo de flexión de la rodilla es superior a $15^{\circ}(239)$ ó, incluso, a $30^{\circ}(240,241)$.

En un estudio prospectivo realizado sobre 205 adolescentes femeninas se encontró que las jugadoras que se lesionaron durante los 3 años de estudio tenían un ángulo de abducción de la rodilla $8^{\circ}$ mayor y ejercieron un $20 \%$ más de fuerza de reacción contra el suelo al recepcionar tras un salto (120), lo que podría indicar una relación entre el valgo de rodilla y las lesiones de LCA (234), sin embargo otros estudios encuentran valores de valgo similares y concluyen que no hay tal asociación salvo que exista una fuerza que anteriorice la cabeza de la tibia $(236,242)$. Además, el LCA parece no influir en los momentos de valgo y varo de rodilla siempre que el LCM esté intacto (243), que es la principal estructura que evita la abducción de rodilla (244).

En un estudio en el que se analizaron prospectivamente, mediante vídeo, 39 lesiones de LCA de 3 cohortes distintas de futbolistas profesionales, encontraron que el $85 \%$ de las lesiones se producen por contacto indirecto (21\%) (con cualquier parte del cuerpo excepto la rodilla que se lesiona) y sin contacto (64\%), y 3 fueron los principales mecanismos de lesión: la presión o acoso al poseedor de balón, el reequilibrio después de contactar con el balón y la recepción del salto tras una disputa. El resto (15\%) se produjo por contacto directo sobre la pierna lesionada (222). En el $87 \%$ de las situaciones el futbolista estaba en posición unipodal con carga y en el $77 \%$ realizaba una acción defensiva (222). Entre los mecanismos de lesión de LCA encontramos:

a) El acoso al poseedor de balón es el mecanismo sin contacto más frecuente (figura 19). Normalmente el defensor se acerca a alta velocidad y realiza un gesto de corte lateral para intentar interceptar la pelota o interponerse a su rival. En el momento en el que apoya el pie con el que intenta interceptar se produce un giro del tronco y se carga el peso en la pierna que ya estaba apoyada en el suelo, que presentará una rodilla relativamente extendida, en abducción y con peso (222).

b) En el caso del reequilibrio tras el contacto con el balón, la acción más común es el despeje (figura 20). Aquí es frecuente un apoyo unipodal con rotación interna del tronco, seguramente por un desequilibrio que obliga a cargar el peso del cuerpo sobre la pierna apoyada, generando una abducción de rodilla. En este estudio se encontraron valores de flexión de rodilla inferiores a $30^{\circ}$ en todos los casos en el momento de contacto con el suelo (222).

c) En las lesiones tras recepción de salto se entra en contacto con el suelo con una sola pierna, exactamente con la parte delantera del pie (figura 21). Los ángulos de flexión de rodilla fueron inferiores a $10^{\circ}$ en todos los casos (222).

d) En cuanto a las lesiones por contacto directo sobre la rodilla lesionada, en los casos que reflejan este estudio el tackle fue por detrás, ejerciendo una fuerza lateral que provoca un colapso en valgo con el pie apoyado en el suelo y con carga (figura 22) (222).

Como podemos observar, el reducido ángulo de flexión de rodilla está presente en todos los mecanismos de lesión descritos.
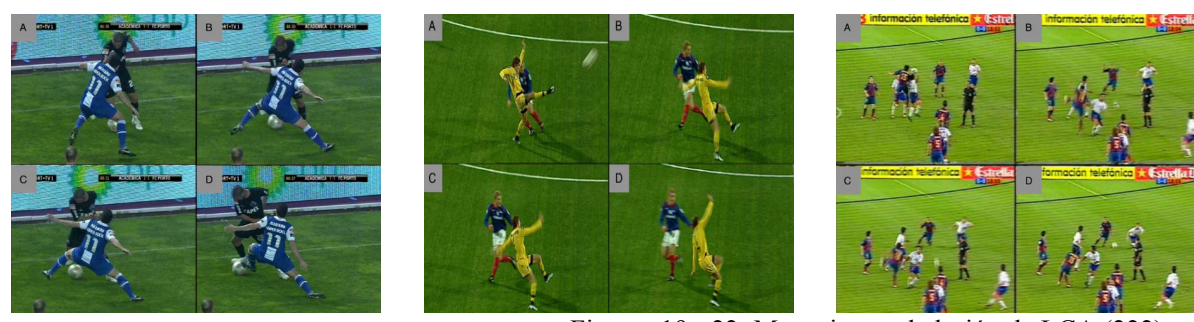

Figuras 19 - 22: Mecanismos de lesión de LCA (222)

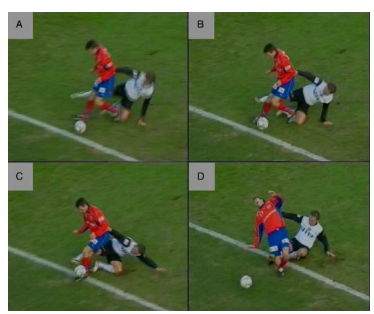




\subsubsection{Desgarros en Cuádriceps.}

Los desgarros en el cuádriceps se producen en deportes en los que se golpea la pelota y se corre a alta velocidad, como el fútbol (160). Dentro del grupo muscular, el recto anterior es el músculo más comúnmente lesionado (245), debido a su elevada capacidad excéntrica y su alto porcentaje de fibras tipo II (246).

La lesión suele ocurrir durante una contracción excéntrica $(247,248)$ y puede aparecer en la unión miotendinosa distal (249), en la unión del tendón con el vientre muscular (245) o en la parte central del tendón $(245,250,251)$. La causa es multifactorial, aunque ocurre especialmente durante la carrera y el golpeo de balón (250).

- Lesiones durante la carrera: El riesgo es mayor durante:

- Aceleración: Durante la primera fase de swing se produce una contracción excéntrica de los flexores de cadera (252) y el máximo alargamiento del recto femoral (253), justo después del apoyo de la pierna contraria y en la transición de la extensión máxima de cadera a la flexión máxima de cadera y rodilla (252). Las altas velocidades angulares de cadera y rodilla durante la fase de swing en la carrera unido a la activación excéntrica, hacen que el recto femoral sea más propenso a lesiones (250).

- Deceleración: Las desaceleraciones y los cambios de dirección son muy frecuentes en fútbol (250) y demandan mucha fuerza porque se producen en un instante (254), durante el cual se debe adaptar la posición del cuerpo, mediante una posición más erguida del tronco primero e inclinada después, para absorber las fuerzas excéntricas que se generan (255), para lo cual la acción del cuádriceps es fundamental (250).

- Lesiones durante el golpeo de balón: Es el mecanismo de lesión más común $(250,256)$ aunque no está claro si los desgarros del recto femoral tienen lugar a) mientras se contacta con la pelota, b) en la fase de swing, o c) en la de contacto con el suelo tras el swing (250). En este sentido podemos indicar:

a) Momento de golpeo de la pelota: Para que aparezca la lesión los músculos deben estar relativamente estirados (257), por lo que los músculos del cuádriceps no corren peligro de lesión por tensión en este momento ya que ni se alargan ni se acortan de manera excéntrica (250).

b) Fase de Swing: Como podemos ver en la figura 23, durante la fase inicial del swing en el golpeo, en la que la pierna se desplaza hacia atrás, la velocidad angular del muslo es mínima y el recto femoral debe frenar la extensión de cadera y la flexión de rodilla mediante una contracción excéntrica, lo que podría ponerlo en situación de riesgo de lesión (258). En la siguiente fase del swing la cadera comienza a flexionarse mientras que la rodilla aumenta su flexión (259). La máxima flexión de rodilla se produce en el $70-75 \%$ de la fase de swing, y es donde se produce la mayor velocidad angular de muslo, en ese momento el recto femoral se contrae excéntricamente para frenar la flexión de rodilla y comenzar a acelerar en sentido positivo (259-261). Es posible que, debido a las distintas velocidades angulares unido a una mayor flexión de rodilla, éste sea el momento de lesión del recto femoral en la acción de golpeo de balón (250).

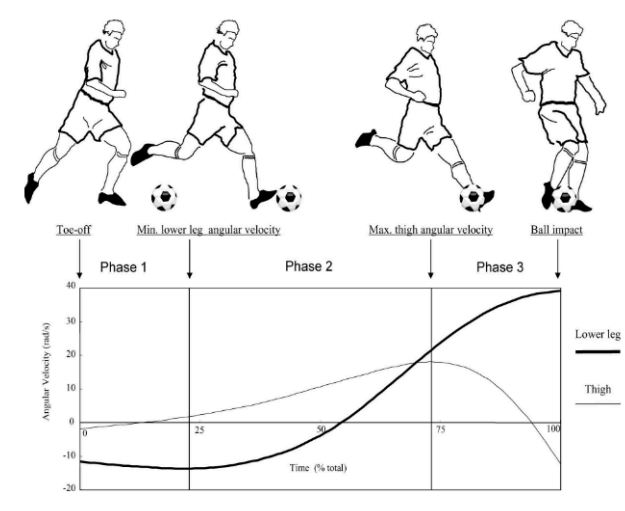

Figura 23: Fases del Swing durante el golpeo de balón (258)

c) Momento de contacto con el suelo: El contacto del pie con el suelo genera mayor fuerza que el contacto con la pelota y una menor velocidad angular del muslo (250). El frenado durante el golpeo de balón hace que el cuerpo se incline hacia atrás, lo que genera una tensión adicional sobre el recto femoral que puede llevar a una lesión (160)(250). 


\subsubsection{Desgarros en Isquiosurales.}

Las lesiones en los isquiosurales son más comunes en deportes que requieren una aceleración rápida, carreras a alta velocidad, saltos, golpeos,... (262) como el fútbol. Comprender la mecánica lesional durante la carrera es clave para entender el motivo de su alta incidencia (252).

La mayoría de los desgarros en isquiosurales se producen cuando el deportista esprinta o corre a velocidades muy altas (263). Ocurren normalmente durante la contracción excéntrica (252). La unión miotendionsa es el lugar más común de lesión, debido a que sufre las cargas excéntricas más elevadas $(264,265)$. Las lesiones en el vientre muscular ocurren con menor frecuencia y el mecanismo suele ser una contusión (265).

En esta musculatura se produce un ciclo de estiramiento - acortamiento durante el sprint; se alarga durante toda la fase de swing para después acortarse, mediante una contracción concéntrica, y continuar haciéndolo mientras el pie está en contacto con el suelo (252). Aunque algunos estudios indican que la máxima actividad tiene lugar cuando el pie contacta con el suelo $(266,267)$, la mayoría de la literatura coincide en señalar que ocurre al final de la fase de swing (252,268-272), ya que es en ese momento cuando se produce la mayor tensión (en la cabeza larga de bíceps femoral), la mayor velocidad de alargamiento (en el semitendinoso) y la mayor fuerza y capacidad de absorción de energía (en el semimembranoso) (252).

En ese instante los isquiosurales ayudan a la extensión de cadera y frenan la extensión de rodilla (262). Como la fuerza y tensión músculo-tendinosa máximas en bíceps femoral, semitendinoso y semimembranoso ocurren justo en este último momento de la fase de swing el riesgo de lesión podría ser mayor (252).

\subsubsection{Desgarros en Aductor.}

Más del 60\% de las lesiones de la ingle se ubican en los aductores de cadera y 9 de cada 10 de ellas afectan al aductor largo (273). En un estudio de lesiones de ingle en jugadores de fútbol masculinos, se encontró que la mayoría de las lesiones de aductor largo ocurrieron en situaciones sin contacto (71\%) (226). Las acciones que llevaron a lesión fueron los cambios de dirección (35\%), golpeos de balón (29\%), gestos en los que se intentó cortar un pase (24\%) y los saltos (12\%) (226).

Los cambios de dirección y los gestos de corte se clasificaron como acciones de cadena cinética cerrada, donde hay contacto con el suelo a medida que avanza la cadera (59\% del total de lesiones), caracterizados por una extensión de cadera y abducción con rotación externa (226). Los cambios de dirección incluyeron ángulos de $<45^{\circ}$ y $>90^{\circ}$ hacia el lado de la pierna no lesionada (226). Como los desgarros en aductores suelen en ocurrir en contracciones excéntricas (274), la rápida activación muscular combinada con un aumento en la longitud muscular puede ser el elemento clave que produzca la lesión (226). Esto mismo puede ocurrir en las lesiones por gesto de corte, ya que parecen seguir un movimiento de cadena cerrada comparable (226).

Las lesiones por golpeos de balón y saltos se clasificaron como cadena cinética abierta, en los que la pierna se mueve sin tocar el suelo $(41 \%)$, caracterizadas por un cambio de extensión a flexión de cadera, y de abducción a aducción con rotación externa (226). En el caso de las lesiones por golpeo de balón, no hay una diferencia significativa que indique si ocurren en pases cortos, largos o en tiros (226). En cuanto a los saltos, es posible que la rápida transición de una extensión de cadera a una flexión sitúe el aductor largo en riesgo de lesión por tensión aguda (260).

Por todo ello, se puede concluir que una rápida activación muscular durante el alargamiento muscular puede ser el mecanismo de lesión principal en lesiones agudas de aductor largo (226).

\subsubsection{Factores de Riesgo.}

Tal y como comentamos anteriormente (ver 3.1.1.2) el segundo paso de la "secuencia de prevención de lesiones deportivas" (167) era analizar los factores de riesgo que afectan a una lesión. Un "peligro" o "factor de riesgo" es "una condición, objeto o situación que puede ser una fuente potencial de daño para las personas", y "riesgo" es "la probabilidad de que un peligro tenga un impacto en esas personas" (275). 
Si revisamos la literatura vemos que los factores de riesgo se dividen en internos o intrínsecos y externos o extrínsecos (167). Los internos se refieren a las características biológicas o psicosociales de la persona, como la edad, el sexo, la condición física aeróbica, la flexibilidad, la inestabilidad funcional, las lesiones previas o la rehabilitación inadecuada $(9,276)$ y suelen ser necesarios para producir una lesión, pero no por sí solos (167); mientras que los externos actúan sobre el deportista, se denominan "habilitantes" porque facilitan que ocurra la lesión (167) e incluyen la cantidad de entrenamiento y partidos jugados, factores climáticos superficie del terreno de juego o el juego sucio $(9,276)$.

Algunos de esos factores serán modificables y otros no $(10,277)$, pero la presencia de ambos tipos coloca al deportista en una situación de vulnerabilidad, aunque será la suma todos los factores, la interacción entre ellos y el mecanismo lesional (evento incitante (167)) lo que provoca la lesión en una situación dada $(28,170)$. Por ello, para analizar los factores de riesgo que intervienen en una lesión un enfoque univariado puede ser simplista y se debe utilizar un enfoque multivariado $(28,167,278)$, porque el motivo que provoca la lesión suele ser multifactorial (279).

Meeuwisse et al plantean un modelo dinámico de etiología de lesiones señalando que "un factor de riesgo puede minimizarse a medida que el deportista participa y se adapta al ambiente o a situaciones potencialmente perjudiciales sin sufrir lesiones, ya que pueden ocurrir adaptaciones o desadaptaciones que modifican los factores de riesgo intrínsecos y / o extrínsecos en función de la interacción de los atributos del evento y los riesgos preexistentes" (280). Por tanto, para comprender la naturaleza de una lesión y diseñar un plan preventivo no sólo hay que analizar los factores de riesgo que preceden a una lesión, sino pensar en cómo esos factores pueden haber mutado durante la práctica deportiva (280).

Cada sujeto tiene un riesgo distinto ante cada lesión (281), por lo que debemos analizar los factores intrínsecos y extrínsecos para determinar el riesgo de cada sujeto y abordar aquéllos que sean modificables antes de que se produzca la lesión (280). El 94\% de las selecciones de máximo nivel lo hacen de esta manera (10). Además, es necesario distinguir entre variables predictivas (aquellas que nos permiten conocer los jugadores que van a sufrir una lesión) y variables asociadas a una lesión (aquellas que indican un jugador con mayor riesgo de lesión, al que se le deberá aplicar un plan preventivo) (282).

Pero al revisar la literatura, se observa que hay resultados contradictorios con respecto a los factores de riesgo propuestos para las lesiones, lo que puede deberse, en parte, a herramientas de medición inexactas, a un tamaño pequeño de la muestra, o a que se analizan deportes o tipos de lesiones diferentes (276). Como muestra de ello, en las figuras 24 y 25 , se presentan los factores extrínsecos e intrínsecos junto con la cantidad de artículos que muestran una asociación entre cada factor de riesgo y la posibilidad de que exista una lesión (en azul) y la cantidad de artículos que no ha encontrado dicha evidencia (en rojo). Además, se muestran barras en verde para reflejar los estudios que fueron realizados en fútbol para cada una de las dos opciones anteriores. Por tanto, al no existir resultados concluyentes no podemos afirmar que unos u otros riesgos estén directamente relacionados con la aparición de lesiones.

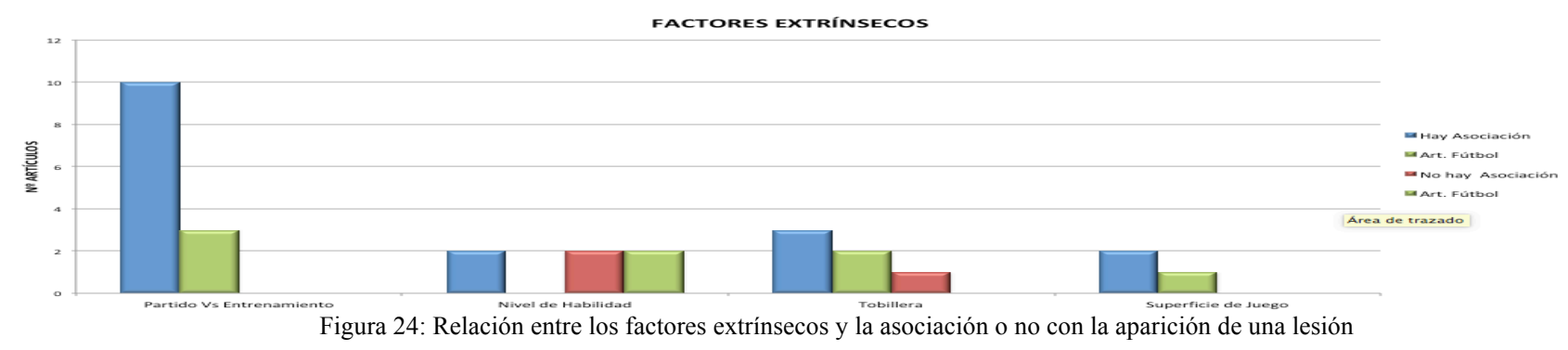

Figura 24: Relación entre los factores extrínsecos y la asociación o no con la aparición de una lesión

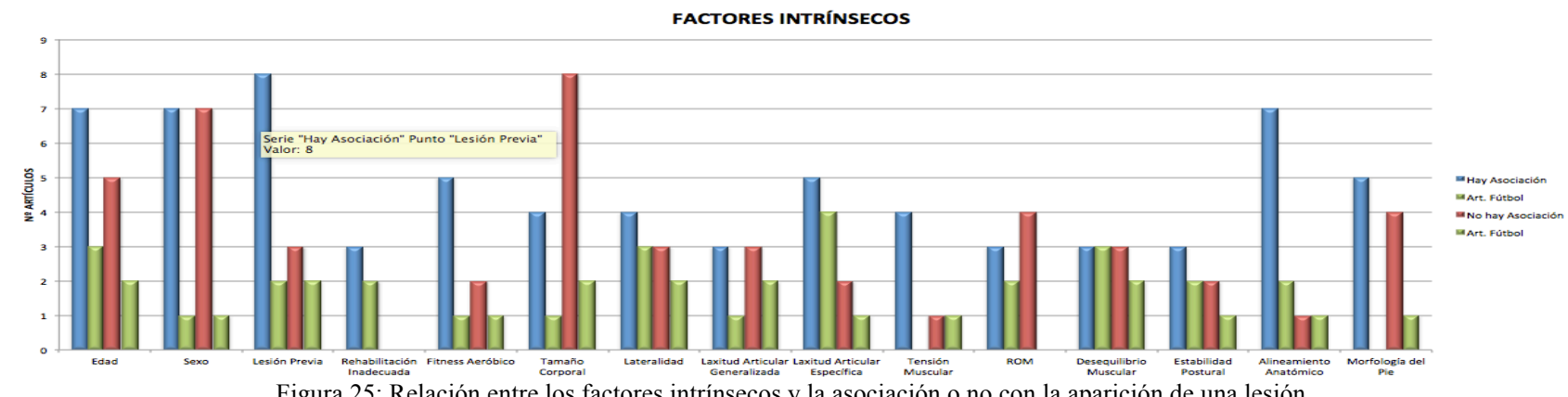

Figura 25: Relación entre los factores intrínsecos y la asociación o no con la aparición de una lesión 
Si nos vamos a la práctica, los factores de riesgo más importantes para provocar una lesión, según una encuesta realizada a 44 equipos de primera división de distintos países (110) y otra presentada a 32 equipos participantes en la Copa Mundial de la FIFA 2014 en Brasil (10) son los siguientes, por orden de clasificación:

\begin{tabular}{|l|l|l|}
\hline $\begin{array}{c}\text { FACTORES DE RIESGO } \\
\text { IDENTIFICADOS EN } \\
\text { EQUIPOS DE ÉLITE (110) }\end{array}$ & \multicolumn{2}{|c|}{ FACTORES DE RIESGO IDENTIFICADOS EN SELECCIONES } \\
A BSOLUTAS (10)
\end{tabular}

A continuación vamos a analizar, brevemente, los factores comunes en ambos estudios, ya que son los que más preocupan a los servicios médicos de los principales clubes de élite del fútbol $(10,110)$.

\subsubsection{Lesión Previa como Factor de Riesgo.}

La lesión previa se identifica, sistemáticamente, como el factor de riesgo más importante para una nueva lesión $(9,11-14)$, aumentando el riesgo hasta 11 veces en lesiones de isquiosural $(11,12,14), 7$ veces en lesiones de ingle $(11,14,188)$ y 5 veces en lesiones de rodilla $(11,14)$ y esguince de tobillo $(11,16,170)$. El nivel general de evidencia para lesiones previas como factor de riesgo es de $2++(283)$.

Las posibles causas que evidencian la lesión previa como factor de riesgo son una rehabilitación inadecuada (incompleta, agresiva, o por subestimar la lesión), una incorporación demasiado temprana al juego o al entrenamiento de alta intensidad, modificaciones tras la aparición de la lesión (debilidad, tejido cicatricial, alteraciones biomecánicas, inhibición neuromuscular,...) $(9,284-286)$, una ROM reducida debido a la lesión inicial (28) o los mismos factores de riesgo que provocaron la lesión inicial (14), no obstante los aspectos psicosociales, el estrés y la ansiedad también pueden influir (287).

Aunque existe una mayor proporción de lesiones recurrentes al final de la temporada competitiva (probablemente porque los equipos necesitan disponer de jugadores lesionados por disputar partidos importantes), la incidencia de estas lesiones está disminuyendo en los últimos años y su proporción es inversamente proporcional al nivel del equipo (3), lo que puede explicarse porque los equipos de alto nivel tienen acceso a personal cualificado y medios óptimos a su disposición para supervisar la rehabilitación del jugador lesionado en todo momento, y a que disponen de plantillas más amplias (3).

\subsubsection{La Fatiga como Factor de Riesgo.}

La fatiga puede aumentar el riesgo de lesión durante un partido $(288,289)$. Es más probable que una lesión muscular ocurra al final de la primera mitad y durante la segunda $(160,186)$, mientras que para lesiones de tobillo y rodilla el riesgo más elevado es al final de cada periodo de juego (179), lo que puede deberse a que no se haya podido recuperar completamente de la fatiga generada (218), a una disminución de la capacidad excéntrica de los isquiosurales (14), a que se ha producido un vaciamiento de glucógeno (197) o que hay una mayor deshidratación (290). También existe una mayor incidencia de lesiones cuando se juega más de un partido a la semana, debido al reducido tiempo de recuperación (291).

Sin embargo, entre los 14 estudios analizados en una revisión sistemática se encontró un nivel de evidencia de 4 (opinión de expertos) para la fatiga como factor de riesgo, posiblemente porque aún no hay una definición adecuada para este término (283). Finalmente, también se encuentran estudios que recomiendan eliminar la fatiga como factor de riesgo de lesiones (277). 


\subsubsection{El Desequilibrio Muscular como Factor de Riesgo.}

La diferencia en la fuerza muscular de los flexores y extensores de rodilla es otro factor intrínseco que puede estar relacionado con las lesiones $(11,292)$, concretamente una relación $\mathrm{H} / \mathrm{Q}>64 \% \mathrm{o}<55 \% \mathrm{o}$ diferencias mayores al $10 \%$ en el pico de torque entre ambos grupos musculares en comparación con la pierna contralateral (35).

La tendencia de los jugadores a tener una pierna dominante para muchas acciones en fútbol puede crear diferencias de flexibilidad o de fuerza entre agonistas y antagonistas o entre una pierna y la contralateral (293), lo que puede llevar a un déficit en el control corporal durante el movimiento y predisponer a lesión (79), especialmente de LCA y de isquiosurales debido a que no se evita la anteriorización de la tibia en recepciones de saltos y cambios de dirección (294), aunque ya vimos que esto sólo ocurre cuando el ángulo de flexión de la rodilla es superior a $15^{\circ}$ (239) ó, incluso, a $30^{\circ}$ $(240,241)$.

Sin embargo, los resultados que se obtienen en las investigaciones en relación al desequilibrio muscular y el riesgo de lesión son limitados y contradictorios (295), por lo que el nivel de evidencia no es concluyente (296).

\subsubsection{La Carga de Entrenamiento como Factor de Riesgo.}

Una lesión por sobreuso se produce cuando existe una inadecuada gestión de la carga de entrenamiento (297), de hecho, parece ser que aumentos muy pronunciados en la carga semanal se relacionan con lesiones sin contacto en fútbol australiano (298) y en rugby (299).

En este sentido, la ratio carga aguda:crónica, aunque no es una variable que pueda predecir una lesión (300) puede ser una medida eficaz para conocer el riesgo de lesión de un deportista $(301,302)$.

\subsubsection{Las Variables Psicológicas como Factor de Riesgo.}

Las variables psicológicas tienen una gran importancia en la producción de lesiones $(40,41)$ tanto en futbolistas profesionales (43) como aficionados (44), por lo que deben ser tenidas en cuenta en nuestro programa preventivo. Entre los modelos más influyentes que estudian la relación entre los factores de riesgo psicológicos y la ocurrencia de lesiones podemos encontrar (303): el "modelo de lesión por estrés" que clasifica los factores de riesgo en factores de personalidad, antecedentes de factores estresantes y recursos de afrontamiento, el "modelo de la influencia de los factores psicológicos en las lesiones deportivas" que los clasifica en factores estresantes psicológicos, recursos de afrontamiento y estado emocional, y el "modelo empírico de los factores de riesgo de lesiones" que indica que los factores de personalidad, estrés y afrontamiento influyen en el riesgo de lesión, sobretodo en el fútbol (303).

Así, podemos observar una mayor incidencia de lesiones en aquéllos futbolistas que muestran valores elevados de estrés (42), que son incapaces de controlarlo (304), o que se ven afectados por la percepción del éxito o acontecimientos estresantes negativos (40). Del mismo modo, también hay una asociación entre valores medios o bajos de autoconfianza y una mayor incidencia de lesiones en jóvenes futbolistas (40).

Otro aspecto psicológico a destacar es la ansiedad, ya que existen numerosos trabajos que relacionan un nivel elevado de ansiedad (especialmente durante la competición) con una mayor aparición de lesiones $(40,305)$. En este sentido, en un estudio realizado con jugadores profesionales de fútbol se encontró que la ansiedad de rasgo, el estrés por eventos negativos en la vida y la molestia diaria fueron predictores significativos de lesión (43).

Por tanto, parece justificado observar si nuestro jugador se ve sometido a una alta presión, tanto externa como autoimpuesta, que pueda elevar los niveles de ansiedad aumentando el riesgo de lesión.

\subsubsection{Factores de Riesgo para las lesiones abordadas en el trabajo.}

Dado que cada grupo muscular de las extremidades inferiores parece presentar factores de riesgo específicos (277), a continuación analizaremos la literatura para indicar cuáles están presentes en cada una de las lesiones que se van a tratar en este trabajo. Para hacerlo de un modo más didáctico, se presenta la información mediante tablas. 
3.1.4.6.1 Factores de Riesgo en Esguinces de Tobillo.

\begin{tabular}{|c|c|c|c|c|c|}
\hline ESTUDIO & AÑo & MUESTRA & PAÍS & $\begin{array}{l}\text { FACTORES ASOCIADOS CON } \\
\text { MAYOR RIESGO DE LESIÓN }\end{array}$ & $\begin{array}{c}\text { FACTORES NO ASOCIADOS CON } \\
\text { MAYOR RIESGO DE LESIÓN }\end{array}$ \\
\hline Kofotolis et al. (17) & 2007 & $\begin{array}{l}312 \text { futbolistas } \\
\text { amateur }\end{array}$ & Grecia & $\begin{array}{ll}\text { - } & \text { Extremidad dominante } \\
\text { - } & \text { Posición del Jugador } \\
\text { - } & \text { Intensidad de Partido } \\
\text { - } & \text { ESGUINCE PREVIO } \\
\end{array}$ & 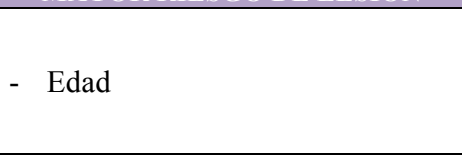 \\
\hline $\begin{array}{l}\text { Engebretsen et al. } \\
\text { (16) }\end{array}$ & 2010 & $\begin{array}{l}769 \text { futbolistas de } \\
\text { primera, segunda } \\
\text { y tercera división }\end{array}$ & Noruega & & $\begin{array}{ll}\text { - } & \text { Edad } \\
\text { - } & \text { Altura } \\
\text { - } & \text { IMC } \\
\text { - } & \text { Posición del Jugador } \\
\end{array}$ \\
\hline Fousekis et al. (25) & 2012 & $\begin{array}{l}100 \text { futbolistas } \\
\text { amateur }\end{array}$ & Grecia & $\begin{array}{l}\text { - } \text { Asimetría de fuerza } \\
\text { Isocinética excéntrica de } \\
\text { flexores dorsales y plantares } \\
\text { de tobillo. } \\
\text { - } \\
\text { - } \\
\text { Aumento del IMC } \\
\text { Aumento del Peso Corporal } \\
\end{array}$ & $\begin{array}{ll}\text { - } & \text { Altura } \\
\text { - } & \text { Flexibilidad Muscular } \\
\text { - } & \text { Déficit Propioceptivo } \\
\text { - } & \text { ESGUINCE PREVIO }\end{array}$ \\
\hline Doherty et al. (306) & 2015 & $\begin{array}{l}69 \text { sujetos con un } \\
\text { primer esguince } \\
\text { reciente y } 20 \\
\text { sujetos sin } \\
\text { esguince } \\
\end{array}$ & Alemania & & - ROM limitado de la dorsiflexión \\
\hline Henry et al. (18) & 2016 & $\begin{array}{l}210 \text { futbolistas } \\
\text { amateur }\end{array}$ & Australia & $\begin{array}{ll}\text { - } & \text { Déficit Propioceptivo } \\
\text { - } & \text { ESGUINCE PREVIO }\end{array}$ & $\begin{array}{ll}\text { - } & \text { ROM limitado de la dorsiflexión } \\
\text { - } & \text { Edad } \\
\text { - Nivel de Juego }\end{array}$ \\
\hline Powers et al. (32) & 2017 & $\begin{array}{l}210 \text { futbolistas de } \\
\text { Primera División }\end{array}$ & Irán & $\begin{array}{l}\text { - Debilidad de Abductores de } \\
\text { Cadera }\end{array}$ & \\
\hline Witchalls et al. (307) & 2012 & \multicolumn{2}{|c|}{$\begin{array}{l}\text { REVISIÓN SISTEMÁTICA Y } \\
\text { META-ANÁLISIS }\end{array}$} & - Déficit Propioceptivo & $\begin{array}{l}\text { - Tiempo de Reacción tras una } \\
\text { perturbación } \\
\text { - ROM limitado de la dorsiflexión }\end{array}$ \\
\hline
\end{tabular}

Tabla 44: Factores de Riesgo en Esguinces de Tobillo. Elaboración Propia

De todos los factores de riesgo presentados, la lesión previa es el que más peso tiene en la literatura. Existen referencias que concluyen que no hay mayor riesgo de sufrir un esguince de tobillo después de haber sufrido un esguince previo $(25,308,309)$, aunque la mayoría de los estudios lo señalan como el factor más importante para tener una nueva lesión debido a un proceso de rehabilitación inadecuado $(11,16,17,310)$, a una alteración de la cadena cinética una vez desaparecen los síntomas (311) o a que aparece una desaferencia parcial en el tobillo en el caso de que se rompa el ligamento (312).

En el caso de la inestabilidad crónica de tobillo, definida como "el desarrollo de esguinces de tobillo repetitivos y síntomas persistentes después del esguince de tobillo inicial" (313) encontramos 2 factores como principales causantes (313):

\begin{tabular}{|l|l|}
\hline \multirow{2}{*}{ Inestabilidad Mecánica del Tobillo } & Laxitud Patológica \\
\cline { 2 - 2 } & Artrocinemática deteriorada \\
\cline { 2 - 2 } & Cambios sinoviales y degenerativos \\
\hline \multirow{2}{*}{ Inestabilidad Funcional del Tobillo } & Déficit propioceptivo \\
\cline { 2 - 2 } & Control neuromuscular alterado \\
\cline { 2 - 2 } & Déficit de fuerza \\
\hline
\end{tabular}

Tabla 45: Factores de Riesgo en Esguinces Crónicos de Tobillo (313)

\subsection{Factores de Riesgo en Esguinces de Rodilla y LCA.}

\begin{tabular}{|c|c|c|c|c|c|}
\hline ESTUDIO & AÑ̃o & MUESTRA & PAÍS & $\begin{array}{l}\text { FACTORES ASOCIADOS CON } \\
\text { MAYOR RIESGO DE LESIÓN }\end{array}$ & $\begin{array}{l}\text { FACTORES NO ASOCIADOS CON } \\
\text { MAYOR RIESGO DE LESIÓN } \\
\end{array}$ \\
\hline Griffin et al. (31) & 2000 & - & - & $\begin{array}{l}\text { - Factores neuromusculares } \\
\text { - Excesiva activación del } \\
\text { cuádriceps }\end{array}$ & $\begin{array}{l}\text { - Uso de Rodilleras } \\
\text { - Alineación anatómica de las } \\
\text { extremidades inferiores } \\
\text { - Tamaño del LCA } \\
\text { - Hormonas sexuales } \\
\text { - } \text { Ciclo menstrual }\end{array}$ \\
\hline Hewett et al. (120) & 2005 & $\begin{array}{l}205 \text { Jugadoras } \\
\text { Adolescentes de } \\
\text { Baloncesto y } \\
\text { Voleibol }\end{array}$ & - & 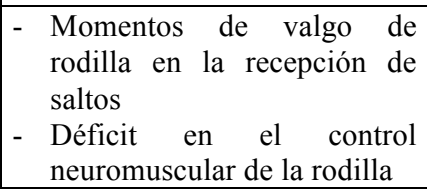 & \\
\hline
\end{tabular}




\begin{tabular}{|c|c|c|c|c|c|}
\hline Claiborne et al. (33) & 2006 & $\begin{array}{l}15 \text { hombres y } 15 \\
\text { mujeres } \\
\text { voluntarios/as }\end{array}$ & - & $\begin{array}{l}\text { - Déficit de fuerza de } \\
\text { abductores de cadera y de } \\
\text { flexores y extensores de } \\
\text { rodilla } \rightarrow \text { valgo de rodilla }\end{array}$ & \\
\hline Zazulak et al. (93) & 2007 & $\begin{array}{l}277 \text { deportistas } \\
\text { universitarios/as }\end{array}$ & - & $\begin{array}{ll}\text { - } & \text { Control inadecuado del Core } \\
\text { - } & \text { Aumento del valgo de rodilla } \\
\text { - } & \text { Historia de dolor lumbar } \\
\end{array}$ & \\
\hline Räisänen et al. (19) & 2018 & $\begin{array}{l}737 \text { futbolistas } \\
\text { jóvenes }\end{array}$ & Finlandia & $\begin{array}{l}\text { - Dorsiflexión limitada de } \\
\text { tobillo }\end{array}$ & $\begin{array}{ll}\text { - } & \text { Altura } \\
\text { - } & \text { Peso } \\
\text { - } & \text { Edad } \\
\text { - } & \text { Control de la rodilla en el plano } \\
& \text { frontal (valgo de rodilla) } \\
\end{array}$ \\
\hline Praz et al. (314) & 2019 & $\begin{array}{c}262 \text { pacientes } \\
\text { operados de LCA } \\
\text { y rotura de } \\
\text { menisco posterior }\end{array}$ & - & & $\begin{array}{l}\text { - Exposición a deportes de contacto } \\
\text { - Presencia de desgarro meniscal } \\
\text { medial }\end{array}$ \\
\hline Lima et al. (48) & 2018 & \multicolumn{2}{|c|}{$\begin{array}{l}\text { REVISIÓN SISTEMÁTICA Y } \\
\text { META-ANÁLISIS }\end{array}$} & $\begin{array}{l}\text { - Dorsiflexión limitada de } \\
\text { tobillo } \rightarrow \text { Valgo dinámico de } \\
\text { rodilla }\end{array}$ & \\
\hline
\end{tabular}

\subsection{Factores de Riesgo en Lesiones de Cuádriceps.}

La literatura encontrada referente a factores de riesgo en lesiones de cuádriceps es bastante menor que la que podemos recoger en otros grupos musculares. Por ello, en lugar de tablas, se presenta la información desarrollada.

La lesión previa es el principal factor de riesgo para una lesión de cuádriceps $(14,250,315)$. A partir de aquí hay cierta contradicción. Los desequilibrios que producen deportes como el fútbol, en los que una extremidad es claramente dominante, es otro factor de riesgo que podemos encontrar en la literatura $(250,277,292)$, aunque otros estudios señalan que esa asociación no está clara (276). Lo mismo ocurre con la flexibilidad del cuádriceps, existen artículos que concluyen que es un factor de riesgo (54), aunque otros no encuentran esa asociación (277).

Por último, parece ser que realizar un calentamiento inadecuado aumenta el riesgo de lesión en cuádriceps ante gestos como golpeos de balón (9), y que la edad no es un factor que predisponga al jugador a este tipo de lesiones (276).

\subsection{Factores de Riesgo en Lesiones de Isquiosurales.}

\begin{tabular}{|c|c|c|c|c|c|}
\hline ESTUDIO & AÑ̃o & MUESTRA & PAÍS & $\begin{array}{l}\text { FACTORES ASOCIADOS CON } \\
\text { MAYOR RIESGO DE LESIÓN }\end{array}$ & $\begin{array}{l}\text { FACTORES NO ASOCIADOS CON } \\
\text { MAYOR RIESGO DE LESIÓN }\end{array}$ \\
\hline Witvrouw et al. (54) & 2003 & $\begin{array}{c}146 \text { futbolistas } \\
\text { de élite }\end{array}$ & Bélgica & $\begin{array}{l}\text { - Flexibilidad de Isquiosurales } \\
\text { reducida }\end{array}$ & \\
\hline Foreman et al. (26) & 2006 & REVISIÓN S & EMÁTICA & & $\begin{array}{ll}\text { - } & \text { Debilidad Isquiosurales } \\
\text { - } & \text { Desequilibrio Ratio Cuádriceps / } \\
& \text { Isquiosural } \\
\text { - } & \text { Control neuromuscular deficiente } \\
\text { - } & \text { Flexibilidad muscular reducida } \\
\text { - } & \text { LESIÓN PREVIA } \\
& \text { ISQUIOSURALES } \\
\text { - } & \text { Lesión previa en otro grupo } \\
& \text { muscular } \\
\text { - } & \text { Factores Antropométricos }\end{array}$ \\
\hline Prior et al. (20) & 2009 & REVISIÓN S & EMÁTICA & $\begin{array}{ll}\text { - } & \text { LESIÓN PREVIA EN } \\
& \text { ISQUIOSURALES } \\
\text { - } & \text { Edad } \\
\text { - } & \text { Desequilibrio Ratio } \\
& \text { Cuádriceps / Isquiosural } \\
\text { - } & \text { Debilidad en Isquiosurales } \\
\text { - } & \text { Competir a alto nivel } \\
\end{array}$ & - Flexibilidad muscular reducida \\
\hline $\begin{array}{l}\text { van Beijsterveldt et al. } \\
\text { (21) }\end{array}$ & 2013 & REVISIÓN S & EMÁTICA & $\begin{array}{lll}\text { - LESIÓN PREVIA } & \text { EN } \\
& \text { ISQUIOSURALES }\end{array}$ & $\begin{array}{ll}\text { - } & \text { Edad } \\
\text { - } & \text { Longitud Muscular } \\
\text { - } & \text { Flexibilidad muscular reducida }\end{array}$ \\
\hline
\end{tabular}




\begin{tabular}{|c|c|c|c|c|}
\hline Freckleton et al (30) & 2013 & $\begin{array}{l}\text { REVISIÓN SISTEMÁTICA Y } \\
\text { META-ANÁLISIS }\end{array}$ & $\begin{array}{ll}\text { - } & \text { LESIÓN PREVIA EN } \\
& \text { ISQUIOSURALES } \\
\text { - } & \text { Edad } \\
\text { - } & \text { Aumento Torque Máximo de } \\
& \text { Cuádriceps }\end{array}$ & $\begin{array}{ll}\text { - } & \text { Flexibilidad muscular reducida } \\
\text { - } & \text { Desequilibrio Ratio Cuádriceps / } \\
& \text { Isquiosural } \\
\text { - } & \text { Altura } \\
\text { - } & \text { Aumento IMC } \\
\text { - } & \text { Longitud Muscular } \\
\text { - } & \text { Extremidad Dominante } \\
\text { - } & \text { Fuerza Abdominal } \\
\text { - } & \text { Resultado Test CMJ } \\
\text { - } & \text { VO2 Máx }\end{array}$ \\
\hline
\end{tabular}

Tabla 47: Factores de Riesgo en Lesiones en Isquiosurales. Elaboración Propia

\subsection{Factores de Riesgo en Lesiones de Aductor.}

\begin{tabular}{|c|c|c|c|c|c|}
\hline ESTUDIO & AÑ̃ & MUESTRA & PAÍS & $\begin{array}{l}\text { FACTORES ASOCIADOS CON } \\
\text { MAYOR RIESGO DE LESIÓN }\end{array}$ & $\begin{array}{l}\text { FACTORES NO ASOCIADOS CON } \\
\text { MAYOR RIESGO DE LESIÓN } \\
\end{array}$ \\
\hline Engebretsen et al. (22) & 2010 & $\begin{array}{c}508 \text { futbolistas } \\
\text { amateur }\end{array}$ & Noruega & $\begin{array}{l}\text { - LESIÓN PREVIA EN LA } \\
\text { INGLE } \\
\text { - Debilidad en aductores }\end{array}$ & 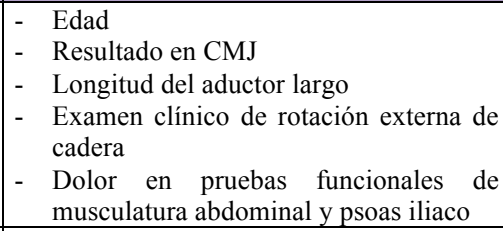 \\
\hline Maffey et al. (34) & 2007 & REVISIÓN SI & MÁTICA & $\begin{array}{l}\text { - LESIÓN PREVIA EN LA } \\
\text { INGLE } \\
\text { - Ratio de fuerza Abductores / } \\
\text { Aductores }\end{array}$ & \\
\hline Ryan et al. (23) & 2014 & REVISIÓN S & MÁTICA & $\begin{array}{ll}\text { - } & \text { LESIÓN PREVIA EN LA } \\
& \text { INGLE } \\
\text { - } & \text { Edad } \\
\text { - } & \text { Aumento IMC } \\
\text { - } & \text { Debilidad en aductores de cadera } \\
\text { - } & \text { ROM de abducción de cadera } \\
& \text { limitado } \\
\end{array}$ & \\
\hline Whittaker et al. (24) & 2015 & REVISIÓN S & MÁTICA & $\begin{array}{ll}\text { - } & \text { LESIÓN PREVIA EN LA } \\
& \text { INGLE } \\
\text { - } & \text { Debilidad en aductores } \\
\text { - } & \text { Cantidad de Entrenamiento } \\
& \text { Específico en Pretemporada }\end{array}$ & 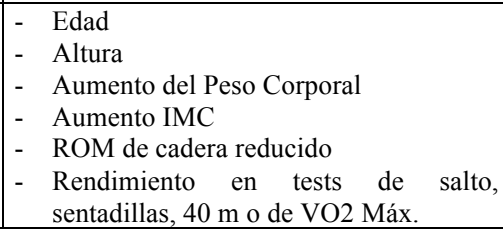 \\
\hline
\end{tabular}

Tabla 48: Factores de Riesgo en Lesiones en Aductor. Elaboración Propia

\subsubsection{Dolor Lumbar.}

El dolor lumbar es uno de los principales problemas que presenta la sociedad actual, llegando a afectar al $84 \%$ de las personas en algún momento de su vida o al $23 \%$ de forma crónica (316). Es muy frecuente en personas de cualquier edad y condición socioeconómica. Normalmente son muchos los factores que intervienen en el dolor lumbar (origen multifactorial), y no se presentan como compartimentos estanco, sino que esos factores interactúan entre sí, por lo que es una afección compleja. En la mayoría de los casos (hasta un 90\% (39)) suele presentarse en forma de episodios cortos, sin que sea posible identificar la fuente nociceptiva, es decir, suele ser un dolor inespecífico (317) que, como su nombre indica, se trata de un "síntoma de causa desconocida" (316).

No existen vías del dolor, es decir, los receptores nociceptivos sólo perciben cambios de presión (mecánicos), temperatura (térmicos) o químicos (químicos). Es el cerebro el que interpreta dicha información y, junto con otras, decide o no reflejar la sensación de dolor. Es por ello que el simple daño estructural no tiene por qué llevar asociada la sensación de dolor. Esto explica el dolor en miembros fantasma o el caso contrario, que ante una situación de estrés y peligro, una persona no sea consciente de una herida importante que haya sufrido.

Por tanto, estamos ante un dolor de origen diverso y que puede manifestarse de forma distinta en cada persona. Dentro de este contexto de complejidad, se utiliza el modelo biopsicosocial para entender el dolor lumbar. Esto quiere decir que el dolor de espalda baja puede estar generado por factores biofísicos, psicológicos y/o sociales (317). 
Nos encontramos, pues, ante una situación que escapa a nuestro control no sólo por la complejidad "per se" del dolor lumbar, sino que, en algunos casos, requiere el diagnóstico y/o tratamiento de médicos especialistas. Por tanto, nuestro trabajo se centrará en identificar aquéllos factores que puedan aumentar la probabilidad de sufrir dolor lumbar y que podamos modificar para actuar sobre ellos. Así, siguiendo la estructura utilizada para mostrar los factores de riesgo en las lesiones anteriores tendremos:

\begin{tabular}{|c|c|c|c|c|c|}
\hline ESTUDIO & AÑo & MUESTRA & PAÍS & $\begin{array}{c}\text { FACTORES ASOCIADOS CON } \\
\text { MAYOR PROBABILIDAD DE } \\
\text { APARICIÓN }\end{array}$ & $\begin{array}{c}\text { FACTORES NO } \\
\text { ASOCIADOS CON MAYOR } \\
\text { PROBABILIDAD DE } \\
\text { APARICIÓN }\end{array}$ \\
\hline Balagué et al. (45) & 1999 & $\begin{array}{r}\text { REVISIÓN S } \\
\text { EN NI } \\
\text { ADOLE }\end{array}$ & $\begin{array}{l}\text { MÁTICA } \\
\text { YTES }\end{array}$ & $\begin{array}{l}\text { - Edad } \\
\text { - Sexo (Más prevalente en } \\
\text { chicas que en chicos) } \\
\text { - Factores genéticos, } \\
\text { ambientales y/o psicosociales } \\
\text { - Flexibilidad de los músculos } \\
\text { del muslo reducida. } \\
\text { - Estar mucho tiempo sentado } \\
\text { - Estrés } \\
\text { - Tabaquismo }\end{array}$ & $\begin{array}{ll}\text { - } & \text { Peso } \\
\text { - } & \text { Altura } \\
\text { - IMC } \\
\text { - Fuerza de los músculos } \\
\text { flexores y extensores del } \\
\text { tronco }\end{array}$ \\
\hline Hartvigsen et al. (317) & 2018 & REVISIÓN S & MÁTICA & $\begin{array}{ll}\text { - } & \text { Episodio previo de dolor } \\
& \text { lumbar } \\
\text { - } & \text { Bajo nivel de actividad física } \\
\text { - } & \text { Obesidad } \\
\text { - } & \text { Tabaquismo } \\
\text { - } & \text { Depresión } \\
\text { - } & \text { Factores genéticos }\end{array}$ & \\
\hline Balagué et al. (316) & 2012 & REVISIÓN S & MÁTICA & $\begin{array}{l}\text { - Episodio previo de dolor } \\
\text { lumbar } \\
\text { - Nivel de actividad física (muy } \\
\text { bajo o extenuante) } \\
\text { - Factores genéticos } \\
\text { - Obesidad } \\
\text { - Tabaquismo }\end{array}$ & \\
\hline
\end{tabular}

Tabla 49: Factores de Riesgo en Dolor Lumbar. Elaboración Propia.

Nuestro sujeto no es obeso, no fuma, tiene un buen nivel de condición física y es bastante joven. Resulta imposible saber si, a nivel genético, está más predispuesto a dolor lumbar o a degeneración de disco. Sin embargo, el estrés sí puede ser uno de los motivos que cause esa sensación.

Además de estos factores, la postura es otro aspecto clave que puede provocar molestias en la espalda. En este sentido, la flexión repetida de columna puede ser un importante mecanismo de lesión (91). A esto debemos añadir la debilidad muscular, ya que varios estudios encuentran, en sujetos con dolor lumbar, una menor producción de fuerza del Core, a nivel general, y en la musculatura de extensora lumbar y abductora y aductora de la cadera, en concreto $(318,319)$.

La excesiva rigidez de movimiento de la articulación de la cadera puede ser otro aspecto a tener en cuenta. El movimiento del cuerpo se produce utilizando el mínimo de esfuerzo y energía, lo cual puede suponer un problema de movimiento si la flexión de cadera es limitada en comparación con la región lumbar ya que, posiblemente, esa flexión se realizará en la espalda (flexión lumbar), pudiendo ocasionar un daño estructural si se realiza de forma reiterada (39).

Si atendemos ahora al deporte (recordemos que nuestro sujeto es deportista profesional), la actividad física puede ser tanto un factor de riesgo (ejercicio extenuante) como protector (el sedentarismo aumenta la probabilidad de dolor lumbar). Sin embargo, no se conoce la "dosis efecto óptima" (320) y no creo que exista como tal, ya que la actividad física (o su ausencia) no es el único factor influyente y no todo el mundo asimila un mismo estímulo de igual manera.

En el caso del fútbol, la prevalencia en jugadores profesionales puede ser de hasta el 64\% (319) y suele asociarse al uso excesivo (lesión por sobreuso más frecuente (15)) o a lesiones traumáticas, aunque no se debe descartar la postura y el estilo de vida, ya que esta sintomatología también puede aparecer al comienzo de la pretemporada (319). Además, puede ser que el mero hecho de jugar a fútbol sea un factor de riesgo (321) ya que es un deporte que conduce a un desequilibrio en la musculatura del Core, 
debido especialmente a los golpeos y las disputas de balón (322). Como ya se ha comentado, la mayoría de las acciones del fútbol se realizan con un solo apoyo, donde la función de los oblicuos para estabilizar el cuerpo es fundamental. En jugadores adolescentes, una asimetría en esta musculatura puede predisponer al dolor lumbar (321).

Por último, se presentan una serie de aspectos que, si bien pueden ser consecuencias del dolor lumbar, también pueden ser factores que lo provoquen. Así, en un estudio realizado con futbolistas de élite se observó que el grupo de jugadores con dolor lumbar tuvo puntuaciones más bajas (diferencia significativa) en tests para medir el control motor lumbopélvico, concluyendo que el dolor lumbar puede alterar el control motor lumbopélvico en estos sujetos (15), lo cual se manifiesta a través de la postura, activación muscular y movimiento (36).

En relación a esto, parece ser que los deportistas con esta sintomatología mueven más (y antes) la región lumbopélvica en los movimientos de las extremidades inferiores. Este aumento "extra" en la frecuencia de movimiento de esta zona genera un estrés tisular que conlleva un microtrauma acumulativo y la aparición del dolor lumbar (37). Si a esto sumamos una movilidad de cadera reducida, la columna lumbar deberá, además de estabilizar, compensar esa falta de movimiento, añadiendo más estrés a los tejidos.

Además, el dolor de espalda crónico suele desactivar la musculatura glútea, por lo que, para realizar una extensión de cadera, se deba realizar una compensación utilizando los isquiosurales. La extensión posterior de la espalda puede provocar cargas de aplastamiento (91) perjudiciales para la salud de la columna.

\subsubsection{El Complejo Articular del Hombro.}

En deportistas overhead (nadadores, tenistas, jugadores de baseball, balonmano,...) ocurre lo que se conoce como "paradoja de los lanzadores", ya que el hombro debe ser lo suficientemente móvil para realizar movimientos a gran velocidad pero lo suficientemente estable para evitar que la articulación ceda (323).

El pase largo con la mano (como un lanzamiento en un deportista overhead), es relativamente frecuente en un portero. Esto puede conllevar un aumento en la rotación externa y una limitación de la rotación interna de la articulación del hombro en el brazo dominante (324) conocido como DRIG (Déficit de Rotación Interna Glenohumeral) (325), que disminuye el espacio subacromial (326) y suele asociarse a lesiones en hombro $(327,328)$, en este sentido parece ser que el riesgo de lesión es 5 veces mayor si se pierden $25^{\circ}$ de rotación interna en comparación con el hombro contralateral (329). No existe consenso sobre por qué sucede esto. Por un lado existen autores que defienden que la ganancia de rotación externa se debe a una adaptación ósea, concretamente un aumento de la retroversión de la cabeza del húmero, que permite disminuir la probabilidad de lesión ya que al realizar la rotación externa se ejerce una menor tensión sobre la cápsula anterior (330), mientras que otros argumentan que el déficit de rotación interna es debido a un estiramiento de la cápsula anterior y una engrosamiento de la cápsula posterior $(331,332)$, que se produce debido al microtrauma continuado que supone frenar el movimiento de lanzamiento, y se agrava cuando el arco total de movimiento (desde la rotación externa máxima a la rotación interna máxima) se reduce, es decir, la ganancia de rotación externa es menor que la pérdida de rotación interna (331), hecho que puede aumentar la inestabilidad y la probabilidad de pinzamiento (332).

Además de esto, entre las adaptaciones musculares que se producen, aparece un aumento de la fuerza muscular de los rotadores internos pero no de los rotadores externos, en otras palabras, aparece debilidad en la musculatura encargada de frenar excéntricamente y estabilizar el hombro durante el movimiento, lo que aumenta el riesgo de lesión $(333,334)$.

Otro problema que podemos encontrar en el hombro es la disquinesia escapular, definida como "una alteración en la posición o movimiento normal de la escápula durante los movimientos escapulohumerales" (335). No es una lesión en sí misma, pero sí suele asociarse a un mayor número de lesiones en hombro (336), como por ejemplo mayor tensión de la articulación acromioclavicular, tendinopatía y roturas del manguito rotador o impingement de hombro (337). Puede producirse por una debilidad de la musculatura periescapular, en concreto del serrato anterior y trapecio medio e inferior, ante movimientos 
overhead repetidos $(72,338)$, un patrón de activación anormal (tardío) de esta musculatura (339), que suele compensarse con una mayor y temprana activación del trapecio superior (340), una falta de flexibilidad de la musculatura que hay alrededor del hombro (pectoral menor o cabeza corta del bíceps) o una cifosis torácica excesiva (335).

\subsubsection{Lesión de Recto Anterior.}

Justo la semana que terminaba la primera fase de intervención el sujeto se lesionó (viernes 4 de Octubre). Según el jugador, fue justo al realizar un pase largo (el futbolista lo define como "golpe seco". El balón se encontraba demasiado alejado de la pierna de golpeo y el portero estaba siendo presionado por un delantero, por lo que tuvo que golpear rápido y en "una posición muy extraña". No es hasta mitad de la semana siguiente cuando hay un diagnóstico: "Lesión de Grado I en el recto anterior del Cuádriceps que le genera un pequeño edema". Se estima que el jugador volvería a competir en 3 semanas.

El desgarro muscular "consiste en la laceración de un mayor o menor número de fibras que se rompen, sangran y producen hemorragia" (341). Si se producen por una contracción rápida del músculo (mecanismo interno) se denominan desgarros por elongación, mientras que si el mecanismo es externo (laceración o traumatismo) se llaman desgarros por compresión (ver figura 26).

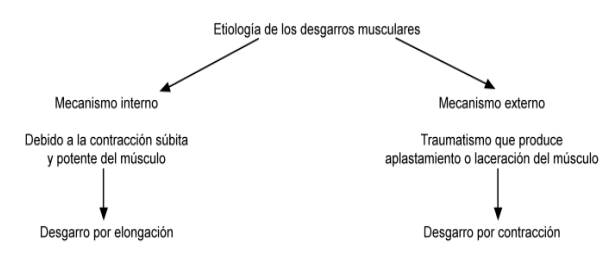

Figura 26: Etiología de los Desgarros Musculares (341)

Los desgarros musculares por elongación (como el de nuestro sujeto) pueden clasificarse en (342):

- Grado I (leves) (la que nos ocupa): Se desgarran pocas fibras musculares, menos de un $5 \%$ (341). Es una lesión microscópica. La incomodidad e hinchazón son leves, así como la pérdida de fuerza.

- Grado II (moderadas): El daño muscular es mayor, llegando incluso a perderse la capacidad de contracción.

- Grado III (graves): Se produce una rotura de toda la sección transversal del músculo impidiendo toda función muscular.

El músculo esquelético está formado por 2 estructuras: 1) las miofibras, encargadas de la función contráctil, y 2) el tejido conectivo, encargado de que esas miofibras actúen de forma conjunta, de modo que la contracción individual se transforme en locomoción eficiente (342). Cuando ocurre una tensión excesiva sobre esas miofibras pueden romperse cerca de la unión miotendinosa (342), especialmente en deportes que implican correr, saltar y desacelerar como el fútbol y el caso de músculos biarticulares que soportan grandes fuerzas internas como el recto anterior $(343,344)$. El mecanismo de lesión se describe en el apartado 3.1.3.3.

En una lesión como la de nuestro sujeto podemos distinguir 3 fases en el proceso de recuperación $(342,345)$ :

- Fase de Destrucción: Debido a la tensión excesiva, las fibras se rompen cerca de la unión miotendinosa y se necrosan. La "banda de contracción" actúa como cortafuegos para evitar que la necrosis se extienda por toda la longitud de las miofibras. Los vasos sanguíneos se desgarran y permiten que las células inflamatorias lleguen al epicentro de la lesión. Posteriormente ese proceso inflamatorio se amplifica debido a la liberación de hormonas por las células satélite y las partes necrotizadas de las miofibras. Además, en una fase muy aguda, los leucocitos participan en la proteólisis y fagocitan el material necrótico.

- Fase de Reparación: Comienza cuando disminuye la fase anterior y se lleva a cabo mediante dos procesos:

- Regeneración de Miofibras: Las células satélite proliferan, se diferencian en mioblastos (en la fase anterior) y se unen entre sí para formar "miotubos multinucleados" que se unen a la parte de la miofibra que no está dañada.

- Formación de la Cicatriz del Tejido Conectivo: Las células inflamatorias que habían llegado al núcleo de la lesión al romperse los vasos fagocitan el hematoma y comienzan a eliminar el coágulo sanguíneo. Posteriormente, la fibrina y la fibronectina 
(derivados sanguíneos) se entrecruzan para formar un tejido que confiere al músculo fuerza para resistir una ligera tensión que se aplique sobre él. Finalmente, se sintetizan proteínas con propiedades elásticas que, unido a la producción de colágeno tipo I, ayudarán a soportar la carga mecánica, aunque será el punto más débil de la estructura.

- Fase de Remodelación: Unos 10 días después de la lesión la cicatriz madura y deja de ser tan débil, aunque si ocurre una recidiva lo hará en este punto. De los vasos que no se han roto salen nuevos capilares hacia la zona lesionada, para vascularizarla (esto es clave para la recuperación morfológica y funcional). Las nuevas miofibras se adhieren con fuerza a la matriz extracelular (parece ser que es necesario estrés mecánico para que esto se produzca), reduciendo el riesgo de rotura y permitiendo el trabajo muscular antes de la curación completa.

\subsection{Interpretación de los datos obtenidos en la Evaluación Inicial.}

En base a los resultados obtenidos en los test (ver apartado 2.3) y los valores de referencia, vamos a analizar los datos de nuestro sujeto, buscando la aplicación a la actividad que realiza, es decir, el fútbol.

\subsubsection{Interpretación de los datos de los Tests de Flexibilidad y ROM.}

A1. Lunge Test: No se han encontrado en la literatura valores específicos para comparar el ROM de un futbolista, por lo que se ha optado por equipararlos con jugadores de baloncesto, un deporte que, como el fútbol, requiere continuos cambios de dirección, aceleraciones y frenadas. La dorsiflexión del jugador no es limitada, además no hay una excesiva diferencia entre una pierna y otra, por lo que se puede concluir que los valores son óptimos para el desempeño de sus funciones.

A2. Test de Kea: No se han encontrado valores de referencia para este test en nuestro deporte. Además, tampoco se han podido encontrar (pese a una muy profunda revisión) valores de referencia que pudiesen ser aplicados a nuestro jugador. Como conclusión, se terminó acudiendo a páginas de internet, donde se encontró un artículo sobre jugadores de rugby (146). La fiabilidad de ese dato podría estar en entredicho, aunque el rango coincide con otras páginas de internet.

Así, para un valor ideal de $15^{\circ}$, nuestro jugador presenta un marcado acortamiento, siendo aún más pronunciado en la pierna derecha $\left(40^{\circ}\right.$ frente a los $35^{\circ}$ de la izquierda). Aunque no existe consenso al respecto, ya se ha indicado que hay estudios que asocian una limitación en la longitud de esta musculatura con un mayor riesgo de lesión en futbolistas de élite (54). Además, una excesiva rigidez isquiosural podría, por la teoría de la flexibilidad relativa, provocar compensaciones de movimiento a nivel lumbar, por lo que será un valor a corregir.

A3. Thomas Test: Tras valorar los flexores de cadera se comprueba que el psoas derecho del jugador sufre un acortamiento. Es positivo encontrar que no hay un déficit de extensibilidad en el recto anterior, lo que podría suponer un factor de riesgo para una lesión en cuádriceps (54), sin embargo, la limitación en psoas, unido a la que presenta en la musculatura isquiosural, podría provocar una falta de movilidad en las caderas. Además, debido a que algunas fibras del psoas se insertan en la zona lumbar, un acortamiento podría contribuir a la sensación de dolor lumbar que indica nuestro jugador. Este acortamiento puede estar relacionado con la debilidad que presenta el jugador en la musculatura del core y glúteo, ya que podría estar compensando ese déficit de fuerza. En este caso, no deberíamos estirar esta musculatura sino fortalecer la que está débil, para evitar alterar la estabilización del raquis (346).

A4. Test de Ober Modificado: El resultado del test es negativo en ambas piernas, lo que indica que no existe una excesiva tensión en TFL o en la banda iliotibial que pueda limitar la aducción de cadera

A5. Hip Internal Rotation Test; A6. Hip External Rotation Test: El jugador presenta un déficit bastante marcado tanto en la rotación interna como externa de cadera, bien con la cadera neutra o con $90^{\circ}$ de flexión. El hecho de tener una reducción en la movilidad de la cadera se asocia a jugadores con lesión inguinal previa, aunque no es el caso. Tampoco vemos que la cintilla iliotibial suponga una restricción, pues el test de Ober ha sido negativo. Una reducción de la rotación interna de la cadera puede ser debida a factores óseos como la retroversión femoral o la orientación hacia retroversión del acetábulo. Sin embargo, esas posiciones estructurales provocarían un aumento de la rotación externa, que no se produce en nuestro jugador. 
A7. Passive Hip Flexion Test: Frente a los $125^{\circ}$ de referencia, el jugador alcanza $145^{\circ}$, con lo que se deduce que no presenta limitación en la flexión de cadera.

A8. Passive Hip Extension Test: Lo mismo ocurre en la extensión, ya que alcanza los $10^{\circ}$ establecidos como valor estándar.

A9. Passive Hip Abduction Test: El jugador presenta una pequeña limitación en el movimiento de abducción de cadera de $5^{\circ}\left(40^{\circ}\right.$ frente a $\operatorname{los} 45^{\circ}$ de referencia). Recordemos que el patrón de golpeo en nuestro deporte implica extensión de cadera y abducción. Quizás estos grados no sean limitantes en ningún caso para el golpeo, sin embargo, dada la especificidad de su posición y la necesidad de realizar gestos de gran amplitud para detener balones a distintas alturas, es posible que esos grados sí sean muy importantes para él.

A10. Passive Hip Adduction Test: No se encuentra limitación en la aducción de cadera, ya que se alcanzan los $10^{\circ}$ de referencia.

A11. Shoulder Flexion: La flexión de hombro no se ve limitada, aspecto positivo por su demarcación de portero. El jugador realiza, sin compensaciones, un movimiento de $180^{\circ}$ de flexión, llegando a contactar con los pulgares en la camilla por encima de la cabeza.

A12. Shoulder Internal Rotation ROM: La limitación en la rotación interna de hombro de nuestro jugador es muy marcada. La diferencia entre un hombro y otro es de $10^{\circ}$ y la diferencia en el arco de movimiento entre un brazo y otro es de $5^{\circ}$, por lo que no podemos indicar que el jugador tenga un GIRD, que sería factor de riesgo y podría generar dolor local $(73,74)$. Sin embargo, debido a la gran diferencia con los valores estándar (casi la mitad de recorrido), será un aspecto que deberemos corregir con nuestro jugador.

A13. Shoulder External Rotation ROM: La rotación externa del jugador se encuentra dentro de los valores "normales". Esto es positivo porque no ha generado una adaptación crónica por los movimientos que realice, que sería un exceso de rotación externa, sin embargo limita el arco de movimiento.

A14. Posterior Shoulder Flexibility Test: Existe una limitación de $5^{\circ}$ en los rotadores externos de cada hombro. Esto podría tener consecuencias sobre el frenado excéntrico de un movimiento de rotación interna.

A15. Scapular Dyskinesis Test: El resultado del test de disquinesia escapular indica una anomalía sutil, ya que se encuentran pequeñas anomalías tanto en el movimiento de flexión como en el de abducción. Como veremos en el análisis postural, se aprecia una báscula axilar de ambas escápulas, lo que indica dominancia del trapecio superior sobre el inferior y el serrato; cuando se observa dinámicamente, se comprueba que el trapecio es el primero en activarse tanto en elevación frontal como lateral, en lugar del deltoides, y que el serrato presenta un pequeño déficit de activación en el control excéntrico escapular que da lugar a un pequeño aleteo en la escápula izquierda (ver figura 27).

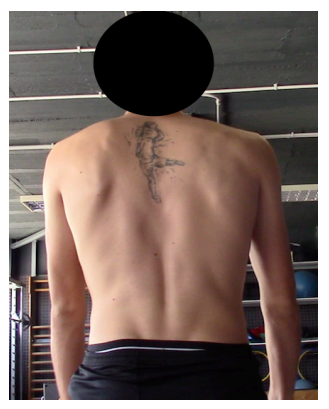

Figura 27: Aleteo y elevación de escápula izquierda

A16. Longitud del Pectoral Menor: Existe un acortamiento en el pectoral menor de ambos lados, especialmente en el derecho. Esto encaja con los resultados obtenidos en la valoración postural estática (hombros adelantados).

\subsubsection{Interpretación de los datos de los Tests de Fuerza Analítica}

B1. Eccentric Hip Adduction; B2. Eccentric Hip Abduction; B3. Squeeze Test: Los valores obtenidos en los test de dinamometría, una vez normalizados al peso corporal del sujeto $(68 \mathrm{~kg})$, se encuentran dentro de los parámetros de referencia establecidos en jugadores profesionales de fútbol. Estos datos nos permiten calcular el ratio aductor / abductor para cada pierna. En la izquierda es de $1 \mathrm{y}$ en la derecha de 0,91. Ambos se encuentran dentro de los valores de referencia (83). 
B4. Biering Sorensen Modificado; B5. Side Bridge; B6. Trunk Flexor Endurance Test: El principal déficit de fuerza del sujeto se encuentra en los tests realizados sobre el Core (ver figuras 28 - 30). Además, coincide que el resultado obtenido en los 3 tests está muy por debajo de lo que debería obtener un deportista profesional. En el fútbol, la mayoría de las acciones se producen en apoyo monopodal y muchas en condiciones inestables (347), donde una inestabilidad central podría provocar un importante factor de riesgo. Se ha comprobado electromiográficamente que la activación de esta musculatura ocurre antes que la de los músculos que producen el movimiento en brazos y piernas, esto se conoce como "estabilidad proximal para el movimiento distal" (92), y es clave tanto para el rendimiento deportivo como para la prevención de lesiones. Por tanto, los resultados obtenidos en estos 3 tests son un factor a corregir de forma prioritaria en nuestro jugador.
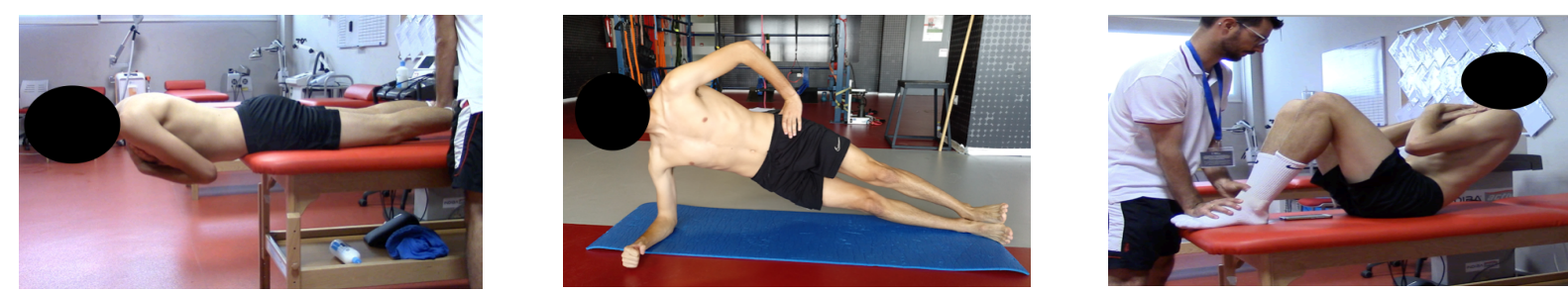

Figuras 28 - 30: Ejecución del Biering Sorensen Modificado, Side Bridge y Trunk Flexor Endurance Test

\subsubsection{Interpretación de los datos del SEBT Modificado}

La diferencia entre la pierna izquierda y derecha, una vez normalizados los resultados, es de $7 \mathrm{~cm}$., por lo que podríamos concluir que el pie izquierdo tener más riesgo de esguince que el derecho. Personalmente no sé hasta qué punto el valor con el que se compara el resultado (aunque aparece reflejado en varios estudios científicos), puede interpretarse como predictivo o, en el mejor de los casos, asociado a un riesgo de lesión, ya que no indica un valor a partir del cual el jugador tendría un déficit propioceptivo. Supongamos dos jugadores con, exactamente, la misma longitud de pierna. El jugador A obtiene, en la dirección anterior, $87 \mathrm{~cm}$ con una pierna y 80 con la otra. El jugador B obtiene $68 \mathrm{~cm}$ con la derecha y 66 con la contralateral. Según el test el jugador A tendría más riesgo de lesión en una pierna porque existe una diferencia de más de $4 \mathrm{~cm}$., pero al comparar (entiendo que para eso se normalizan los resultados), la extremidad con la que marca $80 \mathrm{~cm}$ (la peor para ese jugador) es mucho mejor que las del jugador $\mathrm{B}$ en cuanto a resultados. En ese caso... ¿podría ocurrir que los parámetros de ambas piernas en el jugador A fuesen buenos (uno aún mejor que otro) y en el jugador $\mathrm{B}$ los dos indicasen déficit? ¿O es la diferencia entre una pierna y otra la que indica ese riesgo?.

En el caso de nuestro jugador, existe una diferencia de $7 \mathrm{~cm}$. en la dirección anterior a favor del pie izquierdo y de $11 \mathrm{~cm}$. en dirección posterolateral a favor del pie derecho. No obstante, la literatura señala como principal aspecto a tener en cuenta la dirección anterior, por lo que prestaremos especial atención a ese posible déficit. En la figura 31 se presenta la realización del test.

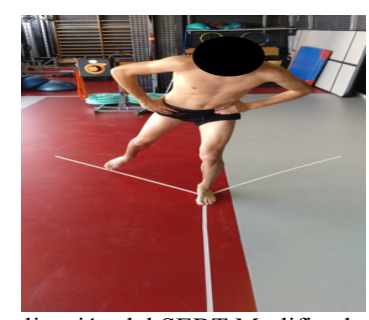

\subsubsection{Interpretación de la Valoración Postural Estática}

Según los resultados obtenidos en la valoración postural estática y en base a la literatura especializada (27) podemos realizar la siguiente interpretación:

Los extensores de la columna cervical podrían estar retraídos por la posición de la cabeza, así como los flexores elongados. El trapecio superior también podía estar retraído por la protracción de cabeza y hombros y por la báscula axilar de la escápula, por lo que tanto trapecio medio como inferior podrían estar elongados. La distancia de las escápulas a la línea media es visiblemente distinta en un lado y otro, lo que puede indicar una mayor elongación en un lado (izquierdo) que podría ir acompañado de debilidad. Los hombros adelantados y la cifosis de columna también indicarían un pectoral menor acortado. Estos resultados se confirman con los obtenidos en el test de longitud de pectoral menor (acortamiento) y disquinesia escapular (aleteo escapular mal patrón de activación de la musculatura). 
La cadera está ligeramente más adelantada de lo que debería (posiblemente por la debilidad en zona abdominal que se encuentra en los test correspondientes), hecho que quizás compensa llevando la columna dorsal hacia atrás y provocando mayor tensión sobre la zona lumbar.

\subsubsection{Interpretación de la Valoración Postural Dinámica}

E1. Single Leg Squat: El rango de dorsiflexión de tobillo es adecuado, como se ha visto en el lunge test, por lo que el movimiento de valgo de rodilla que aparece puede estar provocado por un déficit en la coactivación del glúteo medio y los aductores de cadera, es decir, un exceso de activación de la musculatura aductora que no se compensa con la activación del glúteo (348).

El balanceo de rodilla que se observa, junto con la separación de brazos del cuerpo y el descenso brusco al final del ejercicio puede indicar un déficit en la fuerza excéntrica de los cuádriceps, que no pueden mantener el peso del cuerpo sin realizar compensaciones de tronco y brazos. Finalmente, el drop de cadera y la inclinación y rotación del tronco hacia la pierna de apoyo puede indicar debilidad de glúteo y de oblicuos (118), lo que coincide con los resultados de los tests de fuerza de Core.

E2. Landing Error Scoring System (LESS): La puntuación en este test es 0, lo cual coincide, exactamente, con el valor de referencia. Este aspecto es muy positivo, debido a que no se aprecia un valgo de rodilla a pesar del bajo nivel de Core que presenta nuestro sujeto (ver figura 32).
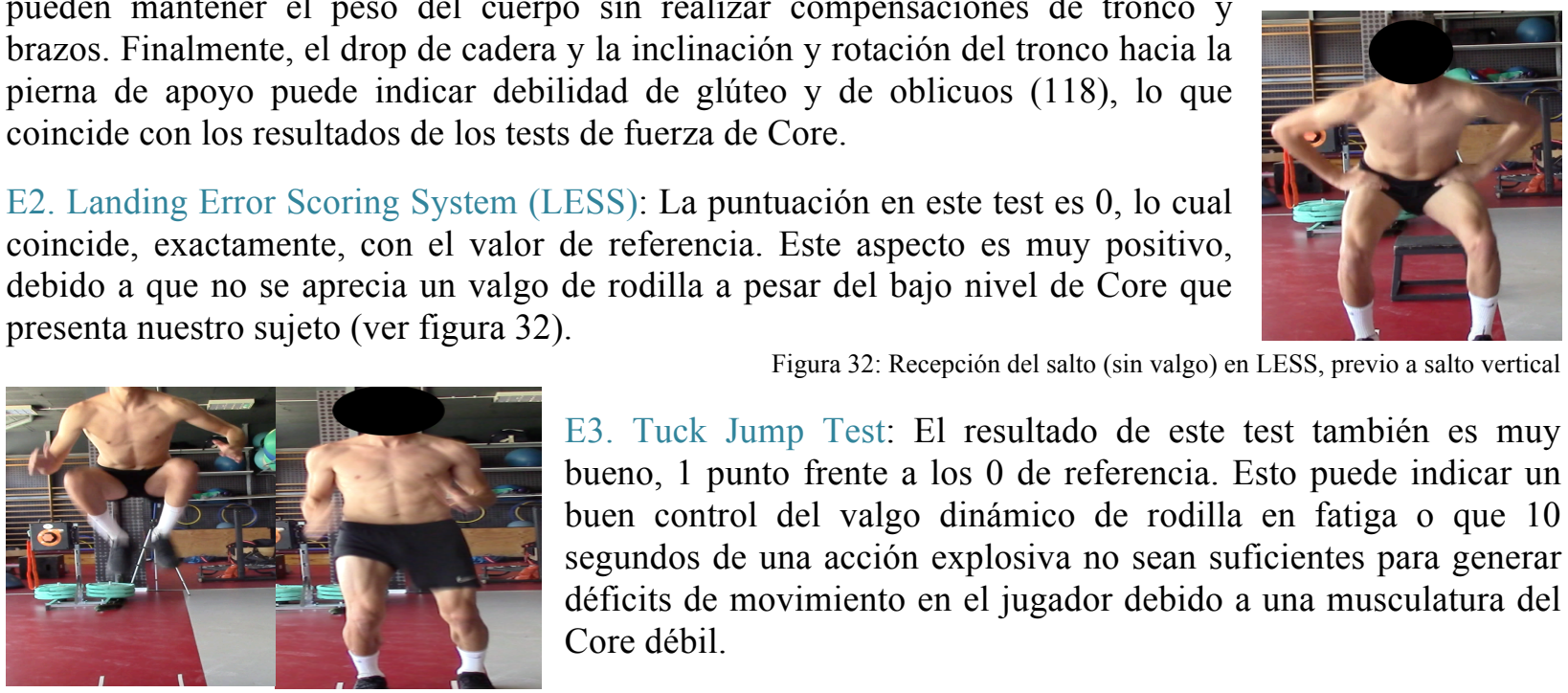

Figura 32: Recepción del salto (sin valgo) en LESS, previo a salto vertical

Figuras 33 y 34: Salto en Tuck Jump Test y recepción (sin valgo)

E4.1. Hinge: El patrón de movimiento realizado en este test es correcto, siendo capaz de disociar el movimiento de la región coxolumbopélvica. El movimiento comienza con una flexión de la articulación coxofemoral, sin compensación lumbar y se mantiene la neutralidad espinal durante todo el movimiento. Sin embargo, se observa que flexiona las rodillas más de lo necesario y lleva la cadera un poco hacia atrás. Eso puede indicar una excesiva tirantez en la musculatura posterior del muslo, lo que está en consonancia con los resultados obtenidos en el test de KEA. En el retorno del movimiento, la extensión de cadera y columna dorsal y lumbar se realiza al mismo tiempo.

\subsubsection{Interpretación de los datos del Cuestionario de Dolor Lumbar}

Como era de esperar, los resultados del cuestionario de dolor lumbar no indican que la sensación que indica el jugador en partidos sea un factor limitante en su vida diaria. El resultado del test fue muy bajo y sólo obtuvo puntuación cuando indicó que el dolor durante la semana previa a la encuesta había sido moderado. Si tenemos en cuenta los resultados de los test de Core (aunque hay otros valores en test que podrían asociarse con esas molestias como por ejemplo un acortamiento en psoas), quizás el déficit tan grande de fuerza que tiene el jugador sea la principal causa de esta sintomatología.

\subsubsection{Interpretación de los Tests de Control Motor del Complejo Coxolumbopélvico}

Los tests de control motor realizados indican un déficit en la disociación segmentaria de la región lumbopélvica tanto en flexión de cadera (Forward Bending), como en flexión (Prone Lying Active Flexion) y extensión (Sitting Knee) de rodilla o en flexión de cadera y rodilla (Rocking Backward).

En el caso del One Leg Stance Test existe una diferencia de $2 \mathrm{~cm}$. en el desplazamiento lateral de la cadera en un lado y otro, sin embargo, en ambos casos el desplazamiento es superior a $10 \mathrm{~cm}$., lo que podría estar provocado por una debilidad en la musculatura glútea, aspecto que ya se ha destacado como posibilidad en otros tests como el Single Leg Squat. 


\subsubsection{Interpretación de los datos del Cuestionario de Perfil Psicológico}

El cuestionario de Perfil Psicológico analiza 5 categorías que son: Autoconfianza, Actitud y Preparación Mental, Control de Estrés y Ansiedad, Concentración y Motivación. De ellas, nuestro sujeto obtiene los peores valores (aunque no son bajos) en la categoría de Control del Estrés y la Ansiedad y esto puede relacionarse con una mayor incidencia de lesiones $(40,43,305)$ o con el dolor lumbar (45). Cuando comentamos esto con el jugador nos indica que está trabajando con una psicóloga deportivo este tema.

\section{4-. OBJETIVOS DEL PROGRAMA DE INTERVENCIÓN}

“No hay ningún viento favorable para el que no sabe a qué puerto se dirige”

Arthur Schopenhauer, filósofo alemán (1788 - 1860)

Como se comentó en el apartado de evaluación no tiene demasiado sentido analizar las necesidades motrices de la vida diaria de este sujeto en particular. Sin embargo, sí se han tenido en cuenta aspectos que, por la especificidad de su puesto dentro del deporte que realiza, puedan suponer un riesgo de lesión (movimientos overhead, recepciones de saltos,...). Así, me he marcado objetivos para corregir los déficits que he encontrado en este sentido, cumpliendo así con las necesidades motrices de su entorno laboral. Me gustaría aclarar que no se han establecido objetivos para la recuperación de la lesión de recto anterior porque es un trabajo que han realizado tanto los fisios como el readaptador del equipo del jugador.

En base a la entrevista inicial realizada al sujeto y los resultados obtenidos en la evaluación inicial, así como la información recogida en el análisis de la casuística, se plantean los siguientes objetivos para el plan de intervención:

\subsection{Objetivos Principales}

Objetivo General: P.1) Disminuir el Riesgo de Lesión del jugador

Objetivos Específicos:

P.1.1 Normalizar los valores de rango de movimiento articular (evaluado directamente mediante los tests planteados en el apartado $2.2 \mathrm{~A}$ ).

P.1.1.1 Aumentar los valores de rotación interna de cadera (evaluado direct. mediante Test A.5).

P.1.1.2 Aumentar los valores de rotación externa de cadera (evaluado direct. mediante Test A.6).

P.1.1.3 Aumentar los valores de abducción de cadera (evaluado direct. mediante Test A.9).

P.1.1.4 Aumentar los valores de rotación interna glenohumeral (evaluado direct. mediante Test A.12).

P.1.1.5 Aumentar los valores de aducción de hombro (evaluado direct. mediante Test A.14).

P.1.2 Normalizar los valores de extensibilidad muscular (evaluado directamente mediante los tests planteados en el apartado $2.2 \mathrm{~A}$ ).

P.1.2.1 Aumentar la longitud de la musculatura isquiosural (evaluado direct. mediante Test A.2).

P.1.2.2 Aumentar la longitud de los aductores de cadera (evaluado indirect. Mediante Test A.9)

P.1.3 Normalizar los valores de fuerza muscular (evaluado directamente mediante los tests planteados en el apartado 2.2 B).

P.1.3.1 Mejorar la fuerza de glúteo medio (evaluado indirect. mediante Test E1 y One Leg Stance).

P.1.3.2 Integrar la musculatura glútea en los diferentes movimientos (no evaluable. Observación).

P.1.4 Mejorar el sentido propioceptivo del sujeto (evaluado indirectamente a través del test SEBT modificado $2.2 \mathrm{C}$ ).

P.1.4.1 Corregir la asimetría presente entre pie izquierdo y derecho (evaluado direct. mediante Test C.1).

P.1.4.2 Mejorar los valores obtenidos en el test propioceptivo en las 3 direcciones (evaluado direct. mediante Test C.1). 
P.1.4.3 Mejorar la capacidad de respuesta ante estímulos que provoquen perturbaciones de un estado de equilibrio (no evaluable. Observación durante los ejercicios).

P.1.4.4 Mejorar la preactivación muscular ante situaciones desconocidas (feedforward) (no evaluable).

P.1.4.5 Mejorar la capacidad de respuesta ante estímulos inesperados que desestabilicen al jugador durante la ejecución de acciones específicas de juego (no evaluable).

P.1.4.6 Mejorar la preactivación muscular (feedforward) previa a la recepción de saltos unipodales (no evaluable).

P.1.5 Ejecutar correctamente los patrones de movimiento básicos del entrenamiento de Fuerza (evaluado mediante observación sistemática. Se podrá grabar la ejecución con el móvil para utilizarla en el proceso de evaluación).

P.1.5.1 Ejecutar correctamente el patrón de sentadilla.

P.1.5.2 Ejecutar correctamente el patrón de peso muerto y sus variantes.

P.1.5.3 Ejecutar correctamente la recepción de salto unipodal / bipodal con diferentes trayectorias.

P.1.5.4 Ejecutar correctamente las tracciones horizontales y verticales.

P.1.5.5 Ejecutar correctamente los empujes horizontales y verticales.

P.1.5.6 Ejecutar correctamente el patrón de extensión de cadera.

P.1.5.7 Ejecutar correctamente el patrón de Hinge de cadera.

P.1.5.8 Realizar correctamente estos patrones de movimiento de forma combinada en ejercicios más específicos.

P.1.6 Mejorar la fuerza y la estabilidad del Core evitando "fugas de energía" (medición indirecta a través de los test propuestos por McGill (ver apartado 2.2 B).

P.1.6.1 Aprender la maniobra de "Bracing" y aplicarlo a distintos ejercicios (No evaluable. Observación Sistemática).

P.1.6.2 Aumentar la fuerza de la musculatura del Core (evaluado indirect. mediante Test B.4-6).

P.1.6.3 Corregir la asimetría de fuerza encontrada en el side bridge (evaluado direct. mediante Test B.5).

P.1.6.4 Utilizar la co-contracción muscular para mantener la postura frente a fuerzas de distintos planos (No evaluado. Observación Sistemática).

Objetivo General: P.2) Disminuir o eliminar el dolor lumbar que padece el jugador en la fase final de los partidos y entrenamientos desde hace 3 años.

\section{Objetivos Específicos:}

P.2.1 Mejorar la fuerza y estabilidad del Core (igual que P.1.6).

P.2.2 Mejorar el control motor del complejo coxolumbopélvico (evaluado indirectamente mediante Test G. 1 - 5).

P.2.3 Mejorar la disociación de la región coxolumbopélvica (no evaluable. Observación Sistemática).

P.2.4 Aprender la maniobra de "Hollowing" y aplicarlo a distintos ejercicios de control motor (No evaluado. Observación Sistemática).

P.2.5 Concienciar al jugador de la importancia de la higiene postural en su vida diaria (no evaluable).

Objetivo General: P.3) Disminuir o eliminar el dolor en hombro dominante que sufre el jugador.

Objetivos Específicos:

P.3.1 Reeducar el patrón de activación de la musculatura periescapular (medición indirecta a través del test B.7).

P.3.2 Aumentar el rango de rotación interna glenohumeral (evaluado direct. mediante Test A.12).

P.3.3 Mejorar la activación de serrato anterior y trapecio medio e inferior (no evaluable).

P.3.4 Aumentar la longitud del pectoral menor, especialmente el derecho (evaluado directamente mediante Test A.15).

P.3.5 Potenciar el manguito de rotadores (no evaluable). 
Objetivo General: P.4) Disminuir la probabilidad de tener una recidiva.

Objetivos Específicos:

P.4.1 Mejorar la capacidad excéntrica de la musculatura del cuádriceps (no evaluado)

P.4.2 Someter, de forma progresiva y segura, a la musculatura a estímulos específicos (en cuanto a velocidad y elongación) en los que ocurran este tipo de lesiones (no evaluable)

P.4.3 Evitar la rigidez del recto anterior (evaluado mediante Test A.3)

Objetivo General: P.5) Disminuir la probabilidad de tener una lesión muscular en otro músculo.

Objetivos Específicos:

P.5.1 Mejorar la capacidad excéntrica de la musculatura isquiosural (no evaluado)

P.5.2 Mejorar los valores de fuerza de la musculatura abductora de cadera (evaluado mediante B.2)

P.5.3 Mejorar los valores de fuerza de la musculatura aductora de cadera (evaluado mediante B.1;3)

\subsection{Objetivos Secundarios}

Objetivo General: S.1) Asesorar al jugador sobre la importancia de llevar una vida sana para prevenir lesiones.

\section{Objetivos Específicos:}

S.1.1 Dar información sobre la importancia del descanso para mantener un adecuado rendimiento en entrenamientos y partidos y para la prevención de lesiones (no evaluable).

S.1.2 Dar información sobre la importancia de la alimentación en el rendimiento deportivo, la calidad de vida y la prevención de lesiones (no evaluable).

\subsection{Informe Personalizado para el Jugador}




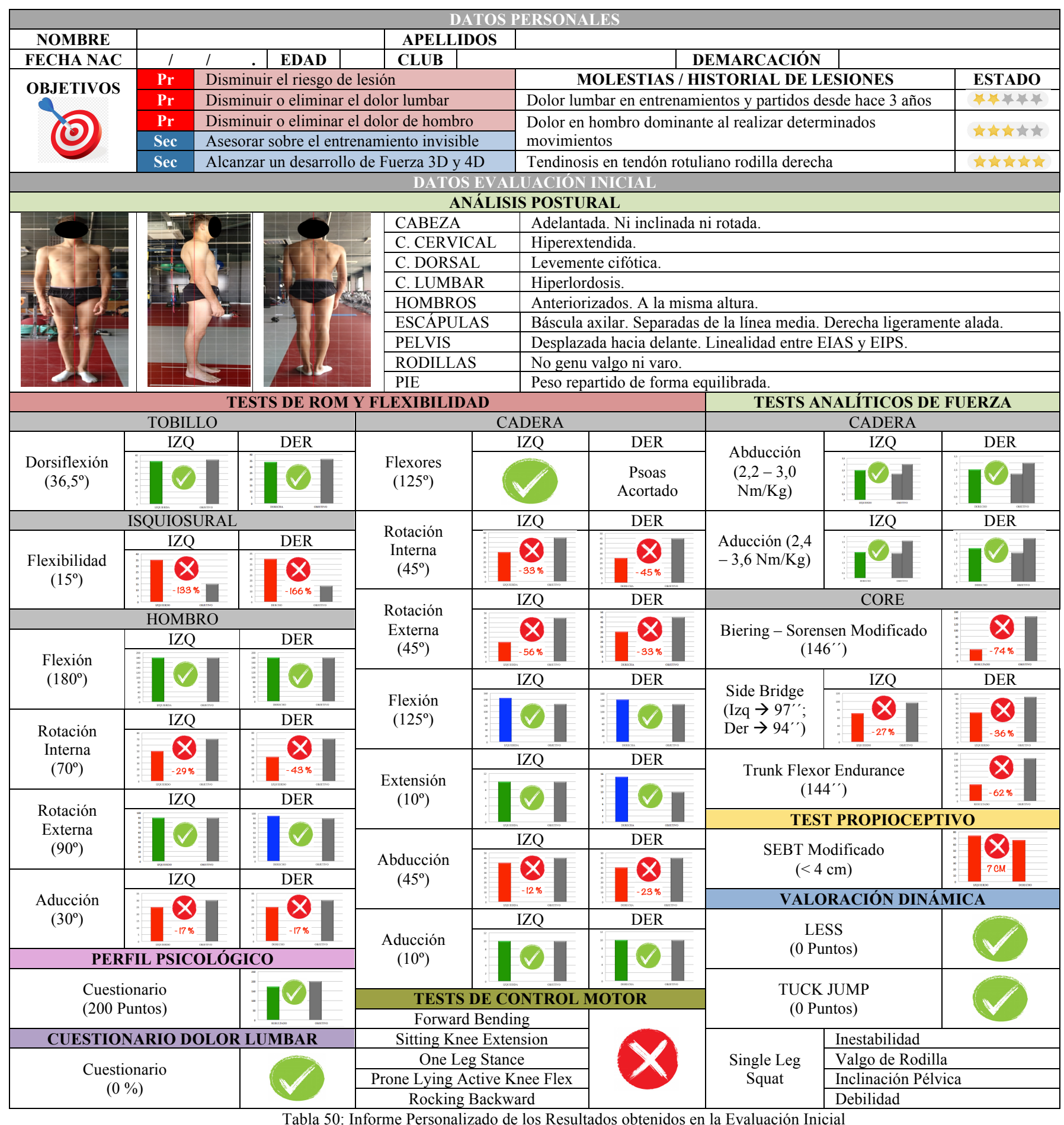

\title{
5-. JUSTIFICACIÓN DEL PROGRAMA DE INTERVENCIÓN
}

\author{
"El hombre de ciencia ha aprendido a creer en la justificación; no \\ por la fe, sino por la verificación" \\ Thomas Henry Huxley, biólogo y filósofo británico (1825 - 1895)
}

Pensar en el cuerpo humano como la suma de unas estructuras (figura 35) es una visión simplista basada en teorías conductistas y mecanicistas propias de la cultura occidental. Bajo esta premisa, y buscando mejorar la unidad a través de la mejora de cada una de las partes, se trabajan aspectos parciales, y a menudo poco conectados entre sí. Por tanto, resultaría erróneo plantear un programa preventivo en este contexto, ya que las partes no son homogéneas y están íntimamente interrelacionadas (pensamiento holístico). Por lo tanto, debemos partir de un modelo que suponga una conexión multidireccional y 
sinérgica entre todas las partes (figura 36) (29). De este modo, por ejemplo, podríamos entender que una disminución de la activación de los glúteos puede explicar una mayor activación de la musculatura isquiosural y, por lo tanto, un mayor riesgo de lesión por sobrecarga.

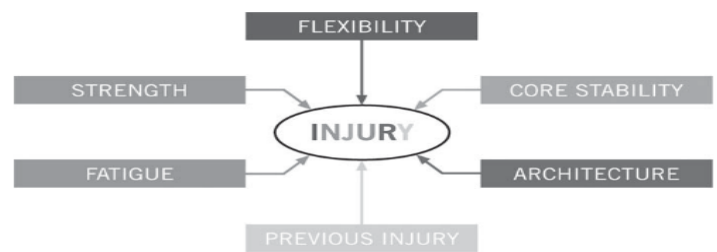

Figura 35: Modelo Causa - Efecto para la lesión de Isquiosurales (29)

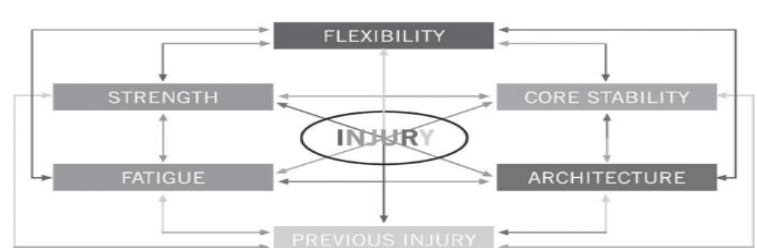

Figura 36: Nuevo Modelo Conceptual para la lesión de Isquiosurales (29)

A la hora de aplicar un plan preventivo se pueden seguir dos estrategias $(277,349)$ :

- Un planteamiento grupal: Es más sencillo de elaborar y requiere menos tiempo para evaluar. Aquí todos los jugadores realizan los mismos ejercicios, por lo que es lógico pensar que pueda resultar insuficiente si el riesgo de lesión de un jugador es demasiado elevado $(277,350,351)$. Existen en la literatura protocolos como "The 11" o la versión actualizada "The 11+", que intentan disminuir los factores de riesgo de las lesiones en el fútbol (262). Se trata de un calentamiento preventivo que incluye 10 sencillos ejercicios excéntricos, propioceptivos y de Core (352) que no necesitan material. Se ha demostrado que los equipos que lo realizan disminuyen la incidencia de lesiones en partido y entrenamiento (353-355) pero sólo a nivel amateur, porque jugadores de más nivel requerirán adaptaciones en el trabajo (354). Otro protocolo es el "KCP" sueco, que ha conseguido disminuir la incidencia de lesiones de rodilla tras 5 años de implementación a nivel educativo (353).

- Un planteamiento individualizado: Se debe ajustar a las necesidades de cada jugador, mediante evaluaciones relevantes y una intervención precisa para reducir el riesgo de lesión. Requiere mayor inversión de tiempo, organización y presupuesto pero su efectividad es superior al anterior planteamiento $(81,277)$.

Obviamente este trabajo consiste en un planteamiento individualizado, pero tener conocimiento de un plan preventivo y buenas intenciones no garantiza el éxito (356). El programa debe contar con la confianza del jugador, ya que puede suponer un cambio en su comportamiento y podría entender que va a afectar negativamente a su rendimiento (279), y debemos estar presentes cuando se realice, no sólo porque así se "pide" en el TFM, sino porque se ha demostrado una mayor eficacia en comparación con un plan realizado sin supervisión, ya que hay un mayor cumplimiento y podemos corregir los ejercicios para poner el foco en la ejecución perfecta (357). También debe involucrar al médico, readaptador y fisioterapeutas con un enfoque multidisciplinario $(3,9)$, sin olvidar al entrenador, como prueba una encuesta realizada a los servicios médicos de varios equipos nacionales (10) (ver figura 37), generalmente preocupado exclusivamente por el rendimiento, para lo cual es muy interesante transformar los datos médicos para que decida teniéndolos en cuenta (164).

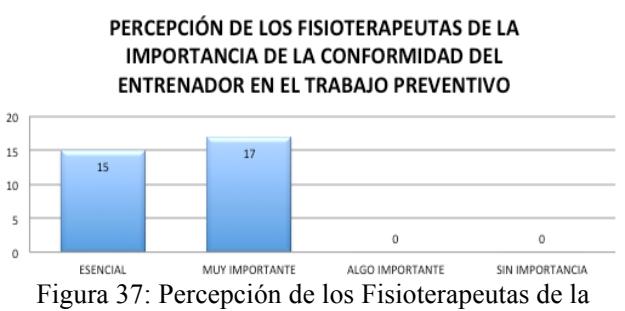

Figura 37: Percepción de los Fisioterapeutas de la importancia de la conformidad del entrenador en el trabajo preventivo (10)

No existe ninguna referencia en la literatura sobre cuándo aplicar un plan preventivo, por lo que me voy a basar en una encuesta realizada a 44 equipos de alto nivel sobre su percepción y cómo lo aplican en sus semanas de entrenamiento (110). En este sentido, el tiempo de recuperación entre una sesión preventiva y el partido fue de 48 horas en la mayoría de los casos (ver figura 38), el tiempo de recuperación entre dos sesiones preventivas suele ser de 24 o de 48 horas (ver figura 39) y entre una sesión preventiva y otra de fortalecimiento del tren inferior de 24 horas (ver figura 40) (110).

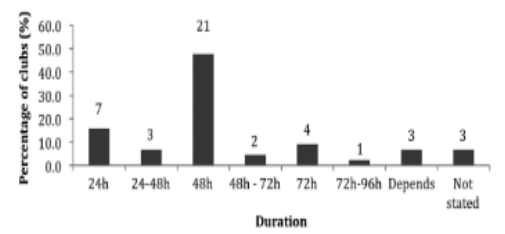

Figura 38: Tiempo de recuperación entre un partido y una sesión preventiva (110)

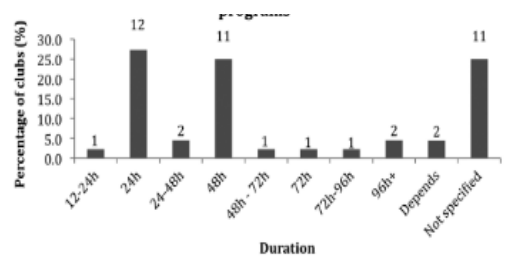

Figura 39: Tiempo de recuperación entre 2 sesiones preventivas (110)

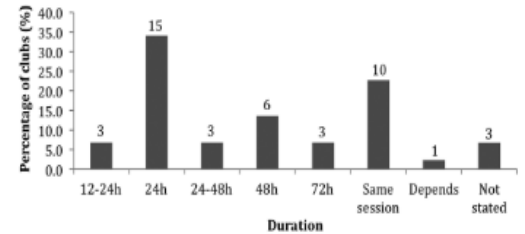

Figura 40: Tiempo de recuperación entre 1 sesión de fuerza de tren inferior y 1 preventiva (110) 
Tampoco existe consenso sobre cuáles son los mejores ejercicios para prevenir lesiones (110). En una encuesta realizada a 32 selecciones participantes en el campeonato del mundo de Fútbol de 2014 se indicó que el entrenador tenía más confianza en los ejercicios de flexibilidad, de Core, la combinación de modos de contracción muscular, la propiocepción y los ejercicios excéntricos como los más importantes para la prevención de lesiones (10) (ver figura 41). Mientras que los más utilizados por los mejores equipos de las principales ligas fueron los excéntricos, la propiocepción, el excéntrico de isquiosural, el trabajo de Core, la activación de glúteo y el nórdico (110) (ver figura 42).

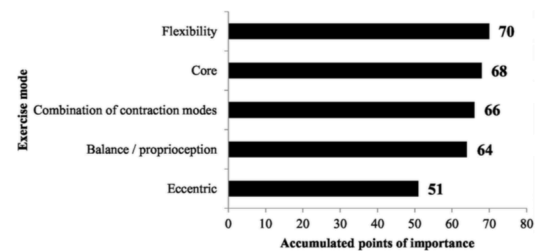

Figura 41: Ejercicios con los que los entrenadores pueden estar más conformes para individualizar la prevención (10)

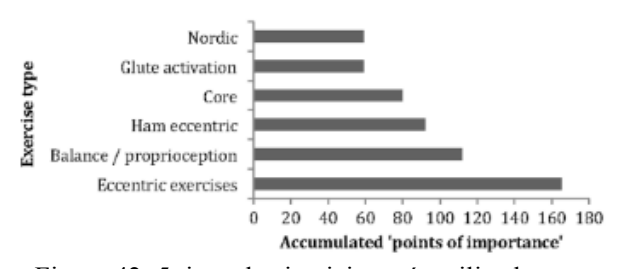

Figura 42: 5 tipos de ejercicios más utilizados para prevenir lesiones por los equipos de primer nivel (110)

En cuanto a las herramientas más utilizadas por las selecciones nacionales en la Copa del Mundo de 2014 para monitorizar el entrenamiento encontramos, por orden de importancia, los registros médicos diarios, el seguimiento del número de partidos / minutos jugados, el bienestar subjetivo (escala Wellness, ver 5.7), la frecuencia cardiaca y los marcadores bioquímicos y el bienestar objetivo (10), tal y como puede verse en la figura 43.

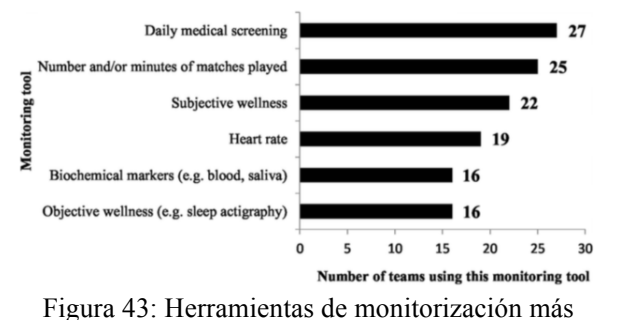

Figura 43: Herramientas de monitorización más utilizadas por las selecciones nacionales (10)

En base a la información recogida, en el presente trabajo se realizarán 2 sesiones semanales (hay que tener en cuenta que el jugador ya realiza trabajo preventivo con su equipo), lo que concuerda con el

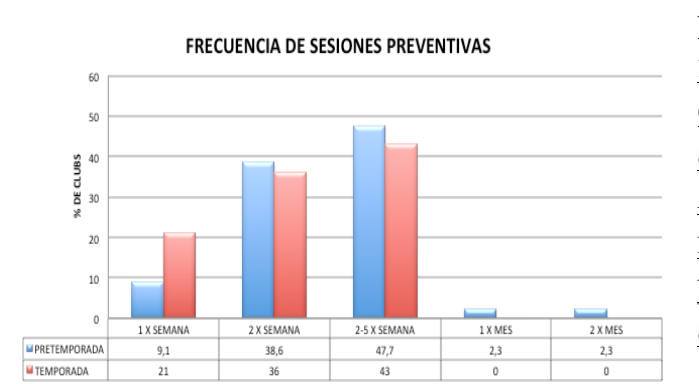
trabajo realizado en los mejores equipos de las principales ligas de fútbol (110), tal y como podemos ver en la figura 44. Estas sesiones distarán, como mínimo, 48 horas de cualquier partido (oficial o amistoso) y 24 horas de una sesión de fuerza del tren inferior. Además, habrá un mínimo de 24 y un máximo de 48 horas entre nuestras sesiones preventivas o entre una de nuestras sesiones y la preventiva que realice con su equipo, aunque siempre nos adaptaremos a las circunstancias que se presenten cada semana.

Figura 44: Frecuencia de sesiones preventivas en equipos de primer nivel (110)

La aplicación del plan preventivo se reforzará con la teoría OPTIMAL (Optimización del rendimiento a través de la motivación intrínseca y la atención para el aprendizaje) del aprendizaje motor, que implica encontrar los enfoques correctos para aumentar o apoyar la motivación positiva y dirigir la atención hacia focos externos efectivos (358). "La confianza en la propia capacidad para ejecutar bien, en combinación con un foco externo instruido, debe facilitar los resultados exitosos del movimiento, lo que, a su vez, promoverá aún más la autoeficacia y el afecto positivo que ayudan a solidificar la correcta ejecución, dando como resultado un ciclo virtuoso con consecuencias generales positivas para el aprendizaje y la motivación" (358). En líneas resumidas, esta teoría se basa en (358):

- Motivación: Actuamos cuando las perspectivas de futuro indican que se producirán resultados positivos, especialmente si creemos ser los agentes que van a producir dicho resultado. Por ello, es lógico pensar que las condiciones que mejoran las expectativas de rendimiento del jugador o su necesidad de sentirse autónomo facilita el aprendizaje motor. Por ello es tan importante mantener un alto grado de motivación del jugador durante nuestros entrenamientos.

- Expectativas mejoradas: Las experiencias de éxito previas, o la falta de las mismas, puede influir enormemente en la calidad del entrenamiento. Por ello buscaremos generar expectativas de éxito en el jugador mediante un feedback positivo, la utilización de videos para que pueda ver sus movimientos y aquello que hace bien o necesita mejorar, mediante una actitud cercana al jugador, intentando variar su percepción de la dificultad de la tarea. 
- Autonomía: La motivación humana depende de la percepción que tenemos de que las decisiones que tomamos tienen efectos sobre el medio en el que estamos inmersos, incluso si esos efectos son triviales. Esto se denomina "motivación de efecto de control". En este sentido, dejaremos que el sujeto forme parte de su plan preventivo decidiendo aspectos como series, repeticiones o tiempo de descanso.

- Foco Externo: Se ha demostrado que la utilización de un foco externo acelera el aprendizaje frente a un foco interno, por lo que utilizaremos referencias externas para garantizar un mayor control motor durante la realización de los ejercicios. Por ejemplo, durante un Clam Shell podemos colocar nuestro brazo (o la pared) detrás de la cadera del jugador, de modo que si se produce una báscula pélvica, va a notar el contacto y puede corregir su ejecución.

\subsection{Justificación del Trabajo Excéntrico.}

El entrenamiento excéntrico mejora la masa muscular, la fuerza y la potencia en mayor medida que el trabajo concéntrico o isométrico (359). Una contracción excéntrica brusca puede lesionar la musculatura, sin embargo, si se aplica de forma progresiva y continua generará unas adaptaciones que serán claves para (1) la mejora de las actividades deportivas de alta potencia, (2) la prevención y (3) la rehabilitación de lesiones deportivas (359).

El entrenamiento excéntrico puede aumentar el tamaño y la fuerza muscular, y puede cambiar la longitud óptima del músculo (360), lo que conduce a una reducción en la tensión pasiva total (350), además, permite al músculo absorber más energía antes de fallar $(359,361)$, por tanto, el fortalecimiento excéntrico es efectivo para reducir lesiones $(191,350,362,363)$ y debe incluirse como trabajo preventivo en jugadores de fútbol $(250,351)$. Como contrapartida, este tipo de trabajo puede provocar dolor muscular de inicio tardío en los jugadores (DOMS) (364).

Ya se comentó en los mecanismos de lesión que la lesión en isquiosurales suele ocurrir en la fase final del swing. Un aumento de fuerza y resistencia en este grupo muscular en una posición más funcional durante la carrera de velocidad aumentará la capacidad para absorber cargas excéntricas repetidas antes y durante el apoyo del talón, por lo que los programas preventivos deben orientarse a ejercicios excéntricos (226) con cargas elevadas, movimientos funcionales (252) y en posiciones alargadas (hasta la extensión de rodilla) (295).

En este sentido, uno de los ejercicios más estudiados en la literatura es el nórdico (figura 45). Existen estudios que concluyen que reduce la incidencia de lesiones primarias y recidivas en isquiosurales en jugadores de fútbol aficionados $(351,364)$ y profesionales $(161,350,365)$, así como revisiones sistemáticas y meta-análisis (366). Además, una lesión puede modificar la arquitectura de un músculo, disminuyendo la longitud del fascículo y aumentando el ángulo de penación (367). El ejercicio nórdico puede aumentar la longitud del fascículo y del grosor muscular y disminuir el ángulo de penación, efectos que desaparecen tras un periodo de desentrenamiento, por lo que puede ser eficaz para la prevención de lesiones (368).

El ejercicio de extensión de cadera a $45^{\circ}$ (figura 46) provoca una mayor hipertrofia en la cabeza larga del bíceps femoral y el semimembranoso, mientras que el ejercicio nórdico desarrolla el semitendinoso y la cabeza corta del bíceps femoral (369). Además, el ejercicio de extensión de cadera se realiza en longitudes musculares más largas que el nórdico, por lo que hay estudios que indican que puede ser más efectivo (370), aunque eso no implica una modificación en la longitud óptima muscular (369).

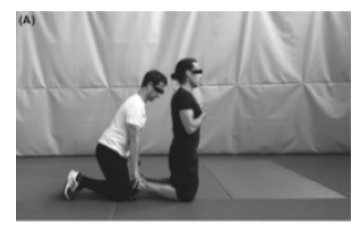

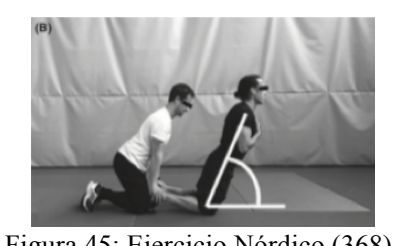

Figura 45: Ejercicio Nórdico (368)

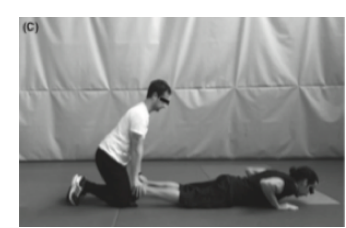

Por otro lado, también existen estudios que no encuentran esa relación entre el ejercicio nórdico y la disminución en la incidencia de lesiones (371), ya que la cadera se mantiene fija, al contrario de lo que sucede en la fase final de swing (29), y que los isquiosurales no actúan cerca de la extensión de rodilla, que son los ángulos en los que hay mayor riesgo (372). Para investigar esta última cuestión se realizó un estudio con jugadores de fútbol en el que se midió con electromiografía (EMG) la activación de los 
isquiosurales en este ejercicio a $30 \%$, concluyendo que 1) los isquiosurales de ambas piernas tienen una activación similar y, aunque el mayor pico se encuentra en la fase media del ejercicio, se encontraron valores elevados incluso en posiciones articulares extendidas, 2) los beneficios se obtienen independientemente de la velocidad de ejecución y 3) aunque el ejercicio se realice a una velocidad baja, produce adaptaciones transferibles a movimientos a alta velocidad (361). Otro estudio posterior que comparó el ejercicio nórdico y la extensión de cadera a $45^{\circ}$ obtuvo la misma conclusión, que el nórdico produce un aumento de la longitud óptima de los isquiosurales (369).

Aunque hay pocos estudios sobre trabajo excéntrico en otra musculatura distinta a los isquiosurales (277) o poca evidencia para reducir la incidencia de lesiones en otros grupos musculares (110), podemos encontrar un estudio que concluye que es importante aumentar la capacidad del aductor largo para tolerar la carga rápida en un estado alargado para prevenir lesiones, lo que puede lograrse con el entrenamiento excéntrico (226); otro estudio, realizado con jugadores de fútbol profesional, muestra que se reduce la incidencia de lesiones en cuádriceps después de realizar entrenamiento excéntrico (373) y otro muestra cómo, tras ejercicio excéntrico adicional realizado en pretemporada en futbolistas profesionales, aumenta la longitud óptima durante la flexión y extensión de rodilla (373), lo cual es un efecto protector (374).

A pesar de todo lo que indica la literatura, en una revisión sistemática se otorga una recomendación graduada "C" (débil) para el ejercicio excéntrico de isquiosurales para la prevención de lesiones en futbolistas profesionales y de "D" para el excéntrico para otros grupos musculares, ya que no se puede determinar de forma concluyente que la disminución en la incidencia de lesiones se deba al trabajo excéntrico porque se realizan muchos ejercicios debido al enfoque multidimensional de un programa preventivo (283).

No obstante, si nos fijamos en lo que se hace en la práctica, en una encuesta realizada al personal médico de varios equipos profesionales de fútbol se señaló el trabajo excéntrico como el más importante para la prevención de lesiones (110) (ver figura 42), mientras que en otra realizada al personal médico de las 32 selecciones que participaron en la Copa del Mundo de 2014 apareció en $5^{\circ}$ lugar, por detrás de la "combinación de tipos de contracción muscular", reflejando así el enfoque multidimensional de los planes preventivos en la práctica (10) (ver figura 41) que se comentaba anteriormente y demostrando que se deben incluir en nuestro plan.

Dentro del entrenamiento excéntrico, es obligado hablar del entrenamiento isoinercial, que se realiza con un dispositivo específico que utiliza resistencia inercial independiente de la gravedad. Así, durante la contracción concéntrica, la carga se acelera y, en la fase excéntrica, se frena por el mismo grupo muscular que trabajó en la contracción concéntrica (375), esto permite ofrecer una resistencia sin restricciones durante todo el movimiento (376) y provoca fases excéntricas más fuertes y una mayor activación muscular (sobrecarga excéntrica) (377). El entrenamiento excéntrico inercial es efectivo para prevenir lesiones y para la recuperación de las mismas $(378,379)$.

Además, se ha encontrado que el entrenamiento con sobrecarga excéntrica puede conllevar una mejora en las habilidades de salto y sprint (380) y en el cambio de dirección (381) al disminuir el tiempo de frenado y aumentar la fuerza de propulsión (382). Una opción muy interesante es realizarlo en un calentamiento previo a entrenamientos y partidos sin llegar a producir fatiga, como una potenciación postactivación, ya que mejoraría el rendimiento (en salto, sprint y cambio de dirección como se acaba de comentar), y además tendría un efecto beneficioso sobre la prevención de lesiones (383).

Al comparar el ejercicio nórdico y el leg-curl con máquina yoyo, la sobrecarga excéntrica es mucho mayor en este último, por lo que este tipo de ejercicios debe incluirse en un plan preventivo (380). El dispositivo versapulley nos permite, no sólo provocar una sobrecarga excéntrica, sino realizar una simulación del movimiento en las 3 dimensiones del espacio, siendo mucho más específico que el trabajo convencional (379). Ambas, la tecnología yo-yo y la versapulley, son complementarias, ya que la primera permite el desarrollo de altos niveles de fuerza a velocidades moderadas y bajas; y la otra el desarrollo de una alta velocidad excéntrica con niveles de resistencia de moderados a altos (379).

Ante la opción de combinar dispositivos isoinerciales e inestabilidad, se ha encontrado que no hay diferencias electromiográficas en la velocidad pico al realizar sentadillas con versapulley en superficie estable o inestable, aunque la superficie inestable supone un mayor desafío neuromuscular que podría ayudar a prevenir esguinces de tobillo sin disminuir la velocidad de ejecución (384). 


\subsection{Justificación del Trabajo de Fuerza.}

Ya se ha argumentado que un desequilibiro cuádriceps / isquiosural es un factor de riesgo de lesión, por lo que la corrección de esos desequilibrios puede reducir significativamente el riesgo de lesión, siempre que se haya realizado una evaluación isocinética (277). Del mismo modo, un ratio de fuerza aductor / abductor por debajo del $80 \%$ puede ser un factor de riesgo para una lesión de aductores, por lo que la corrección de este desequilibrio puede reducir la incidencia de este tipo de lesión (385).

El psoas iliaco y el recto femoral son flexores de cadera. Una reducción en la fuerza y/o activación del psoas iliaco puede conllevar una compensación del recto femoral para generar más fuerza en la flexión de cadera (386), lo que puede provocar en un futbolista una sobrecarga del recto femoral y, por tanto, un aumento del riesgo de lesión (250). Por motivos anatómicos, el entrenamiento efectivo de los flexores de cadera debe incluir ángulos de flexión de cadera superiores a $90^{\circ}$ (387), además se realizará de forma concéntrica en pretemporada, cuidando los golpeos en largo en los primeros días (por ejemplo saques de puerta en el caso de nuestro jugador) y, tras las primeras semanas, el entrenamiento de los flexores de cadera deberá realizarse durante los calentamientos (250).

En el caso de aductor, se sugiere un tratamiento triplanar en los ejercicios (movimiento diagonal) en conjunto con la musculatura sinérgica que puede tener riesgo de lesión, como pueden ser flexores de cadera, extensores de rodilla, rotadores de tronco y extensores y abductores de cadera (226). También es importante una gran variedad de movimientos en el entrenamiento y preparar al jugador para acciones reactivas / no anticipadas, pues la mayoría de las lesiones aparecen en presencia de un oponente (226).

El movimiento de rodilla en el plano frontal, es decir, el valgo o varo en la recepción de un salto, puede mejorarse con un aumento de fuerza muscular de cuádriceps e isquiosurales (388) y de abductores y aductores de cadera $(33,389)$. Los abductores estabilizan el fémur, disminuyendo la aducción de cadera y el valgo de rodilla, además, la contracción de cuádriceps e isquiosurales puede aumentar la rigidez articular, por lo que su fortalecimiento será clave para la prevención de lesiones del tren inferior (33).

Por último, es importante señalar que la combinación de ejercicios de sobrecarga excéntrica y vibración tiene efectos muy positivos sobre el rendimiento de los futbolistas, por lo que es un complemento muy interesante para realizarlo $1 \mathrm{vez}$ por semana (381). En este sentido, parece ser que el entrenamiento de fuerza mediante ejercicios desafiantes realizados sobre plataforma vibratoria "aumenta las adaptaciones de varias habilidades funcionales a largo plazo" (381).

\subsection{Justificación del Trabajo de CORE o de Estabilización Coxolumbopélvica.}

La estabilidad del Core es "la capacidad de los estabilizadores pasivos y activos implicados en la región lumbopélvica para mantener la postura adecuada del tronco y la cadera, el equilibrio y el control durante los movimientos estáticos y dinámicos" (390) y es clave para prevenir lesiones en las extremidades inferiores $(250,391$ ) en general, en los isquiosurales (392) o en la ingle (393), ya que la actividad muscular del tronco, a menudo, ocurre antes que la actividad de la musculatura del tren inferior, creando una base estable mediante la co-contracción de transverso y multífidos (93). Por tanto, el desarrollo de esta musculatura es importante para la realización de las actividades de la vida diaria, pero además mejora el rendimiento deportivo y previene el dolor lumbar (91).

A grandes rasgos, podemos decir que el Core está integrado por (147):

- Unidad Interior: Formado por la musculatura profunda y tónica de la región lumbopélvica. Estos músculos generan poco o ningún movimiento y funcionan de manera sinérgica. Su cocontracción proporciona estabilización segmentaria de la columna vertebral. Lo integran los músculos transverso, fibras posteriores del oblicuo interno, diafragma, músculos del suelo pélvico, multífidos y porciones lumbares de los iliocostales y longísimo.

- Unidad Exterior: Formada por la musculatura superficial y fásica de la región lumbopélvica. Su función principal es cocontraerse para proporcionar una importante estabilidad cuando el cuerpo está bajo carga o durante movimientos de alta velocidad. También se encarga de controlar el rango de movimiento para proporcionar estabilidad y producir movimiento. Lo forman los músculos oblicuo externo e interno, recto anterior, erector espinal, dorsal ancho, glúteos, cuadrado lumbar, aductores e isquiosurales. 
El aspecto más importante del rendimiento muscular abdominal es obtener el control necesario para estabilizar adecuadamente la columna vertebral, mantener relaciones óptimas de alineación y movimiento entre la pelvis y la columna vertebral, y prevenir el estrés excesivo y movimientos compensatorios de la pelvis durante los movimientos de las extremidades. Lo ideal es que las estructuras del Core "fluyan" y, de repente, se co-contraigan para producir movimiento rápidamente en cualquier dimensión (147).

Para la mayoría de las actividades de la vida diaria un bajo nivel de activación muscular puede producir la rigidez necesaria en las articulaciones raquídeas como para asegurar la estabilidad de la columna. Esto lo conseguiría el sistema de control motor mediante la acción coordinada de todos los músculos del Core, desde los de la unidad interior, que actúan localmente (sistema de estabilización local) hasta los de la unidad exterior, más grandes y superficiales (sistema de estabilización global) (92). Sin embargo, una alteración del sistema de control motor podría producir magnitudes de fuerza inapropiadas que conllevarían a una falta de estabilidad (394).

Sin embargo, ese aumento de la rigidez articular no es suficiente para estabilizar el movimiento del tronco ante movimientos rápidos y precisos como los que puede requerir un futbolista (92). En la literatura podemos encontrar 2 técnicas para mejorar la estabilidad de la columna ante esos movimientos bruscos e inesperados, propios de nuestro deporte, hablamos del Bracing y el Hollowing. El Hollowing se ha utilizado eficazmente para reeducar patrones de movimiento alterados por lo que se pensó que podría dar estabilidad a la columna (395). No obstante, se ha demostrado que la coactivación de toda la musculatura del Core y la preactivación reduce el desplazamiento del tronco y mejora la estabilidad (395), aspecto que está muy relacionado con la producción de presión intra-abdominal (396). En este sentido, es importante destacar que el Hollowing aumenta las cargas de compresión sobre la columna pero no reduce el desplazamiento del tronco tras una perturbación (395), por lo que la maniobra de Bracing es bastante más efectiva de cara a estabilidad que el Hollowing $(395,396)$, que tiene su sentido en el trabajo de control motor (397).

Además es interesante aplicar la técnica del Bracing a distintos ejercicios que realizaremos en nuestro plan de intervención como puede ser la abducción de cadera en decúbito lateral para incidir en el glúteo. En este ejercicio, la activación del cuadrado lumbar puede provocar una flexión lateral de la pelvis que conlleve una inestabilidad. Al realizar la maniobra de bracing se produce una co-contracción isométrica de todos los músculos del Core, por lo que el cuadrado lumbar se activa de forma bilateral, evitando así el desplazamiento lateral de la pelvis y contribuyendo a la estabilidad (398).

En el fútbol, la estabilidad del Core es necesaria para contrarrestar la torsión hacia atrás, flexión lateral (gracias al cuadrado lumbar) y, especialmente, los momentos de extensión de cuádriceps que se producen durante el golpeo de balón y las carreras de alta velocidad (250). Además, la mayoría de las acciones se producen en condiciones inestables (saltos y aterrizajes en un césped desigual, golpeos impedidos por un oponente,...) (347). El entrenamiento del Core también puede mejorar el valgo de rodilla ya que aumenta el control de la aducción y rotación interna de la cadera (399), disminuyendo así el riesgo de lesión de rodilla $(120,400,401)$.

En los últimos años, los dispositivos desestabilizantes se han vuelto muy populares para entrenar esta musculatura (402). En este sentido, es necesario saber que se ha reportado una mayor activación en la musculatura del Core al realizar ejercicios similares en situaciones perturbadoras en comparación con las estables $(347,403,404)$, aunque no en sujetos altamente entrenados $(405)$, lo que sugiere que debemos establecer una progresión para evitar un estancamiento en el entrenamiento, a través de una combinación de carga (sentadillas o pesos muertos) e inestabilidad, de una disminución de la base de sustentación, un cambio en la superficie desestabilizante (paso de dyn-air o bosu a swiss ball) o la inclusión de perturbaciones (405). En este sentido, las "swiss ball" proporcionan condiciones desestabilizadoras que pueden estimular los propioceptores para proporcionar información para el mantenimiento del equilibrio y la detección de la posición corporal (406) pero generan una menor activación de la musculatura del Core que el entrenamiento en suspensión (407).

Además de esos beneficios, el entrenamiento del Core también podría mejorar la propiocepción, aunque no se sabe cuánto tiempo se mantiene esta mejora (406). Por lo tanto, el uso de dispositivos desestabilizantes en el fútbol puede suponer un estímulo adicional para mejorar el rendimiento en comparación con ejercicios en condiciones estables $(347,403)$. 
Del mismo modo, el uso de dispositivos perturbadores en rehabilitación y acondicionamiento físico general ayuda a disminuir el dolor lumbar y aumentar la eficiencia sensorial de los tejidos blandos que estabilizan tobillo y rodilla (402). Sin embargo, también parece ser que los ejercicios de fuerza en inestabilidad pueden inhibir la fuerza, la potencia, la velocidad y el rango de movimiento (403), debido, en parte, a un aumento en la rigidez de las articulaciones (406).

\subsection{Justificación del Trabajo Propioceptivo.}

El término propiocepción se usa para describir "toda la información originada en propioceptores neurales de las articulaciones, músculos, tendones, ligamentos y cápsulas, que se envían al sistema nervioso central a través de vías aferentes, consciente o inconscientemente, además de las relaciones biomecánicas de los tejidos articulares, que puede influir en el tono muscular, el equilibrio postural y la estabilidad articular" (408). Un déficit propioceptivo va a generar una pérdida del control del movimiento articular, lo que conlleva una alteración de la estabilidad (409).

Una lesión en rodilla o tobillo, podría interrumpir el sentido de la posición, disminuyendo así la propiocepción y provocando una actividad neuromuscular anormal y una inestabilidad funcional que predisponga a una nueva lesión (409), además de asociarse a una disminución de la fuerza muscular y el equilibrio (410).

El entrenamiento propioceptivo del tobillo disminuye esa inestabilidad funcional del tobillo y la incidencia de una nueva lesión, además de mejorar el tiempo de reacción muscular y la estabilidad articular y postural, ofreciendo así una protección contra futuras lesiones (409). Además, el mayor control neuromuscular podría ayudar al jugador, en algunos casos, a corregir la posición de inversión de tobillo antes de cargar el peso del cuerpo (227), evitando así la aparición de una lesión. En este sentido y aplicado al fútbol, se ha demostrado que el entrenamiento propioceptivo reduce la incidencia de lesiones en rodilla $(411,412)$ y tobillo $(413-416)$. Sin embargo, también podemos encontrar estudios que señalan una falta de evidencia científica en torno al trabajo propioceptivo y la reducción de la incidencia de lesiones de tobillo (10) y que encuentran una recomendación graduada " $\mathrm{D}$ " en este tipo de ejercicios para la prevención de esguinces de tobillo y de rodilla, aunque terminan concluyendo que, al no encontrar efectos adversos, se pueden seguir incluyendo en los programas preventivos (283).

Una ayuda para reducir el riesgo de lesión es el uso de órtesis o protecciones de tobillo, especialmente en tobillos inestables o previamente lesionados $(227,276)$, ya que limita el movimiento del tobillo hacia la inversión (417).

El uso de superficies desestabilizadoras en el trabajo propioceptivo provoca modificaciones rápidas en la longitud de los ligamentos del tobillo, y lo hace desde distintos planos, lo cual obliga a generar una estabilización articular rápida. Por lo tanto, el objetivo de este entrenamiento es inducir alteraciones imprevisibles (410), tal y como puede ocurrir en un partido de fútbol.

En un estudio en el que se comparó la actividad electromiográfica (EMG) en Tibial Anterior, Peroneo Largo y cabeza medial del gemelo en BOSU, plataforma de equilibrio, disco propioceptivo y trampolín (ver figura 47) se concluyó que el BOSU y el BOSU invertido proporcionaron una mayor actividad EMG en estos músculos que la plataforma de equilibrio y el trampolín, por lo que debe emplearse en programas preventivos y de rehabilitación (410). El BOSU y el disco son similares en cuanto a estructura inflable y alto grado de inestabilidad, por lo que debe utilizarse en etapas avanzadas de entrenamiento propioceptivo. En este sentido, el uso de diferentes dispositivos en el entrenamiento del equilibrio es importante para respetar las dificultades y limitaciones de cada individuo y proporcionar una sobrecarga progresiva (410).
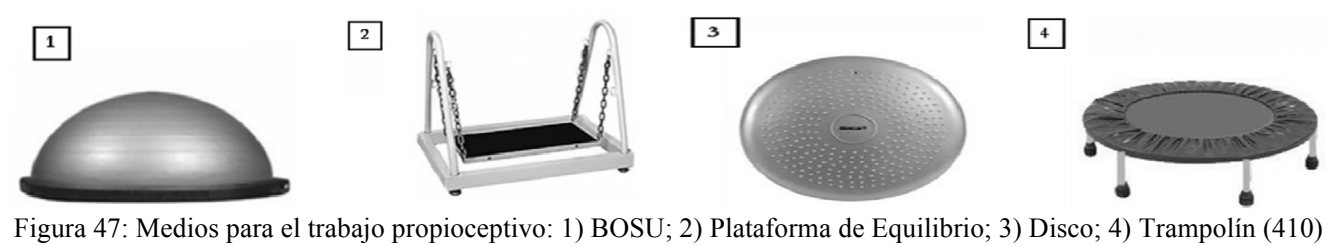

Figura 47: Medios para el trabajo propioceptivo: 1) BOSU; 2) Plataforma de Equilibrio; 3) Disco; 4) Trampolín (410)

Si comparamos ambos lados del BOSU, encontramos un artículo que no encuentra diferencia en la actividad de EMG entre un lado y otro (418), y otro estudio en el que el BOSU invertido demuestra valores más altos (410). 


\subsection{Justificación del Trabajo para la Mejora del ROM.}

Ya se ha comentado que la Flexibilidad de los extensores de rodilla y flexores de cadera puede ser un factor de riesgo (54), por lo que debe tenerse en cuenta en un programa preventivo $(292,419)$ para evitar la sobrecarga del recto femoral en acciones que requieran una extensión de cadera (como despejes o saques de puerta en nuestro jugador) o una irritación del nervio femoral (relacionado con lesiones de recto femoral) debido a un psoas acortado (250), y deberá realizarse antes y después de cada sesión de entrenamiento para mitigar la reducción de movimiento producida por el entrenamiento (250).

El efecto que los estiramientos producen sobre el rendimiento, particularmente sobre la potencia, es muy confuso (420). Tampoco está claro que provoque mejoras en el ROM, ya que las características tan dispares de los estudios (en cuanto a muestra, metodología, tipo de estudio,...) dificultan la comparación y los resultados que se obtienen son contradictorios. Además, al contrario del pensamiento extendido, dos revisiones sistemáticas concluyen que el estiramiento no reduce la incidencia de lesiones en el fútbol $(421,422)$, aunque sí es una de las prácticas preventivas más valoradas por los profesionales $(10)$.

El estiramiento puede clasificarse como (423):

- Activo: Se coloca la articulación en su ROM máximo gracias a la contracción agonista que se opone a la resistencia elástica de la musculatura antagonista.

- Pasivo: Se coloca la articulación en su ROM máximo gracias a la gravedad o la inercia.

- Estático: Bien con ayuda de un compañero, por efecto de la gravedad o por contracción agonista, se adquiere una posición de estiramiento y se mantiene en el tiempo.

- Dinámico: Se mueve la articulación a través de su ROM sin pausas largas. Es el más adecuado previo al ejercicio (424).

- Agudo: 1 solo ejercicio que se mantiene durante 30 segundos o menos.

- Crónico: Varios ejercicios y series repetidos durante días y semanas.

En nuestro deporte no se han encontrado efectos perjudiciales del estiramiento estático antes de la realización de un RSA (Repeat Sprint Ability) (425). Es importante señalar que se escoge esta prueba porque la recuperación tras un esfuerzo de alta intensidad en fútbol no suele ser pasiva de 3 minutos, como se plantea en la mayoría de los artículos. Sin embargo, el tiempo de estiramiento en este estudio fue muy corto, lo cual puede explicar los resultados. Esto está en concordancia con una revisión sistemática y meta-análisis que indica que los efectos negativos del estiramiento estático no se relacionan con la edad, sexo o nivel del sujeto pero sí con el tiempo, observándose efectos menos perjudiciales cuando se mantiene la posición menos de 45 segundos, recomendando rangos de entre 15-30 segundos (426).

Algunos autores han estudiado la generación de una Potenciación post Activación para aumentar el ROM (420), entendida como "un aumento en la contracción muscular y la fuerza tetánica de baja frecuencia después de una actividad contráctil "condicionante"m" (427). La conclusión fue que, aunque puede generar un aumento en la ROM, también puede producir fatiga.

La vibración mecánica es un medio que podemos utilizar para conseguir una ganancia en el ROM $(424,428,429)$ y puede aplicarse de forma local o sobre el cuerpo entero $(430)$. La frecuencia que se utiliza en miembro inferior es de $10-50 \mathrm{~Hz}$ (431). Aunque no se sabe a ciencia cierta, existen hipótesis que indican que esa ganancia de ROM con la vibración se debe a una mayor tolerancia al dolor $(429,430)$, un aumento del flujo sanguíneo (429) (lo que puede provocar un aumento de la temperatura muscular y se asocia a una mayor extensibilidad (424)), una disminución de la rigidez muscular (429), la relajación de los músculos estirados (429) o la inhibición autógena (el órgano tendinoso de Golgi inhibe la excitabilidad del músculo, permitiendo que las fibras musculares se estiren más allá de su límite de tolerancia y mejorando así las características viscoelásticas pasivas) $(424,429)$.

Las mejoras que provoca la vibración son aún mayores y no suponen una pérdida de fuerza explosiva cuando se utiliza de forma simultánea con los estiramientos $(424,428,429)$, aunque desaparecen si no se sigue el principio de continuidad en su aplicación (432). Sin embargo, también hay referencias que indican que la vibración mecánica no produce ganancias de flexibilidad. Así, un estudio obtiene resultados que no indican una mejora, aunque señala que la metodología empleada puede ser el motivo, y registra el momento en el que los sujetos tenían la primera sensación de estiramiento. Se esperaba, debido al efecto analgésico de la vibración, que al final del estudio la sensación de estiramiento se percibiese más tarde, pero no fue así (430). 
Otro medio utilizado con frecuencia para aumentar el ROM es la Facilitación Neuromuscular Propioceptiva (FNP). Una de las técnicas más utilizadas, efectivas y seguras dentro de la FNP es el "Contract Relax" (CR) (433), que consiste en realizar una breve contracción isométrica del músculo que se trabaja mientras se mantiene en una posición estirada; una vez termina la contracción el estiramiento continúa o, incluso, puede ir más allá (434). Se ha demostrado que la contracción submáxima es tan efectiva como la máxima (433).

Este tipo de estiramiento produce mayores ganancias de ROM que el estiramiento estático, ya que genera una respuesta adaptativa mayor que conlleva una disminución no sólo de la rigidez muscular (como el estiramiento estático) sino también tendinosa (435). Esos cambios podrían perjudicar la capacidad del jugador de responder ante perturbaciones o un entorno inestable. No obstante, la aplicación de CR sobre la musculatura abductora y aductora de la cadera (recordemos el acortamiento del jugador) no tiene un efecto negativo sobre el equilibrio dinámico (433). Sin embargo, la hipótesis de la rigidez muscular parece haber sido refutada, y un meta-análisis arroja evidencia de que es la mayor tolerancia al dolor (y no la rigidez muscular) la que posibilita que la FNP tenga esas ganancias en el ROM (436).

Parece ser que 6 segundos de contracción isométrica seguidos de 4 segundos de relajación aplicados durante 20 segundos y 3 veces de forma alternativa para ambas extremidades es el tiempo mínimo para la aplicación del estiramiento CR (435). Además, según una revisión sistemática, los efectos que se consiguen con la CR no duran más de 24 horas, por lo que recomiendan su aplicación, al menos, 1 vez por semana para mantener las ganancias y de forma rutinaria si se quieren conseguir mejoras (437).

La principal dificultad para su aplicación es que suele ser necesaria la ayuda de otra persona (436), con frecuencia generan dolor y pueden inducir daño muscular, aunque estos problemas pueden reducirse si se aplica la "Contract-Relax Technique" (438).

Sin embargo, los resultados aquí tampoco están claros. Existen estudios que indican una reducción en la fuerza al comparar el CR con el estiramiento estático (434) (aunque el tiempo dedicado a isometría puede haber generado una fatiga previa en este estudio), o en el rendimiento en un Test de Salto Vertical (439). Otros, por su parte, indican que la inhibición autógena no se produciría, y que la contracción previa supone sólo una "distracción" y la mejora en el ROM se produce debido a una mayor intensidad en el estiramiento (436).

Por último, como medio para mejorar el ROM de nuestro jugador podemos utilizar el Flossing. La restricción del flujo sanguíneo (RFS) es una estrategia muy reciente que se usa con dos finalidades distintas: 1) para promover la hipertrofia muscular y 2) para aumentar el ROM articular, que es el que nos interesa en este apartado.

En relación a la ganancia de hipertrofia, una revisión sistemática con metaanálisis (440) concluye que el entrenamiento con RFS, también denominado Kaatsu (441), es un medio ideal para conseguir un aumento tanto en la fuerza muscular como en el tamaño de la estructura. Sobre la extremidad a trabajar se coloca un manguito o correa que se infla hasta alcanzar una presión que ocluya el retorno venoso del músculo pero mantenga el flujo de sangre arterial hacia el músculo activo (441). Es especialmente interesante su aplicación en poblaciones que no pueden trabajar con grandes pesos como son los ancianos (previniendo la sarcopenia) o en la recuperación de lesiones $(442,443)$, o un complemento ideal para atletas entrenados y con experiencia que requieran mayores adaptaciones (444). Se realiza un trabajo de baja intensidad $(20-30 \%$ de $1 \mathrm{RM})$ y en torno a 75 repeticiones organizadas en 4 series mientras se produce la oclusión $(445,446)$ y se obtienen resultados similares al entrenamiento tradicional de alta intensidad (70 - 80\% de $1 \mathrm{RM})$ (447), especialmente si se realiza un trabajo concéntrico, debido a la mejora del metabolismo de las proteínas musculares (445). Sin embargo, parece ser que la activación muscular es mayor en el ejercicio tradicional (448).

En cualquier caso, los datos sobre las adaptaciones neuromusculares del entrenamiento con RFS son muy limitados y no se han explicado por completo (448). Es importante saber que dispositivos de restricción más anchos provocan una menor presión sobre las estructuras blandas que los estrechos (442) y un volumen más alto de series o repeticiones no implica mejores resultados (446) pero sí aumenta el esfuerzo percibido, la incomodidad y el DOMS (449). No obstante parece ser que la adaptación está asociada a la intensidad, es decir, que trabajar al $30 \%$ de $1 \mathrm{RM}$ provoca mayores beneficios que hacerlo al $20 \%(440)$. 
En segundo lugar, la compresión de los tejidos y la oclusión vascular puede utilizarse para obtener un aumento en el ROM. En este caso, la literatura presenta muchas más contradicciones que en el anterior, pues no hay consenso sobre si, con la aplicación de bandas elásticas para comprimir los tejidos, se pueda obtener dicho beneficio, posiblemente debido a que la banda no cubre eficientemente todos los grupos musculares o a la falta de protocolos (450). Así, podemos encontrar referencias en las que se obtiene una mejora en el ROM de dorsiflexión de tobillo y en el salto con una sola pierna (451), que podrían mantenerse hasta 45 minutos después de realizar el trabajo (452) y otras en las que no se observa mejora en el rango de movimiento del codo en tenistas (450) o que indican que son mínimas en deportistas entrenados (453).

Los mecanismos fisiológicos que provoca el flossing no parecen estar demasiado claros. No obstante, tras retirar las bandas se produce una reperfusión de sangre a la zona y una alteración hormonal, concretamente un aumento de la hormona del crecimiento y la noradrenalina, que podrían explicar las mejoras en el rendimiento en salto o sprint (454); mientras que las alteraciones fasciales y una mayor lubricación tras la reperfusión sanguínea podrían ser los mecanismos que provoquen un aumento en el ROM (452), además del efecto placebo, que puede aumentar la adherencia de un sujeto si cree que la intervención será efectiva (455).

Como vemos, la evidencia de la eficacia de este medio es limitada y contradictoria en la literatura, sin embargo, no se encuentran efectos negativos en su utilización ni requiere excesivo tiempo para aplicarlo. Además, se trata de un material que no es costoso, por lo que su utilización podría quedar justificada.

\subsection{Justificación del Trabajo del Complejo Articular del Hombro.}

Está ampliamente demostrado en la literatura que los estiramientos son efectivos para abordar el déficit de flexibilidad en los tejidos blandos y minimizar el DRIG, concretamente en la cápsula posterior $(72,326,330,331,333,456)$ y pectoral menor $(340)$.

Dos son los estiramientos que se pueden encontrar en la literatura para la cápsula posterior: el sleeper stretcher $(325,326,457)$ y el cross body stretch $(458,459)$. El primero de ellos, al realizarse en decúbito lateral, permite la estabilización de la escápula contra la colchoneta, aislando mejor la articulación glenohumeral posterior (457). Sin embargo, un estudio que los compara concluye que el cross body stretch es más efectivo (458), aunque con una muestra demasiado pequeña. En nuestro programa de intervención utilizaremos ambos.

Además de los estiramientos para aumentar el ROM, es importante incluir ejercicios para fortalecer la musculatura encargada de la rotación externa (recordemos la descompensación en relación a los rotadores internos) y para el control escapular $(72,333,334,339)$, así como ejercicios para fortalecer serrato anterior y trapecio medio e inferior y disminuir la activación del trapecio superior (460). En estos ejercicios es importante tener en cuenta que el espacio subacromial es muy pequeño (apenas $1 \mathrm{~cm}$ de altura) y alberga el tendón del supraespinoso, el largo del bíceps y la cabeza subacromial. Debemos buscar ejercicios que no reduzcan ese espacio, es decir, que mantengan el techo de esa cavidad lo más alejado posible, para evitar choques entre estructuras y no comprometer la articulación (76).

\subsection{Justificación del Control de la Carga de Entrenamiento.}

Para optimizar el entrenamiento es necesario aplicar cargas de trabajo lo suficientemente altas para mejorar el rendimiento pero no tanto como para provocar lesiones (301). Tener un nivel alto de condición física puede ayudar al deportista a adaptarse a situaciones adversas y protegerlo ante lesiones (461-463), ya que, al limitar la fatiga, los jugadores pueden responder más rápidamente ante movimientos imprevistos propios del juego (151), por lo que, si existe una relación entre las altas cargas de entrenamiento y las lesiones, el problema no es el entrenamiento en sí mismo, sino una inadecuada prescripción de trabajo (461).

En este sentido, se ha reportado que cuando la variación de carga semanal es constante (entre un $5 \%$ menos y un $10 \%$ más que la semana anterior), el riesgo de lesión es inferior al 10\%, mientras que cuando la carga se incrementa más del $15 \%$ con respecto a la semana anterior, el riesgo aumenta entre un $21 \%$ y un $49 \%$ (461). Por lo tanto, para minimizar el riesgo de lesión en profesionales se debe limitar el 
aumento de carga semanal a un $10 \%$ como máximo (461). En otras palabras, la relación carga aguda:crónica debe encontrarse entre 0,8 y 1,3 , lo que se conoce como "punto dulce" del entrenamiento, en el que la probabilidad de lesiones sin contacto es menor (461) tal y como puede verse en la figura 48.

Existe evidencia de que la exposición a cargas bajas no sólo no protege de lesiones sino que pone al jugador en riesgo. Del mismo modo, la aplicación crónica y progresiva de grandes cargas de entrenamiento en cuanto a distancia recorrida y, especialmente, carreras de alta intensidad y aceleraciones, puede contribuir a una reducción en las lesiones sin contacto (464).

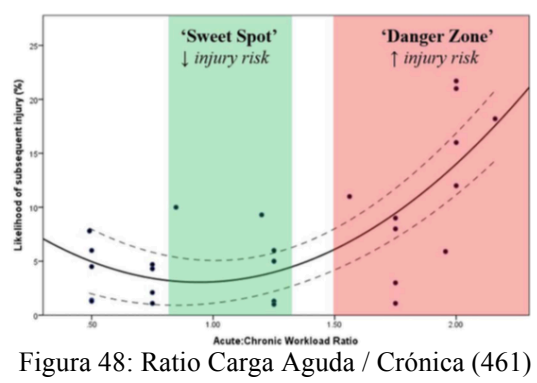

Por lo tanto será necesario controlar la carga de entrenamiento y, para ello, utilizaremos el concepto de ratio carga aguda:crónica, donde la carga aguda se refiere a la carga de la semana más reciente y la carga crónica a la media de las 4 últimas semanas (301), y buscaremos elevar la carga de entrenamiento de forma gradual (menos de un 10\%) para superar las demandas de fatiga aguda (301). Como carga externa se suele utilizar un Sistema de Posicionamiento Global (GPS), que determinará "en tiempo real" no sólo la velocidad y aceleración, sino acciones específicas como saltos (465), aunque en nuestro caso ha sido imposible acceder a esa herramienta.

Para la carga interna se va a utilizar la escala de esfuerzo percibido (RPE) (466), que es una medida sencilla y validada para la intensidad del esfuerzo $(465,467)$. La principal desventaja de esta herramienta es que no distingue entre sesiones cortas y muy intensas y otras largas de baja intensidad (302), sin embargo se acepta la limitación y se reconoce la importancia del contexto y la experiencia del profesional para interpretar los datos (300). Otra desventaja es que el jugador puede falsear los resultados (468), no obstante se trata de una persona acostumbrada a trabajar con RPE, además se ha prestado voluntario para un programa preventivo, por lo que no tiene demasiado sentido que se "equivoque" intencionadamente. Aún así, se le explicará la importancia de esta herramienta.

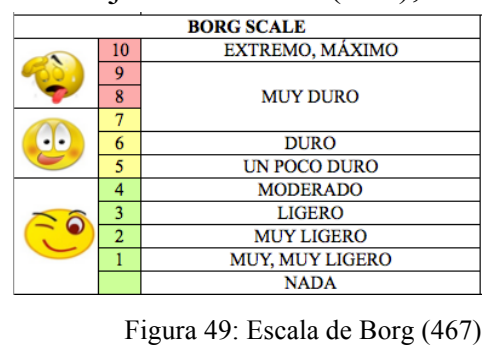

Así, 30 minutos después de finalizar cada sesión el jugador debe proporcionar una calificación de 1 a 10 sobre la intensidad de dicha sesión. El resultado se multiplicará por los minutos de entrenamiento o partido para calcular las "unidades arbitrarias" que indicarán la carga de entrenamiento (469). La carga de trabajo de cada semana se calcula sumando las cargas de cada sesión de entrenamiento y partido de esa semana (300).

Además, para asegurar un retorno al juego lo más seguro posible (en caso de lesión), también es importante conocer la cantidad de acciones que realiza el sujeto durante los entrenamientos o partidos y que pueden llegar a ser lesivas (no de forma aislada, pero sí por repetición), como pueden ser saques de puerta / despejes con el pie o caídas (461). Para ello sería interesante llevar un registro del número de acciones de este tipo que se realizan y esto serviría para 1) no elevar la cantidad de acciones por encima del $10 \%$ mientras el sujeto entrena y 2) tener una referencia de lo que el jugador realiza, en condiciones normales, en entrenamientos y partidos para prescribir la carga durante el proceso de recuperación minimizando el riesgo de lesión. Sin embargo, tampoco fue posible obtener estos datos.

Cuando aparece una lesión, la carga de trabajo a la que se expone el jugador se detiene bruscamente y, si se produce un aumento demasiado pronunciado durante el proceso de recuperación, el riesgo de lesión aumenta considerablemente (301). Para asegurarnos que la progresión y la cantidad de entrenamiento es óptima si el jugador estuviese lesionado, la relación carga aguda:crónica también debe incluirse en la rehabilitación del jugador (470).

\subsection{Justificación de la utilización de Medios de Recuperación}

Nuestro sujeto puede llegar a entrenar con 3 equipos distintos en una semana, lo que puede suponer una gran fatiga mental, física y psicológica por la continua inestabilidad. La fatiga que aparece tras un partido es multifactorial, y se relaciona con la deshidratación, el vaciado de glucógeno, el daño muscular inducido por el ejercicio y la fatiga central $(471,472)$. La fatiga fisiológica es una mezcla de factores 
centrales (limitan el rendimiento técnico) y periféricos (limitan el rendimiento físico) (471). Por tanto, es importante mantener un equilibrio entre la aplicación de estímulos de trabajo y de recuperación para evitar una disminución en su rendimiento y permitirle entrenar y competir al máximo de su capacidad.

Para distinguir a un jugador fatigado de uno que no lo está, en los deportes de equipo se suelen utilizar marcadores, de modo que un cambio en el rendimiento de ese marcador indique la aparición de fatiga. Así, pueden utilizarse marcadores subjetivos (como el RPE y la escala Wellness), cognitivos (tiempo de reacción, precisión,...) o biológicos (CK, Lactato o amoniaco en sangre,...). Sin embargo, no hay consenso sobre si los marcadores son útiles o no para controlar la fatiga y la recuperación (471).

En nuestro caso, se vigilará continuamente el ratio carga aguda:crónica y los datos reflejados en la escala Wellness, además de preguntar diariamente al jugador a este respecto. Si detectáramos que no está recuperando correctamente y hay un mayor cansancio, podríamos optar por incluir estrategias de recuperación. Para ello es importante acudir a la literatura para ver cuáles son las más recomendadas. Es importante realizar intervenciones simples, que no interfieran en el trabajo del cuerpo técnico, además de explicar al jugador, en caso de llevarse a cabo, los beneficios de la estrategia elegida para que actúe por convicción (473).

La recuperación es un proceso bifásico a través del cual el músculo vuelve a su estado previo al ejercicio después del ejercicio (474), contrarrestando los efectos de la fatiga, tanto periférica como central (471) y previniendo la aparición de lesiones (475). Los principales medios de recuperación utilizados son:

- Contrastes: Los baños de contraste producen una vasoconstricción y vasodilatación que estimula el flujo sanguíneo, reduce la inflamación de los tejidos, favorece la eliminación de los metabolitos de deshecho y la reparación muscular (476). En el caso de lesiones, la proporción de la duración de los baños de agua caliente y fría es de 3:1 ó 4:1, con temperaturas de $37-43^{\circ} \mathrm{C}$ en agua caliente y de $12-15^{\circ} \mathrm{C}$ para la fría, con tratamientos de $20-30$ minutos repetidos 2 veces al día (476). No obstante, la evidencia sobre la eficacia de los contrastes de agua fría y caliente es contradictoria y muy limitada $(475,476)$.

- Inmersión en Agua Fría: La inmersión en agua fría disminuye la temperatura de la piel, subcutánea y muscular, provoca una vasoconstricción que disminuye la inflamación y limita el daño muscular (476). Además, también reduce la velocidad de conducción nerviosa, por lo que disminuye la sensación de dolor muscular (476). Sin embargo, existen grandes diferencias metodológicas en los estudios realizados (temperatura entre $1^{\circ}$ y $15^{\circ} \mathrm{C}$ y tiempo de exposición entre 1 y 20 minutos), lo que conlleva una falta de consenso sobre su eficacia para reducir la CK y el lactato en sangre tras un ejercicio intenso (475). No obstante, parece que es más efectiva que los contrastes o la inmersión en agua caliente en cuanto a recuperación se refiere y que esa eficacia aumenta si se realiza de forma inmediata a la finalización del ejercicio intenso (477). Además es más efectiva la inmersión del cuerpo entero que de una parte (478) y es importante que la actividad que se hace una vez se sale del agua permita la caída de temperatura, ya que los tejidos más profundos disminuirán la temperatura cuando haya cesado la inmersión (479). Como conclusión, parece una estrategia efectiva en periodos agudos de congestión, pero no se recomienda al finalizar entrenamientos para evitar que afecte negativamente los procesos de reparación y adaptación (477).

- Recuperación Activa: Es la técnica de recuperación más antigua (475). Realizar ejercicio aeróbico a una intensidad del 20-50 \% VO2 Máx (475) y durante 15 minutos permite una mayor eliminación de ácido láctico en comparación con una recuperación pasiva $(476,480)$ y será el nivel de condición física del sujeto lo que determine que se trabaje a una intensidad u otra (475). Sin embargo, la eliminación de lactato no es el mejor criterio para determinar una buena recuperación (477) y este trabajo podría disminuir las reservas de energía y retrasar la síntesis de glucosa tras ciclos de alta intensidad (476), por lo que deberían realizarse series cortas (475).

- Masaje: Se define como la "manipulación mecánica de los tejidos corporales con movimientos rítmicos y cadenciales" (475) y tiene como objetivo reducir el dolor y el edema. La diferencia en los protocolos utilizados y en la presión ejercida por los fisioterapeutas podría dificultar el establecimiento de conclusiones ampliamente aceptadas (475).

- Estiramientos: No hay evidencia que indique que los estiramientos favorezcan la recuperación después del ejercicio en el fútbol (477) o que reduzcan la DOMS tanto si se realizan antes como después del ejercicio (481). 
- Aspectos nutricionales: Realizar una ingesta de aproximadamente 1,2 gr. de carbohidratos por $\mathrm{Kg} / \mathrm{h}$ con un alto índice glucémico tras un partido permite la resíntesis máxima de los depósitos de glucógeno muscular (477). Junto con los carbohidratos es muy interesante consumir aminoácidos esenciales, que estimulen la síntesis proteica. El mejor momento para realizar la ingesta es en las 2 horas siguientes a la finalización del ejercicio, debido a una mayor actividad de las enzimas asociadas a la síntesis de glucógeno (480).

- Rehidratación: Cuando se pierde agua, a través del sudor, equivalente a más del $1 \%$ del peso corporal el rendimiento disminuye. Por este motivo es importante comenzar la competición bien hidratado. Sin embargo, durante un partido se pierde más líquido del que se ingiere, y es importante beber agua con electrolitos, especialmente sodio (480).

- Estilo de vida: Para facilitar la recuperación es importante evitar el consumo de alcohol y cuidar la cantidad y calidad del sueño (480). El sueño, aspecto clave para la fatiga mental, paga el coste neural y metabólico de la vigilia por lo que, un sueño alterado (bien por acostarse tarde o por un partido nocturno) tiene muchos efectos negativos (477). Para facilitar el sueño es importante evitar el alcohol, la cafeína y la hiperhidratación además de utilizar ambientes tranquilos y oscuros para descansar, con música relajante,... así como echarse una siesta después de comer (477).

Además de lo anteriormente comentado, el jugador realiza bastantes kilómetros sentado cuando tiene que jugar fuera de casa y podría aparecer una fatiga asociada a los viajes, que conlleva unos trastornos fisiológicos entre los que destaca el "edema periférico" (482), relacionado con una acumulación de líquido en las piernas. Esta sintomatología podría reducirse utilizando medias de compresión de baja presión (473), sin embargo podrían resultar molestas para dormir.

En conclusión, aún no hay consenso sobre cuál es la mejor estrategia para acelerar la recuperación, aunque esto no quiere decir que no sean efectivas. Sin embargo, la mayoría de los estudios se han hecho con sujetos desentrenados, por lo que no pueden aplicarse a un futbolista de alto nivel.

\subsection{Justificación de la Liberación Miofascial.}

La liberación miofascial se refiere a una gran variedad de técnicas de terapia manual en las que se aplica presión sobre el músculo y la fascia (483). La autoliberación miofascial es un tipo de liberación miofascial en la que el propio sujeto se realiza el masaje a través de un foam roller o un palo de automasaje (484). La fascia, por su parte, es un tejido fibroso colagenoso que conecta huesos, músculos, órganos y fibras nerviosas y transmite la tensión generada en la contracción muscular a otras regiones del cuerpo $(485,486)$.

La liberación miofascial, bien con foam roller o con palo de automasaje, puede provocar un aumento en la ROM (487), aunque su efecto parece estar limitado a 10 minutos (484), por ello puede ser una técnica útil antes del ejercicio (488). En este sentido, se han encontrado ganancias después del uso del foam roller en el ROM de dorsiflexión de tobillo (486) y de flexión de cadera $(486,489)$, por lo que se recomienda en sujetos con menos de $90^{\circ}$ de ROM de isquiosurales tras un estiramiento estático (489). Además, el aumento de la ROM es mayor si se combina con un movimiento activo de la articulación que se esté masajeando, ya que una actividad muscular agonística puede modular la actividad del músculo antagonista a través de la inhibición recíproca y otras vías neurales (490).

También mejora la eficiencia neuromuscular, la actividad muscular y disminuye las DOMS al reducir las adherencias entre las capas de la fascia, cambiando su propiedad tixotrópica o aumentando la temperatura (491). El ejercicio intenso es necesario para aumentar el rendimiento pero puede generar DOMS (y ya vimos que el trabajo excéntrico también podía provocarlo), lo cual reduce el ROM (492). Las adherencias fibrosas se forman cuando aparecen adherencias fasciales como respuesta a una lesión, enfermedad, inactividad o inflamación. Son dolorosas, disminuyen la extensibilidad de los tejidos blandos y alteran la mecánica muscular normal (488). Por todo ello la liberación miofascial se puede utilizar para la recuperación tras el entrenamiento (491). Además, no parece tener efectos negativos en el rendimiento (484) salvo cuando se realiza entre series en un trabajo de fuerza máxima (493).

Si comparamos un rodillo liso con uno de tejido profundo (que contiene nódulos semiflexibles similares a los pulgares de un fisioterapeuta), encontramos un artículo que indica que el rodillo multinivel (con nódulos), permite aplicar la misma presión sobre una superficie menor, por lo que produce mayores 
beneficios (494), mientras que otro no encuentra diferencia ya que ambos (rodillo liso y con nódulos) obtienen ganancias similares de ROM (495). Los autores indican que la naturaleza agresiva de este tipo de foam roller produce incomodidad y dolor, y como es el propio sujeto el que regula la presión que ejerce sobre el tejido, puede haberse reducido para evitar esa sensación, por lo que puede no haberse obtenido el beneficio completo (495).

En una revisión se concluye que el masajeador de rodillo es más efectivo que el foam roller en cuanto a aumentos de flexibilidad de isquiosural se refiere. Además se indica que es más efectivo si se aplica por un fisioterapeuta cualificado que por el propio sujeto (496).

La vibración es otro método muy popular en la última década (497) que puede aumentar el ROM y aliviar el dolor muscular después de realizar un ejercicio excéntrico (498). En un estudio se comparó el efecto de $3 \times 20$ segundos de foam roller y un foam roller con vibración a $49 \mathrm{~Hz}$, (la frecuencia ideal es de $20 \mathrm{~Hz}$ a $50 \mathrm{~Hz}(499)$ ) con un grupo control sobre la dorsiflexión de tobillo, y se concluyó que ambos grupos aumentaron el ROM de dorsiflexión en la extremidad tratada y la contralateral (efecto cruzado), no así el grupo control. Los mismos resultados se obtuvieron en el ROM de rodilla entre un grupo con rodillo sin vibración ( 2 minutos) y otro con rodillo con vibración, y se observó que éste último aumentaba la tolerancia de los sujetos al dolor en mayor medida que el rodillo sin vibración (500). Además, otro estudio encontró mayores ganancias en el ROM de isquiosurales tras 10 minutos de rodillo con vibración a $32 \mathrm{~Hz}$ que en rodillo sin vibración (501).

\subsection{Justificación del Control del dolor y otras variables subjetivas.}

Para evaluar la recuperación psicosocial y el estado de estrés del jugador suele utilizarse la versión holandesa del Cuestionario de estrés de recuperación (RESTQ-Sport), que consta de 12 escalas generales ( 7 de estrés y 5 recuperación) y 7 específicas del deporte (3 de estrés y 4 de recuperación), con 4 preguntas por escala y 1 pregunta de preparación (214), lo que permite clasificar los puntajes en estrés general y específico y recuperación general y específica del deporte. Los puntajes altos en las escalas de estrés reflejan una frecuencia de actividades de estrés, mientras que puntajes altos en escalas de recuperación muestran una alta frecuencia de actividades de recuperación (214). Esta escala tiene suficiente confiabilidad y validez para ser utilizada en la práctica deportiva (502).

Aunque no es el único, el dolor puede ser considerado como el síntoma principal de las lesiones por uso excesivo (210), además puede reducir el rendimiento del jugador y afectar a su confianza, su tiempo de juego o su proyección. En este sentido es interesante observar la evolución de éste a lo largo de las semanas de entrenamiento, sin embargo los instrumentos de puntuación se han creado para pacientes no atléticos y su uso no necesariamente se puede extender a la prevención de lesiones en deportistas (210). Por tanto, crearemos un cuestionario muy simple que deberá rellenar diariamente el jugador y nos permita obtener la información que necesitamos.

Por último, es necesario controlar el bienestar del jugador en el alto rendimiento (503). En este sentido los cuestionarios psicológicos proporcionan una herramienta de monitoreo simple y rentable que debe implementarse regularmente durante la temporada (504), por lo que se utilizará un cuestionario de bienestar en el que se buscará conocer el nivel de fatiga, calidad de sueño, dolor muscular, nivel de estrés y estado de ánimo antes de comenzar cualquier entrenamiento o partido (504).

\begin{tabular}{|c|c|c|c|c|c|}
\hline \multicolumn{6}{|c|}{ WELLNESS SCALE } \\
\hline & 1 & 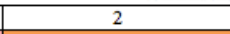 & . & 4 & 5 \\
\hline FATIGA & Siempre Cansado & Más Cansado de lo Normal & Normal & Fresco & Muy fresco \\
\hline CALIDAD SUEÑo & Insonmino & Sueño Alterado & Dificultad para Dormir & Buena & Muy Descanado \\
\hline DOLOR MUSCULAR & Muy Dolorido & Aumento del Dolor & Normal & Buena Senación & Senación Excelente \\
\hline NIVEL DE ESTRÉS & Muy Estreado & Sensación de Estrés & Normal & Relajado & Muy Relajado \\
\hline ESTADO DE ÁNIMO & Muy Molesto, Irritable & $\begin{array}{c}\text { Irritado con compañeros } \\
\text { equipo, amigos o familiares }\end{array}$ & $\begin{array}{l}\text { Menos Sociable que de } \\
\text { Costumbre }\end{array}$ & Buen Estado de Ánimo & Muy Positivo \\
\hline
\end{tabular}

Figura 50: Escala Wellness (504)

\subsection{Justificación de la Readaptación de la Lesión de Recto Anterior.}

Los principios para el tratamiento de las lesiones musculares no tienen un soporte científico debidamente justificado, ya que la gravedad de las lesiones es muy diferente y se producen en distinta musculatura (345). En fase aguda se debe aplicar el protocolo RICE (Reposo - Hielo - Compresión - 
Elevación) (342,345). El reposo impedirá la retracción de los extremos de las miofibras desgarradas y reducirá el tamaño del hematoma y la cicatriz; El hielo disminuye la inflamación, el sangrado y acelera la regeneración temprana; La compresión reduce el flujo sanguíneo intramuscular a la zona de lesión; La elevación disminuirá la presión hidrostática y la acumulación de líquido intersticial. En este momento se recomienda inmovilizar la zona y, en caso de lesión grave, el uso de muletas (342).

A los pocos días es recomendable la movilización de la extremidad ya que produce cambios histológicos (mejor regeneración y orientación de las nuevas miofibras) y alcanzar el nivel anterior de fuerza más rápidamente. Esta movilización no debe realizarse en fase aguda para permitir que el tejido cicatricial gane fuerza para resistir las fuerzas que se apliquen sobre él $(342,345)$.

Poco a poco se irán realizando ejercicios que se basarán en $(342,345)$ :

- Trabajo Isométrico: Primero sin carga, luego carga resistida y se irá aumentando la intensidad. Es importante realizar los ejercicios dentro de los límites del dolor.

- Trabajo Isotónico: Se inicia cuando el trabajo isométrico se realiza sin dolor con cargas resistidas. Del mismo modo, primero se realizan sin carga y se va aumentando progresivamente.

- Trabajo Dinámico Isocinético: Debe iniciarse con carga mínima una vez que los ejercicios anteriores se ejecutan sin dolor. En esta fase pueden iniciarse actividades con el objetivo de aumentar el nivel cardiovascular, como la bicicleta o la carrera (345).

Los estiramientos repetidos dentro de los límites del dolor son recomendados en este momento, ya que van a distender la cicatriz durante el proceso de maduración cuando aún es "moldeable" pero tiene fuerza suficiente para evitar la retracción de los extremos de las miofibras lesionadas (342).

Existen en la literatura ejemplos de tratamiento no quirúrgico de lesiones de recto anterior (505), pero se refieren a lesiones graves, que no es el caso que nos ocupa. Sin embargo pueden servir como base para la recuperación de esta lesión pero reduciendo los tiempos de cada fase.

En cuanto al "return to play" no existe consenso sobre el momento idóneo. Normalmente se busca obtener un rendimiento óptimo con una probabilidad de recidiva mínima. Sin embargo, en los deportes de equipo, pretender una tasa de recurrencia del $0 \%$ implicaría adoptar criterios muy conservadores que dejaría a jugadores potencialmente sanos fuera de la convocatoria. Dadas las necesidades de un equipo profesional, quizás sea más interesante regresar unas semanas antes aún sabiendo que hay cierto riesgo de recaída (506). Entre los factores que pueden guiar la decisión de "return to play" encontramos (506):

\begin{tabular}{|l|l|}
\hline \multicolumn{1}{|c|}{ Factores que indican una postura conservadora } & \multicolumn{1}{c|}{ Factores que permiten un rápido Return to Play } \\
\hline Persistencia de déficit de fuerza & Fuerza equivalente al miembro contralateral \\
\hline Persistencia de déficit de flexibilidad & Flexibilidad equivalente al miembro contralateral \\
\hline No completa entrenamiento sin dolor & Posibilidad de realizar cualquier entrenamiento \\
\hline Señal en imagen anormal & Imagen de ultrasonido y/o de resonancia normal \\
\hline Jugador mayor & Jugador joven pero con experiencia en lesiones \\
\hline Momento temprano de la temporada & Playoff o partido de vital importancia \\
\hline Desgarro en localización de alto riesgo & Desgarro en localización de bajo riesgo \\
\hline \multicolumn{2}{|l|}{ Tabla 51: Factores que orientan la decisión de "return to play" (506) }
\end{tabular}

Además de esto, para asegurar una vuelta a la competición segura, es necesario prestar atención a otros grupos musculares que, por el tiempo de inactividad, hayan podido sufrir un déficit de fuerza y/o flexibilidad. Así, será importante realizar un trabajo excéntrico de la musculatura isquiosural y controlar el ratio ADD:ABD (recordemos que ya se está incidiendo en la disminución de la rigidez muscular), además de un fortalecimiento de Core que ya se viene realizando con anterioridad.

En este sentido, se realizará un trabajo excéntrico que buscará, de forma progresiva, aumentar la velocidad de ejecución, el rango de movimiento y asemejarse a la realidad competitiva. 


\title{
6-. PROGRAMA DE INTERVENCIÓN
}

\author{
"No basta con alcanzar la sabiduría, es necesario saber utilizarla” \\ Cicerón, filósofo y escritor romano (106 AC - 43 AC)
}

\subsection{Secuenciación de las Fases de Entrenamiento del programa de intervención}

Tal y como se acordó en la entrevista inicial el principal objetivo de este programa de intervención es prevenir lesiones. Para ello, en primer lugar se realizó una profunda revisión bibliográfica para ver cuáles eran las lesiones más prevalentes en nuestro deporte; a continuación se analizaron los mecanismos en los que se producían esas lesiones y cuáles eran los principales factores de riesgo; posteriormente se volvió a acudir a la literatura para ver cuáles eran los test más fiables para medir esos factores de riesgo. De igual modo, una vez se realizó la entrevista inicial, la búsqueda se completó con aspectos relacionados con el dolor lumbar y de hombro.

Con todo eso se planteó una valoración bastante extensa, que pudiese atender a los principales factores de riesgo de las lesiones más frecuentes en fútbol así como las molestias que refería nuestro sujeto (he de recordar que no ha sufrido lesiones previas salvo una tendinosis rotuliana de la que está completamente recuperado).

Tras realizar la evaluación inicial encontramos que había varios parámetros alejados de los valores de referencia, por lo que se decidió dividir el programa de intervención en 2 fases. La primera de ellas de "normalización", con el objetivo de corregir los déficits encontrados a distintos niveles (ROM, fuerza, propiocepción, alteraciones de movimiento,...). Me gustaría destacar que no se secuenciaron los objetivos durante esta primera fase y se buscó abordarlos todos desde el principio, ya que se trabajaron contenidos que no se afectaban negativamente entre sí y mi intención fue optimizar el tiempo de entrenamiento lo máximo posible. Los contenidos empleados para normalizar las carencias del futbolista fueron estiramientos y fortalecimiento de la musculatura débil en el caso del complejo articular del hombro, trabajo propioceptivo para la prevención de esguinces de tobillo y rodilla, disociación lumbopélvica para la mejora del control motor, fortalecimiento del Core, activación de la musculatura glútea, aprendizaje de los patrones de movimiento y flexibilidad muscular a través de la vibración mecánica y la FNP. La progresión en los contenidos se realizó buscando una mayor intensidad, velocidad o complejidad, siempre sin perder de vista la correcta ejecución (en el apartado 6.2.2 y 6.3.2 se puede ver más detalladamente cómo se progresa en cada contenido).

El trabajo preventivo no puede quedarse únicamente en acercarnos a un valor de referencia de forma analítica, es necesario presentar un escenario en el que aparezcan multitud de estímulos para que el jugador pueda actuar en consecuencia del modo más seguro y eficaz. Es por esto que, en principio, el objetivo principal de la segunda fase era, una vez corregidos todos los déficit y asimilados los patrones correctos de movimiento, exponer al jugador a situaciones similares a las que podía encontrarse en competición para ofrecerle experiencias que le sirviesen para prevenir lesiones. Sin embargo, esta fase estuvo marcada por la lesión que apareció justo el último día de la primera fase. La readaptación de la lesión se iba a llevar a cabo por los fisios y readaptador del club y el jugador pasó a entrenar lunes, miércoles y viernes (readaptación de su lesión) y martes y jueves (trabajo de fuerza en gimnasio), por lo que no tenía sentido que yo entrase a trabajar en esa lesión. Mi actuación durante ese tiempo se limitó a incidir en aquéllos aspectos que podían disminuir el riesgo de lesión y no interferir en el proceso de readaptación y, una vez se tuvo el alta competitiva, a disminuir la probabilidad de recidiva y mejorar los niveles de fuerza mediante un trabajo global. La progresión en los contenidos en esta segunda fase se realizó utilizando otro tipo de material, implicando más segmentos corporales en la ejecución, aumentando la velocidad y variando la ejecución en todo momento.

El programa de intervención tuvo una duración de 12 semanas (desde el 26 de Agosto hasta el 17 de Noviembre) y se realizaron 2 sesiones semanales. Como ya se explicó anteriormente las sesiones no fueron fijas en cada semana, pues dependían de la planificación del equipo del jugador.

Es necesario señalar que se ha intentado mantener un contacto continuo y fluido con los miembros del cuerpo técnico, por un lado con los fisioterapeutas durante la valoración y cuando ha ocurrido alguna situación especial (por ejemplo cuando en la tercera semana de entrenamiento el jugador tuvo una 
compresión del compartimento externo de la rodilla como consecuencia de una caída durante su entrenamiento específico de porteros o durante la lesión de recto anterior) para ver el estado y la evolución del jugador; y, por otro, con el preparador físico, para ver cuándo se ubicaban mis sesiones de entrenamiento cada semana (se decidió que lunes y miércoles si el jugador no competía el domingo y miércoles y viernes si jugaba el partido de liga), para conocer el trabajo que había realizado durante sus sesiones y no sobrecargar al jugador y para obtener la cuantificación de la carga de los entrenamientos del futbolista con el equipo, ya que todo esto afecta directamente a mi planificación con el sujeto.

Para poder ver con total claridad el trabajo que ha realizado el jugador durante el programa de intervención se presenta un calendario, a modo de línea temporal, que ilustra tanto la actividad que realizó con su equipo como la que llevó a cabo conmigo, ya que ambas están íntimamente ligadas.
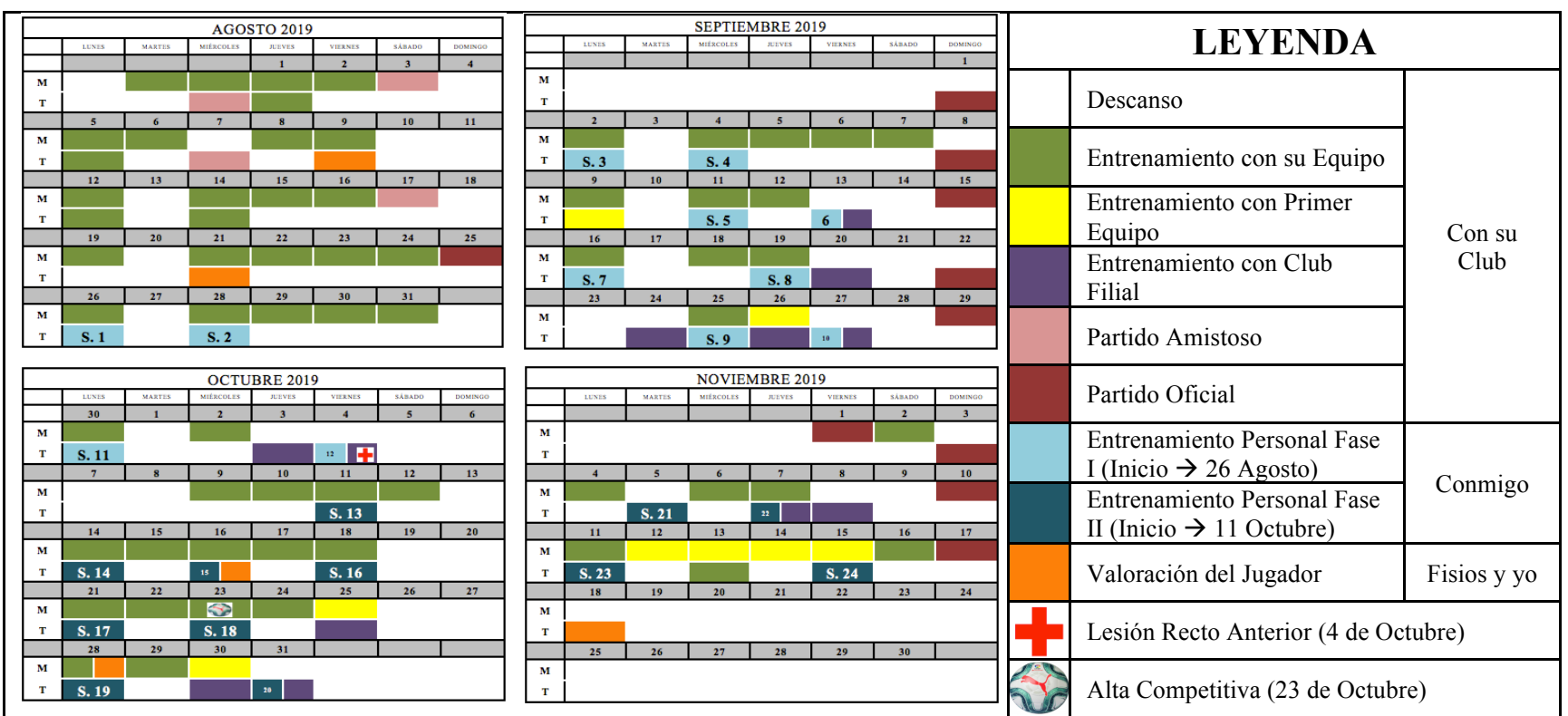

Figura 51: Calendario de Entrenamientos del Jugador

\subsection{Fase I del Programa de Intervención}

\subsubsection{Objetivos Específicos}

\begin{tabular}{|c|c|c|c|}
\hline OBJ. GEN & OBJ. PRINCIPAL & $\begin{array}{l}\text { CONCRECIÓN } \\
\end{array}$ & PRIORIDAD \\
\hline \multirow{14}{*}{ 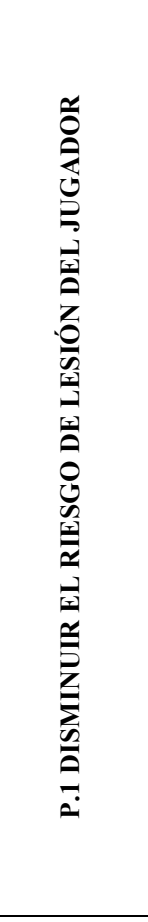 } & P.1.1.1 Aumentar los valores de rotación interna de cadera & $\begin{array}{l}\text { Acumular, al menos, } 120 \text { repeticiones semanales de movilidad de } \\
\text { cadera }\end{array}$ & 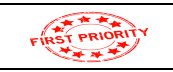 \\
\hline & P.1.1.2 Aumentar los valores de rotación externa de cadera & $\begin{array}{l}\text { Acumular, al menos, } 120 \text { repeticiones semanales de movilidad de } \\
\text { cadera }\end{array}$ & 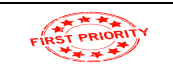 \\
\hline & P.1.1.3 Aumentar los valores de abducción de cadera & $\begin{array}{l}\text { Realizar } 8 \text { series semanales de estiramiento estático con } \\
\text { vibración de la musculatura aductora de cadera }\end{array}$ & 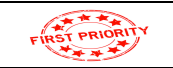 \\
\hline & $\begin{array}{llllll}\text { P.1.1.4 Aumentar los valores de rotación interna } \\
\text { glenohumeral }\end{array}$ & $\begin{array}{l}\text { Realizar entre } 4 \text { y } \\
\text { estiramientos para el aumento de la RI Glenohumeral }\end{array}$ & 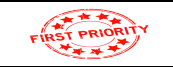 \\
\hline & P.1.1.5 Aumentar los valores de aducción de hombro & $\begin{array}{l}\text { Realizar entre } 4 \text { y } 6 \text { series semanales con flossing de } \\
\text { estiramientos para el aumento de la ADD Glenohumeral }\end{array}$ & 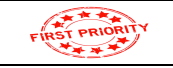 \\
\hline & P.1.2.1 Aumentar la longitud de la musculatura isquiosural & $\begin{array}{l}\text { Realizar } 8 \text { series semanales de estiramiento estático con } \\
\text { vibración de la musculatura isquiosural }\end{array}$ & (PRIORIITV \\
\hline & $\begin{array}{l}\text { P.1.2.2 Aumentar la longitud de la musculatura aductora de } \\
\text { cadera }\end{array}$ & $\begin{array}{l}\text { Realizar } 8 \text { series semanales de estiramiento estático con } \\
\text { vibración de la musculatura aductora de cadera }\end{array}$ & 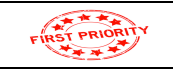 \\
\hline & P.1.3.1 Mejorar la fuerza de glúteo medio & $\begin{array}{l}\text { Activar de forma analítica el glúteo previo a un trabajo de } \\
\text { patrones de movimiento }\end{array}$ & 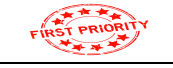 \\
\hline & $\begin{array}{l}\text { P.1.3.2 Integrar la musculatura glútea en los diferentes } \\
\text { movimientos }\end{array}$ & $\begin{array}{l}\text { Activar de forma analítica el glúteo y realizar ejercicios para } \\
\text { llevarlo a función, similares a los de competición }\end{array}$ & 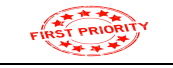 \\
\hline & $\begin{array}{l}\text { P.1.4.1 Corregir la asimetría presente entre pie izquierdo y } \\
\text { derecho }\end{array}$ & $\begin{array}{l}\text { Empezar y terminar las series de ejercicios propioceptivos con el } \\
\text { pie derecho }\end{array}$ & 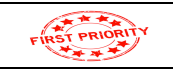 \\
\hline & $\begin{array}{l}\text { P.1.4.2 Mejorar los valores obtenidos en el test propioceptivo } \\
\text { en las } 3 \text { direcciones }\end{array}$ & $\begin{array}{l}\text { Acumular un volumen de } 30-40 \text { minutos semanales de trabajo } \\
\text { propioceptivo }\end{array}$ & (PRIORITY \\
\hline & $\begin{array}{l}\text { P.1.4.3 Mejorar la capacidad de respuesta ante estímulos que } \\
\text { provoquen perturbaciones de un estado de equilibrio }\end{array}$ & $\begin{array}{l}\text { Incluir perturbaciones variadas, de forma progresiva, en los } \\
\text { distintos ejercicios propioceptivos planteados }\end{array}$ & 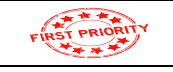 \\
\hline & $\begin{array}{l}\text { P.1.4.4 Mejorar la preactivación muscular ante situaciones } \\
\text { desconocidas (feedforward) }\end{array}$ & $\begin{array}{l}\text { Incluir perturbaciones inesperadas en los distintos ejercicios } \\
\text { propioceptivos planteados }\end{array}$ & 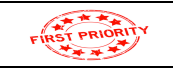 \\
\hline & $\begin{array}{l}\text { P.1.4.6 Mejorar la preactivación muscular (feedforward) } \\
\text { previa a la recepción de saltos unipodales }\end{array}$ & $\begin{array}{l}\text { Incluir estabilización tras recepciones de saltos en diversas } \\
\text { superficies, con y sin perturbaciones conocidas o no }\end{array}$ & 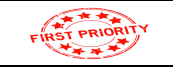 \\
\hline
\end{tabular}




\begin{tabular}{|c|c|c|c|}
\hline & P.1.5.1 Ejecutar correctamente el patrón de sentadilla & $\begin{array}{l}\text { Revisar el patrón de sentadilla y las variantes y realizar las } \\
\text { correcciones oportunas }\end{array}$ & 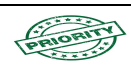 \\
\hline & $\begin{array}{l}\text { P.1.5.2 Ejecutar correctamente el patrón de peso muerto y sus } \\
\text { variantes }\end{array}$ & $\begin{array}{l}\text { Revisar el patrón de peso muerto y las variantes y realizar las } \\
\text { correcciones oportunas }\end{array}$ & Fingain \\
\hline & $\begin{array}{l}\text { P.1.5.3 Ejecutar correctamente la recepción de salto unipodal } \\
\text { / bipodal con diferentes trayectorias }\end{array}$ & $\begin{array}{l}\text { Revisar el patrón de recepción de saltos variados (perturbación, } \\
\text { uni-bipodal, diferentes trayectorias,...) }\end{array}$ & 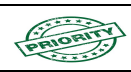 \\
\hline & $\begin{array}{l}\text { P.1.5.4 Ejecutar correctamente las tracciones horizontales y } \\
\text { verticales }\end{array}$ & $\begin{array}{l}\text { Revisar el patrón de tracción horizontal y vertical y realizar las } \\
\text { correcciones oportunas }\end{array}$ & 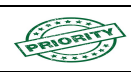 \\
\hline & $\begin{array}{l}\text { P.1.5.5 Ejecutar correctamente los empujes horizontales y } \\
\text { verticales }\end{array}$ & $\begin{array}{l}\text { Revisar el patrón de empuje vertical y horizontal y realizar las } \\
\text { correcciones oportunas }\end{array}$ & Fingin \\
\hline & P.1.5.7 Ejecutar correctamente el patrón de Hinge de cadera & $\begin{array}{l}\text { Revisar el patrón de flexión de cadera y realizar las correcciones } \\
\text { oportunas }\end{array}$ & Fingin \\
\hline & $\begin{array}{l}\text { P.1.6.1 Aprender la maniobra de "Bracing" y aplicarlo a } \\
\text { distintos ejercicios }\end{array}$ & $\begin{array}{l}\text { Progresar, en amplitud, velocidad o miembros movilizados, en } \\
\text { ejercicios mientras se pide una co-contracción del Core }\end{array}$ & \\
\hline & P.1.6.2 Aumentar la fuerza de la musculatura del Core & $\begin{array}{l}\text { Aplicar un mínimo de } 15 \text { series semanales de ejercicios para la } \\
\text { mejora de la estabilización del Core }\end{array}$ & 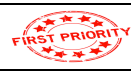 \\
\hline & $\begin{array}{l}\text { P.1.6.3 Corregir la asimetría de fuerza encontrada en el Side } \\
\text { Bridge }\end{array}$ & $\begin{array}{l}\text { Empezar y terminar las series de ejercicios anti-rotación o anti } \\
\text { flexión lateral con el lado derecho }\end{array}$ & 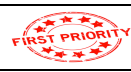 \\
\hline \multirow{3}{*}{ 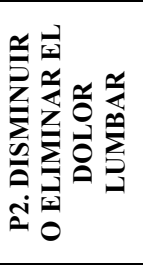 } & P.2.3 Mejorar la disociación de la región coxolumbopélvica & $\begin{array}{l}\text { Corregir la flexión lumbar en movimientos de flexión de cadera } \\
\text { en distintas posiciones (sentado, supino o bipedestación) }\end{array}$ & \\
\hline & $\begin{array}{l}\text { P.2.4 Aprender la maniobra de "Hollowing" y aplicarlo a } \\
\text { distintos ejercicios de control motor }\end{array}$ & $\begin{array}{l}\text { Progresar, en amplitud o miembros movilizados, en ejercicios } \\
\text { mientras se realiza la maniobra de Hollowing con stabilizer }\end{array}$ & 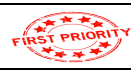 \\
\hline & $\begin{array}{l}\text { P.2.5 Concienciar al jugador de la importancia de la higiene } \\
\text { postural en su vida diaria }\end{array}$ & $\begin{array}{l}\text { Asociar acciones diarias frecuentes (mirar el móvil, conducir, } \\
\text { sentarse a comer,...) con correcciones posturales }\end{array}$ & 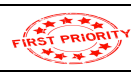 \\
\hline \multirow{4}{*}{ 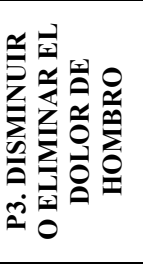 } & $\begin{array}{l}\text { P.3.1 Reeducar el patrón de activación de la musculatura } \\
\text { periescapular }\end{array}$ & $\begin{array}{l}\text { Corregir la activación previa del trapecio superior en los } \\
\text { movimientos de flexión y abducción de brazos }\end{array}$ & \\
\hline & $\begin{array}{l}\text { P.3.3 Mejorar la activación de serrato anterior y trapecio } \\
\text { medio e inferior }\end{array}$ & $\begin{array}{l}\text { Aplicar } 2 \text { estímulos suficientes por semana para activar esta } \\
\text { musculatura }\end{array}$ & 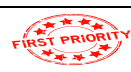 \\
\hline & $\begin{array}{l}\text { P.3.4 Aumentar la longitud del pectoral menor, especialmente } \\
\text { el derecho }\end{array}$ & $\begin{array}{l}\text { Realizar liberación miofascial y estiramientos estáticos y } \\
\text { balísticos previo a la movilidad glenohumeral }\end{array}$ & 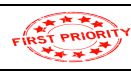 \\
\hline & P.3.5 Potenciar el manguito de rotadores & $\begin{array}{l}\text { Acumular un mínimo de } 4-6 \text { series semanales de ejercicios para } \\
\text { el fortalecimiento del manguito de rotadores externo }\end{array}$ & 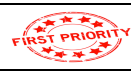 \\
\hline
\end{tabular}

\subsubsection{Metodología}

\subsubsection{Metodología empleada en los Calentamientos y la Vuelta a la Calma.}

El trabajo que vamos a realizar en las sesiones de esta primera fase tiene partes claramente diferenciadas y no es demasiado exigente, por lo que no requiere de un calentamiento como el que puede realizar el jugador previo a una sesión de campo o un partido.

Por tanto, durante estos entrenamientos no se estructurará la sesión de forma clásica (calentamiento, parte principal y vuelta a la calma), sino que, en función del tipo de trabajo que se vaya a ejecutar, se realizará un trabajo de movilidad, de liberación miofascial, de activación analítica de la musculatura inhibida (si fuese necesario),... tal y como viene desarrollado en los siguientes apartados. Cuando pasemos a otro contenido se llevará a cabo la misma operación pero orientada a ese contenido.

En cuanto a la vuelta a la calma, volveremos a utilizar el foam roller, esta vez con pasadas más lentas, sobre la musculatura que ha intervenido en la sesión. Además preguntaremos al jugador por las sensaciones que ha tenido durante el trabajo realizado.

\subsubsection{Estructura e Intensidad de la Sesión.}

Las sesiones de esta primera fase comenzarán con el trabajo del complejo articular del hombro, que no tiene conexión con otros ejercicios que podamos realizar. Posteriormente se llevará a cabo el entrenamiento propioceptivo ya que, como se indica más adelante, se recomienda al principio de la sesión 
(incidir previamente en la articulación glenohumeral no causa fatiga para el trabajo propioceptivo de tren inferior) porque, de momento, no interesa abordarlo en fatiga. Después se incidirá en la región coxolumbopélvica, con el trabajo de disociación y de fortalecimiento del Core. A continuación se corregirá la ejecución de los distintos patrones de movimiento y se finalizará con el aumento del ROM con vibración o FNP.

En cuanto a la intensidad... la cantidad de entrenamientos que realiza el jugador semanalmente dificulta la realización de un trabajo de intensidad elevada. Además no es el objetivo de esta fase ni de este trabajo. Se buscará una RPE de $4-6$ o incluso menos, en función de la planificación de entrenamientos del jugador y siempre me adaptaré a las circunstancias que se presenten cada día.

6.2.2.3 Metodología del Entrenamiento para la reeducación del patrón de activación de la musculatura periescapular.

A nivel metodológico, en el trabajo escápulo-humeral se tendrán en cuenta las orientaciones propuestas por Héctor García (76) entre las que destacamos:

- No priorizar el trabajo en el plano frontal, ya que la glenoides no está bien orientada y se anterioriza la cabeza del húmero.

- Mantener el ratio de 2 tracciones por cada acción de empuje.

- A partir de $60^{\circ}$ de abducción la presión aumenta considerablemente al cerrarse el espacio subacromial, especialmente si se acompaña de una rotación interna, donde habría presión sobre la apófisis coracoides y el ligamento coracoacromial. Lo mismo ocurre en flexión con rotación interna (aumento de la presión sobre el tendón del supraespinoso y el ligamenteo coracoacromial).

- La realización de flexión y abducción con rotación externa (agarre en ligera supinación) puede evitar el problema anterior, al aumentar el espacio subacromial y disminuir la presión sobre las estructuras.

- En los push ups los brazos deben formar un ángulo de $30-45^{\circ}$ con el cuerpo para evitar disminuir el espacio subacromial.

- En los ejercicios en los que busquemos activar trapecio medio e inferior siempre daremos prioridad a aquéllos ejercicios que, electromiográficamente, tienen una menor implicación del trapecio superior, es decir, aunque haya una participación menor de la musculatura que nos interesa, lo sacrificaremos para no alimentar más al trapecio superior. Así, dentro de la propuesta de ejercicios de Blackburn (507), le daremos especial importancia al ejercicio 6 de extensión (se corresponde con la letra I en el YTWL $+\mathrm{I}$ ). La progresión entonces sería I $\rightarrow \mathrm{L} \rightarrow$ $\mathrm{T} \rightarrow \mathrm{W} \rightarrow \mathrm{Y}$. Además, en los push up plus priorizaremos la fase "plus" para evitar la mayor activación del trapecio superior en la flexión de brazos e incluiremos ejercicios que, electromiográficamente, supongan una progresión (508).

- Previo a los ejercicios de la propuesta de Blackburn hay que realizar estiramientos balísticos de pectoral menor para evitar la inhibición recíproca de la retracción escapular.

- En el caso de las tracciones, el dorsal ancho deprime la cabeza del húmero, ampliando el espacio subacromial (lo que no ocurría en los empujes). Sin embargo, es interesante sacar el hombro del plano frontal para que la escápula oriente la glenoides hacia la cabeza del húmero.

- En los ejercicios tipo remo procurar que el codo no sobrepase la línea del cuerpo, ya que esto anteriorizaría la cabeza del húmero impidiendo la retracción escapular.

- No trabajaremos con pesos elevados ya que es el eslabón débil (trapecio medio, inferior y serrato anterior) el que va a determinar el peso del ejercicio.

- No progresaremos pensando en la carga (series, repeticiones, peso,...) sino creando desafíos motores y trabajando para integrar la postura dando libertad al resto del cuerpo.

- Como se ha argumentado, es importante trabajar el manguito de rotadores externos. Lo ideal es hacerlo con $30^{\circ}$ de flexión, $30^{\circ}$ de abducción y $30^{\circ}$ de inclinación transversal.

- En los ejercicios en supino o cuadrupedia podemos apoyar la cabeza para relajar trapecio superior, favoreciendo el trabajo de trapecio medio e inferior que será la musculatura a activar.

- Para los ejercicios de activación de trapecio medio e inferior buscaremos elevaciones de 0 $60^{\circ}$ con retracción escapular y controlando siempre la hiperextensión del hombro. 
- Atendiendo a la cinemática escapular se debe progresar de ejercicios unilaterales a bilaterales. Esto me permite, en el inicio, centrarme en un solo hombro e incluir un componente de rotación torácica que facilita el movimiento de la escápula (para la elevación máxima bilateral necesito $15^{\circ}$ de extensión torácica pero no así en movimientos unilaterales).

- Dentro de la propuesta de trabajo, es necesario atender a la extensión torácica, que realizaremos con ejercicios tumbados sobre bosu, foam, pelota,...

- Del mismo modo, también corregiremos la posición cervical ya que una posición adelantada de la cabeza impide el movimiento correcto de la escápula debido a la tensión de trapecio superior y angular del omóplato, inhibiendo así la acción del serrato anterior. Por lo que realizaremos trabajo de flexores profundos de cuello.

- En relación a esto, en cada ejercicio corregiremos la posición de la cabeza, para evitar que se protraiga, colocando la mano en la región occipital y permitiendo una correcta alineación cervical y torácica con una adecuada movilidad escapular y estabilidad glenohumeral.

- Es necesario estirar pectoral menor, ya que su acortamiento puede impedir una correcta orientación escapular.

- Por último, es importante variar los ejercicios bajo estas premisas para realizar un entrenamiento equilibrado.

Para disminuir la protracción escapular en sujetos con disquinesia escapular y acortamiento de pectoral menor, como nuestro sujeto, es muy recomendable el Dual Push Up Plus ya que se produce una activación de serrato anterior y trapecio medio e inferior al empujar la pared mientras se mantiene la longitud de elevador de la escápula y pectoral menor (509).

¿Qué consejos podemos dar al jugador cuando realice trabajo de fuerza con su equipo?

- Cuando tenga la espalda apoyada las escápulas no pueden moverse con libertad para orientar la glenoides hacia la cabeza del húmero. Realizar una retracción máxima escapular permitirá que la glenoides descienda y no se produzcan compensaciones con el húmero.

- En el agarre clásico en press de banca los $90^{\circ}$ de abducción generan presión en el espacio subacromial, por lo que un agarre ligeramente por encima de los hombros (con un ángulo de $45^{\circ}$ ) podría ser mejor para la salud de su hombro.

6.2.2.4 Metodología del Entrenamiento Propioceptivo.

A nivel metodológico, en el trabajo propioceptivo debe tenerse en cuenta (510):

- Tipos de Plataformas: Estables o desestabilizadoras.

- Puntos de Inestabilidad: Externos (punto de contacto con la superficie estable o inestable) o Internos (propios del sujeto, debidos a déficit de equilibrio o lesión).

- Puntos y ejes de inestabilidad: En plataformas como bosu, dynair,... el desequilibrio viene desde cualquier plano y eje, por lo que, en una progresión, esos elementos se incluyen al final.

- Participación global del cuerpo aunque el ejercicio vaya orientado a una articulación.

- Resistencia: Si colocamos bandas elásticas, la tensión suele organizarse por colores.

- Punto de anclaje: Variar el punto de anclaje provoca cambios en la musculatura implicada en el movimiento.

- Intensidad: Se puede modificar variando la posición del cuerpo, la velocidad de ejecución o la distancia al eje de giro.

Entre las variables que podemos utilizar para diseñar los ejercicios propioceptivos podemos encontrar (510):

- Posición: De pie, sentado o tumbado.

- Sin / con uso de superficies desestabilizadoras.

- Aumento o reducción de aferencias visuales: Frente a espejo, ojos abiertos o cerrados.

- Cambios en la base de sustentación: Dos apoyos o uno.

- Diferentes ángulos de aplicación de cargas: Aquí es necesario tener en cuenta las posiciones de alta compresión articular. Por ejemplo, en el caso de la rodilla, no es lo mismo aplicar una 
fuerza anteroposterior, que puede ser estabilizada por la musculatura, que en sentido lateral, a expensas de ligamentos.

- Uso de therabands, poleas y resistencias manuales.

- Mantener posiciones (en diferentes ángulos) o llegar a posiciones (en diferentes ángulos).

- Diferentes velocidades de ejecución y aceleraciones-desaceleraciones.

- Uso de electroestimulación o plataformas vibratorias.

La combinación de estos elementos (a los que podríamos añadir el uso de implementos y las perturbaciones) indicará la dificultad del ejercicio, que deberá adaptarse en todo momento a nuestro sujeto. Así, debemos progresar para aproximar la situación de no competición a la realidad competitiva ya que la repetición de un estímulo (con perturbación) hace que la situación de desequilibrio se reconozca más rápidamente, lo que permitirá una respuesta motriz más rápida y adaptada a las necesidades del momento, protegiendo así de una posible lesión.

Debemos plantear un trabajo estático y dinámico, tendiendo hacia lo dinámico y con mucha variedad que iremos incluyendo progresivamente (equilibrio más perturbaciones, equilibrio tras salto, tras cambio de dirección,...), es decir, acumularemos muchas experiencias motrices en cantidad y variabilidad para que los modelos de coactivación inapropiados desaparezcan y se sustituyan por patrones musculares más coordinados (511).

Es interesante incluir este tipo de ejercicios al principio de la sesión, ya que aún no hay fatiga (disminuye la capacidad de respuesta del sistema propioceptivo) y la atención y concentración será mayor. El tiempo de trabajo dependerá de los objetivos de la sesión. Ante trabajos como los realizados en la primera fase podemos mantener volúmenes de $20-25$ minutos con una frecuencia de $2-3$ veces semanales (aquí hay que tener en cuenta el trabajo que realiza el jugador con su equipo) para obtener resultados con nuestro sujeto (510). En relación a los ejercicios, es importante no empezar una serie con fatiga (a no ser que nuestro objetivo sea trabajar en fatiga). En función de la intensidad del ejercicio, la pausa puede variar de 30 segundos a 1 minuto, que aprovecharemos para ejecutar con la extremidad contralateral (510).

El jugador es bastante estable en superficie estable (valga la redundancia) y muy inestable en superficie desestabilizadora, por lo que decidí comenzar en suelo, variando aferencias visuales e incluyendo perturbaciones esperadas. Las superficies desestabilizadoras se incluyeron desde las que producen menos desequilibrio a las más exigentes, variando las posiciones corporales, con diferentes aferencias visuales, con gomas ancladas a diferentes alturas y con implementos como pelotas de tenis o de fútbol que suponían una perturbación esperada. A medida que avanzaba la fase se procuró que el jugador dejase de centrar su atención únicamente en estabilizar y realizara otras acciones, además se fueron incluyendo perturbaciones no esperadas, jugando con distintas superficies perturbadoras y desequilibrios desde múltiples planos,... preparando así la fase 2 (ver punto 6.3.2.4).

\subsubsection{Metodología del Trabajo de la Región Coxolumbopélvica.}

Cuando intentamos estabilizar la columna vertebral, ningún músculo del Core domina sobre el resto, por lo que no tiene sentido intentar actuar sobre un único músculo y sí incluir ejercicios que impliquen varios a la vez (512). Así, en primer lugar atenderemos al entrenamiento de la Unidad Interior (musculatura profunda y tónica de la región lumbopélvica) ya que su función principal es la estabilidad segmentaria de la columna vertebral, aprendiendo la maniobra de "Bracing", para ello (147):

- Lo realizaremos en posición supina, con variantes, en cuadrupedia y terminaremos en bipedestación.

- Le colocamos las manos en zona lumbar para que él note si hay movimiento de flexión al realizar el bracing. También se puede poner un stabilizer a $40 \mathrm{~mm}$ de $\mathrm{Hg}$ y trabajar a velocidad progresiva, colocar dedos en el abdomen para que los saque pero sin inflar el recto anterior, lo que indicaría mala activación del transverso... Lo mismo se haría en oblicuos,...

- Es importante soltar el aire de golpe, no progresivamente, y mantener la activación. Durante la fase de reposo (flow) hay relajación absoluta.

- Cuando hay problemas de activación la velocidad es lenta. Si la repetición no es correcta no dejo que termine la ejecución. Los ojos cerrados para concentrarse al máximo en la tarea. 
- A medida que el concepto se aprende empiezo a incluir movilización de segmentos corporales (una pierna, otra, ambas, un brazo, otro, ambos, brazo y pierna contraria,...). Es importante la variabilidad una vez más.

- A medida que realiza el ejercicio se puede golpear el abdomen del jugador, para garantizar la activación.

- Cuando domina el ejercicio se incluye la alta velocidad, pasando, por ejemplo, de flow con rodillas apoyadas a plancha frontal o lateral con bracing en el mínimo tiempo posible.

- Se realizan 3 - 5 series cortas, de 3 - 4 segundos de isometría.

Otro aspecto que debemos atender es la Disociación Lumbopélvica. En este sentido la articulación coxofemoral debe ser el segmento móvil mientras que la columna lumbar debe mantener un efectivo control del movimiento (estabilidad). La pérdida de movimiento se produce en la zona débil, lo cual puede suceder por debilidad o por falta de ROM. Para este trabajo se realizarán ejercicios muy variados (tumbados supino movilizando extremidades desde cadera en posición neutra, con flexión de cadera, ejercicios de abducción /aducción o flexo / extensión, Bird Dog en supino,... en cuadrupedia mediante Rocking Backward, Bird Dog,... sentado el Knee Extender,... de pie un Hinge de cadera, posición de tándem,...) En los descansos se introducirá trabajo para la zona desactivada (por ejemplo, trabajo de extensores si en sentadilla realiza flexión lumbar) (147).

Una vez que se realicen adecuadamente este tipo de trabajos en distintas posiciones corporales, dominantes de cadera y rodilla y ante distintos movimientos de extremidades, se incluirán gomas y poleas para seguir realizando los ejercicios pero con una mayor dificultad.

A medida que el jugador vaya asimilando estas pautas metodológicas (bracing y disociación lumbopélvica) se realizará un entrenamiento global de carácter isométrico buscando los fenómenos de cocontracción, esto es, movimientos antiflexión, antiextensión y antirotacionales. Las series serán cortas, de 3 - 5 segundos en los que se pedirá un buen bracing y una co-contracción. El número de repeticiones será aquel que impida una pérdida de control del movimiento. La variabilidad en cuanto a ejercicios, material a utilizar (trx, fitball, gomas, polea, aerosling,...) y dirección de la fuerza (frontal, diagonal arriba, diagonal abajo, lateral,...) son muy importantes (147).

\subsubsection{Metodología del Trabajo de Flexibilidad y ROM.}

Para el aumento de la extensibilidad muscular y las ganancias de ROM de nuestro jugador he aplicado tres técnicas que han sido justificadas en el apartado 5.5. Durante las dos primeras semanas utilicé la vibración mecánica en combinación con estiramientos. Se realizó a una frecuencia de entre 30 y $40 \mathrm{~Hz}$, y $2 \mathrm{~mm}$. de amplitud, ya que la gran mayoría de artículos revisados obtienen mejoras significativas con esos parámetros. En cuanto al tiempo de estiramiento, de acuerdo a la literatura consultada, se realizaron 4 series de 10 segundos de estiramiento y 5 de descanso (428).

A las dos semanas me dijeron que no podía utilizar la máquina vibratoria, por lo que, para adaptarme a esta situación, opté por aplicar un foam roller con vibración. Como se ha demostrado en el apartado 5.9 es una técnica muy efectiva para lograr un aumento del ROM, incluso mayor que el foam roller sin vibración. No puedo progresar en la dureza ni la superficie del foam roller, ya que sólo hay un modelo con vibración por lo que se utilizó siempre el mismo. En cuanto a aspectos metodológicos, basándome en una revisión sistemática (513), he realizado 3 series de 30 segundos de masaje con 30 segundos de descanso, aplicados a velocidad lenta. Aquí me encontré con dos problemas, el primero que no sabía los herzios a los que trabajaba, y lo segundo que no siempre ese foam roller se encontraba en el gimnasio. Al final opté por pedirle al jugador que hiciese el trabajo de vibración con la máquina por las mañanas, que sé que no habría ningún problema.

La segunda técnica empleada para conseguir un aumento del ROM es la FNP, concretamente el "Contract Relax". Como se ha justificado debidamente en el apartado 5.5, se realizaron 6 segundos de contracción isométrica (submáxima (433)) seguidos de 4 segundos de relajación aplicados durante 20 segundos y 3 veces de forma alternativa para cada extremidad (435). Además, para conseguir unas mejoras adecuadas se recomienda realizar este trabajo 2 días a la semana, por lo que lo incluí los dos días de entrenamiento que teníamos cada semana. 
La última de las estrategias de aumento de ROM llevadas a cabo en esta primera fase de intervención ha sido el Flossing. El vendaje se aplicó con la mano del jugador apoyada en un banco, la primera vuelta con una tensión aproximada del $50 \%$ y se siguió enrollando en sentido craneal. A medida que ascendía, el vendaje solapaba la mitad de la banda de la pasada anterior. En la parte superior del hombro, en el lado ventral se aplicó una tensión del 60 - $80 \%$ mientras que en el lado dorsal del $50 \%$. Mientras se tiene puesto el vendaje, es importante realizar movimientos con la mayor amplitud posible. El vendaje se debe retirar a los 2 minutos aproximadamente (514).

\subsubsection{Metodología para el Trabajo Miofascial}

El protocolo al trabajar con este medio aún no está claro en la literatura, encontrando estudios que incluyen trabajos desde 1 a 5 series y desde 30 segundos a 2 minutos de duración (486). En una revisión sistemática sobre los parámetros del automasaje miofascial se encuentra (513):

- $\quad$ Tipo de Foam Roller: Un estudio indica que un rodillo más duro produce mayores beneficios mientras que otro no muestra diferencias en cuanto a ROM o umbrales de dolor por presión. Y acaba concluyendo que deberían utilizarse rodillos más blandos con principiantes y otros más duros cuando se necesitan mayores beneficios.

- Fuerza de Aplicación: Se recomienda mantener el rodillo en el lugar donde se siente mayor incomodidad. Se debe aplicar hasta el momento en que la resistencia se convierte en dolor, y mantenerlo hasta que la sensación se elimina o disminuye significativamente.

- Duración de la Aplicación: La mayoría de los estudios realiza series de 30, 60 y 90 segundos. En la revisión destacan 30 segundos divididos en 3 series como suficientes para lograr un resultado positivo.

- $\quad$ Número de Series por Sesión: Normalmente se realiza 1 serie o 3.

- Número de Sesiones: La mayoría de los estudios consiguen los beneficios en una única sesión, mientras que otros realizan 2 ó incluso 3 sesiones.

- $\quad$ Velocidad de Rodadura: La fascia no responde a estímulos cortos y rápidos a alta amplitud. Es similar a la plastilina, por lo que lo mejor es realizar pasadas a baja velocidad debido a sus características tixotrópicas.

- Descanso: En 1 de cada 3 estudios la pausa entre series es de 30 segundos.

Como conclusión, se debe utilizar un rodillo firme, con la mayor fuerza de aplicación posible (según la tolerancia del sujeto), durante un periodo de 30 - 120 segundos. Cada pasada debe durar unos 3 segundos. También se recomienda mantener el rodillo en áreas especialmente sensibles. En una sesión se realizará entre 1 y 3 series por grupo muscular con 30 segundos de descanso (513) que se usarán para incidir en otra zona.

\subsubsection{Metodología para el Aprendizaje de los Patrones Básicos de Movimiento.}

Entrenar y ejecutar los ejercicios con una técnica correcta es un modo de prevenir lesiones. El jugador realiza entrenamientos de "Fuerza" con su equipo y se incluyen ejercicios con cargas que, de no realizarse correctamente, podrían provocar molestias. En este sentido, es necesario que aprenda los patrones básicos de movimiento para que pueda aplicarlos siempre que realice este tipo de trabajos.

Para abordar los patrones básicos de movimiento seguiremos los siguientes aspectos metodológicos

- La RPE será baja (4 - 6), no interesa trabajar con peso sino corregir los posibles errores que detectemos en su ejecución.

- Trabajaremos en torno a $8-10$ repeticiones para no generar fatiga.

- En el momento que observemos un error no terminaremos la ejecución, buscaremos corregir.

- Si es necesario se realizará una activación previa de la musculatura que necesite intervenir y pueda estar inhibida (por ejemplo el caso del glúteo).

- Se progresará de posición bipodal a unipodal.

- No nos detendremos en movimientos fijos y estereotipados como pueden realizarse en deportes individuales (sentadilla, peso muero, tracciones y empujes verticales y horizontales,...). Intentaremos variar continuamente la ejecución. Los aspectos a incidir serán los mismos en 
cada patrón, pero la variabilidad será muy alta. Por ejemplo, se realizarán sentadillas bipodales, unipodales, zancadas laterales, salidas cruzadas o frontales, sin y con desplazamiento previo en cualquier dirección,... que serán la base del entrenamiento realizado en la fase 2 .

- La resistencia a vencer será baja, lo cual nos permitirá no acumular fatiga y trabajar (una vez dominado el patrón) a velocidades más altas.

- Se utilizará el foco externo para la corrección del movimiento.

- En las variantes de los patrones planteadas se pensará en las acciones que realiza el jugador durante la competición, para tratar de imitarlas en la medida de lo posible.

Justo antes de realizar la ejecución de los patrones de movimiento se realizará una activación del glúteo, con la intención de integrar esta musculatura en movimientos específicos. Además, se buscará aquéllos ejercicios en los que, electromiográficamente, haya una menor activación del TFL (516).

\subsubsection{Secuenciación de Contenidos}

En la tabla 53 aparecen los distintos contenidos abordados en esta primera fase junto con la forma de progresar durante las sesiones o la fase. La flecha hacia abajo indica que los contenidos han sido realizados en ese orden, bien durante la sesión o a lo largo de la fase, según donde se encuentre. En la columna adyacente se especificará cómo ha sido la progresión que falta, es decir, si la flecha aparece en la columna de sesión se indicará cómo se ha planteado la progresión durante la fase y viceversa.

\begin{tabular}{|c|c|c|c|c|}
\hline $\begin{array}{c}\text { TIPO DE } \\
\text { TRABAJO }\end{array}$ & SECUENCIACIÓN DE CONTENIDOS & PROG. SES. & PROG. FASE & $\begin{array}{c}\text { RELAC. } \\
\text { CON OBJ. }\end{array}$ \\
\hline \multirow{5}{*}{$\begin{array}{l}\text { Reeducación del } \\
\text { patrón de } \\
\text { Activación del } \\
\text { Complejo } \\
\text { Articular del } \\
\text { Hombro }\end{array}$} & Liberación Miofascial (pectoral menor) & & \multirow{5}{*}{$\begin{array}{l}\text { Variando los } \\
\text { ejercicios, } \\
\text { aumentando la } \\
\text { intensidad e } \\
\text { incluyendo } \\
\text { distinto material. }\end{array}$} & P.3.4 \\
\hline & Flossing + movimientos amplios + Estiramientos (Rotación Interna y Aducción) & & & P.1.1.4-5 \\
\hline & Estiramientos balísticos de pectoral menor & & & P.3.4 \\
\hline & $\begin{array}{l}\text { Ejercicios de Retracción Escapular, Protocolo Blackburn y activación de Serrato } \\
\text { Anterior y Trapecio Medio y superior }\end{array}$ & & & P.3.3 \\
\hline & Potenciación Manguito Rotadores & & & P.3.5 \\
\hline \multirow{6}{*}{ Propioceptivo } & $\begin{array}{l}\text { Mantener postura en diferentes superficies desestabilizadoras (con diferentes } \\
\text { angulaciones) }\end{array}$ & \multirow{6}{*}{\multicolumn{2}{|c|}{$\begin{array}{l}\text { Progresando de trabajo } \\
\text { bipodal a monopodal, ojos } \\
\text { abiertos a cerrados, sin y } \\
\text { con perturbaciones, sin y } \\
\text { con impacto y variando } \\
\text { sentido y dirección de } \\
\text { desequilibrio }\end{array}$}} & P.1.4.3 \\
\hline & Saltos y recepciones sobre superficies estables / desestabilizadoras & & & P.1.4.6 \\
\hline & Elementos desestabilizadores (gomas, polea, entrenador,...) en diferentes planos & & & P.1.4.1-6 \\
\hline & Perturbaciones esperadas & & & P.1.4.4 \\
\hline & Perturbaciones inesperadas & & & P.1.4.5 \\
\hline & Combinación de todos los contenidos anteriores & & & P.1.4.1-6 \\
\hline \multirow{7}{*}{$\begin{array}{l}\text { Entrenamiento de } \\
\text { la Región } \\
\text { Coxolumbopélvica }\end{array}$} & Maniobra de Hollowing con movilización de brazos, pies y combinación & & \multirow{7}{*}{$\begin{array}{l}\text { Variar posiciones (decúbito } \\
\text { supino, cuadrupedia, de } \\
\text { pie). Aumentar velocidad. } \\
\text { Incluir material para } \\
\text { aumentar intensidad } \\
\text { (gomas, TRX, polea, } \\
\text { inestabilidad,...) }\end{array}$} & P.2.2-4 \\
\hline & Ejercicios de Movilidad de Cadera & supi & & P.1.1.1-3 \\
\hline & Maniobra de Bracing con stabilizer & pie). & & P.1.6.1 \\
\hline & Ejercicios anti flexión, anti rotación, anti extensión y anti flexión lateral & In & & P.1.6.1-4 \\
\hline & Perturbaciones conocidas y desconocidas & au & & P.1.6.1-4 \\
\hline & Material desestabilizante (fitball, bosu,...) & $(\mathrm{gc}$ & & P.1.6.1. -4 \\
\hline & Combinación de lo anterior & & & P.1.6.1. -4 \\
\hline \multirow{3}{*}{$\begin{array}{l}\text { Patrones de } \\
\text { Movimiento }\end{array}$} & Activación analítica de glúteo & EMG & \multirow{3}{*}{\begin{tabular}{|c|} 
Intensidad y Especific. \\
$\begin{array}{c}\text { No hubo progresión, sólo } \\
\text { me interesaba la técnica }\end{array}$
\end{tabular}} & P.1.3.1-2 \\
\hline & Ejecución de patrones de movimiento con carga baja & 1 patrón & & \\
\hline & Variantes de los distintos patrones & $\mathrm{x}$ sesión & & P.1.5.1-7 \\
\hline \multirow{2}{*}{ Aumento del ROM } & Estiramiento estático con vibración mecánica / Contract Relax & & \multirow{2}{*}{$\begin{array}{l}\text { No hubo progresión como } \\
\text { tal, se realizó ese trabajo } \\
\text { durante toda la fase }\end{array}$} & D 19 \\
\hline & Liberación Miofascial & $\begin{array}{r}\text { tal, } \mathrm{s} \\
\mathrm{du}\end{array}$ & & $1.1 .2 .1-2$ \\
\hline
\end{tabular}

Tabla 53: Secuenciación de los Contenidos de la Fase 1 del Programa de Intervención y relación con Objetivos 


\subsubsection{Sesiones}

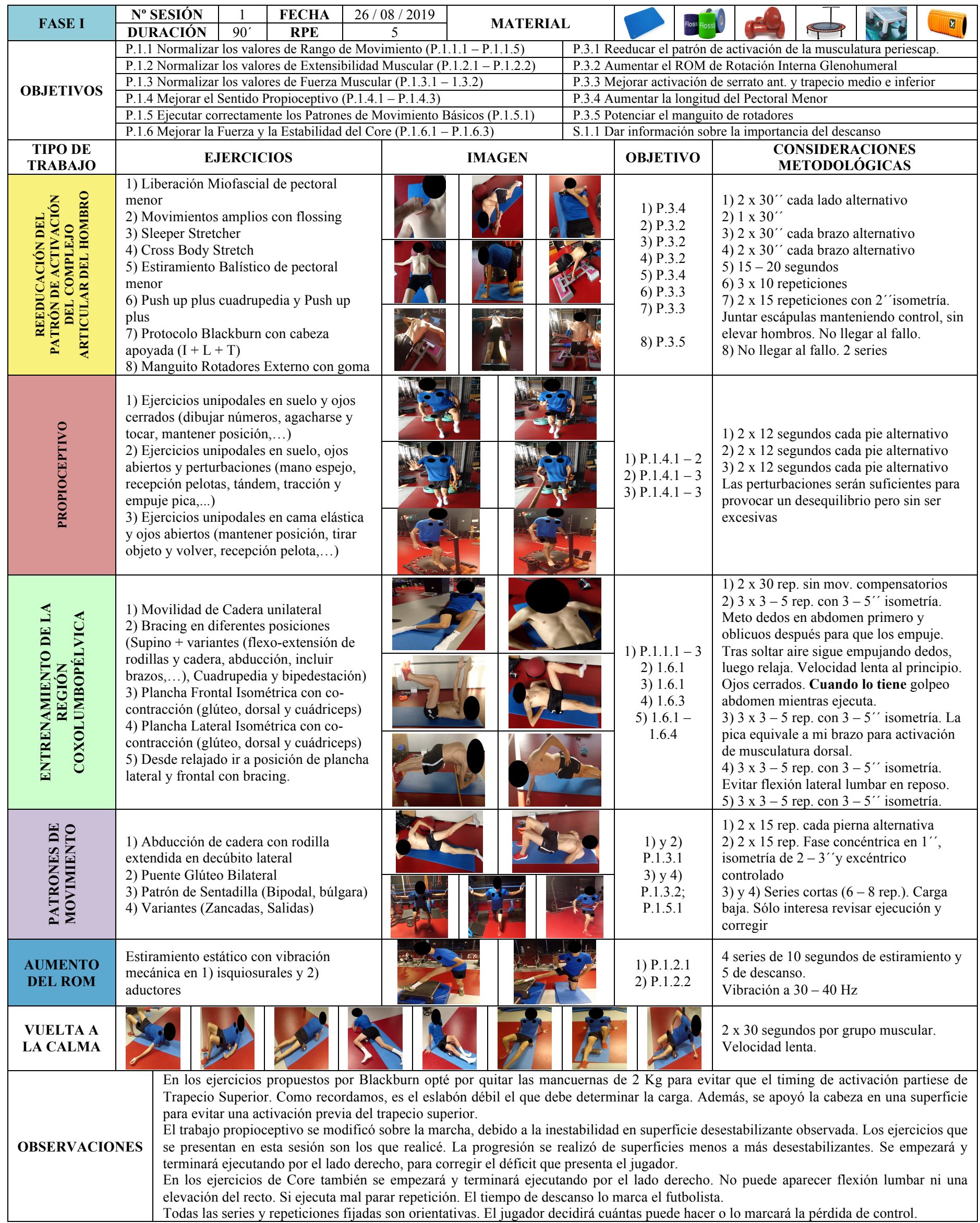
Tabla 54: Sesión de Entrenamiento $\mathrm{n}^{\circ} 1$ 


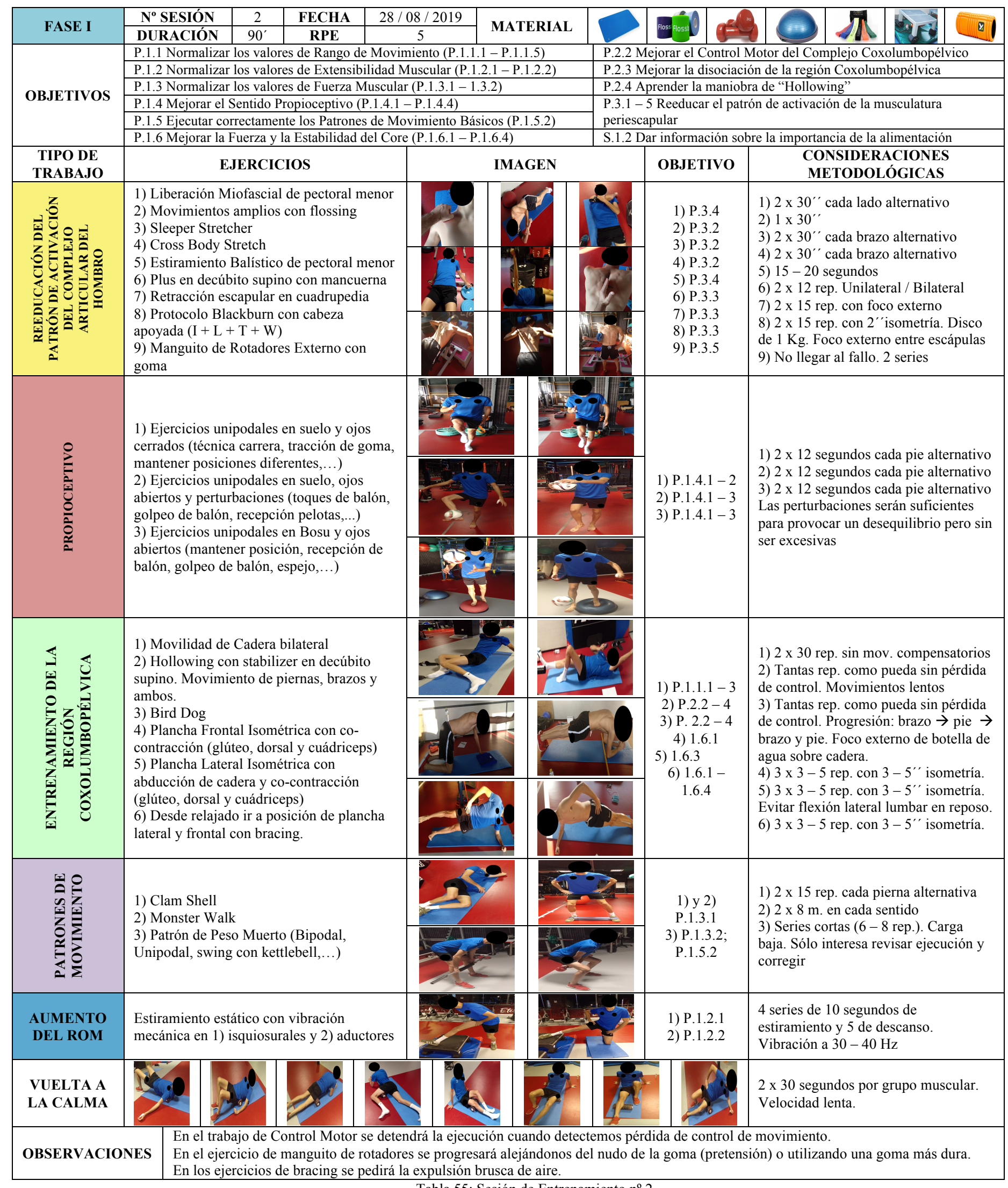




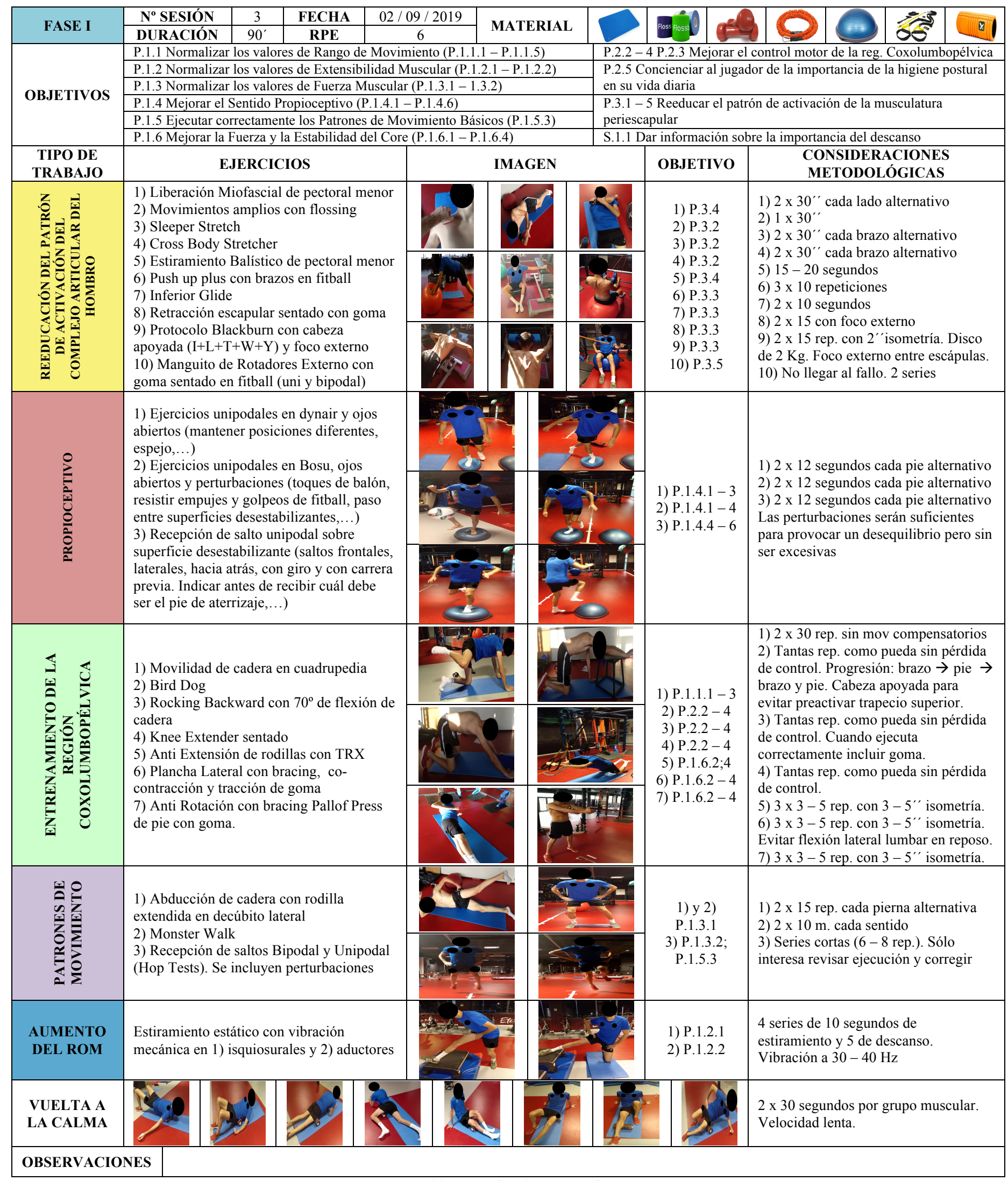

Tabla 56: Sesión de Entrenamiento ${ }^{\circ} 3$ 


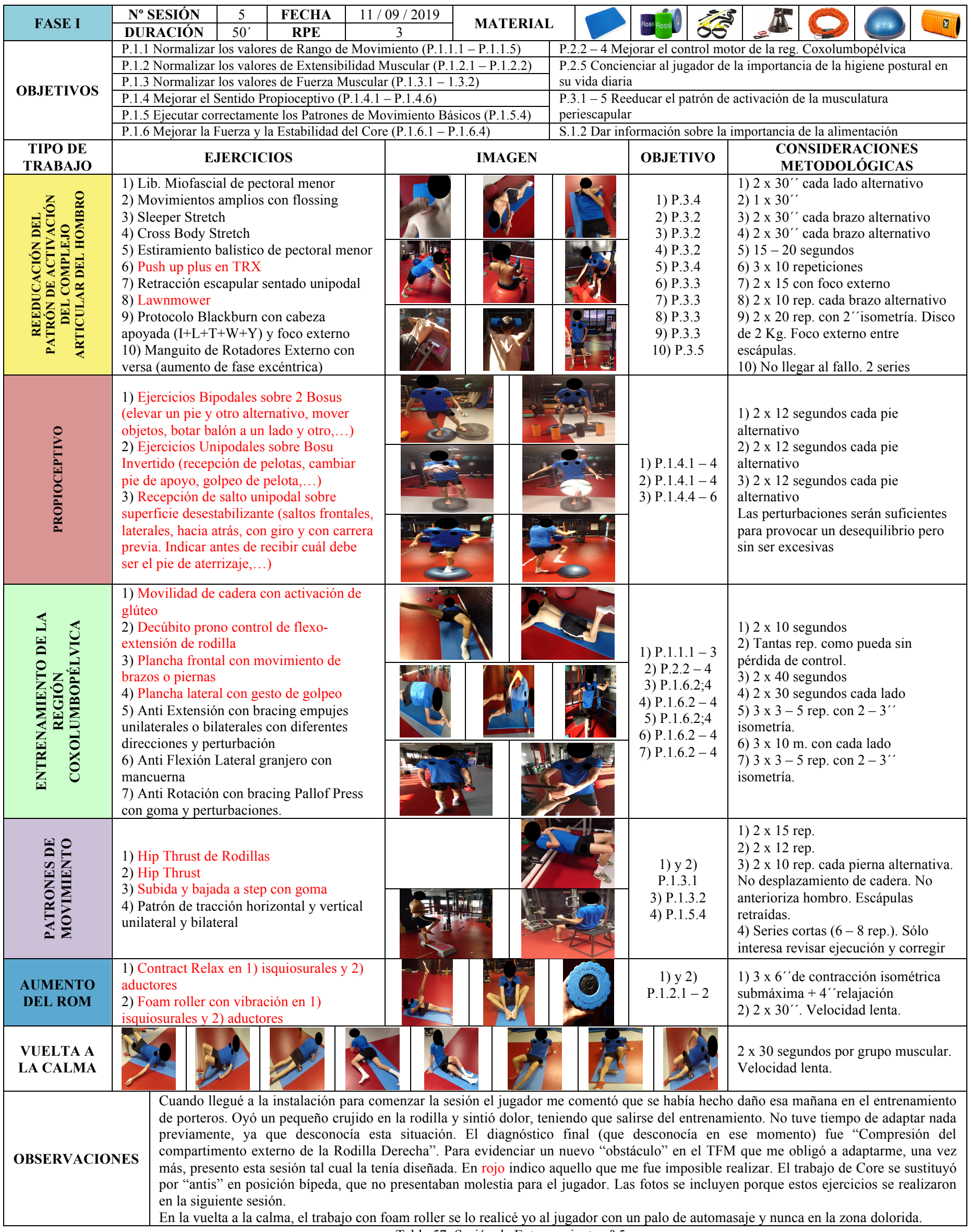




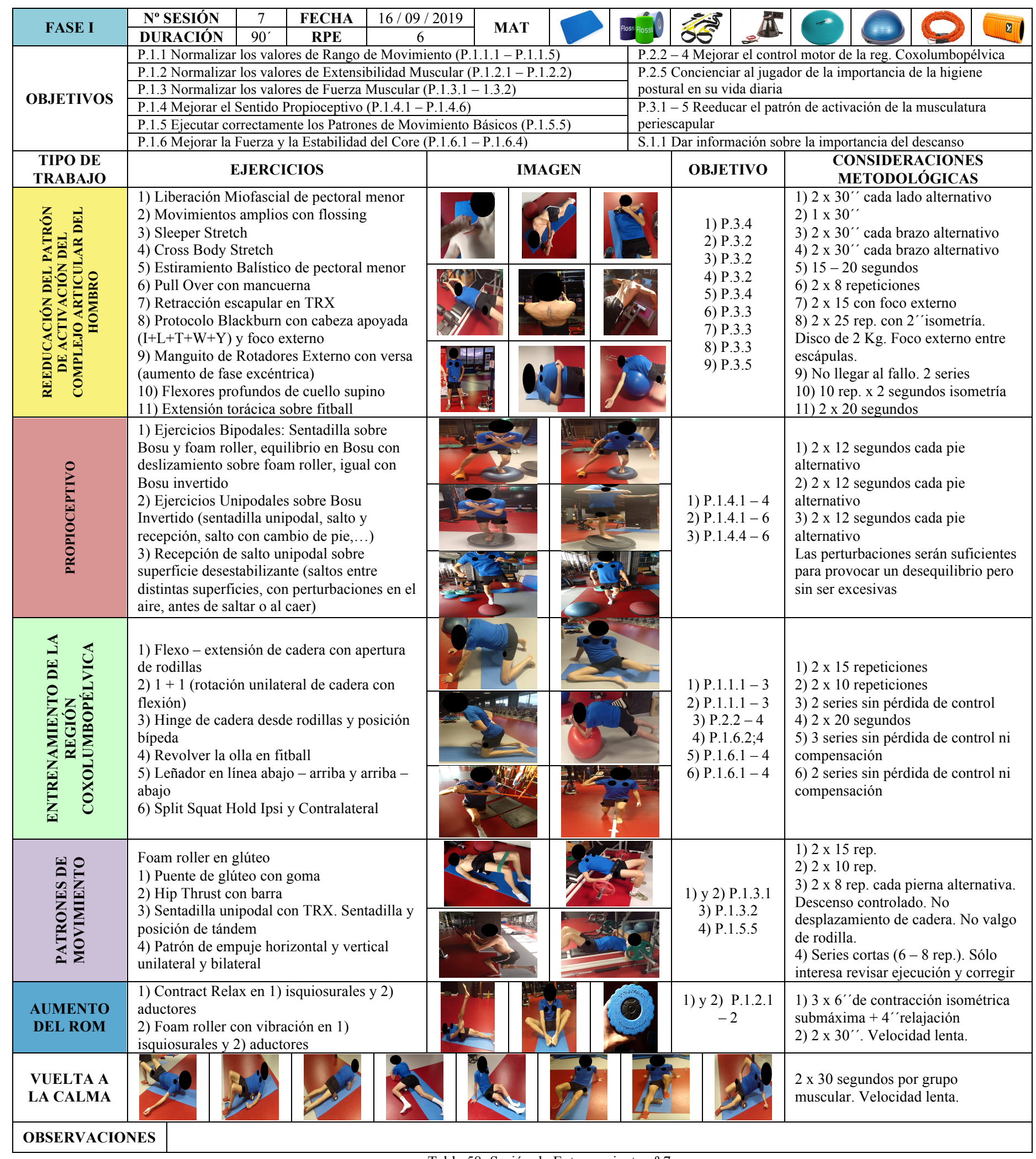




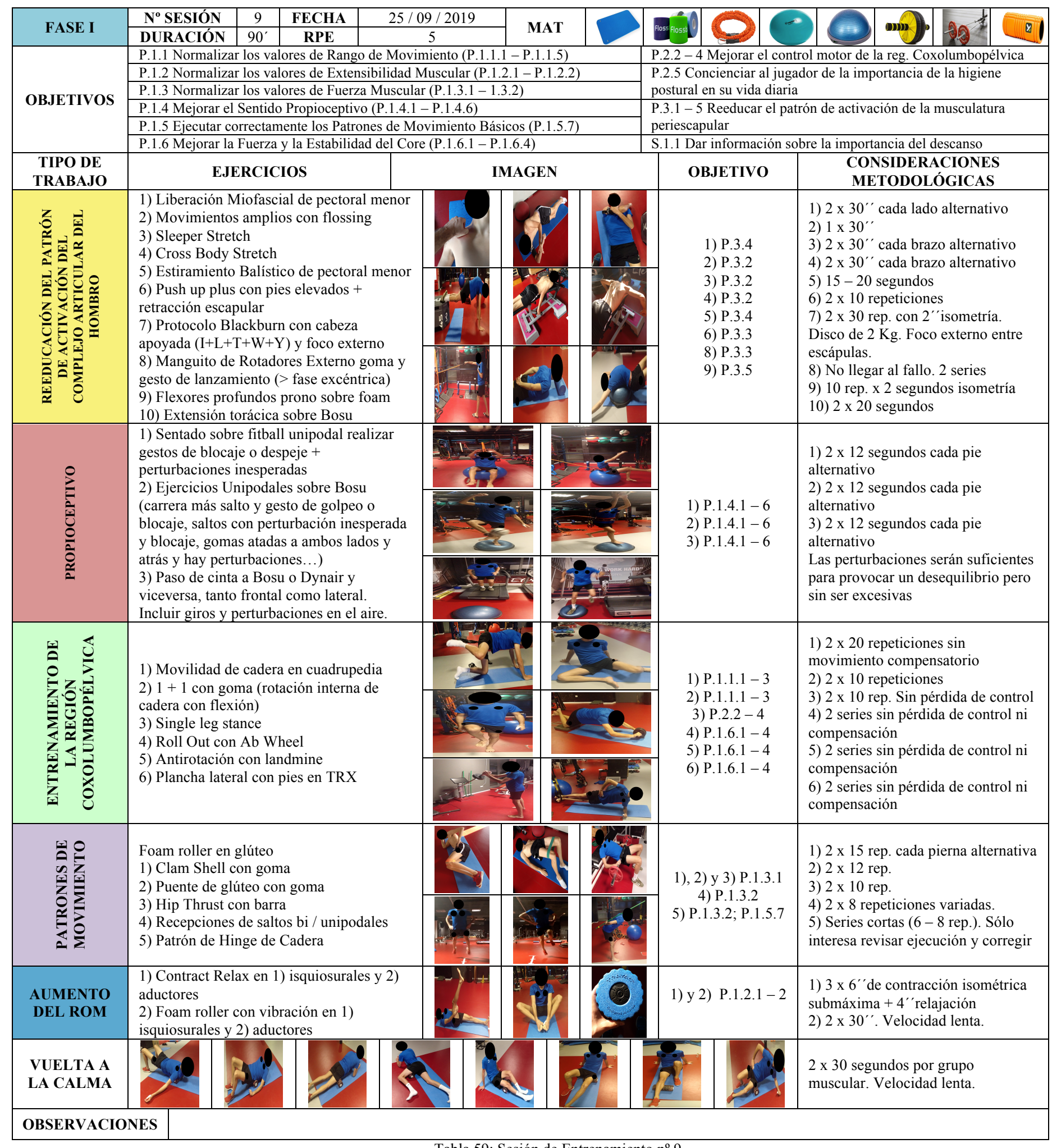

Tabla 59: Sesión de Entrenamiento $\mathrm{n}^{\circ} 9$

\subsubsection{Control / Monitorización del Entrenamiento.}

\subsubsection{Control de la Carga de Entrenamiento.}

Como ya se ha comentado en el apartado 5.7, un incremento demasiado pronunciado de la carga de entrenamiento (más de un 10\% semanal) puede ser un factor de riesgo. Para controlar este aspecto utilizaremos el ratio carga aguda:crónica. Hay que aclarar que se trata de una persona que está acostumbrada a trabajar con la Escala de Borg, así que no ha sido necesaria ninguna familiarización al 
respecto. Además, como el futbolista ya realiza entrenamientos organizados con su equipo, los valores que obtengamos en nuestras sesiones serán sumados a los que el jugador acumule en su semana de entrenamiento, ya que ambos trabajos están muy ligados y lo que yo realizo en las sesiones viene marcado por lo que ha hecho previamente con su equipo.

Así, en la figura 52 se muestran los valores de carga aguda, crónica y el ratio aguda:crónica del jugador durante esta primera fase de entrenamiento. Y en la figura 53 las unidades arbitrarias y los valores de RPE obtenidos en nuestras sesiones en este mismo periodo. Como puede comprobarse, el incremento de la carga aguda no ha sido demasiado brusco, respetando el límite que comentábamos en el apartado 5.7 .

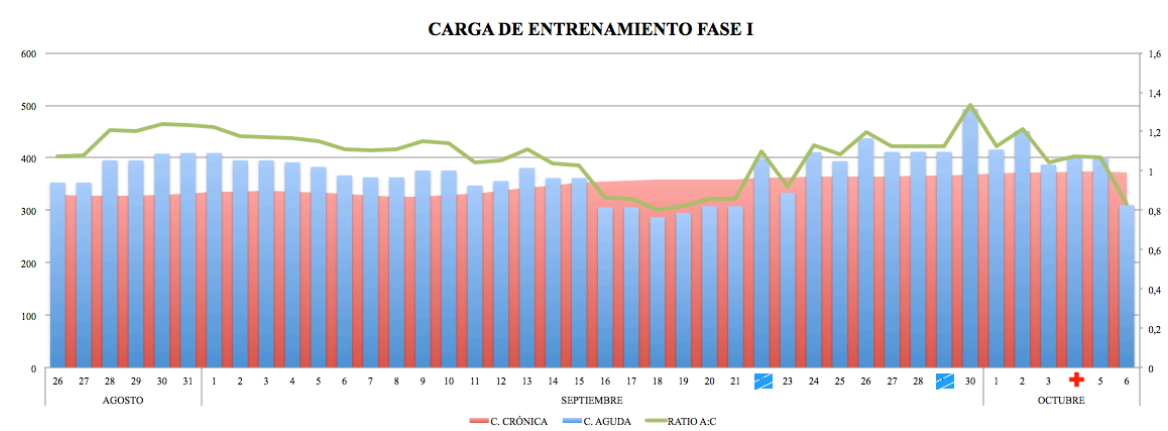

Figura 52: Carga de Entrenamiento Aguda:Crónica durante la Fase I
CARGA DE ENTREYAMIENTO EN SESIONES DE ENTRENAMIENTO PERSONAL EN LAFASEI

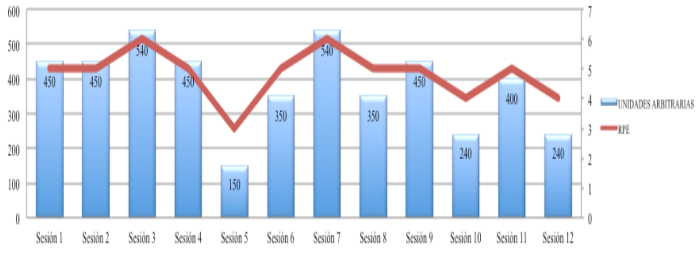

Figura 53: Carga de Entrenamiento en mis sesiones de Entrenamiento Personal de la Fase I

\subsubsection{Control del Volumen de Entrenamiento.}

Es importante señalar que, en el caso de cualquier otra posición en fútbol, deberíamos incluir los datos obtenidos del GPS en cuanto a distancia recorrida a alta intensidad (normalmente por encima de 23 $-25 \mathrm{Km} / \mathrm{h}$ ) como parte de este control del entrenamiento. Sin embargo, al tratarse de un puesto tan específico como el de portero y que en su equipo no realizan este control a los guardametas, no lo incluyo como parte del control del volumen de entrenamiento.

Otro aspecto interesante a controlar es la cantidad de acciones que, por repetición, podrían aumentar el riesgo de lesión, como es el caso de los golpeos (saques de puerta, pases en largo o despejes) o las caídas. Tener una referencia del número de veces que suceden estas acciones técnicos en partidos y entrenamientos nos podría haber ayudado a realizar una progresión adecuada tras la lesión de recto anterior que redujese la probabilidad de recidivas. Sin embargo ha sido imposible obtener estos datos.

No existe en la literatura (al menos no he sido capaz de encontrarlo), un método para cuantificar este trabajo preventivo. Sabemos que, en cuanto a tracciones y empujes, es interesante el ratio 2:1, especialmente en nuestro sujeto por los resultados obtenidos en la evaluación inicial. De esto modo, en la tabla 60 se indican las repeticiones estimadas (luego el jugador hizo las que pudo sin pérdida de control) en ejercicios de empujes y de tracción, sólo para comprobar que estamos dentro del ratio recomendado.

\begin{tabular}{|c|c|c|c|c|c|c|c|c|c|c|c|c|c|}
\hline & Ses. 1 & Ses. 2 & Ses. 3 & Ses. 4 & Ses. 5 & Ses. 6 & Ses. 7 & Ses. 8 & Ses. 9 & Ses. 10 & Ses. 11 & Ses. 12 & TOT \\
\hline Tracciones & 60 & 90 & 90 & 90 & 90 & 90 & 90 & 90 & 90 & 90 & 90 & 90 & 1050 \\
\hline Empujes & 30 & 24 & 30 & 30 & 0 & 30 & 50 & 50 & 20 & 20 & 30 & 30 & 344 \\
\hline
\end{tabular}

En cuanto al resto... como ya se ha comentado en el apartado 5.7, el control de la carga en los deportes colectivos no puede (ni debe) realizarse de la misma forma que en los individuales. En esta primera fase, más orientada al control motor, no me he guiado por el número de repeticiones sino por la calidad de la ejecución, deteniendo la serie cuando se detectaba pérdida de control. Así, las repeticiones no estaban prefijadas (sólo se indicaba una orientación) ni los tiempos de recuperación, era el propio jugador el que me indicaba cuándo estaba preparado para continuar el trabajo.

\subsubsection{Control de la Escala de Bienestar.}

En la figura 54 se muestran los datos indicados por el jugador en cada uno de los ítems de la escala de bienestar durante cada uno de los días de esta fase de entrenamiento (independientemente de haber 
realizado entrenamiento conmigo o no ya que, como se ha comentado, está íntimamente ligado). Para una mejor y más rápida interpretación, a cada valor numérico se le ha atribuido un color $(1=$ rojo; $2=$ naranja; $3=$ amarillo; $4=$ azul; $5=$ verde) de modo que sea muy fácil detectar cuándo el jugador se encuentra en algún parámetro que no consideremos adecuado. Además, para poder comparar unos valores con otros y ver las fluctuaciones que se han producido, las figuras 55 - 59 reflejan la cantidad total de cada uno de los ítems en cada semana.

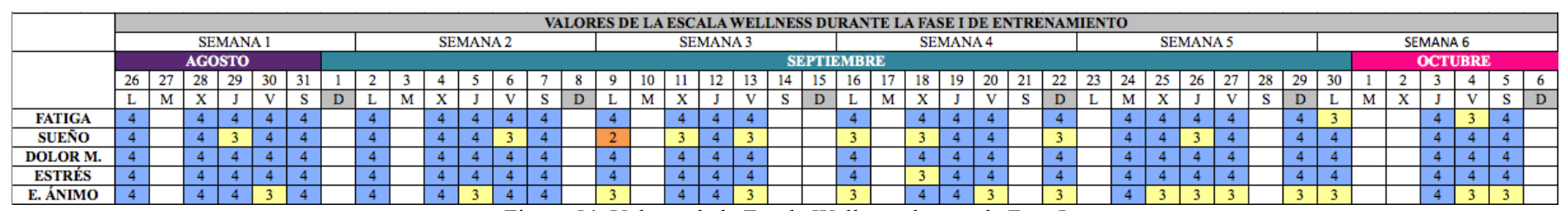
Figura 54: Valores de la Escala Wellness durante la Fase I
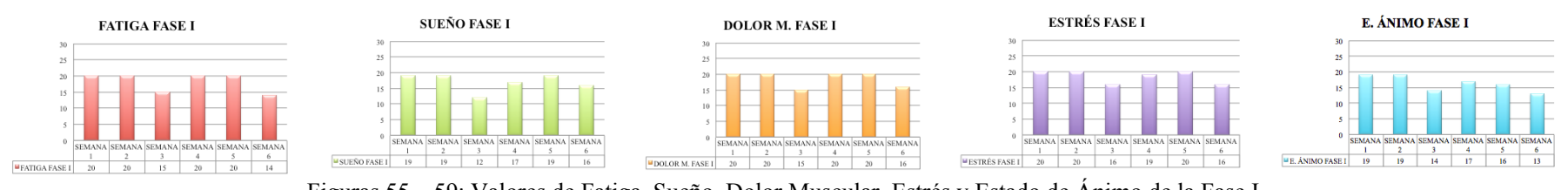

Figuras 55 - 59: Valores de Fatiga, Sueño, Dolor Muscular, Estrés y Estado de Ánimo de la Fase I

\subsubsection{Control del Dolor Lumbar.}

Para controlar la evolución del dolor lumbar, se pide al jugador que indique, cada entrenamiento, la sensación de dolor en base a una escala de $1-10$ (Escala analógica visual. Ver figura 60). En la figura 61 se muestran los resultados de su percepción durante la primera fase de entrenamiento. Habría sido muy interesante obtener los valores de las semanas previas a trabajar con él, pero como ya se ha explicado, yo conocí al jugador a principio de Agosto y el anterior sujeto no refería dolor lumbar, por lo que era imposible haberlo previsto.

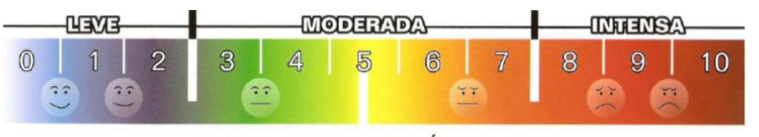

ESCALA VISUAL ANALÓGica - EVA

Figura 60: Escala Analógica Visual de Dolor entregada al jugador

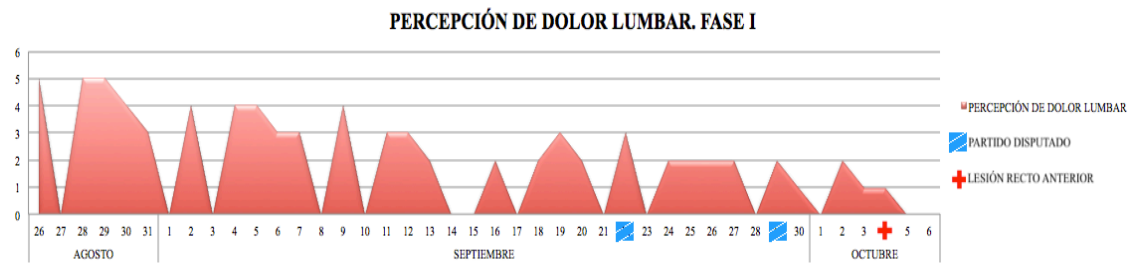

Figura 61: Percepción de Dolor Lumbar durante la Fase I

\subsubsection{Reflexión sobre lo planificado en la Fase I.}

Las dos primeras semanas de entrenamiento fueran "estables", es decir, el jugador entrenaba días establecidos con su equipo y conmigo. A partir de ahí... vino el caos y tuve que adaptarme semanalmente. El futbolista tuvo varios entrenamientos con el primer equipo y asistió con frecuencia a los de un club filial. El problema es que él mismo no sabía con quién ni cuándo entrenaba hasta 24 horas antes. Esto nos ha condicionado enormemente y ha hecho que tengamos que variar días de entreno casi sobre la marcha. En este sentido ha sido una ventaja trabajar mediante repeticiones postfijadas porque habría sido imposible, dada la dinámica semanal, intuir el grado de fatiga con el que vendría cada día.

En función de las características de cada semana y las condiciones en las que llegaba el jugador cada día, hacíamos dos series o una de algún ejercicio. Por ejemplo, reducía bastante el trabajo propioceptivo en cuanto a volumen los días que entrenaba conmigo y, justo después, con el club filial, para evitar saturar los mecano-receptores y aumentar el riesgo de lesión. Además, tuve que adaptarme a la pequeña compresión del compartimento externo de la rodilla que me limitó una sesión de entrenamiento.

La comunicación con su cuerpo técnico (preparador físico y fisios) no ha sido todo lo fluida que, quizás, debía haber sido. El motivo es que ellos estaban saturados de trabajo en muchas ocasiones y yo no quería ser una carga más ni que me vieran como un "pesado". Así que, salvo que fuese algo que realmente necesitase, trataba de molestar lo justo. 
Otro problema que me encontré fue que en la $3^{\mathrm{a}}$ semana me dijeron que no podía utilizar ni la plataforma vibratoria ni las máquinas yo-yo. Esto supuso un problema para mi trabajo de flexibilidad de la fase I y para lo que tenía pensado hacer a nivel de fuerza en la fase II. Para subsanar el problema de la Fase I opté por realizar la técnica de FNP "contract relax" y pasar el foam roller con vibración, aunque a las pocas semanas le pedí al jugador que realizase el trabajo con plataforma vibratoria por su cuenta al finalizar 2 de sus entrenamientos.

Pero no todo ha sido negativo, la profesionalidad y compromiso del jugador ha sido absoluto, ofreciéndose a trabajar incluso en su día de descanso (que he respetado durante todas las semanas de esta fase como acordé con su preparador físico). Si no llega a ser por eso habría tenido realmente difícil realizar esta parte del programa de intervención, pues me he encontrado numerosos obstáculos.

\subsubsection{Evaluación del Progreso}

Justo al final de la Fase I del programa de intervención el sujeto se lesionó. Completé mis sesiones de entrenamiento pero no pude llegar a evaluar. La semana siguiente sólo entrené el viernes y fue en la posterior a esa cuando se pudo realizar la evaluación, pero por partes porque había test que era imposible pasar (aquéllos que implicaban directa o indirectamente el recto anterior). Obviamente los datos de la evaluación no son los mismos que si se hubiese realizado cuando estaba planificado, pero tampoco sirve de mucho obtener un valor, por bueno que sea, si el sujeto se ha lesionado.

Para comprobar objetivamente si los objetivos que nos habíamos marcado en esta primera fase de entrenamiento se han cumplido y para orientar la posterior fase de trabajo, se ha realizado una evaluación de aquéllos parámetros que intentábamos corregir. Los resultados obtenidos se han comparado con los de la evaluación inicial. En la tabla 61 aparece esta información. Además, se incluye una escala de colores que, de forma visual, nos permite identificar si no ha habido mejora o ha sido muy leve en un valor (color rojo) si ha habido mejora pero no se ha conseguido llegar al parámetro de referencia (color amarillo), si hemos conseguido normalizar al jugador y situarlo en los valores que marca la literatura (color verde) o si hemos superado esos valores (color azul). Si hubiesen aparecido objetivos en rojo se habría modificado la forma de intervenir sobre ellos; los amarillos se seguirán incluyendo en la Fase II; y los verdes y azules se realizarán buscando mantener los valores conseguidos.

\begin{tabular}{|c|c|c|c|c|c|c|c|c|c|c|}
\hline \multirow{2}{*}{\multicolumn{2}{|c|}{ OBJETIVOS }} & \multicolumn{2}{|c|}{$\begin{array}{c}\text { RESULT. } \\
\text { EV. INICIAL }\end{array}$} & \multirow{2}{*}{ TEST } & \multicolumn{2}{|c|}{$\begin{array}{c}\text { RESULT. } \\
\text { EV. FASE I }\end{array}$} & \multirow{2}{*}{$\begin{array}{c}\text { VALOR } \\
\text { REF. }\end{array}$} & \multicolumn{2}{|c|}{ MEJORA } & \multirow{2}{*}{$\begin{array}{c}\text { ESC. } \\
\text { COLOR }\end{array}$} \\
\hline & & IZQ & DER & & IZQ & DER & & IZQ & DER & \\
\hline \multirow{2}{*}{ P.1.1.1 Aumentar los valores de rotación interna de cadera } & Cadera $0^{\circ}$ & $40^{\circ}$ & $38^{\circ}$ & \multirow[b]{2}{*}{ A. 5} & $45^{\circ}$ & $45^{\circ}$ & $35^{\circ}-40^{\circ}$ & $5^{\circ}$ & $7^{\circ}$ & \\
\hline & Cadera $90^{\circ}$ & $30^{\circ}$ & $25^{\circ}$ & & $35^{\circ}$ & $30^{\circ}$ & $35^{\circ}-45^{\circ}$ & $5^{\circ}$ & $5^{\circ}$ & \\
\hline \multirow{2}{*}{ P.1.1.2 Aumentar los valores de rotación externa de cadera } & Cadera $0^{\circ}$ & $20^{\circ}$ & $30^{\circ}$ & \multirow{2}{*}{ A. 6} & $30^{\circ}$ & $42^{\circ}$ & $45^{\circ}$ & $10^{\circ}$ & $12^{\circ}$ & \\
\hline & Cadera $90^{\circ}$ & $25^{\circ}$ & $30^{\circ}$ & & $35^{\circ}$ & $40^{\circ}$ & $45^{\circ}$ & $10^{\circ}$ & $10^{\circ}$ & \\
\hline \multicolumn{2}{|l|}{ P.1.1.3 Aumentar los valores de abducción de cadera } & $40^{\circ}$ & $35^{\circ}$ & A.9 & $45^{\circ}$ & $42^{\circ}$ & $45^{\circ}$ & $5^{\circ}$ & $7^{\circ}$ & \\
\hline \multicolumn{2}{|l|}{ P.1.1.4 Aumentar los valores de rotación interna glenohumeral } & $50^{\circ}$ & $40^{\circ}$ & A.12 & $62^{\circ}$ & $58^{\circ}$ & $70^{\circ}$ & $12^{\circ}$ & $18^{\circ}$ & \\
\hline \multicolumn{2}{|l|}{ P.1.1.5 Aumentar los valores de aducción de hombro } & $25^{\circ}$ & $25^{\circ}$ & A.14 & $30^{\circ}$ & $30^{\circ}$ & $30^{\circ}$ & $5^{\circ}$ & $5^{\circ}$ & \\
\hline \multicolumn{2}{|l|}{ P.1.2.1 Aumentar la longitud de la musculatura isquiosural } & $35^{\circ}$ & $40^{\circ}$ & A.2 & $30^{\circ}$ & $32^{\circ}$ & $15^{\circ}$ & $3^{\circ}$ & $8^{\circ}$ & \\
\hline \multicolumn{2}{|c|}{ P.1.4.1 Corregir la asimetría presente entre pie izquierdo y derecho } & \multicolumn{2}{|c|}{$7 \mathrm{~cm}$} & C.1 & \multicolumn{2}{|c|}{$2 \mathrm{~cm}$} & $<4 \mathrm{~cm}$ & \multicolumn{2}{|c|}{-} & \\
\hline \multicolumn{2}{|c|}{ P.1.4.2 Mejorar los valores del test propioceptivo en las 3 direcciones } & 74 & 67 & C.1 & 80 & 78 & - & 6 & 11 & \\
\hline \multicolumn{2}{|c|}{ P.1.6.2 Aumentar la fuerza de la musculatura del Core } & \multicolumn{2}{|c|}{$38^{\prime \prime} / 56^{\prime \prime}$} & B. $4-6$ & \multicolumn{2}{|c|}{$158 / 156$} & $146 / 144$ & \multicolumn{2}{|c|}{$120^{\prime \prime} / 100^{\prime \prime}$} & \\
\hline \multicolumn{2}{|c|}{ P.1.6.3 Corregir la asimetría de fuerza encontrada en el Side Bridge } & $71^{\prime \prime}$ & $61^{\prime \prime}$ & B.5 & $91^{\prime \prime}$ & $100^{\prime \prime}$ & $97^{\prime \prime} / 94^{\prime}$ & $20^{\prime \prime}$ & $39^{\prime \prime}$ & \\
\hline \multicolumn{2}{|c|}{ P.2.3 Mejorar la disociación de la región coxolumbopélvica } & \multicolumn{2}{|c|}{ Control Pobre } & G. $1-5$ & \multicolumn{2}{|c|}{ Control } & - & \multicolumn{2}{|l|}{ 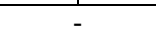 } & \\
\hline \multicolumn{2}{|c|}{ P.3.1 Reeducar el patrón de activación de la musculatura periescapular } & \multicolumn{2}{|c|}{ Anom. Sutil } & B.7 & \multicolumn{2}{|c|}{ Normal } & Normal & \multicolumn{2}{|c|}{-} & \\
\hline \multicolumn{2}{|c|}{ P.3.4 Aumentar la longitud del pectoral menor, especialmente el derecho } & 7,14 & 6,5 & A.15 & 7,25 & 6,8 & IPM $>7,4$ & 0,11 & 0,3 & \\
\hline
\end{tabular}

Tabla 61: Grado de consecución de los Objetivos de la Fase 1.

Debido a que la evaluación se realizó después de la recuperación de la lesión del jugador, es decir, tras un tiempo de actividad bastante menor del que venía realizando, y que los valores de Fuerza en la musculatura aductora y abductora y el ratio ADD:ABD aunque estaban dentro de los valores de referencia se encontraban en el rango inferior de ese valor, intenté realizar los tests B1, B2 y B3. Sin embargo, el dinamómetro que se utilizó para valorar en pretemporada pertenecía a la universidad y no pudimos utilizarlo nuevamente. Así que supuse que existía una disminución en la fuerza de esta musculatura, como consecuencia del periodo de lesión, y decidí marcarme el objetivo de mejorarla en la siguiente fase.

Aún así, independientemente de los resultados obtenidos en los tests y de la lesión (si es que esto último se puede obviar), hay dos hechos muy positivos e incuestionables: El primero es que el jugador ha 
disminuido considerablemente el dolor lumbar que sufría desde hace 3 años. Esto puede venir por la mejora obtenida en el control motor de la región coxolumbopélvica, por la tremenda mejora en la fuerza y estabilidad del Core, por la mayor activación del glúteo o por la mayor movilidad de cadera... aunque seguramente se deba a todas esas mejoras a la vez.

El segundo aspecto positivo es que el sujeto ha eliminado el dolor en el hombro dominante. La sutil disquinesia escapular que presentaba ha desaparecido, seguramente la activación de serrato anterior y trapecio medio e inferior sea bastante mayor así como la capacidad de su manguito rotador para frenar movimientos específicos de su posición. Además, hay una menor rigidez del pectoral menor, aunque no llega a valores de referencia y deberá seguir abordándose en la siguiente fase

Todo esto, unido a que el jugador ha pulido su ejecución en patrones de movimiento básicos, me permitiría plantear una $2^{\mathrm{a}}$ Fase de entrenamiento mucho más global, orientada a movimientos más específicos y a mejorar la fuerza en 3D y 4D. Sin embargo... la lesión marcaría mi $2^{a}$ Fase del programa. Me gustaría destacar que se trata de un sujeto acostumbrado a entrenar y con profesionales de este campo, por lo que su ejecución era bastante aceptable y no he considerado oportuno incluir los patrones de movimiento en la siguiente fase.

\subsection{Fase II del Programa de Intervención}

Este tramo viene marcado por la lesión en recto anterior del muslo derecho que sufre el jugador al final de la Fase I, que me obligó a adaptarme por completo. Para empezar, comencé esta parte del programa sin saber los valores obtenidos en la evaluación final de la Fase I y sin poder trabajar algunos contenidos, bien porque la lesión me lo impedía o porque ya se realizaban diariamente con su cuerpo técnico, que fueron quienes realizaron la readaptación. Hasta que el médico no indicó el alta competitiva no quise aplicar ningún estímulo sobre tren inferior, más allá de la movilidad de cadera o propiocepción básica (y ya avanzada la lesión).

El jugador recibe el alta 3 semanas después de que comience esta Fase (el miércoles 23 de Octubre), por lo que, únicamente, me quedaban 3 semanas de intervención. Antes de que todo esto ocurriese, uno de los objetivos principales a desarrollar en esta Fase era un trabajo de fuerza en 3D y 4D, sin embargo decidí no realizarlo en estas 3 semanas que me quedaban. Los motivos fueron varios: 1) la incertidumbre que tenía cada semana en cuanto a cuándo entrenar; 2) el hecho de entrenar con 3 equipos distintos, que dificultaba el control de la carga; 3 ) el calendario, ya que en la $1^{\text {a }}$ de las 3 semanas en las que lo podría llevar a cabo el jugador tenía dos partidos y era imposible aplicar ningún estímulo de estas características; 4) que no podría disponer de Smartcoach para monitorizar los ejercicios y, en un trabajo $4 \mathrm{D}$, cada repetición puede variar en cuanto a distancia, tiempo, velocidad, potencia,... y no quería fatigar al jugador, aunque esto se podría haber subsanado sin el resto de problemas; y 5) que, probablemente, la estructura lesionada no estaría preparada para recibir estímulos de este tipo y tampoco había tiempo para realizar una adecuada progresión. Como ya había realizado una revisión para abordar este objetivo, se presentan las pautas metodológicas que se habrían seguido en el Anexo X.

Así, la estructura y objetivos que me planteé en esta $2^{\mathrm{a}}$ Fase fueron: Las 3 primeras semanas mantener (o aumentar) los niveles conseguidos con antelación; y las 3 últimas disminuir la probabilidad de que apareciese una recidiva u otra lesión muscular como consecuencia de la primera.

\subsubsection{Objetivos Específicos}

\begin{tabular}{|c|c|c|c|}
\hline OBJ. GEN & OBJ. PRINCIPAL & CONCRECIÓN & PRIORIDAD \\
\hline \multirow{6}{*}{ 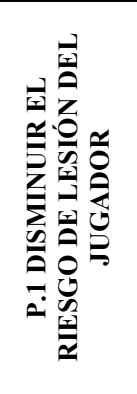 } & P.1.1.1 Aumentar los valores de rotación interna de cadera & $\begin{array}{l}\text { Acumular, al menos, } 120 \text { repeticiones semanales de movilidad de } \\
\text { cadera }\end{array}$ & 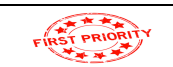 \\
\hline & P.1.1.2 Aumentar los valores de rotación externa de cadera & $\begin{array}{l}\text { Acumular, al menos, } 120 \text { repeticiones semanales de movilidad de } \\
\text { cadera }\end{array}$ & 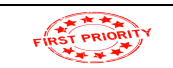 \\
\hline & P.1.1.3 Aumentar los valores de abducción de cadera & $\begin{array}{l}\text { Realizar } 8 \text { series semanales de estiramiento estático con } \\
\text { vibración de la musculatura aductora de cadera }\end{array}$ & Finst \\
\hline & $\begin{array}{l}\text { P.1.1.4 Aumentar los valores de rotación interna } \\
\text { glenohumeral }\end{array}$ & $\begin{array}{l}\text { Realizar entre } 4 \text { y } 6 \text { series semanales con flossing de } \\
\text { estiramientos para el aumento de la RI Glenohumeral }\end{array}$ & 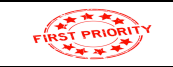 \\
\hline & P.1.1.5 Aumentar los valores de aducción de hombro & $\begin{array}{l}\text { Realizar entre } 2 \text { y } 3 \text { series semanales con flossing de } \\
\text { estiramientos para el aumento de la ADD Glenohumeral }\end{array}$ & fingain \\
\hline & P.1.2.1 Aumentar la longitud de la musculatura isquiosural & $\begin{array}{l}\text { Realizar } 8 \text { series semanales de estiramiento estático con } \\
\text { vibración de la musculatura isquiosural }\end{array}$ & PRIOAITY \\
\hline
\end{tabular}




\begin{tabular}{|c|c|c|c|}
\hline & $\begin{array}{l}\text { P.1.2.2 Aumentar la longitud de la musculatura aductora de } \\
\text { cadera }\end{array}$ & $\begin{array}{l}\text { Realizar } 8 \text { series semanales de estiramiento estático con } \\
\text { vibración de la musculatura aductora de cadera }\end{array}$ & 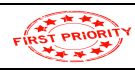 \\
\hline & P.1.3.1 Mejorar la fuerza de glúteo medio & $\begin{array}{l}\text { Activar de forma analítica el glúteo previo a un trabajo de } \\
\text { patrones de movimiento }\end{array}$ & Fing \\
\hline & $\begin{array}{l}\text { P.1.3.2 Integrar la musculatura glútea en los diferentes } \\
\text { movimientos }\end{array}$ & $\begin{array}{l}\text { Activar de forma analítica el glúteo y realizar ejercicios para } \\
\text { llevarlo a función, similares a los de competición }\end{array}$ & 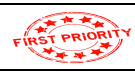 \\
\hline & $\begin{array}{l}\text { P.1.4.2 Mejorar los valores obtenidos en el test propioceptivo } \\
\text { en las } 3 \text { direcciones }\end{array}$ & $\begin{array}{l}\text { Acumular un volumen de } 30-40 \text { minutos semanales de trabajo } \\
\text { propioceptivo }\end{array}$ & fenonily \\
\hline & $\begin{array}{l}\text { P.1.4.3 Mejorar la capacidad de respuesta ante estímulos que } \\
\text { provoquen perturbaciones de un estado de equilibrio }\end{array}$ & $\begin{array}{l}\text { Incluir perturbaciones variadas, de forma progresiva, en los } \\
\text { distintos ejercicios propioceptivos planteados }\end{array}$ & 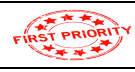 \\
\hline & $\begin{array}{l}\text { P.1.4.4 Mejorar la preactivación muscular ante situaciones } \\
\text { desconocidas (feedforward) }\end{array}$ & $\begin{array}{l}\text { Incluir perturbaciones inesperadas en los distintos ejercicios } \\
\text { propioceptivos planteados }\end{array}$ & 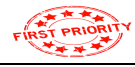 \\
\hline & $\begin{array}{l}\text { P.1.4.6 Mejorar la preactivación muscular (feedforward) } \\
\text { previa a la recepción de saltos unipodales }\end{array}$ & $\begin{array}{l}\text { Incluir estabilización tras recepciones de saltos en diversas } \\
\text { superficies, con y sin perturbaciones conocidas o no }\end{array}$ & 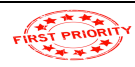 \\
\hline & $\begin{array}{l}\text { P.1.6.1 Aprender la maniobra de "Bracing" y aplicarlo a } \\
\text { distintos ejercicios }\end{array}$ & $\begin{array}{l}\text { Progresar, en amplitud, velocidad o miembros movilizados, en } \\
\text { ejercicios mientras se pide una co-contracción del Core }\end{array}$ & \\
\hline & P.1.6.2 Aumentar la fuerza de la musculatura del Core & $\begin{array}{l}\text { Aplicar un mínimo de } 12 \text { series semanales de ejercicios para la } \\
\text { mejora de la estabilización del Core }\end{array}$ & Rionity \\
\hline & $\begin{array}{l}\text { P.1.6.3 Corregir la asimetría de fuerza encontrada en el Side } \\
\text { Bridge }\end{array}$ & $\begin{array}{l}\text { Empezar y terminar las series de ejercicios anti-rotación o anti } \\
\text { flexión lateral con el lado izquierdo esta vez }\end{array}$ & Rionity \\
\hline & $\begin{array}{l}\text { P.1.6.4 Utilizar la co-contracción muscular para mantener la } \\
\text { postura frente a fuerzas de distintos planos }\end{array}$ & $\begin{array}{l}\text { Realizar ejercicios en los que se pida un bracing para estabilizar } \\
\text { ante perturbaciones conocidas o no }\end{array}$ & \\
\hline \multirow{3}{*}{ 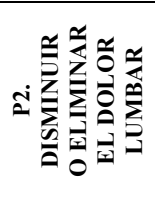 } & $\begin{array}{llllll}\begin{array}{l}\text { P.2.2 } \\
\text { coxolumbopélvico }\end{array} & \text { el control } & \text { motor } & \text { del } & \text { complejo } \\
\end{array}$ & $\begin{array}{l}\text { Acumular un volumen de } 10 \text { minutos semanales de trabajo de } \\
\text { control motor del complejo coxolumbopélvico }\end{array}$ & \\
\hline & $\begin{array}{l}\text { P.2.4 Aprender la maniobra de "Hollowing" y aplicarlo a } \\
\text { distintos ejercicios de control motor }\end{array}$ & $\begin{array}{l}\text { Progresar, en amplitud o miembros movilizados, en ejercicios } \\
\text { mientras se realiza la maniobra de Hollowing con stabilizer }\end{array}$ & \\
\hline & $\begin{array}{l}\text { P.2.5 Concienciar al jugador de la importancia de la higiene } \\
\text { postural en su vida diaria }\end{array}$ & $\begin{array}{l}\text { Asociar acciones diarias frecuentes (mirar el móvil, conducir, } \\
\text { sentarse a comer,...) con correcciones posturales }\end{array}$ & \\
\hline \multirow{4}{*}{ 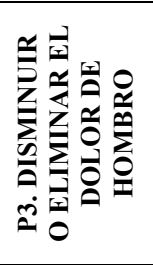 } & $\begin{array}{l}\text { P.3.1 Reeducar el patrón de activación de la musculatura } \\
\text { periescapular }\end{array}$ & $\begin{array}{l}\text { Realizar } 1 \text { estímulo semanal de activación de trapecio medio e } \\
\text { inferior y serrato anterior }\end{array}$ & \\
\hline & $\begin{array}{l}\text { P.3.3 Mejorar la activación de serrato anterior y trapecio } \\
\text { medio e inferior }\end{array}$ & $\begin{array}{l}\text { Aplicar } 1 \text { estímulos suficiente por semana para activar esta } \\
\text { musculatura }\end{array}$ & \\
\hline & $\begin{array}{l}\text { P.3.4 Aumentar la longitud del pectoral menor, especialmente } \\
\text { el derecho }\end{array}$ & $\begin{array}{l}\text { Realizar liberación miofascial y estiramientos estáticos y } \\
\text { balísticos previo a la movilidad glenohumeral }\end{array}$ & 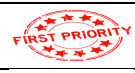 \\
\hline & P.3.5 Potenciar el manguito de rotadores & $\begin{array}{l}\text { Acumular un mínimo de } 4-6 \text { series semanales de ejercicios para } \\
\text { el fortalecimiento del manguito de rotadores externo }\end{array}$ & fringing \\
\hline \multirow{3}{*}{ 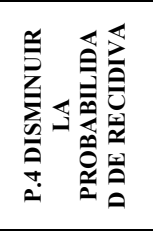 } & $\begin{array}{l}\text { P.4.1 Mejorar la capacidad excéntrica de la musculatura del } \\
\text { cuádriceps }\end{array}$ & $\begin{array}{l}\text { Aplicar un estímulo semanal suficiente como para mejorar la } \\
\text { fuerza excéntrica de este grupo muscular }\end{array}$ & FiRSTPRIOH \\
\hline & $\begin{array}{l}\text { P.4.2 Someter, de forma progresiva y segura, a la musculatura } \\
\text { a estímulos específicos en los que ocurran este tipo de } \\
\text { lesiones }\end{array}$ & $\begin{array}{l}\text { Aplicar un estímulo semanal en el que se realicen acciones de } \\
\text { aceleración, desaceleración (acción de riesgo en carrera) o } \\
\text { frenado excéntrico de flexión de rodilla (riesgo en golpeo) }\end{array}$ & 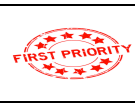 \\
\hline & P.4.3 Evitar la rigidez del recto anterior & $\begin{array}{l}\text { Realizar } 4 \text { series semanales de estiramiento estático con } \\
\text { vibración de esta musculatura }\end{array}$ & tivst \\
\hline \multirow{3}{*}{ 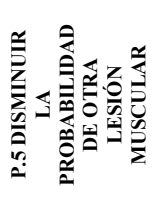 } & $\begin{array}{l}\text { P.5.1 Mejorar la capacidad excéntrica de la musculatura } \\
\text { isquiosural }\end{array}$ & $\begin{array}{l}\text { Aplicar un estímulo semanal suficiente como para mejorar la } \\
\text { fuerza excéntrica de este grupo muscular }\end{array}$ & 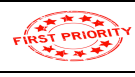 \\
\hline & $\begin{array}{l}\text { P.5.2 Mejorar los valores de fuerza de la musculatura } \\
\text { abductora de cadera }\end{array}$ & $\begin{array}{l}\text { Aplicar dos estímulos semanales suficientes como para mejorar } \\
\text { la fuerza de los abductores de cadera }\end{array}$ & 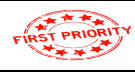 \\
\hline & $\begin{array}{l}\text { P.5.3 Mejorar los valores de fuerza de la musculatura } \\
\text { aductora de cadera }\end{array}$ & $\begin{array}{l}\text { Aplicar un estímulo semanal suficiente como para mejorar la } \\
\text { fuerza de los aductores de cadera }\end{array}$ & First PrioRity \\
\hline
\end{tabular}

Tabla 62: Objetivos Específicos de la Fase II (Rojo = Máxima Prioridad; Amarillo = Prioridad Alta; Verde = Prioridad Moderada)

\subsubsection{Metodología}

\subsubsection{Estructura e Intensidad de la Sesión.}

Es imposible saber con antelación cuándo voy a poder realizar mis entrenamientos semanales con el sujeto ni con quién o cuántas veces entrenará él con el club. En esta fase hay 2 partes bien diferenciadas de 3 semanas de duración cada una: la primera hasta que recibe el alta médica; y la segunda, a partir de ahí. La estructura de la primera parte es igual a la que veníamos haciendo en la fase anterior, con una RPE baja $(4-6)$ y procurando no actuar sobre la musculatura lesionada (que se readapta por su equipo). El trabajo propioceptivo comenzará cuando se tiene constancia de que se realiza con el club (el 14 de Octubre).

En la segunda parte de esta segunda fase hay contenidos más exigentes (trabajo excéntrico) que no deberían realizarse cerca de competición ni de un estímulo similar que pudiese haber realizado con su equipo. Por tanto, en función de cómo se presente cada semana, se intentará aplicar un estímulo excéntrico el día más alejado de competición (siempre que el jugador no entrene justo después de hacerlo con nosotros) y se completará la sesión con aquéllos contenidos que queremos seguir mejorando (movilidad de cadera, rotación interna glenohumeral, propiocepción, Core, Rigidez de pectoral menor y 
ROM de Aductores, Isquiosurales y Recto Anterior). La otra sesión de esa semana se aprovechará para realizar los contenidos a mejorar (los mismos que acabamos de enumerar) más aquéllos que queremos mantener, por haberse alcanzado valores adecuados en la fase anterior (aducción glenohumeral, glúteo, control motor y disociación lumbopélvica, activación de serrato anterior y trapecio medio e inferior o fortalecimiento del manguito de rotadores, además de un trabajo propioceptivo en fatiga).

\subsubsection{Metodología empleada en los Calentamientos y la Vuelta a la Calma}

En la primera parte de esta fase no se realizarán calentamientos tradicionales, ya que se trata de una continuación del trabajo anterior y no existe riesgo ninguno para la zona lesionada, puesto que no se estimula. En la segunda parte, en las sesiones en las que se realiza un trabajo excéntrico, sí es necesario un aumento previo de la temperatura muscular. Así, el calentamiento comenzará con liberación miofascial, posteriormente se realizará una activación en bicicleta estática de $3-5$ minutos y se finalizará con un trabajo de movilidad y estiramientos balísticos.

En la vuelta a la calma se seguirá utilizando el foam roller durante toda la fase, con pasadas lentas sobre la musculatura que ha intervenido en la sesión. Además preguntaremos al jugador por las sensaciones que ha tenido durante el trabajo realizado.

6.3.2.3 Metodología del Entrenamiento para la reeducación del patrón de activación de la musculatura periescapular.

En líneas generales se seguirán las mismas pautas metodológicas de la fase anterior (76). En la primera parte de esta fase el trabajo será una continuación de lo que se venía haciendo, por los mismos motivos. En las últimas 3 semanas esto cambiará. En la sesión más alejada de competición realizaremos: Liberación Miofascial de pectoral menor; Estiramiento estático con flossing para aumentar la rotación interna y la técnica de FNP "Contract Relax" para disminuir la rigidez del pectoral menor. En la justificación de los métodos de entrenamiento se argumenta por qué se utiliza el flossing y la FNP. Se elimina el estiramiento para la aducción de hombro porque se ha alcanzado el rango deseado, pasando a realizarse 1 vez por semana en un estímulo de mantenimiento, lo mismo que ocurre con el trabajo de manguito de rotadores y de activación de Serrato anterior y Trapecio medio e inferior.

La otra sesión que se lleva a cabo en esas 3 semanas (la más cercana a competición) buscará mantener aquéllos valores que se hayan normalizado en la Fase anterior, realizándose un estímulo óptimo para ese objetivo, al mismo tiempo que incidirá en aquéllos que aún no se han alcanzado, como puede ser la rotación interna glenohumeral o la disminución de la rigidez del pectoral menor. Además se seguirá realizando un estímulo de extensión dorsal y de flexores profundos de cuello.

La progresión en la carga se realizará buscando gestos más específicos, globales y de mayor amplitud, y utilizando material más exigente como gomas con mayor tensión o versapulley, que permite aumentar el componente excéntrico. También se pasará de ejercicios unilaterales a bilaterales (76).

\subsubsection{Metodología del Entrenamiento Propioceptivo.}

Durante las 3 primeras semanas se realizó poco trabajo propioceptivo. Tras la lesión se volvió a introducir en las sesiones cuando los miembros del cuerpo técnico hicieron lo propio. La semana del alta competitiva ya realizábamos ejercicios más exigentes en este sentido, y se siguió avanzando hasta el final de las sesiones de entrenamiento.

Se buscaba progresar en el tipo de superficie desestabilizante, las perturbaciones (variando ejes, de esperado a inesperado, de menos a más intensidad,...), la complejidad y especificidad de los movimientos a realizar,... incluyendo material como el láser, que ofrece un feedback tan "minucioso" con los movimientos de la rodilla como visual,...

También se podría progresar utilizando la plataforma vibratoria, ya que parece ser que provoca la activación de un mayor número de receptores motores, aunque también un aumento del umbral de estimulación de las respuestas musculotendinosas, lo cual sobreestimula el sistema neuromuscular y podría aumentar el riesgo de lesión (510). Este problema se podría subsanar realizando este trabajo los 
lunes, ya que el martes "suele" ser día de descanso del jugador. Sin embargo, como ya se comentó, en las primeras semanas de intervención me prohibieron la utilización de este y otros dispositivos.

En esta fase se realizaron $10-15$ minutos de trabajo propioceptivo por sesión en los que se incluyeron saltos desde diferentes trayectorias, aceleraciones y desaceleraciones,... y perturbaciones inesperadas. El objetivo principal era someter al jugador a gestos (controlados) que puedan aparecer en su actividad deportiva y tratar de reproducir el contexto para provocar una respuesta óptima. En competición el jugador no está pendiente de la posición corporal, los ángulos de flexión al caer de un salto,... ya que el balón, rivales, compañeros,... centran toda su atención. Por tanto, a lo largo de esta fase fuimos aumentando la complejidad de las tareas (siempre adaptándonos a su evolución) de modo que el jugador fue expuesto a situaciones que requerían su atención y suponían un estímulo controlado para su sistema propioceptivo y siempre combinando todos los elementos a mi alcance. Además, le di mucha importancia a variar continuamente los estímulos que recibía el jugador (511). Este trabajo se llevó a cabo al final de la sesión, ya que puede haber cierta fatiga, tal y como ocurre en los minutos finales de un partido. El tiempo de recuperación de una pierna era el de ejecución de la contralateral.

\subsubsection{Metodología del Trabajo de la Región Coxolumbopélvica.}

En esta segunda Fase se le dio especial importancia al trabajo isométrico con bracing, es decir, con una co-contracción de toda la musculatura. Se realizaron ejercicios de anti flexión, anti extensión y anti rotación con series cortas $(3-5$ segundos $)$ pero de mayor intensidad. Se realizaron perturbaciones, tanto esperadas como inesperadas en este tipo de trabajos, intentando darle la mayor variedad posible a cada serie (147) (en un pallof press, por ejemplo, no mover siempre los brazos hacia delante, sino hacerlo en diagonal, hacia arriba, abajo, con diferentes angulaciones, con desequilibrios provocados por mi, bien actuando sobre la goma o desestabilizando al sujeto mientras ejecutaba,...) y se incluyeron saltos con estabilización ante diferentes estímulos, ya que es una acción muy común en la posición del jugador.

También se le dio más importancia a materiales como TRX, aerosling, superficies desestabilizantes, fitball, poleas,... que permitían ejercicios más globales y específicos. Era el propio sujeto el que determinaba el número de repeticiones (o yo si detectaba compensaciones). Este trabajo se realizó en cada sesión de entrenamiento durante la Fase II.

En cuanto a la disociación lumbopélvica, al lograr el jugador un mayor control, pasé a realizarla 1 vez por semana (mantenimiento), en el entrenamiento más cercano a competición, y con las mismas premisas de la fase anterior, buscando variedad en los ejercicios y progresando a posiciones bípedas con movimientos más parecidos a los que pueda realizar el jugador (posición de tándem, posiciones específicas de espera del portero controlando valgo de rodilla o flexión lumbar, reincorporaciones desde suelo,...) y con el empleo de gomas para aumentar la dificultad. En cuanto a repeticiones, de nuevo era el jugador el que decidía el momento de parar o empezar o yo si veía que había una pérdida de control continuada o que el jugador se saturaba. Además, al igual que en la fase anterior, no se completaba una repetición si se detectaba pérdida de control.

\subsubsection{Metodología del Trabajo de Flexibilidad y ROM.}

Para el aumento de la extensibilidad muscular y de ROM se seguirán utilizando las mismas estrategias que en la fase anterior, justificadas en el apartado 6.2.2.6. El jugador, una vez recibió el alta competitiva, tuvo 2 estímulos de estiramiento con vibración semanales, realizados de forma autónoma ( $\sin$ mi presencia) por las mañanas, al término de sus entrenamientos. Se le pidió que realizase 4 series de 10 segundos de estiramiento y 5 de descanso con una frecuencia de $30-40 \mathrm{~Hz}$ (428).

Durante nuestras sesiones y sólo en las 3 últimas semanas (debido a la lesión) se realizó la técnica de "Contract Relax" con 6 segundos de contracción isométrica (submáxima (433)) seguidos de 4 segundos de relajación aplicados durante 20 segundos y 3 veces de forma alternativa para cada extremidad (435). Debido a que no alcanzamos los valores de referencia en los tests de flexibilidad, este trabajo se realizó los dos días de entrenamiento en esas últimas 3 semanas.

Por último, el flossing se siguió aplicando dentro del trabajo de hombro, con la intención de aumentar el rango de rotación interna. El vendaje se aplicó con la mano del jugador apoyada en un banco, la primera vuelta con una tensión aproximada del $50 \%$ y se siguió enrollando en sentido craneal. A 
medida que ascendía, el vendaje solapaba la mitad de la banda de la pasada anterior. En la parte superior del hombro, en el lado ventral se aplicó una tensión del $60-80 \%$ mientras que en el lado dorsal del 50 $\%$. El vendaje se retiró a los 2 minutos aproximadamente (514).

\subsubsection{Metodología para el Trabajo Miofascial.}

Al igual que en la fase anterior, se utilizó el foam roller para la vuelta a la calma de nuestras sesiones, realizando pasadas lentas sobre los grupos musculares protagonistas de nuestra sesión. Cada pasada debe durar unos 3 segundos e incidir en los puntos de dolor. Se realizaron 2 series de 30 segundos por grupo muscular (513).

Además, en las sesiones en las que había un trabajo excéntrico, este contenido también se utilizó para los calentamientos, siendo la parte inicial de la sesión. En esta ocasión, las pasadas fueron algo más rápidas que en la vuelta a la calma y también se realizaron 2 series de 30 segundos por grupo muscular.

\subsubsection{Metodología para el Trabajo Excéntrico.}

Una vez que la lesión se ha readaptado completamente y el jugador ha recibido el alta competitiva, es importante aplicar estímulos excéntricos, ya que permitirán al músculo absorber más energía antes de fallar $(359,361)$, teniendo así un efecto preventivo $(191,350,362,363)$. Como ya se ha justificado, el entrenamiento isoinercial es ideal en este sentido $(378,379)$.

En función del grupo muscular que se trabaje se intentará progresar acercándonos, de forma controlada, al gesto y momento en el que se produce la lesión. Por ejemplo, si el recto anterior del cuádriceps tiene mayor riesgo de lesión en acciones de aceleración y deceleración (cambios de dirección) $(250,254,255)$ o en golpeos de balón $(250,256)$, progresaremos hacia ejercicios (siempre excéntricos) que se acerquen a las velocidades (siempre altas) y acciones musculares en las que ese grupo muscular está en riesgo.

Lo ideal en este trabajo sería utilizar la herramienta Smartcoach para monitorizar el entrenamiento, sin embargo no tengo permiso para su uso. Debido a las semanas tan impredecibles que tiene el jugador no busco generar fatiga con la aplicación de este tipo de estímulos. En este sentido, sin utilizar un feedback visual, se pueden realizar entre 3 y 4 series de $6-8$ repeticiones $(377,517)$ y atender a la pérdida subjetiva de velocidad. El tiempo de recuperación será establecido subjetivamente por el jugador. Es importante destacar que sólo se realizan 3 semanas de intervención con este contenido, por lo que no hay mucho margen de progreso.

Además, el sujeto está acostumbrado al trabajo excéntrico y no viene de un periodo transitorio sino de 2 semanas de "parón" (ya que tuvo estímulos excéntricos durante su recuperación). Por ello no es necesario hacer una fase de adaptación a este trabajo aunque tampoco podremos progresar hacia ejercicios que incluyan toma de decisión, perturbaciones inesperadas,... En cualquier caso y aunque disponemos de muy poco tiempo, se intentará durante la ejecución de estos ejercicios aplicar estímulos estocásticos, impredecibles, realizarlos a alta velocidad, incluir la "interferencia intratarea", variando continuamente cada repetición para generar un mayor aprendizaje motor, y tender hacia ejercicios unipodales y vectores horizontales y laterales $(518,519)$.

\subsubsection{Secuenciación de Contenidos}

Como ya se ha comentado, esta fase tiene 2 partes bien diferenciadas. En la tabla 63 se muestra la secuenciación de contenidos de las 3 primeras semanas (hasta el alta competitiva). De nuevo la flecha hacia abajo indica que los contenidos han sido realizados en ese orden, bien durante la sesión o a lo largo de la fase, según donde se encuentre.

\begin{tabular}{|c|c|c|c|c|}
\hline $\begin{array}{c}\text { TIPO DE } \\
\text { TRABAJO }\end{array}$ & SECUENCIACIÓN DE CONTENIDOS & PROG. SES. & PROG. FASE & $\begin{array}{l}\text { RELAC. } \\
\text { CON OBJ. }\end{array}$ \\
\hline \multirow{5}{*}{$\begin{array}{l}\text { Reeducación del } \\
\text { patrón de } \\
\text { Activación del } \\
\text { Complejo } \\
\text { Articular del } \\
\text { Hombro }\end{array}$} & Liberación Miofascial (pectoral menor) & & \multirow{5}{*}{$\begin{array}{l}\text { Variando los } \\
\text { ejercicios, } \\
\text { aumentando la } \\
\text { intensidad e } \\
\text { incluyendo } \\
\text { distinto material. }\end{array}$} & P.3.4 \\
\hline & Flossing + movimientos amplios + Estiramientos (Rotación Interna y Aducción) & & & P.1.1.4-5 \\
\hline & Estiramientos balísticos de pectoral menor & & & P.3.4 \\
\hline & $\begin{array}{l}\text { Ejercicios de Retracción Escapular, Protocolo Blackburn y activación de Serrato } \\
\text { Anterior y Trapecio Medio y superior }\end{array}$ & & & P.3.3 \\
\hline & Potenciación Manguito Rotadores & $\downarrow$ & & P.3.5 \\
\hline
\end{tabular}




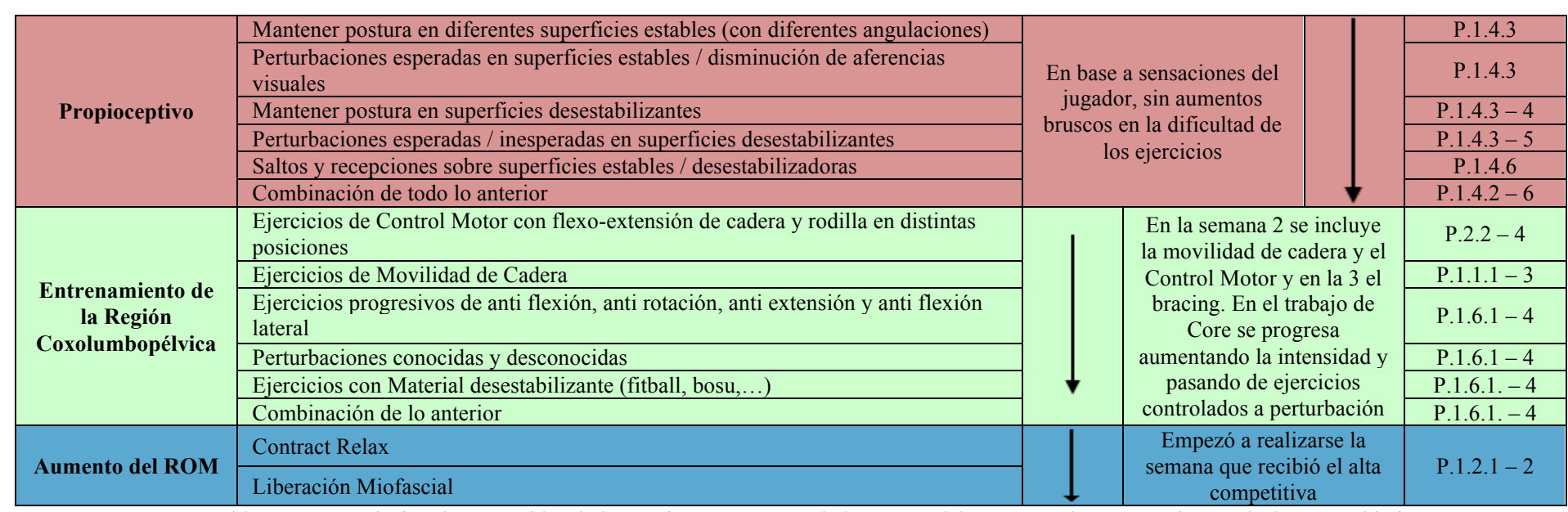

Tabla 63: Secuenciación de Contenidos de las 3 primeras semanas de la Fase 1I del Programa de Intervención y relación con Objetivos

El trabajo propioceptivo se eliminó al principio para evitar un gesto descontrolado que pudiese afectar a la zona lesionada; y se fue incorporando progresivamente. Igual ocurrió con el Bracing, que no se pidió para evitar movimientos bruscos y se incluyó cuando se estimaba que no había riesgo. La vibración no se realizó en estas 3 semanas, porque desconozco el efecto que puede tener sobre la cicatriz (no he encontrado en la literatura nada al respecto, aunque lo he buscado).

En la tabla 64 aparece la secuenciación de las últimas 3 semanas de intervención. Aquí hubo contenidos que necesitaba realizar en los dos entrenamientos (para mejorar) y otros solamente en uno (para evitar perder lo ganado en la fase anterior). El número que aparece en la secuenciación de contenidos indica el orden en el que se realizaba en la sesión; y la cruz si era un contenido que se realizaba una $(\mathrm{x})$ o dos veces $(\mathrm{xx})$ a la semana.

\begin{tabular}{|c|c|c|c|c|c|c|c|}
\hline $\begin{array}{c}\text { TIPO DE } \\
\text { TRABAJO }\end{array}$ & \multicolumn{3}{|c|}{ SECUENCIACIÓN DE CONTENIDOS } & PROG. SES. & \multicolumn{2}{|c|}{ PROG. FASE } & $\begin{array}{c}\text { RELAC. } \\
\text { CON OBJ. }\end{array}$ \\
\hline \multirow{4}{*}{ Excéntricos } & 1 & Excéntrico de cuádriceps con múltiples variantes & $\mathrm{X}$ & \multirow{4}{*}{\multicolumn{3}{|c|}{$\begin{array}{l}\text { Se buscan ejercicios más } \\
\text { específicos y globales, de } \\
\text { mayor intensidad } \\
\text { (sobrecarga excéntrica),... } \\
\text { Cada repetición es distinta } \\
\text { en cuanto a velocidad, } \\
\text { angulaciones o perturbación }\end{array}$}} & P.4.1 \\
\hline & 2 & $\begin{array}{l}\text { Excéntrico de cuádriceps exponiéndolo, de forma controlada a } \\
\text { situación de riesgo }\end{array}$ & $\mathrm{X}$ & & & & P.4.2 \\
\hline & 3 & Excéntrico de isquiosural con múltiples variantes & $\mathrm{X}$ & & & & P.5.1 \\
\hline & 4 & Isométrico / Excéntrico de Aductor & $\mathrm{X}$ & & & & P.5.3 \\
\hline \multirow{6}{*}{$\begin{array}{l}\text { Entrenamiento de } \\
\text { la Región } \\
\text { Coxolumbopélvica }\end{array}$} & 1 & $\begin{array}{l}\text { Ejercicios de Control Motor con flexo-extensión de cadera y rodilla en } \\
\text { distintas posiciones }\end{array}$ & $\mathrm{X}$ & \multirow{6}{*}{\multicolumn{3}{|c|}{$\begin{array}{c}\text { Se incluyen perturbaciones, } \\
\text { primero esperadas y luego } \\
\text { inesperadas, junto con } \\
\text { inestabilidad, intentando } \\
\text { darle variedad a cada } \\
\text { repetición. Además se } \\
\text { varían los materiales } \\
\text { empleados }\end{array}$}} & P. $2.2-4$ \\
\hline & 2 & Ejercicios de Movilidad de Cadera & $\mathrm{XX}$ & & & & P.1.1.1-3 \\
\hline & 3 & $\begin{array}{l}\text { Ejercicios progresivos de anti flexión, anti rotación, anti extensión y } \\
\text { anti flexión lateral }\end{array}$ & $\mathrm{XX}$ & & & & P.1.6.1- 4 \\
\hline & 4 & Perturbaciones conocidas y desconocidas & $\mathrm{XX}$ & & & & P.1.6.1-4 \\
\hline & 5 & Material desestabilizante (fitball, bosu,...) & $\mathrm{XX}$ & & & & P.1.6.1. -4 \\
\hline & 6 & Combinación de lo anterior & $\mathrm{XX}$ & & & & P.1.6.1. -4 \\
\hline \multirow{4}{*}{ Propioceptivo } & 1 & $\begin{array}{l}\text { Ejercicios en distintas superficies desestabilizantes y perturbaciones } \\
\text { esperadas }\end{array}$ & $\mathrm{XX}$ & \multirow{4}{*}{\multicolumn{3}{|c|}{\begin{tabular}{c|} 
Se busca que cada \\
repetición sea distinta, \\
variando la superficie \\
desestabilizante, la posición \\
de partida, los estímulos, la \\
intensidad y dirección de la \\
perturbación,... planteando \\
gestos específicos en \\
situación de fatiga
\end{tabular}}} & P.1.4.1-5 \\
\hline & 2 & $\begin{array}{l}\text { Ejercicios específicos de golpeo o blocaje en superficies } \\
\text { desestabilizantes }\end{array}$ & $\mathrm{XX}$ & & & & P.1.4.1-5 \\
\hline & 3 & $\begin{array}{l}\text { Saltos y recepciones en superficies desestabilizantes con distintos } \\
\text { estímulos }\end{array}$ & $\mathrm{XX}$ & & & & P.1.4.1-6 \\
\hline & 4 & Combinación de lo anterior con perturbaciones inesperadas & $\mathrm{XX}$ & & & & P.1.4.1-6 \\
\hline \multirow{6}{*}{$\begin{array}{l}\text { Reeducación del } \\
\text { patrón de } \\
\text { Activación del } \\
\text { Complejo } \\
\text { Articular del } \\
\text { Hombro }\end{array}$} & 1 & Liberación Miofascial (pectoral menor) & $\mathrm{XX}$ & \multirow{6}{*}{\multicolumn{3}{|c|}{$\begin{array}{l}\text { En los contenidos de } \\
\text { mantenimiento }(\mathrm{X}) \text { se busca } \\
\text { incluir material nuevo, } \\
\text { aumentar la intensidad de } \\
\text { los ejercicios, jugar con la } \\
\text { velocidad, el tipo de } \\
\text { contracción,... }\end{array}$}} & P.3.4 \\
\hline & 2 & $\begin{array}{l}\text { Flossing + movimientos amplios + Estiramientos (Rotación Interna y } \\
\text { Aducción) }\end{array}$ & $\mathrm{XX}$ & & & & P.1.1.4-5 \\
\hline & 3 & Estiramientos balísticos de pectoral menor & $\mathrm{X}$ & & & & P.3.4 \\
\hline & 4 & $\begin{array}{l}\text { Ejercicios de Retracción Escapular, Protocolo Blackburn y activación } \\
\text { de Serrato Anterior y Trapecio Medio y superior }\end{array}$ & $\mathrm{X}$ & & & & P.3.3 \\
\hline & 5 & Potenciación Manguito Rotadores & $\mathrm{X}$ & & & & P.3.5 \\
\hline & 6 & Contract Relax en Pectoral Menor & $\mathrm{XX}$ & & & & P.3.4 \\
\hline \multirow{2}{*}{ Aumento del ROM } & 1 & Estiramiento estático con vibración mecánica / Contract Relax & $\mathrm{XX}$ & \multirow{2}{*}{\multicolumn{3}{|c|}{$\begin{array}{c}\text { No hubo progresión como } \\
\text { tal, se realizó ese trabajo } \\
\text { durante toda la fase }\end{array}$}} & \multirow{2}{*}{$\begin{array}{l}\text { P. } 1.2 .1-2 \\
\quad \text { P. } 4.3\end{array}$} \\
\hline & 2 & Liberación Miofascial & $\mathrm{XX}$ & & & & \\
\hline
\end{tabular}

Tabla 64: Secuenciación de Contenidos de las 3 últimas semanas de la Fase 1I del Programa de Intervención y relación con Objetivos 


\subsubsection{Sesiones}

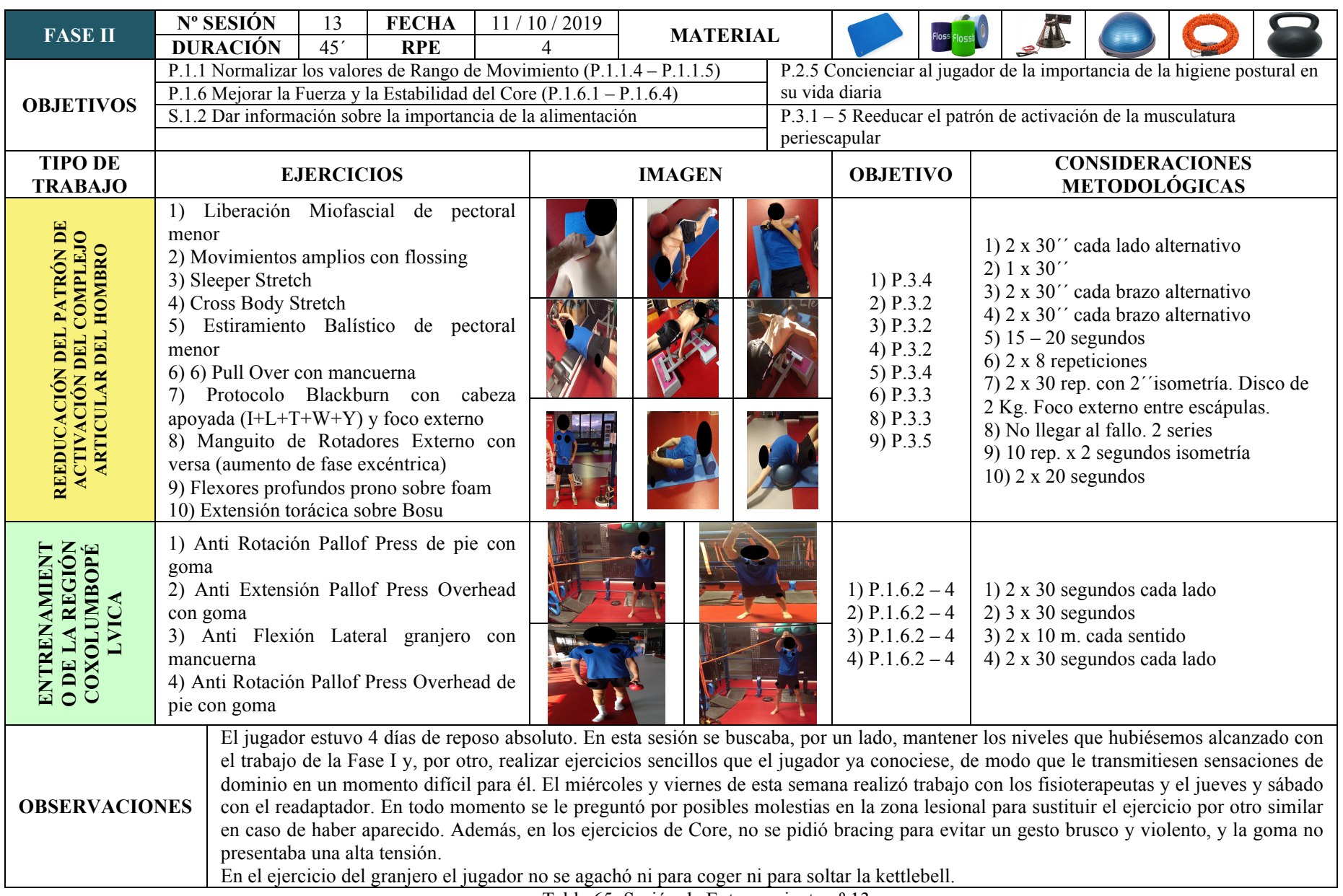

Tabla 65: Sesión de Entrenamiento $n^{\circ} 13$ 


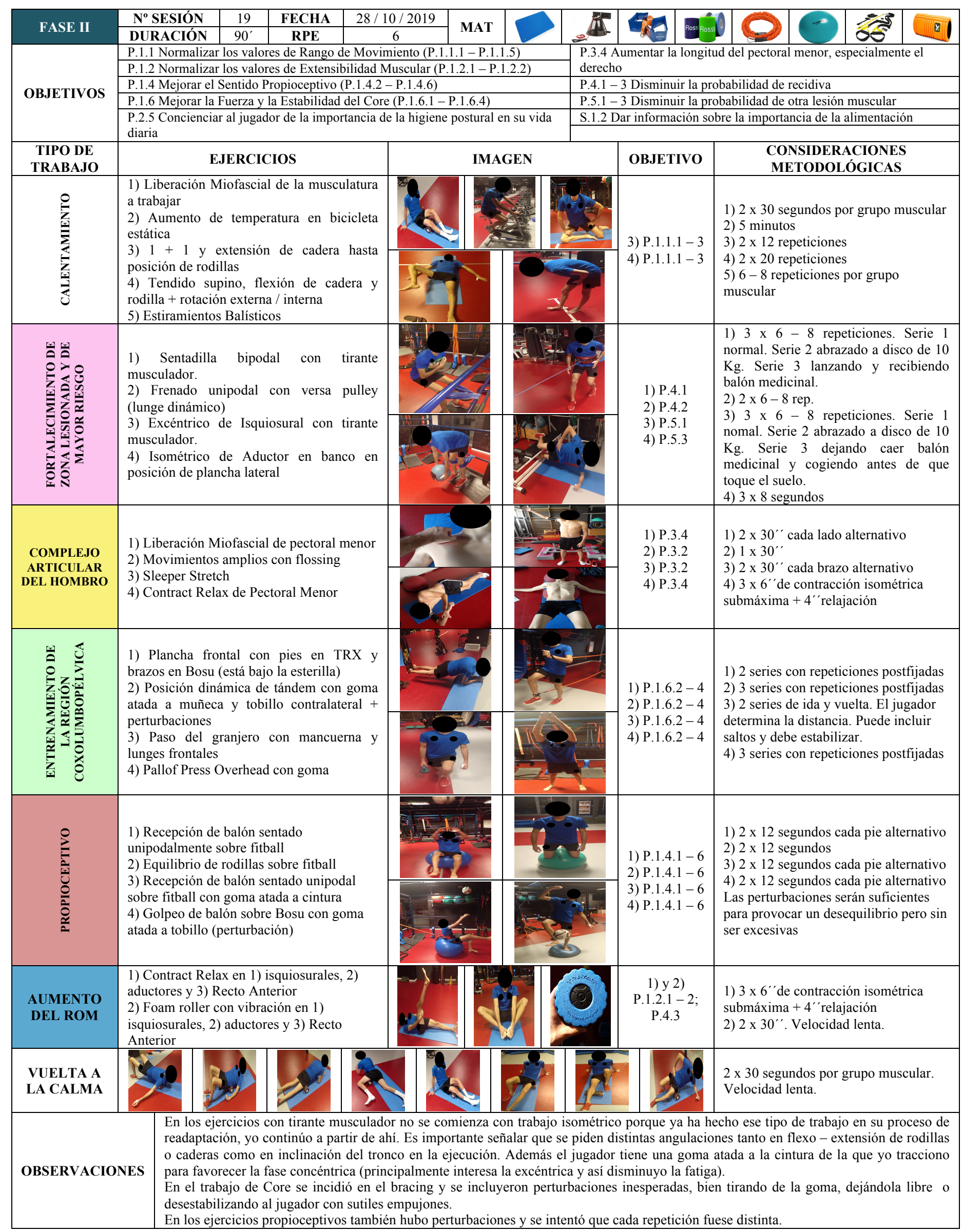
Tabla 66: Sesión de Entrenamiento n ${ }^{\circ} 19$ 


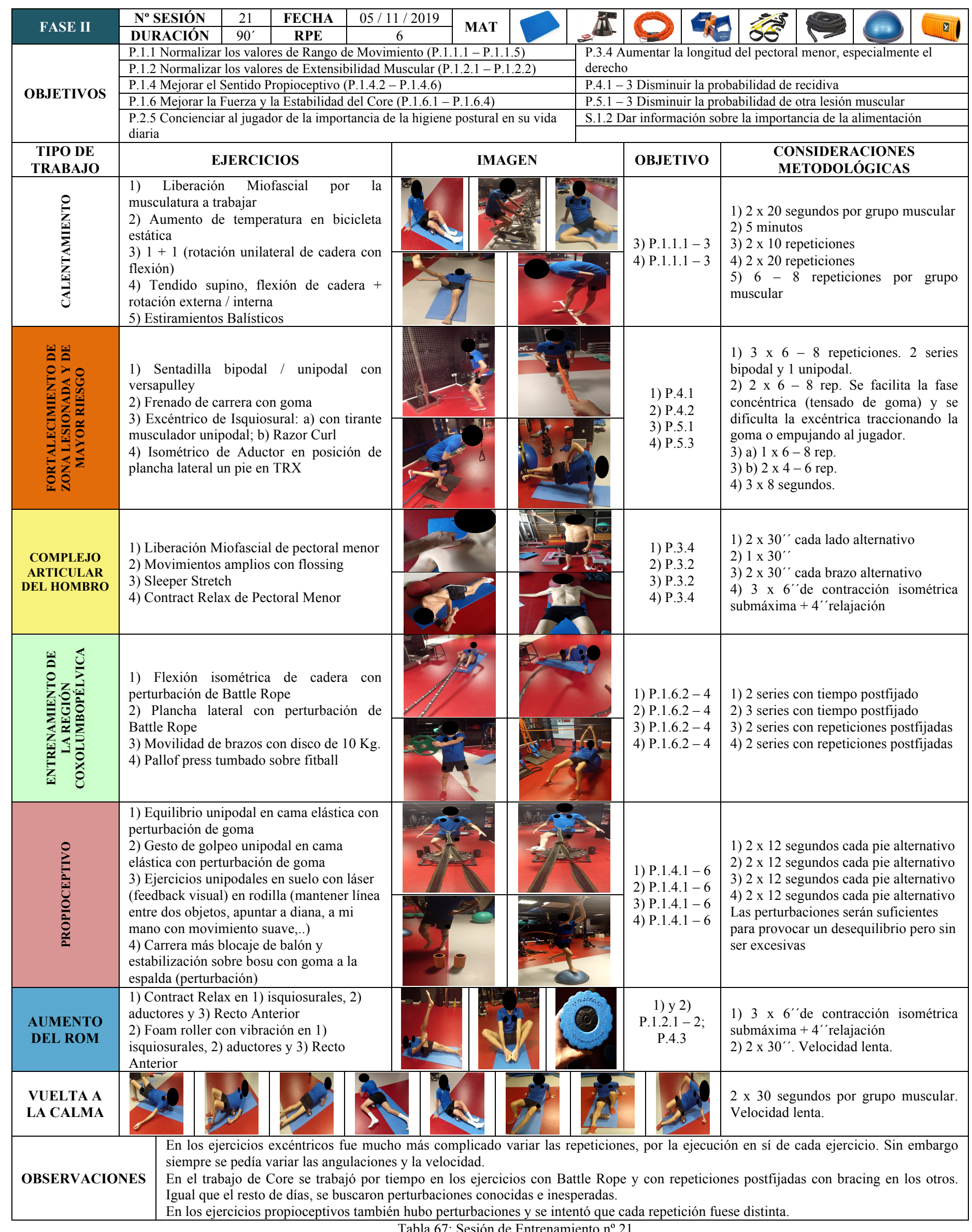
Tabla 67: Sesión de Entrenamiento ${ }^{\circ} 21$ 


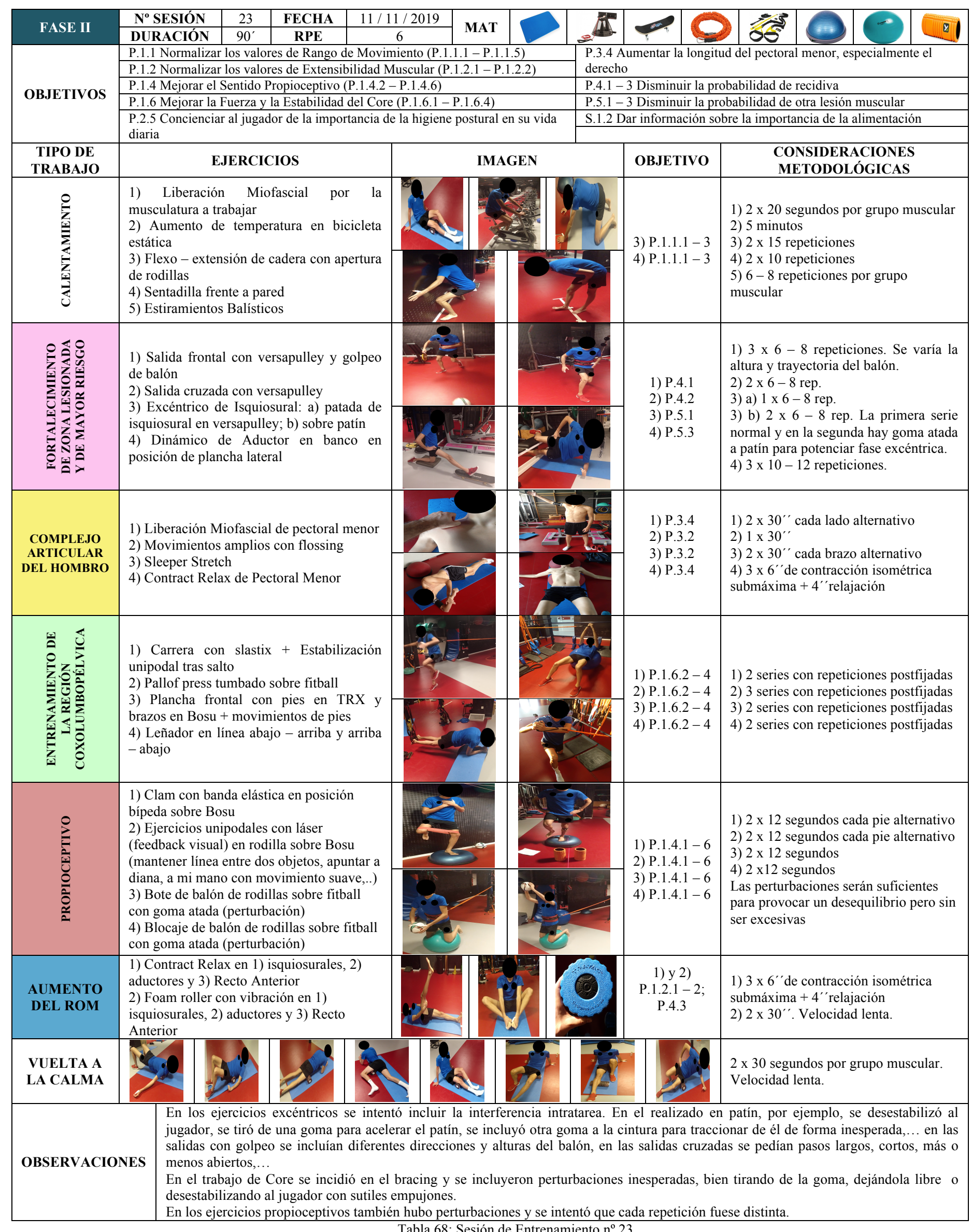
Tabla 68: Sesión de Entrenamiento ${ }^{\circ} 23$ 


\subsubsection{Control / Monitorización del Entrenamiento.}

\subsubsection{Control de la Carga de Entrenamiento.}

En la figura 62 se muestran los valores de carga aguda, crónica y el ratio aguda:crónica del jugador durante esta segunda fase de entrenamiento y en la figura 63 las unidades arbitrarias y los valores de RPE obtenidos en nuestras sesiones en este mismo periodo.

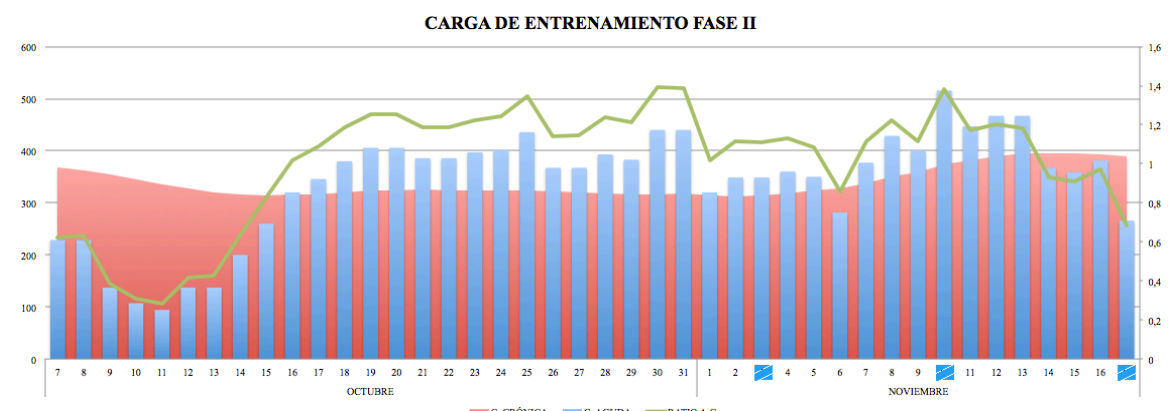

Figura 62: Carga de Entrenamiento Aguda:Crónica durante la Fase II
CARGA DE ENTRENAMIIENTO EN SESIONES DE ENTRENAMIENTO PRRSONAL EN LA FASEII

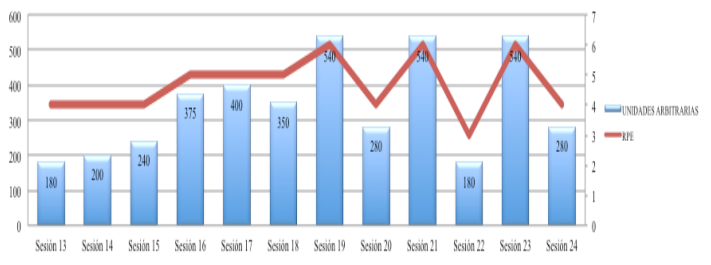

Figura 63: Carga de Entrenamiento en mis sesiones de Entrenamiento Personal de la Fase II

Podemos observar un primer tramo con una disminución considerable de la carga, debido a la lesión. Posteriormente existe un aumento que, en ocasiones, es demasiado brusco, pudiendo exponer al jugador a un mayor riesgo ya que se supera el índice recomendable de carga aguda:crónica, especialmente si tenemos en cuenta que es un jugador que "acaba de salir" de una lesión. El motivo es que el jugador realiza entrenamientos con 3 equipos al mismo tiempo y es necesaria una gran comunicación para evitar situaciones en las que un jugador quede más expuesto. Esas subidas bruscas coinciden con las dobles sesiones pero es imposible prever cuándo tendrán lugar porque el jugador es informado 24 horas antes de cada entrenamiento del equipo y la hora con el que trabaja.

En nuestras sesiones se aprecia que las unidades arbitrarias disminuyen durante la lesión, y en las 6 últimas sesiones ( 3 últimas semanas) se ve cómo las sesiones en la que hacemos los excéntricos tiene una intensidad mayor que las otras, además de por este trabajo porque solía coincidir con otro entrenamiento por la tarde, por lo que había que prestar especial atención a no generar fatiga en el jugador.

\subsubsection{Control del Volumen de Entrenamiento.}

En el caso de haber llevado un control de los desplazamientos largos (saques o despejes) que realizaba el jugador en los entrenamientos, podríamos haber diseñado una progresión segura para su retorno a los entrenamientos y la competición, sin embargo, como no pudimos obtener esa información, no pudimos plantear esta progresión.

La ratio de tracciones y empujes sigue estando dentro de lo recomendable. Además, al igual que ocurría en la primera fase, no se lleva un control de series y repeticiones en la mayoría de los ejercicios, sino que es el jugador el que, en función de cómo se encuentra en cada momento, decide cuánto ejecutar (salvo que detectemos cansancio o pérdida de control)

Por último, en relación a la duración de las sesiones, va aumentando poco a poco durante las 3 primeras semanas, ya que al principio estaba muy limitado en cuanto a contenidos a incluir en las sesiones. En las últimas 3 semanas, el problema no era lo que el jugador podía hacer o no, sino las sesiones de entrenamiento que coincidían casi a la misma hora con las mías y la proximidad de la competición. Para adaptarme a esto, tanto la intensidad como el volumen de esas últimas sesiones de cada semana fueron menores.

\subsubsection{Control de la Escala de Bienestar.}

En la figura 64 se muestran los datos indicados por el jugador en cada uno de los ítems de la escala de bienestar durante cada uno de los días de esta fase de entrenamiento. Por un lado destaca que durante el periodo de lesión indica los mismos valores que estando activo (esto ya se le planteó al jugador). También resalta un valor 2 al ítem "fatiga" del día 10 de Noviembre. Ese día asignó un valor de 9 en la RPE del partido e indicó que se sentía muy pesado y le costaba "hasta sacar de puerta". El jugador llevaba un par de días con fiebre y seguramente ese fuese el motivo de esa fatiga generalizada que mostraba. 
Además, para poder comparar unos valores con otros y ver las fluctuaciones que se han producido, las figuras 65 - 69 reflejan la cantidad total de cada uno de los ítems en cada semana. Los valores de la semana 7 son más bajos en todos los ítems porque esa semana (estaba lesionado) hubo 3 días en los que no entrenó (lunes, martes y domingo). Los valores reflejados en el "Estado de Ánimo" son los más bajos. El motivo es que el jugador no está disputando minutos ni con su equipo ni con el club filial, y este hecho es vital para un futbolista profesional o que aspire a serlo.

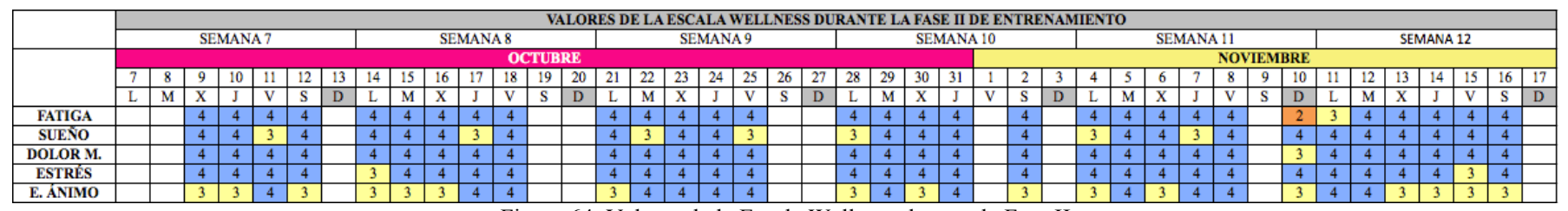

Figura 64: Valores de la Escala Wellness durante la Fase II

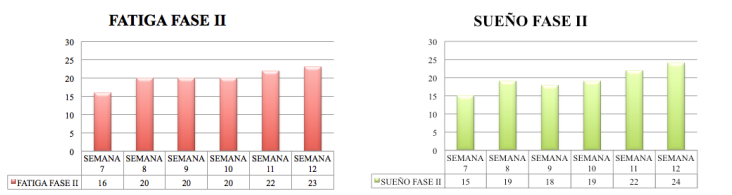

Figuras 65 - 69: Valores de Fatiga, Sueño, Dolor Muscular, Estrés y Estado de Ánimo de la Fase II

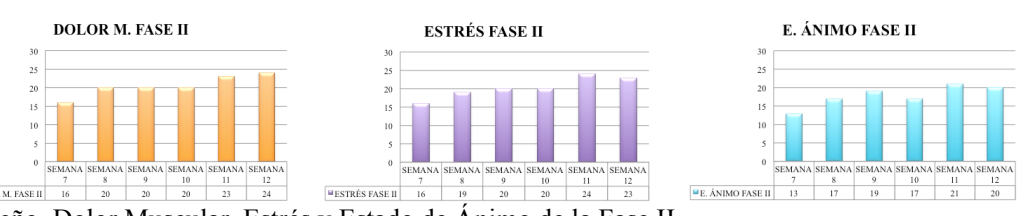

\subsubsection{Control del Dolor Lumbar.}

En la figura 70 se muestran los resultados de su percepción de dolor lumbar durante la Fase II de entrenamiento. El dolor lumbar ha desaparecido totalmente. En la gráfica se observan 3 hitos importantes en este sentido: 1) el día 25 de Octubre, justo 2 días después de su alta competitiva, ya que el jugador tiene doble sesión de entrenamiento (con el primer equipo y con el club filial) y no indica NINGUNA sensación de dolor en ninguna de las dos sesiones); 2) el día 30 de Octubre, por la misma razón; y 3) el día 10 de Noviembre, cuando consigue disputar un partido completo totalmente asintomático.

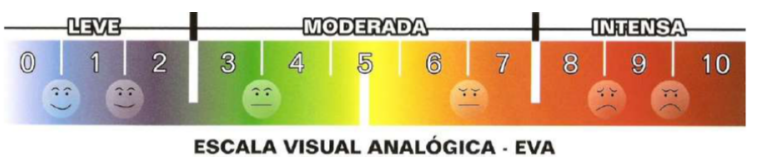

Figura 60: Escala Analógica Visual de Dolor entregada al jugador
PERCEPCIÓN DE DOLOR LUMBAR. FASE II

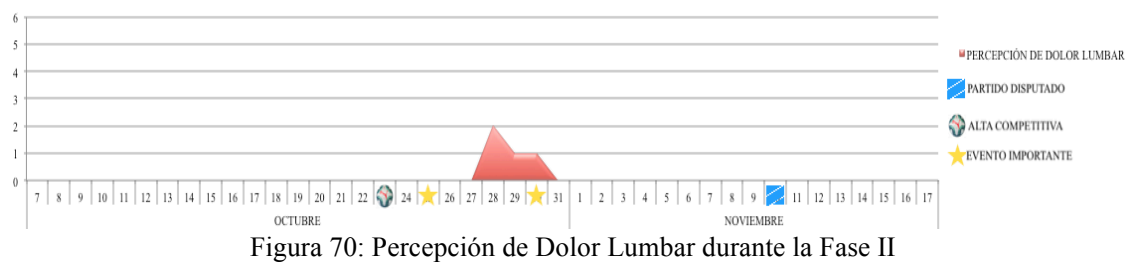

\subsubsection{Reflexión sobre lo planificado en la Fase II.}

Como ya se ha comentado esta fase tiene dos partes bien diferenciadas. Antes del alta competitiva volvió el orden. El jugador entrenaba días alternos con los fisios y con el readaptador. Mi única adaptación era para elegir ejercicios y contenidos que no afectasen o sobre estimulasen la zona lesionada. La carga de entrenamiento fue más baja esos días y con frecuencia le preguntaba cómo se encontraba o si sentía molestia en algún ejercicio.

Una vez recibió el alta comenzaron de nuevo las dobles sesiones y la alternancia de entrenamientos con los 3 equipos (el suyo, el primer equipo y el club filial). Dada la incertidumbre de cada semana, aproveché el día más alejado de competición para incluir un estímulo excéntrico y el otro para trabajo de mantenimiento. Ese día la carga era menor. En función de cómo se encontraba el jugador o la proximidad del próximo entrenamiento podíamos quitar series de algunos ejercicios. Al igual que en la fase anterior, si en la misma tarde entrenaba conmigo y en campo disminuía el volumen de trabajo propioceptivo.

De nuevo la implicación del jugador ha sido máxima ya que, o entrenaba con algún equipo o estaba disponible y dispuesto a trabajar conmigo (salvo el lunes 4 de Noviembre que tenía cita con el oculista y se ofreció a entrenar en su día de descanso). Eso me ha facilitado mucho mi trabajo ya que, de no ser por él habría sido muy complicado realizar todas las sesiones.

\subsubsection{Evaluación del Progreso}

En la tabla 69 se comparan los datos obtenidos en la evaluación de la Fase I y de la Fase II. Además se incluye una escala de valores que indica si el objetivo no se ha cumplido (rojo), si se ha alcanzado (verde) o si ha sobrepasado el valor de referencia (azul). 


\begin{tabular}{|c|c|c|c|c|c|c|c|c|c|c|}
\hline \multirow{2}{*}{\multicolumn{2}{|c|}{ OBJETIVOS }} & \multicolumn{2}{|c|}{$\begin{array}{l}\text { RESULT. } \\
\text { EV.FASE I }\end{array}$} & \multirow{2}{*}{ TEST } & \multicolumn{2}{|c|}{$\begin{array}{l}\text { RESULT. } \\
\text { EV. FASE II }\end{array}$} & \multirow{2}{*}{$\begin{array}{l}\text { VALOR } \\
\text { REF. }\end{array}$} & \multicolumn{2}{|c|}{ MEJORA } & \multirow{2}{*}{$\begin{array}{c}\text { ESC. } \\
\text { COLOR }\end{array}$} \\
\hline & & IZQ & DER & & IZQ & DER & & IZQ & DER & \\
\hline \multirow{2}{*}{ P.1.1.1 Aumentar los valores de rotación interna de cadera } & Cadera $0^{\circ}$ & $45^{\circ}$ & $45^{\circ}$ & \multirow{2}{*}{ A. 5} & $45^{\circ}$ & $45^{\circ}$ & $35^{\circ}-40^{\circ}$ & $0^{\circ}$ & $0^{\circ}$ & \\
\hline & Cadera $90^{\circ}$ & $35^{\circ}$ & $30^{\circ}$ & & $35^{\circ}$ & $35^{\circ}$ & $35^{\circ}-45^{\circ}$ & $0^{\circ}$ & $5^{\circ}$ & \\
\hline \multirow{2}{*}{ P.1.1.2 Aumentar los valores de rotación externa de cadera } & Cadera $0^{\circ}$ & $30^{\circ}$ & $42^{\circ}$ & \multirow{2}{*}{ A. 6} & $34^{\circ}$ & $44^{\circ}$ & $45^{\circ}$ & $4^{\circ}$ & $2^{\circ}$ & \\
\hline & Cadera $90^{\circ}$ & $35^{\circ}$ & $40^{\circ}$ & & $38^{\circ}$ & $42^{\circ}$ & $45^{\circ}$ & $3^{\circ}$ & $2^{\circ}$ & \\
\hline \multicolumn{2}{|l|}{ P.1.1.3 Aumentar los valores de abducción de cadera } & $45^{\circ}$ & $42^{\circ}$ & A.9 & $45^{\circ}$ & $45^{\circ}$ & $45^{\circ}$ & $0^{\circ}$ & $3^{\circ}$ & \\
\hline \multicolumn{2}{|l|}{ P.1.1.4 Aumentar los valores de rotación interna glenohumeral } & $62^{\circ}$ & $58^{\circ}$ & A.12 & $66^{\circ}$ & $64^{\circ}$ & $70^{\circ}$ & $4^{\circ}$ & $6^{\circ}$ & \\
\hline \multicolumn{2}{|l|}{ P.1.1.5 Aumentar los valores de aducción de hombro } & $30^{\circ}$ & $30^{\circ}$ & A.14 & $30^{\circ}$ & $30^{\circ}$ & $30^{\circ}$ & $0^{\circ}$ & $0^{\circ}$ & \\
\hline \multicolumn{2}{|c|}{ P.1.2.1 Aumentar la longitud de la musculatura isquiosural } & $30^{\circ}$ & $32^{\circ}$ & A.2 & $27^{\circ}$ & $29^{\circ}$ & $15^{\circ}$ & $3^{\circ}$ & $3^{\circ}$ & \\
\hline \multicolumn{2}{|c|}{ P.1.4.2 Mejorar los valores del test propioceptivo en las 3 direcciones } & 80 & 78 & C.1 & 83 & 82 & - & 3 & 4 & \\
\hline \multicolumn{2}{|c|}{ P.1.6.2 Aumentar la fuerza de la musculatura del Core } & \multicolumn{2}{|c|}{$158 / 156$} & B. $4-6$ & \multicolumn{2}{|c|}{$168 / 171$} & $146 / 144$ & \multicolumn{2}{|c|}{$10^{\prime \prime} / 15^{\prime \prime}$} & \\
\hline \multicolumn{2}{|c|}{ P.1.6.3 Corregir la asimetría de fuerza encontrada en el Side Bridge } & $91^{\prime \prime}$ & $100^{\prime \prime}$ & B.5 & $103^{\prime \prime}$ & $108^{\prime \prime}$ & $97^{\prime \prime} / 94^{\prime}$ & $12^{\prime \prime}$ & $8^{\prime \prime}$ & \\
\hline \multicolumn{2}{|c|}{ P.3.4 Aumentar la longitud del pectoral menor, especialmente el derecho } & 7,25 & 6,8 & A.15 & 7,35 & 6,98 & IPM $>7,4$ & 0,10 & 0,18 & \\
\hline \multicolumn{2}{|c|}{ P.4.3 Evitar la rigidez del recto anterior } & - & + & A.3 & - & - & Negativo & & & \\
\hline \multicolumn{2}{|c|}{ P.5.2 Mejorar los valores de fuerza de la musculatura abductora de cadera } & $\mathrm{X}$ & $\mathrm{X}$ & B.2 & $\mathrm{X}$ & $\mathrm{X}$ & $2,4-3,6$ & $\mathrm{X}$ & $\mathrm{X}$ & \\
\hline \multirow{2}{*}{\multicolumn{2}{|c|}{ P.5.3 Mejorar los valores de fuerza de la musculatura aductora de cadera }} & $\mathrm{X}$ & $\mathrm{X}$ & B.1 & $X$ & $X$ & $2,2-3,0$ & $X$ & $\mathrm{X}$ & \\
\hline & & $\mathrm{X}$ & $\mathrm{X}$ & B.3 & $\mathrm{X}$ & $\mathrm{X}$ & $2,8-4,4$ & $\mathrm{X}$ & $X$ & \\
\hline
\end{tabular}

Tabla 69: Grado de consecución de los Objetivos de la Fase II.

Si nos fijamos en los resultados, la mejora que se produce en esta fase es menor que la de la anterior. Esto puede deberse a dos motivos: 1) por el principio del entrenamiento de "Retornos en Disminución", que indica que la mejora es bastante grande al principio pero más lenta a medida que el sujeto se acerca a su límite, y más probablemente 2) porque el tiempo entre una evaluación y otra ha sido considerablemente menor (apenas 3 semanas, aunque los valores de la evaluación de la fase I se realizaron tras un periodo de disminución de actividad).

Tampoco pude en esta fase utilizar el dinamómetro para comprobar el ratio ADD:ABD de cadera, habría sido muy interesante no sólo comprobar si había déficit en la fuerza de esta musculatura en la fase anterior sino si se había normalizado tras el trabajo realizado, para extraer conclusiones objetivas. Desgraciadamente fue imposible aunque se intentó.

Al igual que ocurría en la fase anterior e independientemente de que se hayan alcanzado varios de los objetivos planteados, lo más importante es que el jugador puede entrenar, incluso en doble sesión, y competir sin ninguna molestia, ni en hombro ni en zona lumbar. Hacía 3 años que el sujeto no podía decir esto así que es, para mí, toda una satisfacción.

\title{
7-. RESULTADOS (EVALUACIÓN FINAL)
}

\author{
"La calidad nunca es un accidente; siempre es el resultado de un \\ esfuerzo de la inteligencia" \\ John Ruskin, escritor y sociólogo británico $(1819-1900)$
}

\subsection{Resultados de los Tests de Flexibilidad y ROM}

\begin{tabular}{|c|c|c|c|c|c|c|c|c|c|c|c|c|}
\hline \multicolumn{13}{|c|}{ RESULTADOS DE LA EVALUACIÓN FINAL } \\
\hline \multirow{6}{*}{ 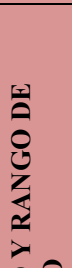 } & \multirow{2}{*}{\multicolumn{2}{|c|}{ TEST }} & \multicolumn{2}{|c|}{$\begin{array}{l}\text { EVALUACIÓN } \\
\text { INICIAL } \\
\text { (9 y } 21 / 08 \text { / 19) }\end{array}$} & \multirow{2}{*}{\multicolumn{2}{|c|}{$\begin{array}{l}\text { VALORES DE } \\
\text { REFERENCIA }\end{array}$}} & \multicolumn{2}{|c|}{$\begin{array}{l}\text { FINAL FASE I } \\
(16 \text { y } 28 / 10 / 19)\end{array}$} & \multicolumn{2}{|c|}{$\begin{array}{c}\text { EVALUACIÓN } \\
\text { FINAL } \\
(18 / 11 / 19)\end{array}$} & \multicolumn{2}{|c|}{$\begin{array}{c}\text { DIFERENCIA } \\
\text { INICIAL / } \\
\text { FINAL }\end{array}$} \\
\hline & & & IZQ & DER & & & IZQ & DER & IZQ & DER & IZQ & DER \\
\hline & \multicolumn{2}{|l|}{ 1. Lunge Test } & $35^{\circ}$ & $34^{\circ}$ & $36,5^{\circ}$ & $(145)$ & $33^{\circ}$ & $33^{\circ}$ & $34^{\circ}$ & $36^{\circ}$ & $+1^{\circ}$ & $-2^{\circ}$ \\
\hline & \multicolumn{2}{|l|}{ 2. Test de Kea } & $35^{\circ}$ & $40^{\circ}$ & $15^{\circ}$ & - & $30^{\circ}$ & $32^{\circ}$ & $27^{\circ}$ & $29^{\circ}$ & $+8^{\circ}$ & $+11^{\circ}$ \\
\hline & \multicolumn{2}{|l|}{ 3. Thomas Test } & \multicolumn{2}{|c|}{ Psoas der acortado } & Negativo & (27) & \multicolumn{2}{|c|}{ Negativo } & \multicolumn{2}{|c|}{ Negativo } & \multicolumn{2}{|c|}{-} \\
\hline & \multicolumn{2}{|l|}{ 4. Test de Ober Modificado } & \multicolumn{2}{|c|}{ Negativo } & Negativo & $(27)$ & \multicolumn{2}{|c|}{-} & \multicolumn{2}{|c|}{ Negativo } & \multicolumn{2}{|c|}{-} \\
\hline \multirow{7}{*}{ 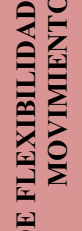 } & \multirow{2}{*}{ 5. Hip Internal Rotation Test } & C. $0^{\circ}$ & $40^{\circ}$ & $38^{\circ}$ & $35^{\circ}-40^{\circ}$ & $(147)$ & $45^{\circ}$ & $45^{\circ}$ & $45^{\circ}$ & $45^{\circ}$ & $+5^{\circ}$ & $+7^{\circ}$ \\
\hline & & C. $90^{\circ}$ & $30^{\circ}$ & $25^{\circ}$ & $35^{\circ}-45^{\circ}$ & $(147)$ & $35^{\circ}$ & $30^{\circ}$ & $35^{\circ}$ & $35^{\circ}$ & $+5^{\circ}$ & $+10^{\circ}$ \\
\hline & \multirow{2}{*}{ 6. Hip External Rotation Test } & C. $0^{\circ}$ & $20^{\circ}$ & $30^{\circ}$ & $45^{\circ}$ & (147) & $30^{\circ}$ & $42^{\circ}$ & $34^{\circ}$ & $44^{\circ}$ & $+14^{\circ}$ & $+14^{\circ}$ \\
\hline & & C. $90^{\circ}$ & $25^{\circ}$ & $30^{\circ}$ & $45^{\circ}$ & (147) & $35^{\circ}$ & $40^{\circ}$ & $38^{\circ}$ & $42^{\circ}$ & $+13^{\circ}$ & $+12^{\circ}$ \\
\hline & \multicolumn{2}{|l|}{ 7. Passive Hip Flexion Test } & $145^{\circ}$ & $140^{\circ}$ & $125^{\circ}$ & $(27)$ & - & - & $140^{\circ}$ & $140^{\circ}$ & $-5^{\circ}$ & $=$ \\
\hline & \multicolumn{2}{|l|}{ 8. Passive Hip Extension Test } & $10^{\circ}$ & $15^{\circ}$ & $10^{\circ}$ & $(27)$ & - & - & $10^{\circ}$ & $12^{\circ}$ & $=$ & $-3^{0}$ \\
\hline & \multicolumn{2}{|l|}{ 9. Passive Hip Abduction Test } & $40^{\circ}$ & $35^{\circ}$ & $45^{\circ}$ & $(27)$ & $45^{\circ}$ & $42^{\circ}$ & $45^{\circ}$ & $45^{\circ}$ & $+5^{\circ}$ & $+10^{\circ}$ \\
\hline$\hat{F}$ & \multicolumn{2}{|l|}{ 10. Passive Hip Adduction Test } & $10^{\circ}$ & $10^{\circ}$ & $10^{\circ}$ & $(27)$ & - & - & $10^{\circ}$ & $10^{\circ}$ & $=$ & $=$ \\
\hline 国 & \multicolumn{2}{|l|}{ 11. Shoulder Flexion } & $180^{\circ}$ & $180^{\circ}$ & $180^{\circ}$ & $(27)$ & $185^{\circ}$ & $190^{\circ}$ & $180^{\circ}$ & $185^{\circ}$ & $=$ & $+5^{\circ}$ \\
\hline$F$ & \multicolumn{2}{|c|}{ 12. Shoulder Internal Rotation ROM } & $50^{\circ}$ & $40^{\circ}$ & $70^{\circ}$ & $(27)$ & $62^{\circ}$ & $58^{\circ}$ & $66^{\circ}$ & $64^{\circ}$ & $+16^{\circ}$ & $+24^{\circ}$ \\
\hline$\gtrless$ & \multicolumn{2}{|c|}{ 13. Shoulder External Rotation ROM } & $90^{\circ}$ & $95^{\circ}$ & $90^{\circ}$ & $(27)$ & $95^{\circ}$ & $95^{\circ}$ & $95^{\circ}$ & $95^{\circ}$ & $+5^{\circ}$ & $=$ \\
\hline & \multicolumn{2}{|c|}{ 14. Posterior Shoulder Flexibility Test } & $25^{\circ}$ & $25^{\circ}$ & $30^{\circ}$ & $(27)$ & $30^{\circ}$ & $30^{\circ}$ & $30^{\circ}$ & $30^{\circ}$ & $+5^{\circ}$ & $+5^{\circ}$ \\
\hline & \multicolumn{2}{|c|}{ 15. Longitud del Pectoral Menor } & 7,14 & 6,5 & IPM $>7,44$ & $(77)$ & 7,25 & 6,8 & 7,35 & 6,98 & $+0,21$ & $+0,48$ \\
\hline
\end{tabular}

Tabla 70: Comparación entre la Evaluación Inicial y Final en los tests de Flexibilidad y ROM 


\subsection{Resultados de los Tests de Fuerza Analíticos}

\begin{tabular}{|c|c|c|c|c|c|c|c|c|c|c|c|}
\hline \multicolumn{12}{|c|}{ RESULTADOS DE LA EVALUACIÓN INICIAL } \\
\hline \multirow{9}{*}{ 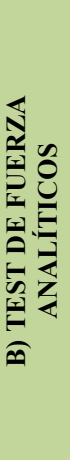 } & TEST & \multicolumn{2}{|c|}{$\begin{array}{l}\text { EVALUACIÓN } \\
\text { INICIAL } \\
\text { (9 y } 21 \text { / } 08 \text { / 19) }\end{array}$} & \multirow{2}{*}{\multicolumn{2}{|c|}{$\begin{array}{l}\text { VALORES DE } \\
\text { REFERENCIA }\end{array}$}} & \multicolumn{2}{|c|}{$\begin{array}{c}\text { FINAL FASE I } \\
(16 \text { y } 28 / 10 / 19)\end{array}$} & \multicolumn{2}{|c|}{$\begin{array}{c}\text { EVALUACIÓN } \\
\text { FINAL } \\
(18 / 11 / 19)\end{array}$} & \multicolumn{2}{|c|}{$\begin{array}{l}\text { DIFERENCIA } \\
\text { INICIAL / } \\
\text { FINAL }\end{array}$} \\
\hline & & IZQ & DER & & & IZQ & DER & IZQ & DER & IZQ & DER \\
\hline & 1. Eccentric Hip Adduction & 2,48 & 2,51 & $2,2-3,0$ & $(83)$ & $\mathrm{X}$ & $\mathrm{X}$ & $\mathrm{X}$ & $\mathrm{X}$ & $\mathrm{X}$ & $\mathrm{X}$ \\
\hline & 2. Eccentric Hip Abduction & 2,48 & 2,75 & $2,4-3,6$ & $(83)$ & $\mathrm{X}$ & $\mathrm{X}$ & $\mathrm{X}$ & $\mathrm{X}$ & $\mathrm{X}$ & $\mathrm{X}$ \\
\hline & 3. Squeeze Test & \multicolumn{2}{|c|}{3,01} & $2,8-4,4$ & $(83)$ & $\mathrm{X}$ & $\mathrm{X}$ & $\mathrm{X}$ & $\mathrm{X}$ & $\mathrm{X}$ & $\mathrm{X}$ \\
\hline & 4. Biering Sorensen Modificado & \multicolumn{2}{|c|}{$38^{\prime}$} & $146^{\prime \prime}$ & $(95)$ & \multicolumn{2}{|c|}{$158^{\prime \prime}$} & \multicolumn{2}{|c|}{$168^{\prime \prime}$} & \multicolumn{2}{|c|}{$130^{\prime \prime}$} \\
\hline & 5. Side Bridge & $71^{\prime \prime}$ & $61^{\prime \prime}$ & $\begin{array}{l}\text { Izq: 97' } \\
\text { Der: 94' }\end{array}$ & $(95)$ & $91^{\prime \prime}$ & $100^{\prime \prime}$ & $103^{\prime \prime}$ & $108^{\prime \prime}$ & $32^{\prime \prime}$ & $47^{\prime \prime}$ \\
\hline & 6. Trunk Flexor Endurance Test & \multicolumn{2}{|c|}{$56^{\prime \prime}$} & $144^{\prime \prime}$ & $(95)$ & \multicolumn{2}{|c|}{$156^{\prime \prime}$} & \multicolumn{2}{|c|}{$171^{\prime \prime}$} & \multicolumn{2}{|c|}{$115^{\prime \prime}$} \\
\hline & 7. Scapular Dyskinesis Test & $\begin{array}{l}\text { Fx: } 2 \\
\text { Abd: } 2 \\
\text { A Sutil }\end{array}$ & $\begin{array}{c}\text { Fx: } 2 \\
\text { Abd: } 1 \\
\text { Normal }\end{array}$ & $\begin{array}{c}\text { Normal / } \\
\text { Anom sutil } \\
\text { / Obvia }\end{array}$ & $(98)$ & $\begin{array}{c}\text { Fx: } 1 \\
\text { Abd: } 1 \\
\text { Normal }\end{array}$ & $\begin{array}{c}\text { Fx: } 1 \\
\text { Abd: } 1 \\
\text { Normal }\end{array}$ & $\begin{array}{c}\text { Fx: } 1 \\
\text { Abd: } 1 \\
\text { Normal }\end{array}$ & $\begin{array}{c}\text { Fx: } 1 \\
\text { Abd: } 1 \\
\text { Normal }\end{array}$ & $\begin{array}{c}\text { Fx: } 2 \text { a } 1 \\
\text { Abd: } 2 \text { a } \\
1\end{array}$ & $\begin{array}{c}\text { Fx: } 2 \\
\text { a } 1\end{array}$ \\
\hline
\end{tabular}

Tabla 71: Comparación entre la Evaluación Inicial y Final en los tests de Fuerza Analíticos

\subsection{Resultados del SEBT Modificado}

\begin{tabular}{|c|c|c|c|c|c|c|c|c|c|c|}
\hline \multicolumn{11}{|c|}{ RESULTADOS DE LA EVALUACIÓN INICIAL } \\
\hline \multicolumn{11}{|c|}{ C) DÉFICIT PROPIOCEPTIVO } \\
\hline \multirow[t]{2}{*}{ TEST } & \multicolumn{2}{|c|}{$\begin{array}{l}\text { EVALUACIÓN } \\
\text { INICIAL } \\
\text { (9 y } 21 \text { / } 08 \text { / 19) }\end{array}$} & \multirow{2}{*}{\multicolumn{2}{|c|}{$\begin{array}{l}\text { VALORES DE } \\
\text { REFERENCIA }\end{array}$}} & \multicolumn{2}{|c|}{$\begin{array}{c}\text { FINAL FASE I } \\
(16 \text { y } 28 / 10 / 19)\end{array}$} & \multicolumn{2}{|c|}{$\begin{array}{c}\text { EVALUACIÓN } \\
\text { FINAL } \\
(18 / 11 / 19)\end{array}$} & \multicolumn{2}{|c|}{$\begin{array}{c}\text { DIFERENCIA } \\
\text { INICIAL / FINAL }\end{array}$} \\
\hline & IZQ & DER & & & IZQ & DER & IZQ & DER & IZQ & DER \\
\hline 1. SEBT Modificado & $\begin{array}{c}\text { A: } 74 \\
\text { PM: } 81 \\
\text { PL: } 72\end{array}$ & $\begin{array}{c}\text { A: } 67 \\
\text { PM: } 84 \\
\text { PL: } 84\end{array}$ & $<4 \mathrm{~cm}$ ANT & $(107)$ & $\begin{array}{c}\text { A: } 80 \\
\text { PM: } 88 \\
\text { PL: } 79\end{array}$ & $\begin{array}{c}\text { A: } 78 \\
\text { PM: } 93 \\
\text { PL: } 88\end{array}$ & $\begin{array}{c}\text { A: } 83 \\
\text { PM: } 88 \\
\text { PL: } 83\end{array}$ & $\begin{array}{c}\text { A: } 82 \\
\text { PM: } 90 \\
\text { PL: } 90\end{array}$ & $\begin{array}{c}\text { A: } 9 \\
\text { PM: } 7 \\
\text { PL: } 11\end{array}$ & $\begin{array}{l}\text { A: } 15 \\
\text { PM: } 6 \\
\text { PL: } 6\end{array}$ \\
\hline
\end{tabular}

Tabla 72: Comparación entre la Evaluación Inicial y Final en el Test SEBT Modificado

\subsection{Resultados de la Valoración Postural Estática}

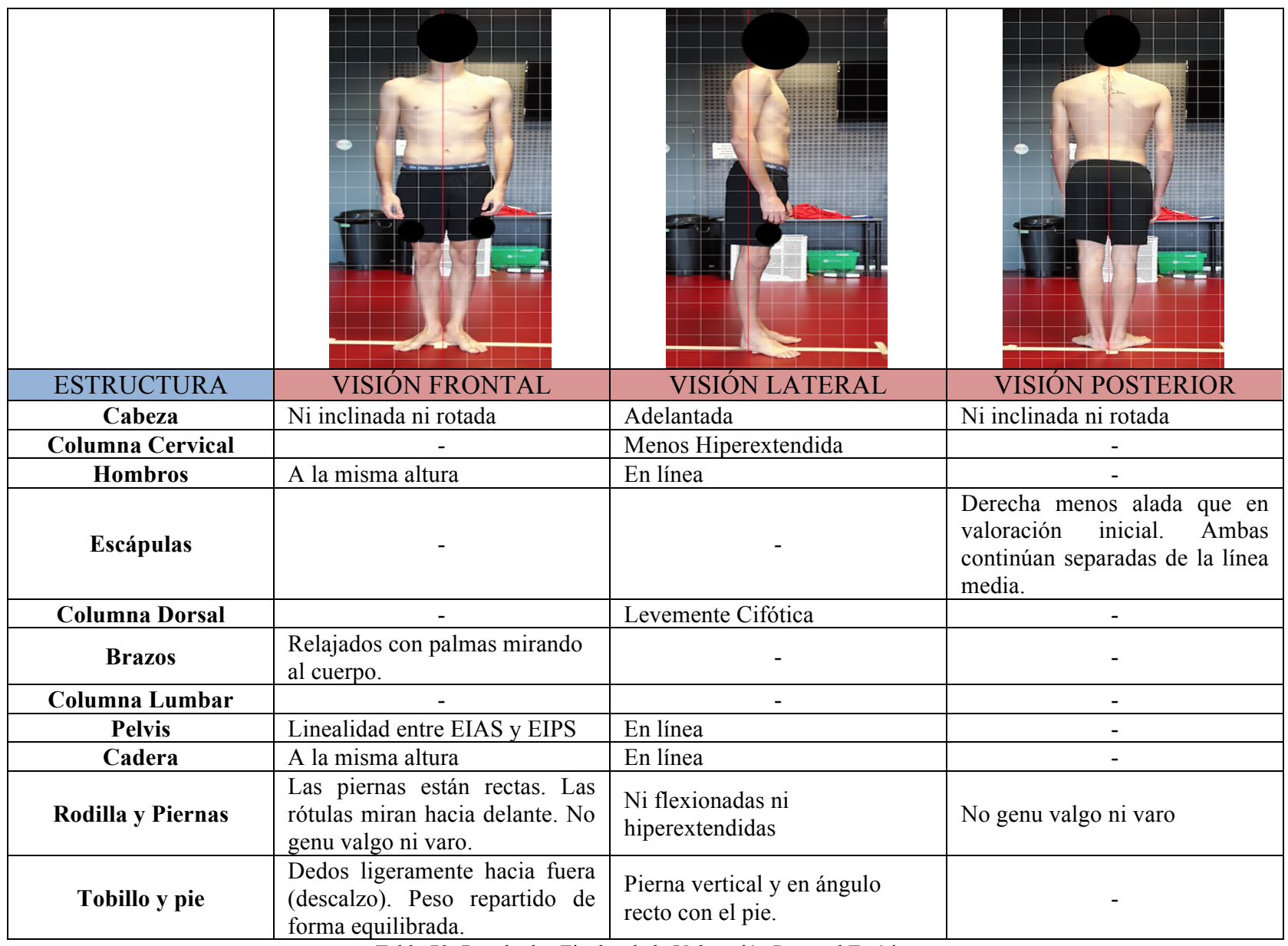




\subsection{Resultados de los Tests de Valoración Dinámica}

\begin{tabular}{|c|c|c|c|c|c|c|c|}
\hline \multicolumn{8}{|c|}{ RESULTADOS DE LA EVALUACIÓN INICIAL } \\
\hline \multirow{3}{*}{ 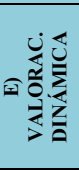 } & TEST & $\begin{array}{c}\text { EVALUACIÓN } \\
\text { INICIAL } \\
\text { (9 y } 21 / 08 / 19)\end{array}$ & \multicolumn{2}{|c|}{$\begin{array}{l}\text { VALORES DE } \\
\text { REFERENCIA }\end{array}$} & $\begin{array}{c}\text { FINAL FASE I } \\
(16 \text { y } 28 / 10 / 19)\end{array}$ & $\begin{array}{c}\text { EVALUACIÓN } \\
\text { FINAL } \\
(18 / 11 / 19)\end{array}$ & $\begin{array}{l}\text { DIFERENCIA } \\
\text { INICIAL / } \\
\text { FINAL }\end{array}$ \\
\hline & 2. Landing Error Scoring System (LESS) & 0 puntos & 0 Puntos & $(128)$ & - & 0 puntos & $=$ \\
\hline & 3. Tuck Jump Test & 1 punto & 0 Puntos & $(132)$ & - & 0 puntos & -1 Punto \\
\hline
\end{tabular}

Tabla 74: Comparación entre la Evaluación Inicial y Final en los Test de Valoración Dinámica

- Single Leg Squat: En visión frontal la inestabilidad de rodilla observada en la valoración inicial ha disminuido considerablemente, así como el valgo de cada rodilla (ver figura 71 y 72). Además no se perciben las inclinaciones laterales del tronco que aparecían en la primera medición (ver figura 71 y 72). En visión lateral se aprecia una menor inclinación anterior del tronco así como una menor separación de brazos del cuerpo (ver figura 73).

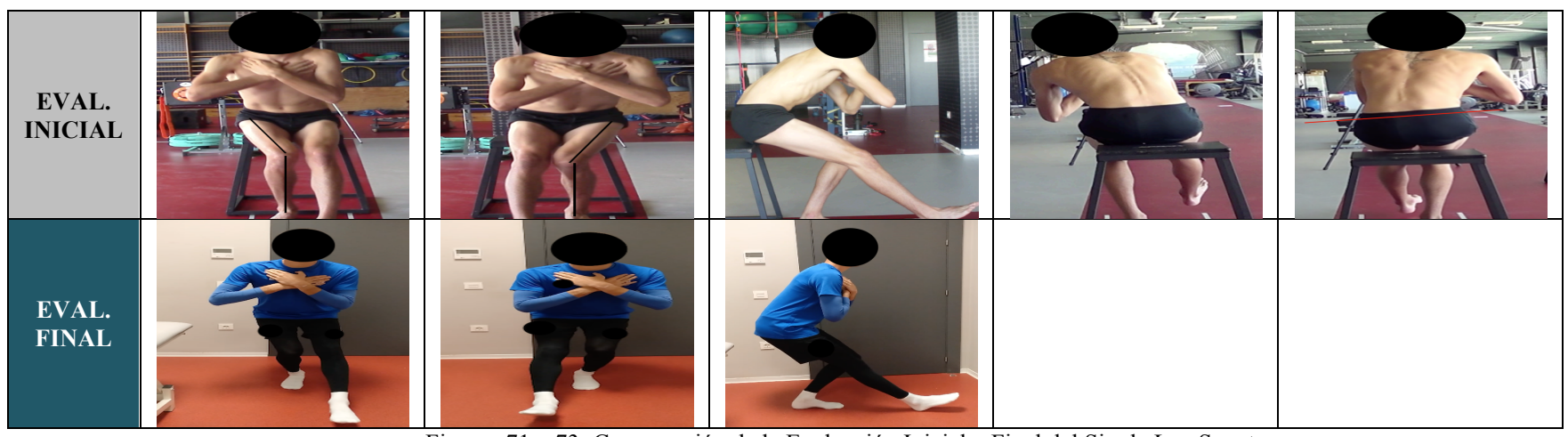

Figuras 71 - 73: Comparación de la Evaluación Inicial y Final del Single Leg Squat

- Hinge: El movimiento se realiza correctamente, la ejecución es dominante de cadera, no de rodilla, y las tibias no se anteriorizan.

\subsection{Resultados del Cuestionario de Dolor Lumbar}

\begin{tabular}{|l|l|l|l|}
\hline Sección 1: Intensidad del Dolor & 0 & Sección 6: Estar de Pie \\
\hline Sección 2: Cuidado Personal & 0 & Sección 7: Dormir \\
\hline Sección 3: Levantar y/o cargar objetos & 0 & Sección 8: Vida Sexual \\
\hline Sección 4: Caminar & 0 & Sección 9: Vida Social & 0 \\
\hline Sección 5: Estar sentado & 0 & Sección 10: Viajar & 0 \\
\hline \multicolumn{2}{|c|}{ Puntuación Final = Puntuación Total del Test / (5 x n ${ }^{\circ}$ Secciones respondidas) x 100\% } & 0 \\
\hline \multicolumn{2}{|c|}{ Tabla 75: Resultados Finales del Cuestionario de Discapacidad de Oswestry } \\
\hline
\end{tabular}

\subsection{Resultados de los Tests de Control Motor del Complejo Coxolumbopélvico}

- Forward Bending: La flexión torácica continúa siendo pronunciada pero el timing de activación en cada segmento de la columna es correcto, tanto en flexión como en extensión de cadera.

- Sitting Knee Extensión: No se aprecia la flexión lumbar que aparecía en el test inicial. Además, el jugador tiene una mayor extensión de rodilla.

- One Leg Stance: El desplazamiento lateral cuando está apoyado sobre el pie izquierdo pasa de 15 a $6 \mathrm{~cm}$., mientras que cuando apoya sobre el derecho pasa de 13 a $5 \mathrm{~cm}$. Además el movimiento se realiza lentamente y de forma correcta y controlada.

- Prone Lying Active Knee Flexion: El movimiento es mucho más controlado que en la evaluación inicial. El jugador puede llegar a $90^{\circ}$ de flexión de rodilla sin realizar compensaciones de ningún tipo.

- Rocking Backward: Continúa sin aparecer rotación pélvica y las caderas se flexionan simétricamente. Además, el control del movimiento es mayor y no aparece flexión lumbar hasta pasados los $125^{\circ}$, frente a los $110^{\circ}$ del test inicial.

\subsection{Resultados del Cuestionario de Perfil Psicológico}

\begin{tabular}{|l|c|c|l|c|c|}
\hline & EV. INICIAL & EV. FINAL & & EV. INICIAL & EV. FINAL \\
\hline Autoconfianza & $42 / 45$ & $42 / 45$ & Concentración & $31 / 35$ & $29 / 35$ \\
\hline Actitud y Preparación Mental & $35 / 40$ & $31 / 40$ & Motivación & $20 / 25$ & $16 / 25$ \\
\hline Control de Estrés y Ansiedad & $44 / 55$ & $48 / 55$ & PUNTUACIÓN TOTAL & $\mathbf{1 7 2 / 2 0 0}$ & $\mathbf{1 6 6 / 2 0 0}$ \\
\hline
\end{tabular}




\subsection{Informe Personalizado para el Jugador}

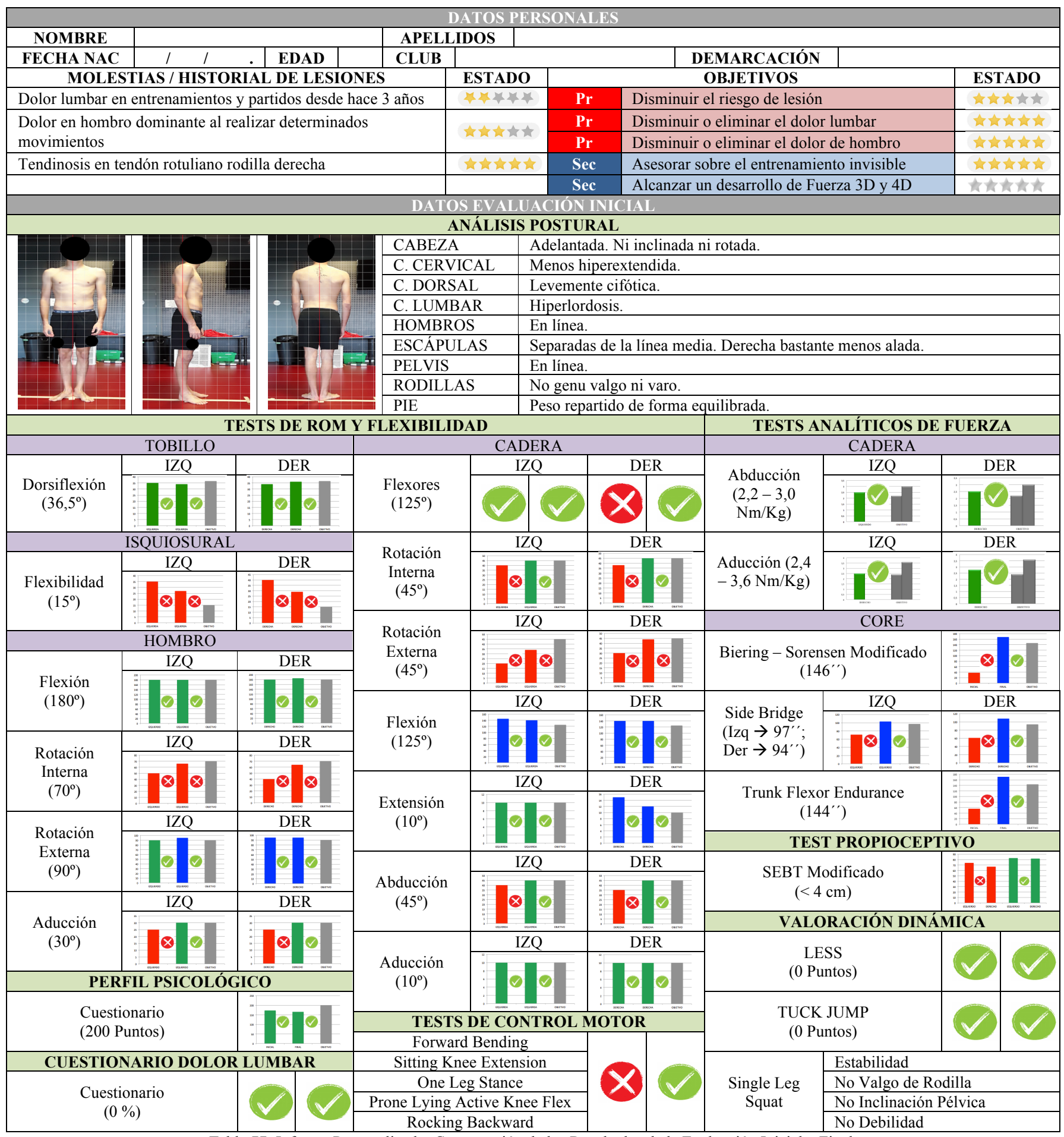

Tabla 77: Informe Personalizado. Comparación de los Resultados de la Evaluación Inicial y Final.

En los gráficos, la primera columna corresponde a la evaluación inicial, la segunda a la evaluación final y la última (en gris) al valor de referencia. El color rojo en alguna columna indica que el valor se encuentra por debajo del objetivo, el verde que el valor es similar y el azul que nos encontramos por encima. Cuando no hay columnas, la primera imagen (aspa o cruz) corresponde a la evaluación inicial y la segunda a la final.

Los objetivos principales se han conseguido. No se marcan 5 estrellas en la disminución del riesgo de lesión porque siempre hay un riesgo intrínseco al jugar o entrenar, no obstante, los valores de todos los tests han mejorado, lo que puede indicar un menor riesgo de lesión, además de provocar la desaparición del dolor lumbar y de hombro. 


\title{
8-. DISCUSIÓN
}

\author{
"Es inútil toda polémica si no hay esperanza de que resulte \\ provechosa” \\ Lluís Vives, filósofo y escritor español (1492 - 1540)
}

\subsection{Discusión del grado de consecución de los Objetivos planteados y posibles causas.}

\subsubsection{Discusión de los Resultados de los Tests de Flexibilidad y ROM.}

La dorsiflexión de tobillo no presentaba limitación en la evaluación inicial, por lo que no fue un aspecto a incidir durante la intervención. En la práctica se suele aceptar que un resultado aceptable en el Lunge Tests es tocar la pared con la rodilla mientras el dedo gordo del pie se sitúa a $10 \mathrm{~cm}$. de la misma pared. No he encontrado esta referencia en ningún artículo, ya que todos reflejaban el valor en ${ }^{\circ}$. No pude encontrar valores para el fútbol por lo que me basé en un artículo de baloncesto (145), debido a la similitud en acciones de alta intensidad y cambios de dirección. Tanto en la evaluación inicial como final el jugador presentó valores dentro de lo recomendado en cuanto a dorsiflexión de tobillo, seguramente por el trabajo que realizase con su equipo, por lo que no he tenido que intervenir en este sentido.

En cuanto a extensibilidad de isquiosurales no se han alcanzado los valores de referencia. He incluido vibración mecánica para aumentar el ROM de este grupo muscular, ya que es un medio muy recomendable en este sentido $(424,428,429)$, con los parámetros que indicaban estudios que habían tenido resultados positivos (428), además de FNP (433), con los parámetros recomendados en la literatura (435); sin embargo "sólo" he obtenido $8^{\circ}$ de mejora en la pierna izquierda y $11^{\circ}$ en la derecha. Si analizamos uno de esos estudios en el que se aplica vibración mecánica a gimnastas (428) vemos que la mejora promedio en flexibilidad es del $18 \%$. En nuestro caso se han obtenido mejoras del $14{ }^{\prime} 5 \%$ en la pierna izquierda y del $22 \%$ en la derecha, por lo que los resultados no se alejan mucho y podrían considerarse "mejoras normales". El problema es que el grado de acortamiento en nuestro sujeto era mucho mayor que el que había en ese estudio por lo que, posiblemente, la mejora debió haber sido mayor.

El acortamiento de los flexores de cadera pasó de identificarse en el psoas derecho en la evaluación inicial a desaparecer en la final. Tal y como indicó el profesor Arturo García en las clases del Máster (346), con una anteversión pélvica, un déficit en la estabilización central y amnesia glútea (en nuestro caso debilidad) no es recomendable estirar el psoas para evitar la desestabilización del raquis. En lugar de relajar el psoas, que está rígido para compensar todo lo anterior, he actuado sobre Core, Glúteo y movilidad de cadera y los resultados en el acortamiento de flexores de cadera han mejorado.

La movilidad de cadera era bastante limitada en cuanto a rotación interna, externa y abducción en la evaluación inicial de nuestro jugador. En el caso de la abducción se han conseguido normalizar los valores (aumento de $5^{\circ}$ en pierna izquierda y $10^{\circ}$ en derecha), quizás por los ejercicios de movilidad de cadera y el estiramiento estático con vibración de los aductores de cadera. En cuanto a las rotaciones interna y externa, a pesar de conseguirse mejoras de entre $5^{\circ}$ y $14^{\circ}$ no hemos conseguido llegar a los valores de referencia, aunque ha faltado muy poco. Posiblemente con varias semanas más de intervención o si no se hubiese producido la lesión (habríamos tenido una continuidad en este trabajo) se habría conseguido.

En el caso de la movilidad del hombro, la flexión bilateral ha aumentado, aunque ya se encontraba el jugador en valores de referencia $\left(180^{\circ}\right)(27)$. El problema era la rotación interna, la aducción y la rigidez del pectoral menor. La aducción se ha conseguido normalizar y en la rotación interna la ganancia total ha sido de $16^{\circ}$ en brazo no dominante y $24^{\circ}$ en el dominante, nada despreciable. Los estiramientos como el sleeper stretcher $(325,326,457)$ y el cross body stretch $(458,459)$ han sido determinantes para esta mejora, además del uso del flossing $(451,452)$. Quizás si hubiésemos incluido un estiramiento con vibración las mejoras hubiesen sido mayores, dados los beneficios de este medio $(428,429)$. En cuanto a la rigidez del pectoral menor, las mejoras obtenidas en las 3 últimas semanas han sido casi las mismas que en las 9 anteriores, quizás por el hecho de incluir la FNP. No se han conseguido normalizar los valores, aunque sí ha habido una mejora significativa, especialmente en el lado dominante, donde existía mayor acortamiento. El hecho de aumentar ligeramente la rotación externa glenohumeral y ampliamente la interna permite tener un arco total de movimiento mayor, reduciendo así el riesgo de lesión $(331,332)$. 


\subsubsection{Discusión de los Resultados de los Tests de Fuerza Analítica.}

Los valores de fuerza de la musculatura abductora y aductora de la cadera estaban dentro del rango recomendado en la evaluación inicial (83) pero justo en el límite por debajo. Quizás debí incluir un estímulo semanal para evitar que disminuyese ese valor o incluso aumentarlo, pero al realizar trabajo preventivo con su equipo no lo consideré en su momento. Con la disminución de la carga provocada por la lesión seguramente los valores no habrían llegado al mínimo aconsejado, pero no hubo forma de medirlo ya que no pude conseguir un dinamómetro. En ese momento sí realicé un trabajo es esta musculatura, primero de forma isométrica y luego excéntrica, pero tampoco pude medir los resultados finales por el mismo motivo.

El gran déficit que presentaba el sujeto a nivel de fuerza lo encontrábamos en la musculatura del Core, encontrando alarmantemente bajos en comparación con los propuestos por McGuill (95). Al final de nuestra intervención, no sólo se consiguió eliminar la asimetría encontrada en el Side Bridge sino que se elevaron los valores por encima de lo recomendado en la literatura (168" en Biering Sorensen Modificado; 103" y $108^{\prime \prime}$ en side bridge; y 171" en trunk flexor endurancte test). Este era uno de mis principales objetivos ya que se trata de un deportista de alto nivel y los requerimientos específicos que necesita son bastante más elevados que los de una persona "de la calle". El principal motivo de este aumento considero que es la aplicación de estímulos de fuerza. Por un lado se ha activado la musculatura glútea, además de los aductores de cadera, también se han aplicado 2 estímulos semanales de antimovimientos de carácter global y progresando hacia la especificidad, incluyendo perturbaciones e inestabilidad. Además, el hecho de aprender y dominar la maniobra de Bracing seguro que ha contribuido a esta mejora, ya que la coactivación de la musculatura es capaz de generar mayor fuerza que la suma de cada músculo por separado (147).

En cuanto a la Disquinesia Escapular sutil que se observaba en la escápula izquierda en la evaluación inicial, el trabajo metódico y progresivo de serrato anterior y trapecio medio e inferior ha sido clave para eliminarla, no apreciándose ningún indicador de debilidad en este test ni en ese lado ni en el contralateral en la evaluación final (como se ve en la figura 74). Además de esto, y aunque no hay forma objetiva de medirlo, estoy convencido de que se ha producido un aumento en la fuerza del manguito rotador externo, aportando estabilidad a esta articulación y facilitando el movimiento de frenado, disminuyendo el riesgo de lesión $(333,334)$.

\subsubsection{Discusión de los Resultados del SEBT Modificado.}

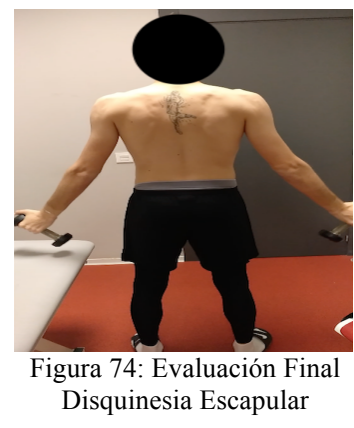

A nivel propioceptivo, los resultados de la evaluación inicial indicaban una diferencia entre ambas piernas de $7 \mathrm{~cm}$, casi el doble del valor máximo establecido para tener un bajo riesgo de esguince de tobillo. Ya en el final de la Fase I esa diferencia se había reducido a $2 \mathrm{~cm}$., y pasó a $1 \mathrm{~cm}$. en la evaluación final. Además, en comparación con los primeros datos obtenidos, ha habido una mejora en el test del $12 \%$ en la pierna izquierda y del $22 \%$ en la derecha. El entrenamiento propioceptivo disminuye la inestabilidad del tobillo y mejora el tiempo de reacción muscular y la estabilidad articular y postural (409), disminuyendo así el riesgo de lesión (227,413-416). Las superficies desestabilizantes son especialmente beneficiosas en este sentido (410). El trabajo propioceptivo en superficies desestabilizantes y con perturbaciones ha sido la causa de esta mejora.

\subsubsection{Discusión de los Resultados de la Valoración Postural Estática.}

En visión Frontal no se aprecian grandes diferencias entre una valoración y otra, encontrándose hombros a la misma altura y linealidad en espinas ilíacas.

En visión Lateral se aprecia una menor hiperextensión de la columna cervical y lumbar. Además se encuentran en línea tanto la pelvis (anteriormente adelantada) como los hombros, aunque continúa una leve protracción de éstos.

En visión Posterior, aunque se sigue apreciando un leve aleteo de la escápula derecha, es significativamente menor que en la valoración inicial. 


\subsubsection{Discusión de los Resultados de los Tests de Valoración Dinámica.}

En el Single Leg Squat apenas se aprecia valgo de rodilla en la evaluación final (muy ligeramente en pierna derecha), eliminando así un importante factor de riesgo de rodilla (93). Además, los brazos permanecen bastante más cerca del cuerpo, evitando así su uso para estabilizar y compensar. Las inclinaciones laterales y anteriores que se producían en la evaluación inicial tampoco aparecen en la evaluación final. No hay ninguna referencia que indique cómo mejorar en este test. Entiendo que la mejora en la estabilidad de tobillo y rodilla por el trabajo propioceptivo y el aumento en la fuerza de la musculatura del Core (que incluye la musculatura glútea) han sido los causantes de esta mejora.

En el LESS y en el Tuck Jump los valores obtenidos en la evaluación inicial eran muy positivos, y se han mantenido en la evaluación final.

\subsubsection{Discusión sobre los Resultados de los Patrones de Movimiento.}

Debido a las características de esta intervención, los patrones básicos de movimiento no han sido un eje central de los entrenamientos. Es importante destacar que se ha cuidado minuciosamente la ejecución en cada ejercicio realizado. En el caso de los patrones de movimiento, el dominio por parte del jugador era aceptable aunque mejoró tras pequeños matices. La intención era que esas premisas las aplicase cuando realizara el trabajo de fuerza con su equipo, garantizando así una mejor ejecución. Incluso en ejercicios isoinerciales la técnica no era mala, ya que el jugador lleva varios años realizando este tipo de entrenamientos.

\subsubsection{Discusión de los Resultados del Cuestionario de Dolor Lumbar.}

Uno de los objetivos principales que me marqué al comienzo de la intervención fue disminuir o eliminar el dolor lumbar que sufría el jugador desde hacía 3 temporadas, tanto en entrenamientos como en partidos. Esta sintomatología sólo se manifestaba en el campo, no así en su vida diaria. Este hecho lo indicaba el propio jugador y se evidenció en el cuestionario inicial de Discapacidad de Oswestry (134), en el que sólo obtuvo una puntuación del 6\%. Al comienzo de la fase de intervención el jugador indicaba un dolor de 5 sobre 10 en entrenamientos (aún no había competido); sin embargo, a finales de la Fase I los valores en la escala analógica visual habían disminuido considerablemente.

Durante toda la Fase II el sujeto ha entrenado (incluso doble sesión) y competido (partidos completos) de forma asintomática, cumpliéndose así este importantísimo objetivo. Al final de la intervención, el resultado fue del $0 \%$. Los beneficios para el futbolista son obvios, no sólo por un aumento en la calidad de vida, sino también laboral, ya que le permitirá entrenar y jugar sin molestia, pudiendo aumentar su rendimiento.

Los motivos de la desaparición del dolor lumbar no sabría decirlos a ciencia cierta. Ya he argumentado que esta molestia puede estar relacionada con aspectos posturales (91), debilidad en Core $(318,319)$, déficit en la movilidad de la cadera (39), déficit en la musculatura glútea o alteración en el control motor de la región lumbopélvica (15). Todos estos aspectos han sido tratados en el plan de intervención por lo que me inclino a pensar que será la mejora en todos ellos lo que ha contribuido a eliminar el dolor lumbar en el jugador.

\subsubsection{Discusión de los Resultados de los Tests de Control Motor del Complejo Coxolumbopélvico.}

En líneas generales el Control Motor del Complejo Coxolumbopélvico ha mejorado con respecto a la valoración inicial. El aumento de la fuerza de la musculatura del Core y del rango de movimiento de cadera permite que los tests se realicen con un mayor control, incluso a menor velocidad, y sin la aparición de flexión lumbar. 


\subsubsection{Discusión de los Resultados del Cuestionario de Perfil Psicológico.}

Los resultados a nivel psicológico no han variado excesivamente. Su autoconfianza sigue siendo alta (42 puntos sobre 45 en ambas evaluaciones) y, posiblemente, ha aprendido a controlar mejor el estrés y la ansiedad, ya que sus valores son mayores en la evaluación final. Sin embargo, muestra una preparación mental, una concentración y una motivación menores al final del programa de intervención que al principio. El motivo de esta disminución podría estar relacionado con el hecho de disputar pocos minutos y entrenar con 3 equipos, lo cual genera mucha inestabilidad. A pesar de ese delicado contexto para un futbolista, se mantiene en valores bastante altos (166 puntos sobre 200), muy probablemente por el trabajo psicológico que realiza el jugador con una especialista desde hace varios años.

\subsubsection{Discusión sobre los Resultados de Dolor de Hombro.}

Otro objetivo importante era reducir el dolor de hombro. Como ya se ha comentado, el jugador presentaba una sutil disquinesia escapular en el lado izquierdo. La intervención consistió en aumentar la rotación interna para evitar el GIRD $(324,325)$, activar el serrato anterior y trapecio medio e inferior $(72,338)$, estirar el pectoral menor (76), aumentar la fuerza del manguito rotador $(333,334)$, realizar un trabajo de flexores profundos de cuello y una extensión dorsal (76). Todo este trabajo estaba destinado a mejorar la salud del complejo articular del hombro y, además, conseguimos eliminar completamente el dolor que el jugador mostraba en la evaluación inicial. Así, al eliminar las molestias del jugador ha quedado en disposición de entrenar y competir de forma totalmente asintomática.

\subsection{Puntos Fuertes y Débiles del Programa de Intervención.}

En relación a los puntos fuertes podemos destacar:

A) Instalaciones: Las instalaciones donde se ha llevado a cabo la intervención eran propias de un club profesional, no están al alcance de cualquier entrenador y, salvo algunas herramientas, me han permitido hacer uso de la mayoría de las cosas que había en el gimnasio del club. Además, salvo algunos miércoles que coincidía con un equipo juvenil, he tenido todo el gimnasio en exclusividad para mi intervención.

B) Trabajo Multidisciplinar: Ha sido un fisioterapeuta experimentado (del propio equipo del jugador) el que ha realizado la mayoría de las valoraciones. Además, conocer de primera mano el diagnóstico o el tratamiento que ha recibido el jugador durante su lesión ha sido muy importante para mí.

C) Formación Deportiva del Jugador: El hecho de que el sujeto estuviese familiarizado con la RPE, con los patrones básicos, el entrenamiento propioceptivo, el material utilizado (como la versapulley),... ha sido clave para avanzar más rápidamente y poder plantear nuevos retos.

D) Evaluación Inicial: Considero que se ha propuesto una evaluación que, dentro de los medios a mi alcance, cubre perfectamente los factores de riesgo de las principales lesiones en fútbol y da respuesta a la información obtenida en la entrevista inicial.

E) Profesionalidad del Jugador: Se ha entregado completamente, ha propuesto trabajar incluso en su día de descanso, nunca ha puesto mala cara a nada ni en duda cualquier cosa que le haya corregido. Su actitud ha sido fundamental para cumplir con las 24 sesiones obligadas.

F) Planificación de la Sesión: Considero que ha sido muy correcta la estructura de sesión planteada y que ha habido una gran variedad de ejercicios dentro de cada contenido trabajado, ofreciendo múltiples situaciones a las que adaptarse, tal y como ocurre en competición.

G) Adaptación en cada Sesión: Nunca se ha tenido en cuenta lo planificado sobre las sensaciones del jugador. En todo momento se ha buscado adaptar tanto el volumen de trabajo como los ejercicios, con el fin de cumplir mis objetivos generando la menor fatiga en el futbolista.

H) Rigurosidad de la Información: He dedicado más de 1200 horas al TFM, tratando de referenciar todo lo que se ha hecho en el trabajo. La totalidad de lo planteado en la intervención ha sido probado con resultados satisfactorios en la literatura científica. 
En cuanto a los puntos débiles del programa considero los siguientes:

A) Uso de Medios de Entrenamiento: A pesar de disponer de muchos medios para entrenar quizás no le he sacado todo el partido que podría haber sacado. He intentado variar ejercicios e incluir progresivamente medios distintos, pero no sé si otro entrenador, en mis circunstancias, habría planteado la intervención de otro modo, por lo que realmente, no sé si esto es punto débil o no.

B) Comunicación con otros Profesionales: No he tenido contacto ni con el nutricionista ni con la psicóloga que trabajan con el jugador. Ha sido un año muy intenso y me habría gustado disponer de bastante más tiempo para realizar este trabajo. Aunque suene a excusa pero ha sido la falta de tiempo la que me ha impedido hablar con estos profesionales y ver cómo podría actuar conjuntamente con ellos.

C) Comunicación con su Cuerpo Técnico: Ha sido bastante menor y más lenta de lo que me habría gustado. Entiendo que tienen mucho trabajo y no quería ser una carga para ellos, por lo que, al final, el contacto que hemos mantenido ha ido de más a menos a lo largo del programa.

D) Fiabilidad de la Evaluación: Ya se ha argumentado que la experiencia a la hora de evaluar es importante para obtener un resultado más "real". Algunos de los tests que llevé a cabo yo mismo no los había realizado con anterioridad, más allá de practicarlos con mi mujer y mis hermanos para no ir de primeras ante el sujeto. Quizás una persona más experimentada podría haber obtenido otra lectura.

E) Sentadilla Unipodal: En la evaluación final, en el test de sentadilla unipodal se me pasó grabar con visión posterior. No había mucho tiempo entre el final de la Fase II y la entrega del trabajo al tutor (debido al cambio de sujeto), por lo que tuve que realizar la evaluación en el despacho de los fisioterapeutas mientras el primer equipo estaba entrenando. Yo estaba nervioso porque sentía que no debía estar ahí, aunque el responsable de los servicios médicos me diese su permiso, y se me pasó por completo realizar todas las fotografías.

\subsection{Limitaciones y Dificultades.}

1. Tiempo: Aunque pertenezco a la VI promoción del Máster, debido al nacimiento de mi segunda hija y a la realización de una oposición no pude realizar el TFM en convocatorias anteriores. Trabajar a 1 hora (para la ida y otra hora para la vuelta) de casa, estar en año de prácticas en el instituto bajo el análisis del inspector, tener 2 hijas pequeñas (5 y 2 años) y diseñar junto con mi mujer los planos de nuestra nueva casa no es algo que me haya facilitado especialmente la elaboración de este TFM.

2. Incertidumbre en la Planificación Semanal: Salvo las primeras semanas nunca he sabido ni qué días iba a entrenar ni cuánto (por ejemplo si tenía sesión un viernes y justo después entrenaba con el club filial).

3. Conocimiento previo sobre el Complejo del Hombro: He trabajado 4 años como readaptador de lesiones en el Club al que pertenece el sujeto y sólo me encontré 1 lesión en miembro superior. Mi formación era prácticamente nula en este sentido y el hecho de trabajar con un portero, tener que incluir tests específicos para valorar su movilidad glenohumeral y comprobar que tenía dolor en hombro dominante en la evaluación inicial fue algo que me preocupó bastante en su momento.

4. Imposibilidad de Utilizar algunos medios: Ya comenzada la Fase I del programa hubo un cambio en el protocolo de seguridad del club y se prohibió que hubiese alguien ajeno al club en las instalaciones sin estar acompañado de algún trabajador. Esto hubiese supuesto un cambio de instalaciones, y un grave problema para mí, sin embargo al final me permitieron terminar mi trabajo. Sin embargo, no pude utilizar ni la plataforma vibratoria ni algunas máquinas isoinerciales ni el smartcoach.

5. Dinamómetro: El dinamómetro utilizado en la evaluación inicial pertenecía a la Universidad de Granada. Aunque intenté pedirlo reiteradamente, al final no pude conseguirlo por lo que no pude realizar los tests B1 - B3 ni al final de la Fase I ni de la Fase II.

6. Extensión del Trabajo: He intentado explicar todo con cierta profundidad y rigor y he tenido muchos contratiempos en este trabajo. Además, el tema era muy amplio ya que no sólo me centraba en una lesión sino en las más prevalentes y no he querido pasar de puntillas por ninguna de ellas para evitar dar la sensación de que "he abarcado mucho y apretado poco". 


\subsection{Posibles Soluciones y Alternativas.}

1. Tiempo: Al principio escribí un correo a la dirección del Máster solicitando más tiempo pero no fue posible. Anteponer este trabajo a todo lo demás ha sido la única solución. He pasado algo más de un año muy agobiado, no he tenido ni un solo día de descanso, no he disfrutado las vacaciones con el resto de mi familia, le he restado tiempo a mi mujer y a mis peques y la calidad de mis clases en el trabajo creo que, sin ser mala, ha sido mejorable. Ahora que todo ha terminado e independientemente de la valoración de mi tutor y del tribunal, puedo decir que me siento orgulloso de mí mismo, contento por el resultado obtenido y por todo lo aprendido y me gustaría recuperar el tiempo que no he tenido antes con mi familia y amigos.

2. Incertidumbre en la Planificación Semanal: Este problema no tiene solución, ya que al jugador le comunicaban con 24 horas de antelación la hora y el equipo con el que entrenaba. Creo que adaptarme cada día e intentar poner al menos un entrenamiento en cuanto supiese que tenía la tarde libre (siempre que no fuese martes) es lo mejor en este caso, y así lo hice.

3. Conocimiento previo sobre el Complejo del Hombro: Una llamada de teléfono a mi compañero de promoción en el Máster Antonio López para que me diera un poco de luz, realizar un curso específico de hombro con el profesor Héctor García y muchas horas de lectura de artículos científicos me permitieron plantear una evaluación e intervención, desde mi punto de vista, bastante coherente.

4. Imposibilidad de Utilizar algunos medios: En el caso de la plataforma vibratoria, la sustituí por técnicas de FNP para aumentar la extensibilidad muscular, y por un foam roller con vibración. Al final se pidió al jugador que realizase el estiramiento en plataforma vibratoria por la mañana ya que el foam roller muchos días no se encontraba en el gimnasio ni sabía la frecuencia a la que vibraba. En cuanto a las máquinas isoinerciales y el smartcoach no me hicieron falta debido a la aparición de la lesión. En caso de no haberse lesionado, habría tenido que trabajar en rangos de $2-3$ series de $6-8$ repeticiones o a pérdida subjetiva de velocidad para no causar fatiga en el jugador en el trabajo de fuerza (377)(517).

5. Dinamómetro: Se podrían haber sustituido los tests planteados por los propuestos por Kendall (27), sin embargo la fiabilidad habría disminuido considerablemente y no se podrían haber comparado con la evaluación inicial.

6. Extensión del Trabajo: He solicitado a la coordinación del Máster que me permitan excederme en 10 páginas sin penalización debido a los contratiempos que me he encontrado aunque, lógicamente, por otro lado, no ha sido posible, por lo que, sin abusar demasiado, he reducido ligeramente la letra, el espacio entre párrafos y he ampliado los márgenes.

\section{9-. CONCLUSIONES}

"Cada conclusión da pie a una nueva pregunta”

David Hume, filósofo y economista escocés $(1711-1776)$

\subsection{Grado de Consecución de los Objetivos planteados y causas más importantes.}

Desde un punto de vista reduccionista diríamos que no se han alcanzado los objetivos planteados, ya que todo el programa de intervención giraba en torno a la prevención de lesiones y el jugador se lesionó. Sin embargo, considero que la actuación ha tenido muchos efectos beneficiosos para el futbolista.

En primer lugar hemos conseguido que entrene y compita sin ninguna molestia, algo que no ocurría desde hacía 3 años. Esto le permitirá aumentar la intensidad y mejorar su rendimiento, además de mejorar su calidad de vida. Los motivos podrían pasar por un aumento en la fuerza del Core, una mejora del control motor de la región coxolumbopélvica o una mayor movilidad de cadera entre otros.

También ha desaparecido su molestia en hombro dominante y la sutil disquinesia escapular que presentaba, quizás porque, aunque no hasta el punto de normalizarse, hemos mejorado el ROM de rotación interna glenohumeral, hemos activado la musculatura periescapular y mejorado la fuerza del manguito de rotadores externo.

Además, dentro del objetivo de prevenir lesiones hemos conseguido muchos "sub-objetivos", como normalizar los valores de aducción de hombro, mejorar la fuerza del glúteo e integrarlo en diferentes movimientos, hemos corregido la asimetría propioceptiva que existía entre un pie y otro y hemos 
aumentado muy muy significativamente la capacidad de estabilización del Core, con la cantidad de beneficios que esto puede aportarle. Realizar una intervención metódica, basada en la literatura científica y en mi experiencia como readaptador ha sido clave para conseguir estas metas.

En cuanto a los patrones de movimiento, el jugador ya tenía una amplia experiencia en el entrenamiento en gimnasio y había sido instruido y corregido con anterioridad. Sólo he tenido que matizar algunos detalles para mejorar su ejecución.

Pero no todo lo que me planteé cuando empecé he conseguido cumplirlo. No he conseguido normalizar los valores de rotación interna glenohumeral, quizás por no haber aprovechado el efecto del flossing si la banda no estaba bien colocada; tampoco he llevado la extensibilidad de isquiosurales y aductores de cadera a valores de referencia, posiblemente por falta de tiempo de intervención; ni he sido capaz de mejorar sus valores de rotación externa de cadera todo lo que habría querido.

Aunque no hay forma objetiva de demostrarlo, creo que he reducido la probabilidad de que tenga una recidiva u otra lesión muscular asociada a su lesión original, que eran objetivos que me marqué a raíz de su lesión, debido al trabajo excéntrico que se ha hecho en la parte final de la Fase II.

Por último, he asesorado al jugador sobre la importancia de mantener una vida sana aunque el futbolista ya era muy consciente de esto y la mayoría de las cosas que le decía no sólo las conocía, sino que se las aplicaba. El motivo es que trabaja con profesionales que se preocupan por este aspecto y le aconsejan continuamente y él es una persona que entiende que el éxito pasa por cumplir con estas premisas, por lo que está abierto a cualquier información que pueda hacerle mejorar en este sentido.

\subsection{Conclusiones personales sobre el trabajo $y$ aspectos a mejorar en futuras intervenciones.}

Entrenar en el contexto en el que se ha desarrollado este TFM es verdaderamente complejo, ya que nunca he podido saber con antelación cuándo iba a entrenar o en qué condiciones llegaría el sujeto. Además, este es un aspecto difícilmente mejorable de cara a otras intervenciones, ya que mi actuación es complementaria a la que realiza el jugador y no puedo decidir lo que hace durante la semana. Sin embargo, creo que la comunicación con su cuerpo técnico es fundamental para evitar problemas. Tanto sus entrenadores como yo buscamos lo mejor para el futbolista. En este sentido, hacer ver al cuerpo técnico que puedo ofrecerles información interesante que puedan tener en cuenta para tomar decisiones con respecto al jugador es algo que podría haber mejorado en esta intervención.

De este modo, elaborar un pequeño informe, únicamente con aspectos destacables que haya percibido (bien sobre estado de ánimo (sin comentar cosas que el jugador y yo hablemos en confianza), sobre algún parámetro a destacar en relación a la carga de entrenamiento, sensaciones en mis sesiones, aspectos sobre la evaluación, su evolución,...) y entregarlo semanalmente a su cuerpo técnico, podría redundar en mayores beneficios para el sujeto y, posiblemente, ayudar a evitar alguna lesión.

\section{0-. LÍNEAS FUTURAS DE INTERVENCIÓN}

"El futuro pertenece a quienes creen en la belleza de sus sueños”

Eleanor Roosevelt, diplomática y escritora estadounidense (1884 - 1962)

Como continuación de este programa de intervención habría que, en primer lugar, aplicar estímulos de mantenimiento de todos los valores que se han normalizado para evitar volver a la situación inicial. Además, se debería intentar cumplir los objetivos que no se han podido alcanzar, especialmente el aumento de la rotación interna glenohumeral, de la movilidad de cadera y de la extensibilidad isquiosural y aductora de cadera. El trabajo de control motor de la región coxolumbopélvica y de fortalecimiento del Core también será fundamental para evitar que aparezcan de nuevo las molestias en zona lumbar.

Y, por último, sería muy interesante realizar un entrenamiento de hipertrofia que le hiciese ganar masa muscular, lo cual podría tener un efecto muy beneficioso para su rendimiento deportivo, aportándole seguridad y confianza. Este trabajo debería combinarse con una mejora de la Fuerza en 3D y 4D, que aumentaría su capacidad neuromuscular y su coordinación inter e intramuscular sin perjudicar la fuerza explosiva. Es importante destacar que el control de la carga de entrenamiento es vital en este jugador, dada la imprevisibilidad que impera en sus semanas de entrenamiento. 
MÁSTER DE ENTRENAMIENTO PERSONAL. VI EDICIÓN.

ANEXOS 
ANEXO I: DATOS PERSONALES Y DEPORTIVOS. HISTORIAL DE LESIONES.*

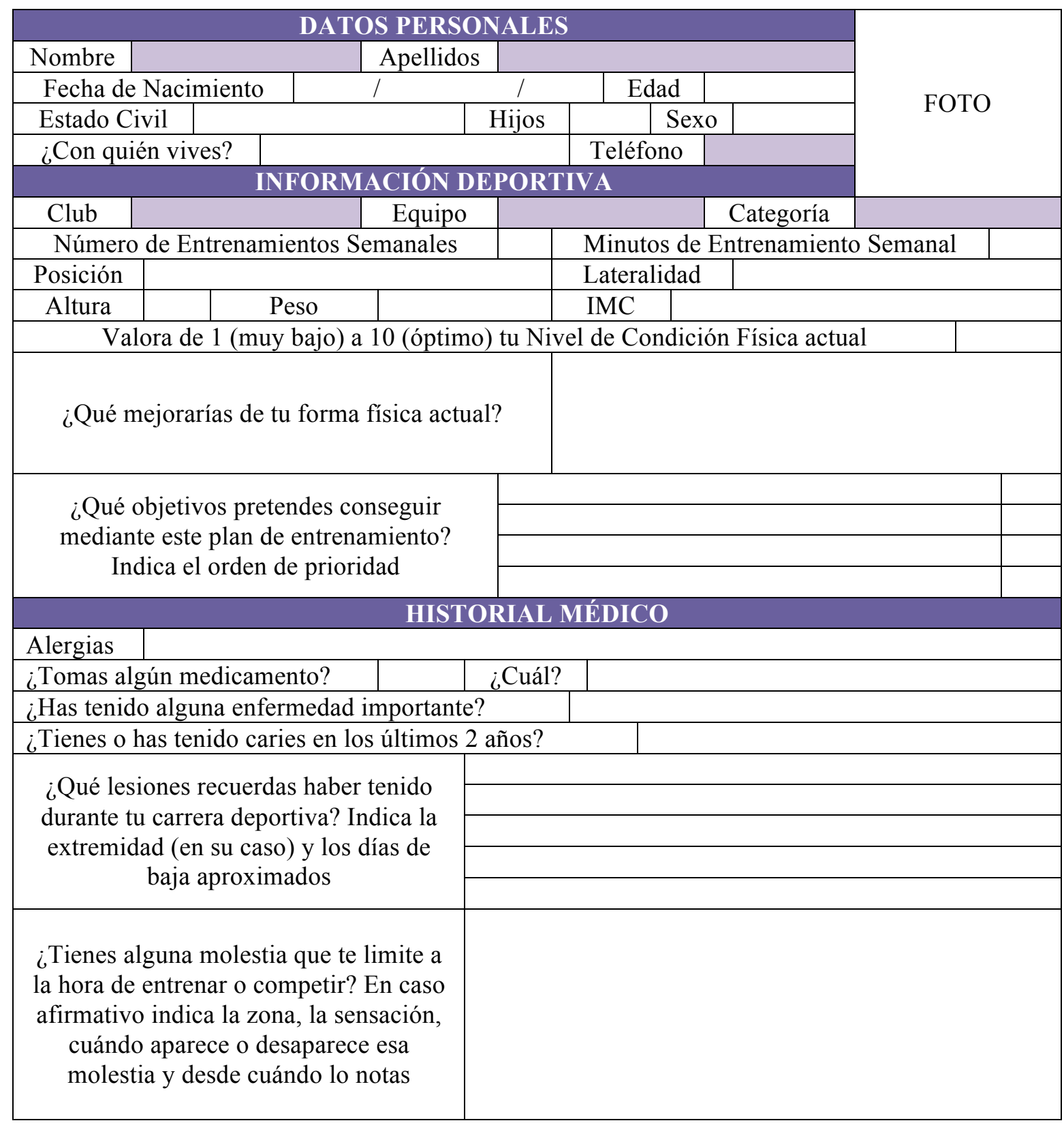




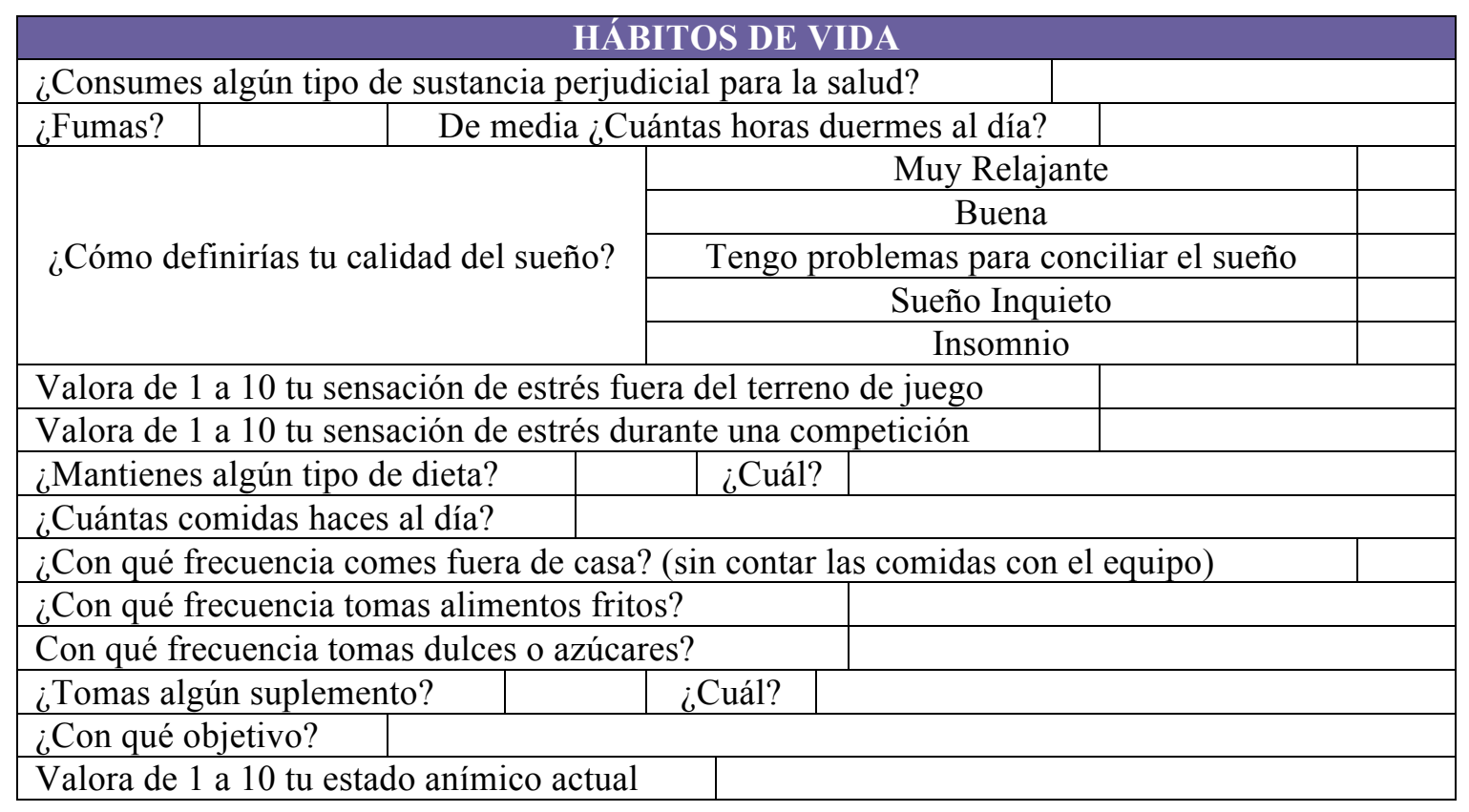

* Señalar que se omiten cuestiones referentes a hábitos laborales, a hábitos de vida deportiva (si practica o no algún deporte, el nivel de competición, la frecuencia de actividad física semanal) o incluso problemas médicos (colesterol, problemas cardiacos, respiratorios,...) porque, por un lado supondrían respuestas obvias al tratarse de un sujeto que vive del deporte y, por otro, el jugador realiza un reconocimiento médico exhaustivo a principio de temporada en el que se descartan esas y otras patologías.

Cláusulas:

- He leído, entendido y rellenado este cuestionario. Cualquier pregunta que tuviera ha sido contestada satisfactoriamente.

- Sé que al otorgar esta información, totalmente voluntaria, el entrenador personal queda excluido de ningún tipo de reclamación o de posibles complicaciones y riesgos que puedan derivar.

\section{Y para que así conste firmo el presente documento:}

El Futbolista: 


\title{
ANEXO II: CONTRATO DE PRESTACIÓN DE SERVICIOS DE ENTRENAMIENTO PERSONAL
}

\section{REUNIDOS}

\author{
De una parte, D. Fidel Muñoz Molina, con domicilio en \\ y con DNI \\ , en adelante el "ENTRENADOR PERSONAL". \\ De otra parte, D. \\ , con domicilio en \\ y con \\ DNI , en adelante el "JUGADOR".
}

Ambas partes, y de común acuerdo, convienen suscribir el presente contrato de entrenamiento personal, el cual se regirá por las siguientes:

\section{CLÁUSULAS}

PRIMERA: OBJETO DEL CONTRATO. El presente contrato tiene por objeto la prestación de los servicios de D. Fidel Muñoz Molina, en su condición y como ENTRENADOR PERSONAL

SEGUNDA: D. Fidel Muñoz Molina se compromete con el JUGADOR a realizar y llevar a cabo sus funciones con la máxima profesionalidad, haciendo saber al JUGADOR que son las siguientes:

- Favorecer la adherencia al programa de entrenamiento del JUGADOR para lograr un óptimo resultado y una elevada motivación.

- Realizar una valoración inicial al JUGADOR.

- Entrenar al JUGADOR de forma eficaz y segura para que logre sus objetivos personales.

- Mantener un contacto continuo con los responsables del cuerpo técnico (médico, fisioterapeutas, preparador físico y readaptador).

- Permanecer con el JUGADOR en todo momento durante las sesiones de entrenamiento.

- Prestar total atención al JUGADOR durante el entrenamiento, y toda la atención que sea posible fuera de éste.

- Enseñar al JUGADOR la correcta ejecución de los movimientos inherentes al entrenamiento a llevar a cabo (si no la supiese), así como del equipamiento a utilizar.

- Vigilar todos aquellos parámetros y signos que indiquen o puedan indicar la correcta ejecución de los movimientos, la intensidad del entrenamiento y los posibles síntomas de sobreesfuerzo.

- Colaborar en todo momento con el cuerpo técnico y no suponer un obstáculo, sino una ayuda continua.

El ENTRENADOR PERSONAL debe informar al JUGADOR y acreditar que está debidamente cualificado para los servicios que va a prestar y que dispone de seguro de responsabilidad civil. En el ejercicio de sus servicios, se compromete a no sobrepasar, dentro de los conocimientos que debe tener, las funciones que le competen.

TERCERA: Ambas partes se comprometen a llevar a cabo el programa de entrenamiento fijado por el ENTRENADOR PERSONAL, objeto de este contrato.

El ENTRENADOR PERSONAL se compromete a llevar a cabo un programa de entrenamiento orientado a la prevención de las principales lesiones en fútbol en el JUGADOR, sin recibir remuneración económica alguna.

El JUGADOR se compromete a seguir las pautas del ENTRENADOR PERSONAL durante todo el programa de entrenamiento, siendo consciente de la importancia de este hecho para la consecución de los objetivos del entrenamiento. 
CUARTA: En caso de incumplimiento de alguna de las anteriores cláusulas por las partes contratantes, la perjudicada podrá reclamarle, judicialmente, la responsabilidad por los posibles perjuicios que se hayan podido ocasionar.

QUINTA: El JUGADOR, habiendo sido informado por el ENTRENADOR PERSONAL, comprende y acepta los posibles riesgos derivados de la actividad a realizar durante el programa de entrenamiento.

En el caso de producirse alguna lesión, el ENTRENADOR PERSONAL se compromete a subsanar, en la medida de lo posible, las consecuencias de esa lesión.

SEXTA: El JUGADOR acepta colaborar con el ENTRENADOR PERSONAL en todo aquello que sea necesario, incluyéndose aquí la entrega de documentación e información útiles para el programa de entrenamiento (fotografías, informes médicos, cuestionarios y entrevistas, resultados de tests funcionales y de capacidades, domicilio personal, número de teléfono y correo electrónico), al igual que acepta someterse a cualquier test (y la grabación del mismo para uso profesional si fuese oportuno) con el fin de valorar su funcionalidad, salud o cualquier otro aspecto necesario para cumplir los objetivos establecidos.

SÉPTIMA: DURACIÓN DEL CONTRATO. El presente contrato tendrá una duración de 12 semanas, las comprendidas entre el 26 de Agosto y el 17 de Noviembre. Se realizarán 2 sesiones semanales con una duración de 1 hora -1 ' 5 horas aproximadamente, dependiendo su duración del tipo de sesión según el plan establecido por el ENTRENADOR PERSONAL.

OCTAVA: Conforme a lo establecido en la Ley Orgánica 3/2018, de 5 de Diciembre, de Protección de Datos Personales y Garantía de los Derechos Digitales, las partes contratantes no podrán transmitir o comunicar por cualquier medio o procedimiento los datos de carácter personal y confidenciales, que queden registrados en un fichero con objeto del cumplimiento y desarrollo del presente contrato.

El JUGADOR acepta que se utilicen las fotografías que se le realicen durante los test y el entrenamiento para aquellas materias que el ENTRENADOR PERSONAL considere necesarias, siempre y cuando se oculte el rostro del cliente y cualquier marca o distintivo que pueda identificarlo.

NOVENA: El incumplimiento de la Cláusula Octava sobre protección de datos personales podría derivar en responsabilidades civiles y/o penales para las partes contratantes.

DÉCIMA: Para el caso de litigio sobre el objeto o incumplimiento del presente contrato, las partes se someten expresamente a los Juzgados y Tribunales de la ciudad de Granada.

Por las partes contratantes se han leído y comprendido las cláusulas enumeradas y expuestas, firmando en prueba de ello y por voluntad propia, el presente contrato.

En Granada, a 01 de Agosto de 2019.

FIRMADO: EL ENTRENADOR PERSONAL

FIRMADO: EL JUGADOR 


\section{ANEXO III: TEST ISOCINÉTICO}

Existe en la literatura una gran confusión en torno a los desequilibrios musculares como factor de riesgo y, por consiguiente, a la utilidad de un test isocinético para predecir lesiones.

Por un lado hay estudios que indican que un desequilibrio H/Q es un factor de riesgo débil, y que un test isocinético no puede distinguir clínicamente a un grupo de jugadores con alto riesgo de lesión de otro con bajo riesgo en jugadores de fútbol $(524,525)$ o fútbol australiano $(526,527)$.

Por otro lado, se argumenta que los desequilibrios musculares $(20,30,79)$ (Relación conveniconal Hcon/Qcon $<0,6$ a $60^{\circ} / \mathrm{s}$; Relación funcional Hexc/Qcon $>1$ o de la extremidad dominante con la contralateral $>15 \%(80)$ ) pueden aumentar el riesgo de lesión (hasta 4 ó 5 veces más probabilidad en el caso de lesión en isquiosurales (81)). Sin embargo, otros estudios señalan que no es el déficit bilateral el que indica el riesgo de lesión, sino un déficit de fuerza excéntrica de isquiosurales (528). Un test isocinético nos permitirá identificar ese desequilibrio para corregirlo (normalizarlo), lo que reduciría el riesgo de lesión $(79,81)$.

No obstante, que haya argumentos en contra de utilizar esta herramienta no quiere decir que no deba utilizarse en pretemporada, tal y como se defiende en un estudio realizado con futbolistas, ya que, en última instancia (en caso de no tener utilidad para identificar riesgo de lesión), puede servir para establecer una referencia para el retorno al juego de un jugador lesionado (525). Además, el test isocinético es una prueba altamente confiable y objetiva para medir la fuerza muscular (529).

Parece ser que los porteros (nuestro sujeto de estudio) no deben compararse con el resto de jugadores a nivel isocinético, ya que obtienen valores más elevados debido al entrenamiento específico que realizan, que incluye trabajo pliométrico (80).

El test isocinético se puede realizar a varias velocidades angulares. A $60 \%$ se considera la más cercana a la fuerza concéntrica máxima, por lo que será la más recomendada (79). Además es una prueba segura, en la que el sujeto nunca encuentra una fuerza que no sea capaz de superar (79). 


\section{ANEXO IV: VALORACIÓN DE LA DISQUINESIA ESCAPULAR}

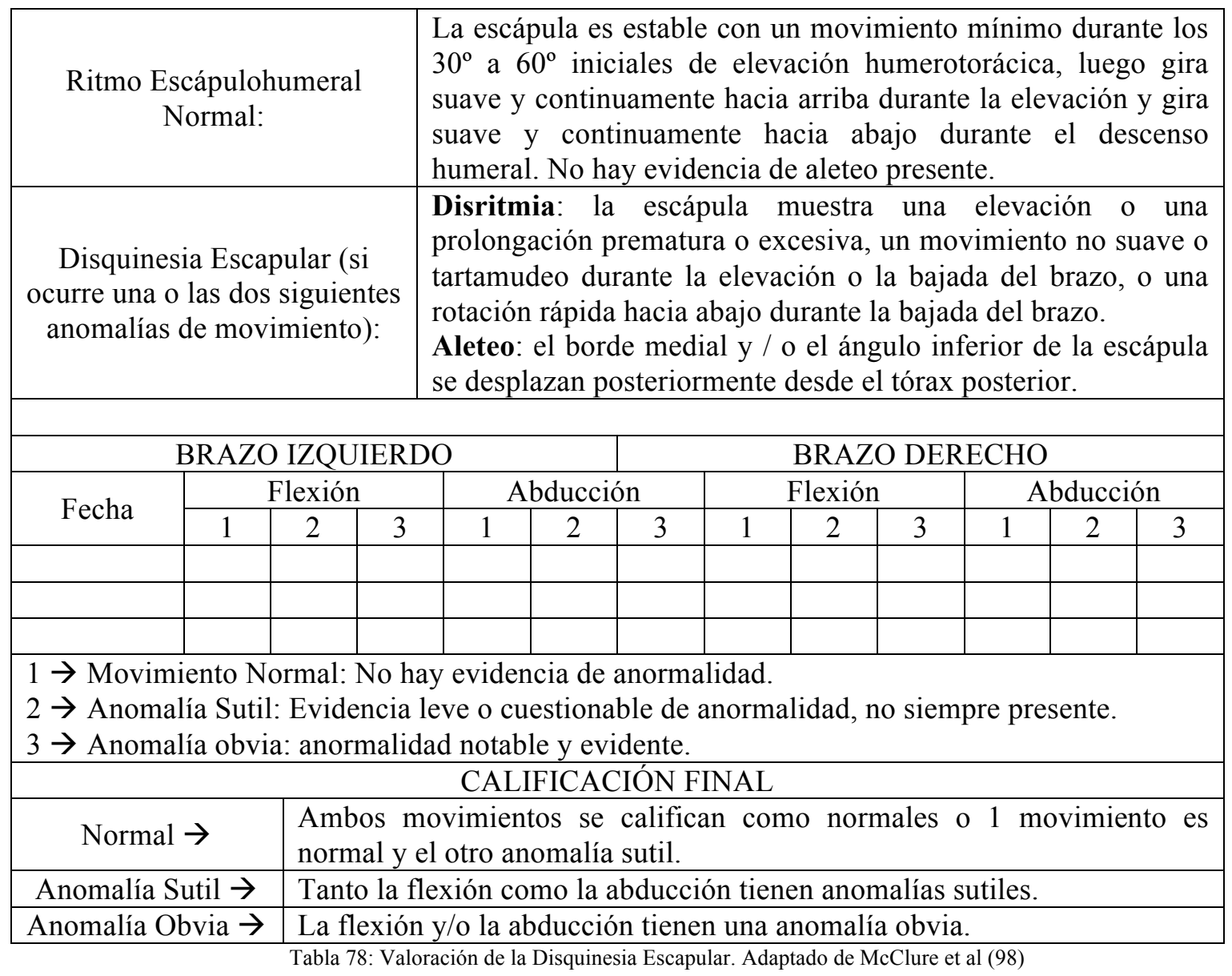


ANEXO V: VALORACIÓN DEL LANDING ERROR SCORING SYSTEM (LESS)

\begin{tabular}{|c|c|c|c|}
\hline ITEM & DEFINICIÓN & VISTA & $\begin{array}{l}\text { EVALUADO } \\
\text { EN SALTO }\end{array}$ \\
\hline $\begin{array}{l}\text { 1-. Ancho de } \\
\text { Postura }\end{array}$ & $\begin{array}{l}\text { Si el jugador aterriza con una postura muy ancha o muy } \\
\text { estrecha se apunta un error }(+1) \text {. }\end{array}$ & Frontal & 1 \\
\hline $\begin{array}{l}\text { 2-. Rotación del } \\
\text { Pie }\end{array}$ & $\begin{array}{l}\text { Si los pies del jugador están moderadamente rotados } \\
\text { externa o internamente en algún momento del aterrizaje se } \\
\text { apunta un error }(+1) \text {. }\end{array}$ & Frontal & 1 \\
\hline $\begin{array}{l}\text { 3-. Simetría } \\
\text { inicial de contacto } \\
\text { con el Pie }\end{array}$ & $\begin{array}{l}\text { Si un pie aterriza antes que el otro o si un pie aterriza de } \\
\text { talón a dedo y el otro de dedo a talón se apunta un error } \\
(+1) \text {. }\end{array}$ & Frontal & 1 \\
\hline $\begin{array}{l}\text { 4-. Valgo de } \\
\text { Rodilla }\end{array}$ & $\begin{array}{l}\text { Si se observa un pequeño valgo de rodilla se apunta un error } \\
(+1) \text {. } \\
\text { Si el valgo es mayor se apunta }+2 \text {. }\end{array}$ & Frontal & 2 \\
\hline $\begin{array}{l}\text { 5-. Flexión } \\
\text { Lateral de Tronco }\end{array}$ & $\begin{array}{l}\text { Si en la recepción el jugador inclina el tronco hacia un lado } \\
\mathrm{u} \text { otro (el tronco no está vertical en el plano frontal) se } \\
\text { apunta un error }(+1) \text {. }\end{array}$ & Frontal & 2 \\
\hline $\begin{array}{l}\text { 6-. Aterrizaje del } \\
\text { Pie } \\
\end{array}$ & $\begin{array}{l}\text { Si el jugador aterriza de talón a pie o con pie plano se } \\
\text { apunta un error }(+1) \text {. }\end{array}$ & Lateral & 3 \\
\hline $\begin{array}{l}\text { 7-. Flexión de } \\
\text { Rodilla }\end{array}$ & $\begin{array}{l}\text { Si el jugador realiza una pequeña }\left(<30^{\circ}\right)(+2) \text { o media }(+1) \\
\text { flexión de rodilla se apunta un error. }\end{array}$ & Lateral & 3 \\
\hline $\begin{array}{l}\text { 8-. Flexión de } \\
\text { Tronco } \\
\end{array}$ & $\begin{array}{l}\text { Si el jugador realiza una pequeña }(+2) \text { o media }(+1) \text { flexión } \\
\text { de tronco se apunta un error. }\end{array}$ & Lateral & 4 \\
\hline $\begin{array}{c}9-. \\
\text { Desplazamiento } \\
\text { total de la } \\
\text { articulación } \\
\text { (Plano Sagital) }\end{array}$ & $\begin{array}{l}\text { Suave }(0 \text { puntos }) \rightarrow \mathrm{Si} \text { el jugador realiza un gran } \\
\text { desplazamiento de tronco y rodillas. } \\
\text { Medio ( } 1 \text { punto }) \rightarrow \mathrm{Si} \text { el jugador realiza un desplazamiento } \\
\text { medio de tronco y rodillas. } \\
\text { Rígido ( } 2 \text { puntos }) \rightarrow \mathrm{Si} \text { el jugador realiza un pequeño } \\
\text { desplazamiento de tronco y rodillas. }\end{array}$ & Lateral & Todos \\
\hline $\begin{array}{l}\text { 10-. Impresión } \\
\text { General }\end{array}$ & $\begin{array}{l}\text { Excelente }(0 \text { puntos }) \rightarrow \mathrm{Si} \text { el jugador aterriza de forma } \\
\text { suave y no hay movimiento de la rodilla en el plano frontal } \\
\text { (valgo). } \\
\text { Pobre ( } 2 \text { puntos) } \rightarrow \text { Si el jugador aterriza de forma rígida y } \\
\text { con un valgo de rodilla grande o sólo con un valgo grande } \\
\text { de rodilla. } \\
\text { Media ( } 1 \text { punto }) \rightarrow \text { El resto de aterrizajes. }\end{array}$ & N/A & Todos \\
\hline
\end{tabular}




\section{TABLA DE PUNTUACIÓN LANDING ERROR SCORING SYSTEM (LESS)}

MOVIMIENTO EN PLANO FRONTAL

\section{1-. Ancho de Postura}

Normal (0)

Ancho (1)

Estrecho (1)

2-. Rotación del Pie

Normal (0)

Rotación Externa (1)

Rotación Interna (1)

3-. Simetría inicial de contacto con el Pie

Simétrico (0)

No Simétrico (1)

\section{4-. Valgo de Rodilla}

Ninguno (0)

Pequẽ̃o (1)

Grande (2)

5-. Flexión Lateral de Tronco

Ninguna (0)

Pequeña a Moderada (1)

MOVIMIENTO EN PLANO SAGITAL

6-. Aterrizaje del Pie

De Dedo del Pie a Talón (0)

De Talón a Dedo del Pie (1)

Con el Pie Plano (1)

7-. Flexión de Rodilla

Grande (0)

Media (1)

Pequeña (2)

8-. Flexión de Tronco

Grande (0)

Media (1)

Pequeña (2)

9-. Desplazamiento total de la articulación

Suave (0)

Medio (1)

Rígido (2)

10-. Impresión General

Excelente (0)

Media (1)

Pobre (2)

Tabla 80: Puntuación del Landing Error Scoring System (LESS) (128) 
ANEXO VI: VALORACIÓN DEL TUCK JUMP TEST

\begin{tabular}{|c|c|c|c|c|c|}
\hline \multicolumn{6}{|c|}{ TUCK JUMP TEST } \\
\hline VISTA & CATEGORÍA & \multicolumn{2}{|r|}{ CRITERIO } & \multicolumn{2}{|l|}{ FECHA } \\
\hline Frontal & \multirow{3}{*}{$\begin{array}{l}\text { Movimiento de } \\
\text { la Rodilla y el } \\
\text { Muslo }\end{array}$} & 1 & Valoo de Rodilla al Atterrizar & & \\
\hline Lateral & & 2 & $\begin{array}{l}\text { Las rodillas no llegan a la horizontal en } \\
\text { el punto más alto del salto }\end{array}$ & & \\
\hline Frontal & & 3 & $\begin{array}{l}\text { Los muslos no ascienden iguales } \\
\text { durante el salto }\end{array}$ & & \\
\hline Frontal & \multirow{4}{*}{$\begin{array}{l}\text { Posición de los } \\
\text { Pies durante el } \\
\text { Aterrizaje }\end{array}$} & 4 & $\begin{array}{l}\text { Recepción con pies NO a la anchura de } \\
\text { los hombros }\end{array}$ & & \\
\hline Lateral & & 5 & $\begin{array}{l}\text { Recepción con pies NO paralelos (uno } \\
\text { adelantado) }\end{array}$ & & \\
\hline Frontal & & 6 & Aterriza antes con un pie que con otro & & \\
\hline \multirow[t]{4}{*}{ Frontal } & & 7 & No aterriza en la misma huella inicial & & \\
\hline & \multirow{3}{*}{$\begin{array}{l}\text { Técnica } \\
\text { Pliométrica }\end{array}$} & 8 & Pausa entre saltos & & \\
\hline & & 9 & $\begin{array}{l}\text { Disminución técnica antes de } 10 \\
\text { segundos }\end{array}$ & & \\
\hline & & 10 & Excesivo movimiento durante el vuelo & & \\
\hline \multicolumn{4}{|c|}{ PUNTUACIÓN TOTAL } & & \\
\hline
\end{tabular}




\section{ANEXO VII: ÍNDICE DE DISCAPACIDAD DE OSWESTRY}

Instrucciones: Este cuestionario ha sido diseñado para obtener información sobre cómo su dolor de espalda afecta a su vida cotidiana. Conteste, por favor, a las siguientes secciones indicando la frase que mejor describe su dolor lumbar durante esta última semana. Puede dejar una o varias secciones sin rellenar si no encuentra una frase que se pueda asociar a su sensación. Puede también marcar más de una frase en cada sección si así lo ha percibido.

\section{SECCIÓN 1: INTENSIDAD DEL DOLOR}

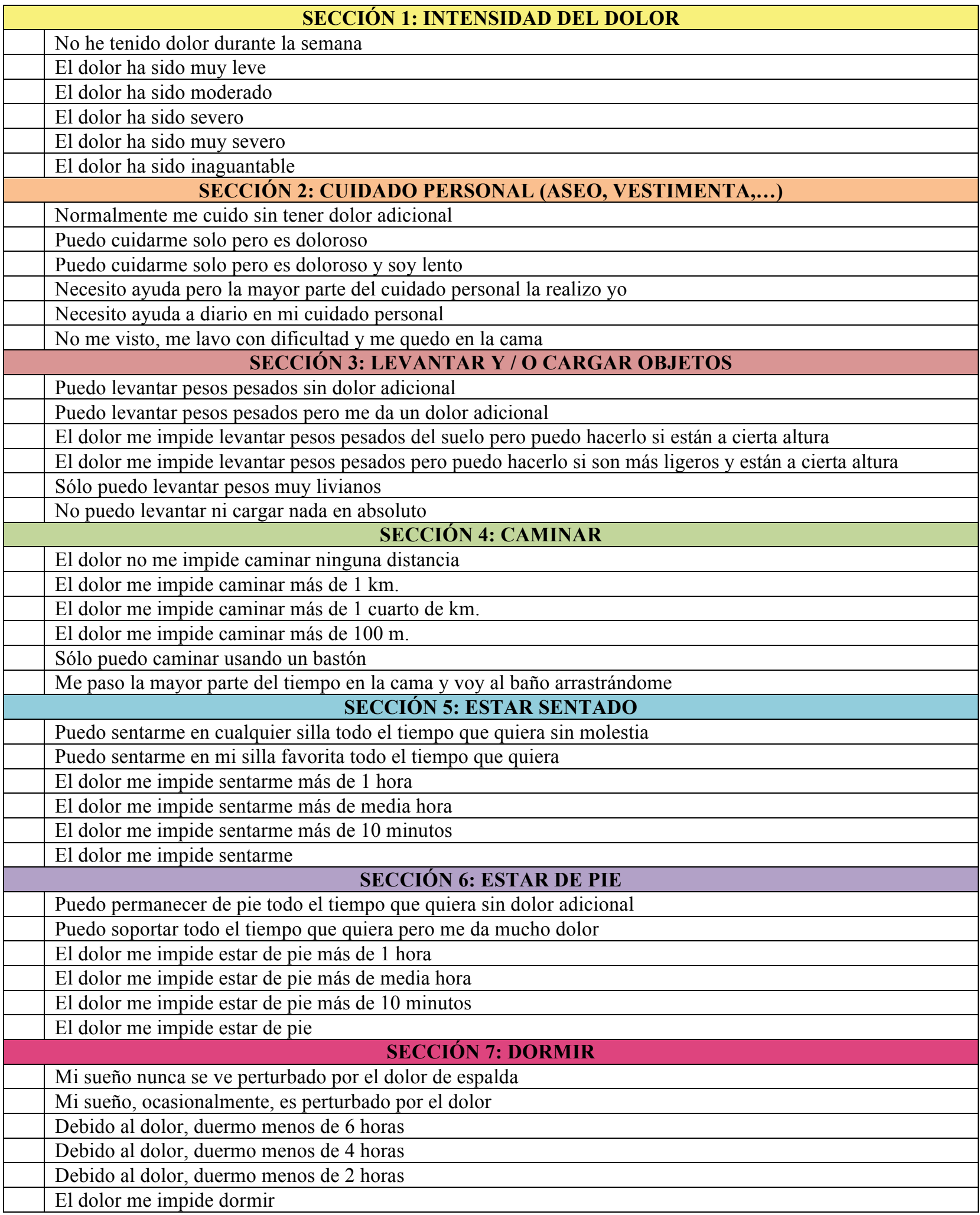




\section{SECCIÓN 8: VIDA SEXUAL (SI CORRESPONDE)}

Mi vida sexual es normal y no causa dolor adicional

Mi vida sexual es normal pero causa un poco de dolor adicional

Mi vida sexual es casi normal pero es muy dolorosa

Mi vida sexual está restringida por el dolor

Mi vida sexual es casi inexistente debido al dolor

El dolor evita cualquier tipo de vida sexual

\section{SECCIÓN 9: VIDA SOCIAL}

Mi vida social es normal y no me causa dolor adicional

Mi vida social es normal pero aumenta el grado de dolor

El dolor no tiene un efecto significativo en mi vida social, aparte de limitar mis intereses más enérgicos

El dolor ha restringido mi vida social y no salgo con tanta frecuencia

El dolor ha restringido mi vida social a mi casa

No tengo vida social debido al dolor

\section{SECCIÓN 10: VIAJAR}

Puedo viajar a cualquier parte sin dolor

Puedo viajar a cualquier parte pero me da un dolor adicional

El dolor es malo pero puedo conducir o realizar viajes durante 2 horas

El dolor me restringe a viajes de menos de 1 hora

El dolor me limita a viajes cortos y necesarios de menos de 30 minutos

El dolor me impide viajar excepto para recibir tratamiento

Tabla 82: Índice de Discapacidad de Oswestry (134) 


\section{ANEXO VIII: CUESTIONARIO DE “CARACTERÍSTICAS PSICOLÓGICAS RELACIONADAS CON EL RENDIMIENTO DEPORTIVO EN FÚTBOL"}

Instrucciones: Conteste, por favor, a cada una de las siguientes cuestiones, indicando en qué medida se encuentra de acuerdo con ellas. Como podrá observar existen seis opciones de respuesta. Elija la que desee, según se encuentre más o menos de acuerdo, marcando con una cruz el lugar correspondiente. En el caso de que no entienda lo que quiere decir exactamente alguna de las preguntas, marque con una cruz en la última columna.

\section{Totalmente en Desacuerdo} ()

\section{Bastante en Desacuerdo} ()

\section{Un poco de Acuerdo \\ ()}

\section{Bastante de Acuerdo ()}
Totalmente de Acuerdo ()

No Entiendo O

\begin{tabular}{|c|c|c|c|c|c|c|}
\hline PREGUNTAS & $\begin{array}{l}\text { Totalmente en } \\
\text { Desacuerdo }\end{array}$ & () & () & () & $\begin{array}{l}\text { Totalmente } \\
\text { de Acuerdo }\end{array}$ & $\begin{array}{c}\text { No } \\
\text { Entiendo }\end{array}$ \\
\hline \multicolumn{7}{|l|}{ 1. Suelo tener problemas concentrándome mientras compito } \\
\hline \multicolumn{7}{|l|}{$\begin{array}{l}\text { 2. Mientras duermo, suelo "darle muchas vueltas" al partido en el que voy a } \\
\text { participar }\end{array}$} \\
\hline \multicolumn{7}{|l|}{$\begin{array}{l}\text { 3. A menudo ensayo mentalmente lo que debo hacer justo antes de comenzar a jugar } \\
\text { en un partido }\end{array}$} \\
\hline \multicolumn{7}{|l|}{ 4. Cuando lo hago mal, suelo perder la concentración } \\
\hline \multicolumn{7}{|l|}{$\begin{array}{l}\text { 6. A menudo estoy "muerto de miedo" en los momentos anteriores al comienzo de mi } \\
\text { participación en un partido }\end{array}$} \\
\hline \multicolumn{7}{|l|}{$\begin{array}{l}\text { 7. Cuando cometo un error me cuesta olvidarlo para concentrarme rápidamente en lo } \\
\text { que tengo que hacer }\end{array}$} \\
\hline \multicolumn{7}{|l|}{ 8. Establezco metas (u objetivos) que debo alcanzar y normalmente las consigo } \\
\hline \multicolumn{7}{|l|}{ 9. Algunas veces siento una intensa ansiedad mientras estoy jugando un partido } \\
\hline \multicolumn{7}{|l|}{$\begin{array}{l}\text { 10. Durante mi actuación en un partido, mi atención parece fluctuar una y otra vez } \\
\text { entre lo que tengo que hacer y otras cosas }\end{array}$} \\
\hline \multicolumn{7}{|l|}{ 11. Tengo frecuentes dudas respecto a mis posibilidades de hacerlo bien en un partido } \\
\hline \multicolumn{7}{|l|}{ 12. Gasto mucha energía intentando estar tranquilo antes de que comience un partido } \\
\hline \multicolumn{7}{|l|}{ 13. Cuando comienzo haciéndolo mal, mi confianza baja rápidamente } \\
\hline \multicolumn{7}{|l|}{ 14. Pienso que el espíritu de equipo es muy importante } \\
\hline \multicolumn{7}{|l|}{$\begin{array}{l}\text { 15. Generalmente, puedo seguir jugando con confianza, aunque se trate de una de mis } \\
\text { peores actuaciones }\end{array}$} \\
\hline \multicolumn{7}{|l|}{$\begin{array}{l}\text { 16. Cuando me preparo para jugar un partido, intento imaginarme, desde mi propia } \\
\text { perspectiva, lo que veré, haré o notaré cuando la situación sea real }\end{array}$} \\
\hline \multicolumn{7}{|l|}{ 17. Mi confianza en mí mismo es muy inestable } \\
\hline \multicolumn{7}{|l|}{$\begin{array}{l}\text { 18. Cuando mi equipo pierde, me encuentro mal con independencia de } \mathrm{mi} \\
\text { rendimiento individual }\end{array}$} \\
\hline \multicolumn{7}{|l|}{ 19. Cuando cometo un error en un partido me pongo muy ansioso } \\
\hline \multicolumn{7}{|l|}{ 20. En este momento, lo más importante en mi vida es hacerlo bien en el fútbol } \\
\hline \multicolumn{7}{|l|}{ 21. El fútbol es toda mi vida } \\
\hline \multicolumn{7}{|l|}{$\begin{array}{l}\text { 22. A menudo pierdo la concentración durante los partidos como consecuencia de las } \\
\text { decisiones de los árbitros que considero desacertadas y que van en contra mía o de mi } \\
\text { equipo }\end{array}$} \\
\hline \multicolumn{7}{|l|}{$\begin{array}{l}\text { 23. Cuando cometo un error durante un partido, suele preocuparme lo que piensen } \\
\text { otras personas como el entrenador, los compañeros de equipo o alguien de entre los } \\
\text { espectadores }\end{array}$} \\
\hline \multicolumn{7}{|l|}{$\begin{array}{l}\text { 24. El día anterior a un partido me encuentro habitualmente demasiado nervioso o } \\
\text { preocupado }\end{array}$} \\
\hline \multicolumn{7}{|l|}{$\begin{array}{l}\text { 25. Creo que la aportación específica de todos los miembros de un equipo, es } \\
\text { sumamente importante para la obtención del éxito del equipo }\end{array}$} \\
\hline \multicolumn{7}{|l|}{ 26. En los partidos suelo animarme con palabras, pensamientos o imágenes } \\
\hline \multicolumn{7}{|l|}{$\begin{array}{l}\text { 27. A menudo pierdo la concentración durante un partido por preocuparme o } \\
\text { ponerme a pensar en el resultado final }\end{array}$} \\
\hline \multicolumn{7}{|l|}{ 28. Suelo aceptar bien las críticas e intento aprender de ellas } \\
\hline \multicolumn{7}{|l|}{$\begin{array}{l}\text { 29. Me concentro con facilidad en aquello que es lo más importante en cada momento } \\
\text { de un partido }\end{array}$} \\
\hline \multicolumn{7}{|l|}{$\begin{array}{l}\text { 30. Me cuesta aceptar que se destaque más la labor de otros miembros del equipo que } \\
\text { la mía }\end{array}$} \\
\hline $\begin{array}{l}\text { 31. Cuando finaliza un partido analizo mi rendimiento de forma objetiva y específica } \\
\text { (es decir, considerando hechos reales y cada apartado del partido por separado). }\end{array}$ & & & & & & \\
\hline
\end{tabular}


32. A menudo pierdo la concentración en el partido a consecuencia de la actuación o los comentarios poco deportivos de los adversarios

33. Me preocupan mucho las decisiones que respecto a mí pueda tomar el entrenador durante un partido

34. Durante los entrenamientos suelo estar muy concentrado/a en lo que tengo que hacer

35. Suelo establecer objetivos prioritarios antes de cada sesión de entrenamiento y de cada partido

36. Mi confianza en el partido depende en gran medida de los éxitos o fracasos en los partidos anteriores

37. Mi motivación depende en gran medida del reconocimiento que obtengo de los demás

38. Las instrucciones, comentarios y gestos del entrenador suelen interferir negativamente en mi concentración durante el partido

39. Suelo confiar en mí mismo aún en los momentos más difíciles de un partido

40. Estoy dispuesto a cualquier esfuerzo por se cada vez mejor

Tabla 83: Cuestionario C.P.R.D. en Fútbol (144)

POR FAVOR COMPRUEBE SI HA CONTESTADO A TODAS LAS PREGUNTAS ANTERIORES CON UNA SOLA RESPUESTA

¡MUCHAS GRACIAS POR SU COLABORACIÓN! 
HOJA DE RESPUESTAS DEL C.P.R.D. - FÚTBOL

\begin{tabular}{|c|ccccc|c|ccccc|}
\hline \multicolumn{3}{|c|}{$\begin{array}{c}\text { AUTOCONFIANZA } \\
\text { (MÁX = 45 P) }\end{array}$} & \multicolumn{5}{c|}{$\begin{array}{c}\text { ACTITUD Y PREPARACIÓN } \\
\text { MENTAL } \\
\text { (MÁX = 40 P) }\end{array}$} \\
\hline $\mathbf{5}$ & 5 & 4 & 3 & 2 & 1 & $\mathbf{3}$ & 1 & 2 & 3 & 4 & 5 \\
\hline $\mathbf{1 3}$ & 5 & 4 & 3 & 2 & 1 & $\mathbf{1 4}$ & 1 & 2 & 3 & 4 & 5 \\
\hline $\mathbf{1 5}$ & 1 & 2 & 3 & 4 & 5 & $\mathbf{1 6}$ & 1 & 2 & 3 & 4 & 5 \\
\hline $\mathbf{1 7}$ & 5 & 4 & 3 & 2 & 1 & $\mathbf{1 8}$ & 1 & 2 & 3 & 4 & 5 \\
\hline $\mathbf{2 7}$ & 5 & 4 & 3 & 2 & 1 & $\mathbf{2 5}$ & 1 & 2 & 3 & 4 & 5 \\
\hline $\mathbf{3 3}$ & 5 & 4 & 3 & 2 & 1 & $\mathbf{2 6}$ & 1 & 2 & 3 & 4 & 5 \\
\hline $\mathbf{3 6}$ & 5 & 4 & 3 & 2 & 1 & $\mathbf{2 8}$ & 1 & 2 & 3 & 4 & 5 \\
\hline $\mathbf{3 7}$ & 5 & 4 & 3 & 2 & 1 & $\mathbf{3 1}$ & 1 & 2 & 3 & 4 & 5 \\
\hline $\mathbf{3 9}$ & 1 & 2 & 3 & 4 & 5 & \multicolumn{7}{c|}{ Puntuación Directa } & \\
\hline \multicolumn{3}{|c|}{ Puntuación Directa } & & \multicolumn{1}{c|}{} \\
\hline
\end{tabular}

\begin{tabular}{|c|c|c|c|c|c|c|c|c|c|c|c|c|c|c|c|c|c|}
\hline \multicolumn{6}{|c|}{$\begin{array}{c}\text { CONTROL DE ESTRÉS Y } \\
\text { ANSIEDAD } \\
(M A ́ X=55 \text { P) }\end{array}$} & \multicolumn{6}{|c|}{$\begin{array}{l}\text { CONCENTRACIÓN } \\
(M A ́ X=35 \text { P) }\end{array}$} & \multicolumn{6}{|c|}{$\begin{array}{l}\text { MOTIVACIÓN } \\
\text { (MÁX = } 25 \text { P) }\end{array}$} \\
\hline 2 & 5 & 4 & 3 & 2 & 1 & 1 & 5 & 4 & 3 & 2 & 1 & 8 & 1 & 2 & 3 & 4 & 5 \\
\hline 6 & 5 & 4 & 3 & 2 & 1 & 4 & 5 & 4 & 3 & 2 & 1 & 20 & 1 & 2 & 3 & 4 & 5 \\
\hline 7 & 5 & 4 & 3 & 2 & 1 & 10 & 5 & 4 & 3 & 2 & 1 & 21 & 1 & 2 & 3 & 4 & 5 \\
\hline 9 & 5 & 4 & 3 & 2 & 1 & 22 & 5 & 4 & 3 & 2 & 1 & 35 & 1 & 2 & 3 & 4 & 5 \\
\hline 11 & 5 & 4 & 3 & 2 & 1 & 29 & 1 & 2 & 3 & 4 & 5 & 40 & 1 & 2 & 3 & 4 & 5 \\
\hline 12 & 5 & 4 & 3 & 2 & 1 & 32 & 5 & 4 & 3 & 2 & 1 & & & & & & \\
\hline 19 & 5 & 4 & 3 & 2 & 1 & 34 & 1 & 2 & 3 & 4 & 5 & & & & & & \\
\hline 23 & 5 & 4 & 3 & 2 & 1 & & & & & & & & & & & & \\
\hline 24 & 5 & 4 & 3 & 2 & 1 & & & & & & & & & & & & \\
\hline 30 & 5 & 4 & 3 & 2 & 1 & & & & & & & & & & & & \\
\hline 38 & 5 & 4 & 3 & 2 & 1 & & & & & & & & & & & & \\
\hline \multicolumn{5}{|c|}{ Puntuación Directa } & & \multicolumn{5}{|c|}{ Puntuación Directa } & & \multicolumn{5}{|c|}{ Puntuación Directa } & \\
\hline
\end{tabular}

PUNTUACIÓN GLOBAL DEL CUESTIONARIO =

/ $200 \mathrm{P}$

( $\Sigma$ Puntuaciones Directas de las 5 Subescalas) 


\section{ANEXO IX: ENTIDADES CLÍNICAS PARA EL DOLOR INGUINAL}

\begin{tabular}{|l|l|}
\hline \multicolumn{2}{|c|}{ SISTEMA DE CLASIFICACIÓN DE DOLOR INGUINAL EN ATLETAS } \\
\hline ENTIDADES CLÍNICAS DEFINIDAS & SÍNTOMAS Y RESULTADOS DE LOS EXÁMENES \\
\hline Dolor inguinal relacionado con Aductor & Sensibilidad en aductor y dolor en pruebas de aducción resistida \\
\hline Dolor inguinal relacionado con Iliopsoas & $\begin{array}{l}\text { Sensibilidad en iliopsoas, más probable con dolor en flexión resistida } \\
\text { de cadera y/o estiramiento de flexores de cadera }\end{array}$ \\
\hline Dolor inguinal relacionado con Ingle & $\begin{array}{l}\text { Dolor en zona del canal inguinal. No hernia palpable. Más probable si } \\
\text { el dolor se agrava con resistencia abdominal, valsalva, tos o estornudo }\end{array}$ \\
\hline Dolor inguinal relacionado con el pubis & $\begin{array}{l}\text { Sensibilidad local en sínfisis púbica. No hay test de fuerza para valorar } \\
\text { específicamente el dolor de ingle relacionado con la zona púbica }\end{array}$ \\
\hline \multicolumn{2}{|c|}{ CATEGORÍAS ADICIONALES } \\
\hline Dolor inguinal relacionado con la cadera & $\begin{array}{l}\text { Sospecha de que la cadera es la fuente del dolor de ingle, ya sea a } \\
\text { través de historia o mediante examen clínico }\end{array}$ \\
\hline Otros & Cualquier otro trastorno que cause dolor en la zona inguinal \\
\hline
\end{tabular}




\section{ANEXO X: PAUTAS METODOLÓGICAS PARA EL ENTRENAMIENTO DE LA FUERZA.}

Es importante señalar que el tratamiento que se ha dado al entrenamiento de la Fuerza en los deportes colectivos no ha sido el más adecuado. Se ha heredado la concepción lineal y reduccionista propia de los deportes individuales, frente a la cual se propone un modelo holístico, basado en el jugador, que no se centra en la estructura condicional, sino que considera las estructuras socio-afectiva, emotivovolitiva y creativas fundamentales (518). Así, bajo esta nueva concepción del entrenamiento de los deportes colectivos podemos señalas las siguientes premisas (518)(519):

- Resistencia Acomodada frente a \% RM: En el fútbol se trabaja muy por debajo de la RM, por lo que no tiene lógica entrenar en base a ella ni calcularla continuamente para cada ejercicio. La referencia no debe ser la RM sino la fuerza que necesito en el juego.

- Duración Postfijada frente a Prefijada: Esto nos permitirá trabajar sin fatiga y adaptarnos a las condiciones en las que se encuentre el jugador en cada momento, es decir, individualizar.

- Estímulos Estocásticos y Perturbadores frente a Situaciones de Alta Estabilidad Corporal: La variabilidad en el fútbol hace que sea imposible predecir qué va a ocurrir en la acción posterior. Permitir al jugador poder realizar un ajuste previo a cualquier acción como aterrizaje, golpeo, forcejeo,... es clave para la prevención de lesiones.

- Bloques de trabajo con Recuperación (clústeres) frente a Repeticiones y Series Convencionales: No se trata de realizar el movimiento, sino de mantener la potencia (Repeated Power Ability (RPA)). Si no le decimos nada al jugador nunca va a trabajar la potencia. Por tanto no es el tiempo el factor determinante sino la intensidad. Es un entrenamiento de Calidad.

- Alternancia y Concatenación de Movimientos frente a Práctica Monótona: En el fútbol no existen los movimientos cíclicos por lo que puede resultar interesante no realizar el mismo movimiento durante todas las series. Frente a ello podemos utilizar la "interferencia intratarea", que aumenta la transferencia y provoca retenciones de aprendizaje mayores, o la concatenación de movimientos relacionados entre sí.

- Variabilidad frente a Práctica Constante: Los movimientos evolucionan y se autoorganizan en formas cada vez más complejas, esto implica un sistema abierto, dinámico, que no esté encorsetado por un Programa General Motor (huella de aprendizaje que deja un movimiento y permitirá realizar ejercicios de la misma familia si no se modifica la secuencia de movimiento).

- Predominio Unilateral frente al Bilateral: La mayoría de las acciones propias del fútbol ocurren en apoyo monopodal, por lo que debemos huir del entrenamiento basado en la halterofilia y orientar las situaciones hacia el apoyo unipodal, que genera mayor transferencia a los cambios de dirección, tan importantes en nuestro deporte.

- Variación en los vectores de fuerza frente al vector vertical: En lugar del vector vertical de la sentadilla, se vectores horizontales y laterales, que cumplan con los movimientos multidireccionales que realizan los futbolistas y generan adaptaciones funcionales diferentes y específicas (530).

- Desarrollo de la Fuerza 3D y 4D frente a la simple Práctica Variada: El entrenamiento 4D de la fuerza lo que hace es deformar la aplicación de fuerza porque en una máquina cerrada no se cumple con las necesidades reales del juego. En un deporte colectivo no siempre iniciamos la acción de salto o salida desde la misma angulación, con el mismo pie, la misma dirección,... unas veces tengo un rival empujando por un lado, otras sobre el hombro,... por esto la máquina cerrada es insuficiente. El entrenamiento 3D deforma la aplicación de fuerza para asemejarla con lo que ocurre en el juego. 


\section{BIBLIOGRAFÍA}

1. Della Villa F, Mandelbaun BR, Lemak LJ. The Effect of Playing Position on Injury Risk in Male Soccer Players: Systematic Review of the Literature and Risk Considerations for Each Playing Position Take-Home Points. Am J Orthop. 2018;1-11.

2. Ekstrand J, Hägglund M, Waldén M. Injury incidence and injury patterns in professional football: The UEFA injury study. Br J Sports Med. 2011;45(7):553-8.

3. Hägglund M, Waldén M, Ekstrand J. Injury recurrence is lower at the highest professional football level than at national and amateur levels: Does sports medicine and sports physiotherapy deliver? Br J Sports Med. 2016;50(12):751-8.

4. Pfirrmann D, Herbst M, Ingelfinger P, Simon P, Tug S. Analysis of Injury Incidences in Male Professional Adult and Elite Youth Soccer Players: A Systematic Review. J Athl Train. 2016;51(5):410-24.

5. Earle R, Baechle T. Fundamentos del entrenamiento personal. Manual NSCA. Barcelona: Editorial Paidotribo; 2008. p. 827.

6. Almirante Sánchez A. Desarrollo de un programa de entrenamiento para la mejora de las cualidades físicas de un varón joven desentrenado a través de un nuevo enfoque de Crossfit. [Internet]. Granada; 2017. Available from: http://hdl.handle.net/10481/47838

7. Bahr R. Why screening tests to predict injury do not work-and probably never will...: A critical review. Br J Sports Med. 2016;50(13):776-80.

8. Bakken A, Targett S, Bere T, Adamuz MC, Tol JL, Whiteley R, et al. Health conditions detected in a comprehensive periodic health evaluation of 558 professional football players. Br J Sports Med. 2016;50(18):1142-50.

9. Dvorak J, Junge A, Chomiak J, Graf-Baumann T, Peterson L, Rösch D, et al. Risk factor analysis for injuries in football players. Possibilities for a prevention program. Am J Sports Med. 2000;28(5 Suppl):S69-74.

10. McCall A, Davison M, Andersen TE, Beasley I, Bizzini M, Dupont G, et al. Injury prevention strategies at the FIFA 2014 World Cup: Perceptions and practices of the physicians from the 32 participating national teams. Br J Sports Med. 2015;49(9):603-8.

11. Arnason A, Sigurdsson SB, Gudmundsson A, Holme I, Engebretsen L, Bahr R. Risk Factors for Injuries in Football. Am J Sports Med. 2004;32(1):5-16.

12. Hägglund M, Waldén M, Ekstrand J. Previous injury as a risk factor for injury in elite football: a prospective study over two consecutive seasons. Br J Sports Med. 2006;40(9):767-72.

13. Ekstrand J, Gillquist J. Soccer injuries and their mechanisms: a prospective study. Med Sci Sports Exerc. 1983;15(3):267-70.

14. Hägglund M, Walde M, Ekstrand J. Risk Factors for Lower Extremity Muscle Injury in Professional Soccer The UEFA Injury Study. Am J Sports Med. 2013;41(2):327-35.

15. Grosdent S, Demoulin C, Rodriguez de La Cruz C, Giop R, Tomasella M, Crielaard JM, et al. Lumbopelvic motor control and low back pain in elite soccer players: a crosssectional study. J Sports Sci. 2016;34(11):1021-9.

16. Engebretsen AH, Myklebust G, Holme I, Engebretsen L, Bahr R. Intrinsic risk factors for acute knee injuries among male football players: A prospective cohort study. Scand J Med Sci Sport. 2010;20(3):403-10.

17. Kofotolis ND, Kellis E, Vlachopoulos SP. Ankle Sprain Injuries and Risk Factors in Amateur Soccer Players During a 2-Year Period. Am J Sports Med. 2007;35(3):458-66.

18. Henry T, Evans K, Snodgrass SJ, Miller A, Callister R. Risk Factors for Noncontact Ankle Injuries in Amateur Male Soccer Players: A Prospective Cohort Study. Clin J Sport Med. 2016;26(3,1):251-8.

19. Räisänen AM, Arkkila H, Vasankari T, Steffen K, Parkkari J, Kannus P, et al. Investigation of knee control as a lower extremity injury risk factor: A prospective study 
in youth football. Scand J Med Sci Sport. 2018;28(9):2084-92.

20. Prior M, Guerin M, Grimmer K. An evidence-based approach to hamstring strain injury: A systematic review of the literature. Sports Health. 2009;1(2):154-64.

21. van Beijsterveldt AMC, van de Port IGL, Vereijken AJ, Backx FJG. Risk Factors for Hamstring Injuries in Male Soccer Players: A Systematic Review of Prospective Studies. Scand J Med Sci Sport. 2013;23(3):253-62.

22. Hauge Engebretsen A, Myklebust G, Holme I, Engebretsen L, Bahr R. Intrinsic Risk Factors for Groin Injuries Among Male Soccer Players: A Prospective Cohort Study. Am J Sports Med. 2010;38(10):2051-7.

23. Ryan J, DeBurca N, Mc Creesh K. Risk factors for groin/hip injuries in field-based sports: A systematic review. Br J Sports Med. 2014;48(14):1089-96.

24. Whittaker JL, Small C, Maffey L, Emery CA. Risk factors for groin injury in sport: an updated systematic review. Br J Sports Med. 2015;49(12,1):803-9.

25. Fousekis K, Tsepis E, Vagenas G. Intrinsic Risk Factors of Noncontact Ankle Sprains in Soccer: A Prospective Study on 100 Professional Players. Am J Sports Med. 2012;40(8):1842-50.

26. Foreman TK, Addy T, Baker S, Burns J, Hill N, Madden T. Prospective studies into the causation of hamstring injuries in sport: A systematic review. Phys Ther Sport. 2006;7(2):101-9.

27. Kendall P, McCheary K, Provance G, Rodgers M, Romani A. Músculos: Pruebas funcionales, Postura y Dolor. Marbán. Madrid; 2007. 625 p.

28. Bahr R, Holme I. Risk factors for sports injuries - a methodological approach. Br J Sports Med. 2003;37(5):384-92.

29. Mendiguchia J, Alentorn-geli E, Brughelli M. Hamstring strain injuries: Are we heading in the right direction? Br J Sports Med. 2012;46(2):81-5.

30. Freckleton G, Pizzari T. Risk factors for hamstring muscle strain injury in sport: A systematic review and meta-analysis. Br J Sports Med. 2013;47(6):351-8.

31. Griffin LY, Agel J, Albohm MJ, Arendt EA, Dick RW, Garrett WE, et al. Noncontact Anterior Cruciate Ligament injuries: Risk factors and prevention strategies. J Am Acad Orthop Surg. 2000;8(3):141-50.

32. Powers CM, Ghoddosi N, Straub RK, Khayambashi K. Hip Strength as a Predictor of Ankle Sprains in Male Soccer Players: A Prospective Study. J Athl Train. 2017;52(11):1048-55.

33. Claiborne TL, Armstrong CW, Ghandi V, Pincivero DM. Relationship Between Hip and Knee Strength and Knee Valgus During a Single Leg Squat. J Appl Biomech. 2006;22(1):41-50.

34. Maffey L, Emery C. What are the Risk Factors for Groin Strain Injury in Sport? A systematic review of the literature. Sport Med. 2007;37(10):881-94.

35. Liporaci RF, Saad MC, Bevilaqua-Grossi D, Riberto M. Preseason intrinsic risk factors Associated odds estimate the exposure to proximal lower limb injury throughout the season among professional football players. BMJ Open Sport Exerc Med. 2018;4(1):1-7.

36. Elgueta-Cancino E, Schabrun S, Danneels L, Hodges P. A clinical test of lumbopelvic control: Development and reliability of a clinical test of dissociation of lumbopelvic and thoracolumbar motion. Man Ther. 2014;19(5):418-24.

37. Scholtes SA, Gombatto SP, Van Dillen LR. Differences in lumbopelvic motion between people with and people without low back pain during two lower limb movement tests. Clin Biomech. 2009;24(1):7-12.

38. Luomajoki H, Kool J, De Bruin ED, Airaksinen O. Movement control tests of the low back; Evaluation of the difference between patients with low back pain and healthy controls. BMC Musculoskelet Disord. 2008;9(170):1-12.

39. Luomajoki H, Kool J, de Bruin ED, Airaksinen O. Reliability of movement control tests 
in the lumbar spine. BMC Musculoskelet Disord. 2007;8.

40. Abenza L, Olmedilla A, Ortega E, Esparza F. Lesiones y factores psicológicos en futbolistas juveniles. Arch Med del Deport. 2009;26(132):280-8.

41. Kleinert J. Mood states and perceived physical states as short term predictors of sport injuries: Two prospective studies. Int J Sport Exerc Psychol. 2007;5(4):340-51.

42. Johnson U, Ivarsson A. Psychological predictors of sport injuries among junior soccer players. Scand J Med Sci Sport. 2011;21(1):129-36.

43. Ivarsson A, Johnson U, Podlog L. Psychological Predictors of Injury Occurrence: A Prospective Investigation of Professional Swedish Soccer Players. J Sport Rehabil. 2013;22(1):19-26.

44. Jansen P, Lehmann J, Fellner B, Huppertz G, Loose O, Achenbach L, et al. Relation of injuries and psychological symptoms in amateur soccer players. BMJ Open Sport Exerc Med. 2019;5(1).

45. Balagué F, Troussier B, Salminen JJ. Non-specific low back pain in children and adolescents: Risk factors. Eur Spine J. 1999;8(6):429-38.

46. Chisholm MD, Birmingham TB, Brown J, MacDermid J, Chesworth BM. Reliability and validity of a weight-bearing measure of ankle dorsiflexion range of motion. Physiother Canada. 2012;64(4):347-55.

47. Konor MM, Morton S, Eckerson JM, Grindstaff TL. Reliability of three measures of ankle dorsiflexion range of motion. Int J Sports Phys Ther. 2012;7(3):279-87.

48. Lima YL, Ferreira VMLM, de Paula Lima PO, Bezerra MA, de Oliveira RR, Almeida GPL. The association of ankle dorsiflexion and dynamic knee valgus: A systematic review and meta-analysis. Phys Ther Sport. 2018;29:61-9.

49. Fong C, Blackburn JT, Norcross MF, Mcgrath M, Padua DA. Ankle-Dorsiflexion Range of Motion and Landing Biomechanics. J Athl Train. 2011;46(1):5-10.

50. Macrum E, Bell DR, Boling M, Lewek M, Padua D. Effect of Limiting AnkleDorsiflexion Range of Motion on Lower Extremity Kinematics and Muscle-Activation Patterns During a Squat. J Sport Rehabil. 2012;21(2):144-50.

51. Backman LJ, Danielson P. Low Range of Ankle Dorsiflexion Predisposes for Patellar Tendinopathy in Junior Elite Basketball Players. A 1-Year prospective study. Am J Sports Med. 2011;39(12):2626-33.

52. Davis DS, Quinn RO, Whiteman CT, Williams JD, Young CR. Concurrent validity of four clinical tests used to measure hamstring flexibility. J Strength Cond Res. 2008;22(2):583-8.

53. Hamid MSA, Mohamed Ali MR, Yusof A. Interrater and Intrarater Reliability of the Active Knee Extension (AKE) Test among Healthy Adults. J Phys Ther Sci. 2013;25(8):957-61.

54. Witvrouw E, Danneels L, Asselman P, D’Have T, Cambier D. Muscle flexibility as a risk factor for developing muscle injuries in male professional soccer players: A prospective study. Am J Sports Med. 2003;31(1):41-6.

55. Silder A, Reeder SB, Thelen DG. The influence of prior hamstring injury on lengthening muscle tissue mechanics. J Biomech. 2010;43(12):2254-60.

56. Gabbe BJ, Bennell KL, Wajswelner H, Finch CF. Reliability of common lower extremity musculoskeletal screening tests. Phys Ther Sport. 2004;5(2):90-7.

57. Harvey D. Assessment of the flexibility of elite athletes using the modified Thomas test. Br J Sports Med. 1998;32(1):68-70.

58. Clapis PA, Davis SM, Davis RO. Reliability of inclinometer and goniometric measurements of hip extension flexibility using the modified Thomas test. Physiother Theory Pract. 2008;24(2):135-41.

59. Wagner T, Behnia N, Ancheta WL, Shen R, Farrokhi S, Powers CM. Strengthening and Neuromuscular Reeducation of the Gluteus Maximus in a Triathlete With Exercise- 
Associated Cramping of the Hamstrings. J Orthop Sports Phys Ther. 2010;40(2):112-9.

60. Moreside JM, Mcgill SM. Quantifying normal 3D hip ROM in healthy young adult males with clinical and laboratory tools: Hip mobility restrictions appear to be plane-specific. Clin Biomech. 2011;26(8):824-9.

61. Kang S, Choung S, Park J, Jeon H, Kwon O. The relationship between length of the iliotibial band and patellar position in Asians. Knee. 2014;21(6):1135-8.

62. Gradoz MC, Bauer LE, Grindstaff TL, Bagwell JJ. Reliability of hip rotation range of motion in supine and seated positions. J Sport Rehabil. 2018;27(4):1-4.

63. Nussbaumer S, Leunig M, Glatthorn JF, Stauffacher S, Gerber H, Maffiuletti NA. Validity and test-retest reliability of manual goniometers for measuring passive hip range of motion in femoroacetabular impingement patients. BMC Musculoskelet Disord. 2010;11:1-11.

64. Malliaras P, Hogan A, Nawrocki A, Crossley K, Schache A. Hip flexibility and strength measures: Reliability and association with athletic groin pain. Br J Sports Med. 2009;43(10):739-44.

65. Prather H, Harris-Hayes M, Hunt DM, Steger-May K, Mathew V, Clohisy JC. Reliability and agreement of hip range of motion and provocative physical examination tests in asymptomatic volunteers. PM R. 2010;2(10):888-95.

66. Cibere J, Thorne A, Bellamy N, Greidanus N, Chalmers A, Mahomed N, et al. Reliability of the hip examination in osteoarthritis: Effect of standardization. Arthritis Care Res. 2008;59(3):373-81.

67. Cejudo A, Sainz de Baranda P, Ayala F, Santonja F. Test-retest reliability of seven common clinical tests for assessing lower extremity muscle flexibility in futsal and handball players. Phys Ther Sport. 2015;16(2):107-13.

68. Verrall GM, Slavotinek JP, Barnes PG, Esterman A, Oakeshott RD, Spriggins AJ. Hip joint range of motion restriction precedes athletic chronic groin injury. J Sci Med Sport. 2007;10(6):463-6.

69. Kevern MA, Beecher M, Rao S. Reliability of measurement of glenohumeral internal rotation, external rotation, and total arc of motion in 3 test positions. J Athl Train. 2014;49(5):640-6.

70. Shanley E, Thigpen CA, Clark JC, Wyland DJ, Hawkins RJ, Noonan TJ, et al. Changes in passive range of motion and development of glenohumeral internal rotation deficit (GIRD) in the professional pitching shoulder between spring training in two consecutive years. J Shoulder Elb Surg. 2012;21(11):1605-12.

71. Cieminski CJ, Klaers H, Kelly SM, Stelzmiller MR, Nawrocki TJ, Indrelie AJ. Total Arc of Motion in the Sidelying Position: Evidence for a New Method To Assess Glenohumeral Internal Rotation Deficit in Overhead Athletes. Int J Sports Phys Ther. 2015;10(3):319_ 31.

72. Borsa PA, Laudner KG, Sauers EL. Mobility and stability adaptations in the shoulder of the overhead athlete: A theoretical and evidence-based perspective. Sport Med. 2008;38(1):17-36.

73. Giles K, Musa I. A survey of glenohumeral joint rotational range and non-specific shoulder pain in elite cricketers. Phys Ther Sport. 2008;9(3):109-16.

74. Clarsen B, Bahr R, Andersson SH, Munk R, Myklebust G. Reduced glenohumeral rotation, external rotation weakness and scapular dyskinesis are risk factors for shoulder injuries among elite male handball players: A prospective cohort study. Br J Sports Med. 2014;48(17):1327-33.

75. Tyler TF, Roy T, Nicholas SJ, Gleim GW. Reliability and Validity of a new method of measuring posterior shoulder tightness. J Orthop Sport Phys Ther. 1999;29(5):262-74.

76. García H. Apuntes del Máster Propio en Entrenamiento Personal ( $6^{\mathrm{a}}$ Edición): Estructura, función y análisis del sistema músculo-esquelético. 2017. 
77. Borstad JD. Measurement of pectoralis minor muscle length: Validation and clinical application. J Orthop Sports Phys Ther. 2008;38(4):169-74.

78. Borstad JD, Ludewig PM. The effect of long versus short pectoralis minor resting length on scapular kinematics in healthy individuals. J Orthop Sports Phys Ther. 2005;35(4):227-38.

79. Grygorowicz M, Kubacki J, Pilis W, Gieremek K, Rzepka R. Selected isokinetic tests in knee injury prevention. Biol Sport. 2010;27(1):47-51.

80. Ruas C V, Minozzo F, Pinto MD, Brown LE, Pinto RS. Lower - Extremity strength ratios of professional soccer players according to field position. J Strength Cond Res. 2015;29(5,7):1220-6.

81. Croisier JL, Ganteaume S, Binet J, Genty M, Ferret JM. Strength imbalances and prevention of hamstring injury in professional soccer players: A prospective study. Am J Sports Med. 2008;36(8):1469-75.

82. Thorborg K, Couppé C, Petersen J, Magnusson SP, Hölmich P. Eccentric hip adduction and abduction strength in elite soccer players and matched controls: a cross-sectional study. Br J Sports Med. 2011;45(1):10-3.

83. Mosler AB, Crossley KM, Thorborg K, Whiteley RJ, Weir A, Serner A, et al. Hip strength and range of motion: Normal values from a professional football league. J Sci Med Sport. 2017;20(4):339-43.

84. Stark T, Walker B, Phillips JK, Fejer R, Beck R. Hand-held dynamometry correlation with the gold standard isokinetic dynamometry: A systematic review. PM R. 2011;3(5):472-9.

85. Jaric S. Muscle Strength Testing: Use of Normalisation for Body Size. Sport Med. 2002;32(10):615-31.

86. Light $\mathrm{N}$. The effect of acute match play loading on hip adductor strength and flexibility in soccer players. J Sports Med Phys Fitness. 2019;59(2):325-9.

87. Light N, Thorborg K. The precision and torque production of common hip adductor squeeze tests used in elite football. J Sci Med Sport. 2016;19(11):888-92.

88. Thorborg K, Branci S, Nielsen MP, Langelund MT, Hölmich P. Copenhagen five-second squeeze: A valid indicator of sports-related hip and groin function. Br J Sports Med. 2017;51(7):594-9.

89. Nevin F, Delahunt E. Adductor squeeze test values and hip joint range of motion in Gaelic football athletes with longstanding groin pain. J Sci Med Sport. 2014;17(2):155-9.

90. Delahunt E, McEntee BL, Kennelly C, Green BS, Coughlan GF. Intrarater reliability of the Adductor Squeeze Test in Gaelic games athletes. J Athl Train. 2011;46(3):241-5.

91. McGill S. Core training: Evidence translating to better performance and injury prevention. Strength Cond J. 2010;32(3):33-46.

92. Vera-García FJ, Barbado D, Moreno Pérez V, Hernández-Sánchez S, Juan Recio C, Elvira JLL. Core Stability. Concepto y aportaciones al entrenamiento y la prevención de lesiones. Rev Andaluza Med del Deport. 2015;8(2):79-85.

93. Zazulak BT, Hewett TE, Reeves NP, Goldberg B, Cholewicki J. Deficits in Neuromuscular Control of the Trunk Predict Knee Injury Risk. A Prospective Biomechanical-Epidemiologic Study. Am J Sports Med. 2007;35(7):1123-30.

94. Molina-García P, Morcillo Losa JA, Cervera F. Estrategias de prevención de lesiones deportivas en jóvenes futbolistas profesionales: Estabilidad del core y propiocepción. Rev Andaluza Med del Deport. 2018;11(4):210-4.

95. McGill SM, Childs A, Liebenson C. Endurance times for low back stabilization exercises: Clinical targets for testing and training from a normal database. Arch Phys Med Rehabil. 1999;80(8):941-4.

96. Latimer J, Maher CG, Refshauge K, Colaco I. The reliability and validity of the BieringSorensen test in asymptomatic subjects and subjects reporting current or previous 
nonspecific low back pain. Spine (Phila Pa 1976). 1999;24(20):2085-90.

97. Tate AR, McClure P, Kareha S, Irwin D, Barbe MF. A clinical method for identifying scapular dyskinesis, part 2: Validity. J Athl Train. 2009;44(2):165-73.

98. McClure P, Tate AR, Kareha S, Irwin D, Zlupki E. A clinical method for identifying scapular dyskinesis, part 1: Reliability. J Athl Train. 2009;44(2):160-4.

99. Hertel J, Miller SJ, Denegar CR. Intratester and Intertester Reliability during the Star Excursion Balance Tests. J Sport Rehabil. 2000;9(2):104-16.

100. Hertel J, Braham RA, Hale SA, Olmsted-Kramer LC. Simplifying the Star Excursion Balance Test: Analyses of Subjects With and Without Chronic Ankle Instability. J Orthop Sports Phys Ther. 2006;36(3):131-7.

101. Gribble PA, Hertel J, Plisky P. Using the star excursion balance test to assess dynamic postural-control deficits and outcomes in lower extremity injury: A literature and systematic review. J Athl Train. 2012;47(3):339-57.

102. Plisky PJ, Gorman PP, Butler RJ, Kiesel KB, Underwood FB, Elkins B. The reliability of an instrumented device for measuring components of the star excursion balance test. North Am J Sport Phys Ther. 2009;4(2):92-9.

103. Chimera NJ, Warren M. Use of clinical movement screening tests to predict injury in sport. World J Orthop. 2016;7(4):202-17.

104. Coughlan GF, Fullam K, Delahunt E, Gissane C, Caulfield BM. A comparison between performance on selected directions of the star excursion balance test and the $\mathrm{Y}$ balance test. J Athl Train. 2012;47(4):366-71.

105. Fullam K, Caulfield B, Coughlan GF, Delahunt E. Kinematic Analysis of Selected Reach Directions of the Star Excursion Balance Test Compared with the Y-Balance Test. J Sport Rehabil. 2014;23(1):27-35.

106. Ko J, Rosen AB, Brown CN. Functional performance tests identify lateral ankle sprain risk: A prospective pilot study in adolescent soccer players. Scand J Med Sci Sport. 2018;28(12):2611-6.

107. Plisky PJ, Rauh MJ, Kaminski TW, Underwood FB. Star Excursion Balance Test as a predictor of lower extremity injury in high school basketball players. J Orthop Sports Phys Ther. 2006;36(12):911-9.

108. Gribble PA, Hertel J. Considerations for Normalizing measures of the Star Excursion Balance Test. Meas Phys Educ Exerc Sci. 2003;7(2):89-100.

109. Kennedy MD, Burrows L, Parent E. Intrarater and Interrater Reliability of the Single-Leg Squat Test. Athl Ther Today. 2010;15(6):32-6.

110. Mccall A, Carling C, Nedelec M, Davison M, Le Gall F, Berthoin S, et al. Risk factors, testing and preventative strategies for non-contact injuries in professional football: current perceptions and practices of 44 teams from various premier leagues. Br J Sports Med. 2014;48(18):1352-7.

111. Moran RW, Schneiders AG, Major KM, John Sullivan S. How reliable are Functional Movement Screening scores? A systematic review of rater reliability. Br J Sports Med. 2016;50(9):527-36.

112. Cuchna JW, Hoch MC, Hoch JM. The interrater and intrarater reliability of the functional movement screen: A systematic review with meta-analysis. Phys Ther Sport. 2016;19(1):57-65.

113. Bonazza NA, Smuin D, Onks CA, Silvis ML, Dhawan A. Reliability, Validity, and Injury Predictive Value of the Functional Movement Screen. A systematic review and metaanalysis. Am J Sports Med. 2017;45(3):725-32.

114. Raïsänen A, Pasanen K, Krosshaug T, Avela J, Perttunen J, Parkkari J. Single-Leg Squat as a Tool to Evaluate Young Athletes' Frontal Plane Knee Control. Clin J Sport Med. 2016;26(6):478-82.

115. Ressman J, Grooten WJA, Rasmussen Barr E. Visual assessment of movement quality in 
the single leg squat test: A review and meta-analysis of inter-rater and intrarater reliability. BMJ Open Sport Exerc Med. 2019;5(1):1-10.

116. Ugalde V, Brockman C, Bailowitz Z, Pollard CD. Single Leg Squat Test and Its Relationship to Dynamic KneeValgus and Injury Risk Screening. PM R. 2015;7(3):229_ 35 .

117. Mizner RL, Chmielewski TL, Toepke JJ, Tofte KB. Comparison of 2-Dimensional Measurement Techniques for Predicting Knee Angle and Moment During a Drop Vertical Jump. Clin J Sport Med. 2012;22(3):221-7.

118. Dingenen B, Malfait B, Vanrenterghem J, Verschueren SMP, Staes FF. The reliability and validity of the measurement of lateral trunk motion in two-dimensional video analysis during unipodal functional screening tests in elite female athletes. Phys Ther Sport. 2014; 15(2):117-23.

119. DiMattia MA, Livengood AL, Uhl TL, Mattacola CG, Malone TR. What Are the Validity of the Single-Leg-Squat Test and Its Relationship to Hip-Abduction Strength? J Sport Rehabil. 2005;14(2):108-23.

120. Hewett TE, Myer GD, Ford KR, Heidt RS, Colosimo AJ, McLean SG, et al. Biomechanical measures of neuromuscular control and valgus loading of the knee predict anterior cruciate ligament injury risk in female athletes: A prospective study. Am J Sports Med. 2005;33(4):492-501.

121. Padua DA, Marshall SW, Boling MC, Thigpen CA, Garrett Jr WE, Beutler AI. The Landing Error Scoring System (LESS) is a Valid and Reliable Clinical Assessment Tool of Jump-Landing Biomechanics. The JUMP-ACL Study. Am J Sports Med. 2009;37(10):1996-2002.

122. Zazulak BT, Hewett TE, Reeves NP, Goldberg B, Cholewicki J. Deficits in neuromuscular control of the trunk predict knee injury risk: A prospective biomechanicalepidemiologic study. Am J Sports Med. 2007;35(7):1123-30.

123. Fitzgerald GK, Lephart SM, Hwang JH, Wainner MRS. Hop Tests as Predictors of Dynamic Knee Stability. J Orthop Sports Phys Ther. 2001;31(10):588-97.

124. Ross MD, Langford B, J WP. Test-retest reliability of 4 single-leg horizontal hop tests. J Strength Cond Res. 2002;16(4):617-22.

125. Reid A, Birmingham TB, Stratford PW, Alcock GK, Giffin JR. Hop testing provides a reliable and valid outcome measure during rehabilitation after anterior cruciate ligament reconstruction. Phys Ther. 2007;87(3):337-49.

126. Barfod KW, Feller JA, Hartwig T, Devitt BM, Webster KE. Knee extensor strength and hop test performance following anterior cruciate ligament reconstruction. Knee. 2019;26(1):149-54.

127. Padua DA, DiStefano LJ, Beutler AI, De La Motte SJ, DiStefano MJ, Marshall SW. The landing error scoring system as a screening tool for an anterior cruciate ligament injuryprevention program in elite-youth soccer athletes. J Athl Train. 2015;50(6):589-95.

128. Padua DA, Boling MC, Distefano LJ, Onate JA, Beutler AI, Marshall SW. Reliability of the Landing Error Scoring System-Real Time, a Clinical Assessment Tool of JumpLanding Biomechanics. J Sport Rehabil. 2011;20(2):145-56.

129. Herrington L, Myer GD, Munro A. Intra and inter-tester reliability of the tuck jump assessment. Phys Ther Sport. 2013;14(3):152-5.

130. Read PJ, Oliver JL, De Ste Croix MBA, Myer GD, Lloyd RS. Reliability of the tuck jump injury risk screening assessment in elite male youth soccer players. J Strength Cond Res. 2016;30(6):1510-6.

131. Hewett TE, Stroupe AL, Nance TA, Noyes FR. Plyometric Training in female athletes decreased impact forces and increased hamstring torques. Am J Sports Med. 1996;24(6):765-73.

132. Myer GD, Ford KR, Hewett TE. Tuck Jump Assessment for Reducing Anterior Cruciate 
Ligament Injury Risk. Athl Ther Today. 2008;13(5):39-44.

133. Kovacs FM, Llobera J, Gil del Real MT, Abraira V, Gestoso M, Fernández C, et al. Validation of the Spanish version of the Roland-Morris Questionnaire. Spine (Phila Pa 1976). 2002;27(5):538-42.

134. Roland M, Fairbank J. The Roland - Morris Disability Questionnaire and the Oswestry Disability Questionnaire. Spine (Phila Pa 1976). 2000;25(24):3115-24.

135. Sahrmann SA. Diagnóstico y Tratamiento de las Alteraciones del Movimiento. Paidotribo. 2006.

136. Wittink H, Turk DC, Carr DB, Sukiennik A, Rogers W. Comparison of the redundancy, reliability, and responsiveness to change among SF-36, Oswestry Disability Index, and Multidimensional Pain Inventory. Clin J Pain. 2004;20(3):133-42.

137. Martens R. Sport Competition Anxiety Test. Ger J Exerc Sport Res. 1979;9(1):101-3.

138. Petrie TA. Psychosocial antecedents of athletic injury: The effects of life stress and social support on female collegiate gymnasts. Behav Med. 1992;18(3):127-38.

139. Gustavsson JP, Bergman H, Edman G, Ekselius L, von Knorring L, Linder J. Swedish universities Scales of Personality (SSP): Construction, internal consistency and normative data. Acta Psychiatr Scand. 2000;102(3):217-25.

140. Smith RE, Schutz RW, Smoll FL, Ptacek JT. Development and Validation of a Multidimensional Measure of Sport-Specific Psychological Skills: The Athletic Coping Skills Inventory-28. J Sport Exerc Psychol. 1995;17(4):379-98.

141. Carver CS. You Want to Measure Coping But Your Protocol's Too Long: Consider the Brief COPE. Int J Behav Med. 1997;4(1):92-100.

142. López López IS, Jaenes Sánchez JC, Cárdenas Vélez D. Adaptación para futbolistas (CPRD-F) del cuestionario "Características Psicológicas relacionadas con el Rendimiento Deportivo" (CPRD). Cuad Psicol del Deport. 2013;13(2):21-30.

143. Gimeno F, Buceta JM, Pérez-Llanta M del C. El Cuestionario "Características Psicológicas relacionadas con el Rendimiento Deportivo" (CPRD): Características psicométricas. Análise Psicológica. 2001;19(1):93-113.

144. López López IS, Jaenes Sánchez JC, Cárdenas Vélez D. Adaptación para futbolistas (CPRD-F) del cuestionario "características psicológicas relacionadas con el rendimiento deportivo" (CPRD). Cuad Psicol del Deport. 2013;13(2):21-30.

145. Backman LJ, Danielson P. Low range of ankle dorsiflexion predisposes for patellar tendinopathy in junior elite basketball players: A 1-year prospective study. Am J Sports Med. 2011;39(12):2626-33.

146. Brooks JHM, Fuller CW, Kemp SPT, Reddin DB. Epidemiology of injuries in English professional rugby union: Part 1 match injuries. Br J Sports Med. 2005;757-66.

147. Conde J. Apuntes del Máster Propio en Entrenamiento Personal ( $6{ }^{\mathrm{a}}$ Edición): Entrenamiento de la Región Coxolumbopélvica. De lo estructuralista a lo dinámico. 2017.

148. Waldén M, Hägglund M, Ekstrand J. The epidemiology of groin injury in senior football: a systematic review of prospective studies. Br J Sports Med. 2015;49(12):792-7.

149. Junge A, Dvorak J. Soccer Injuries: A Review on Incidence and Prevention. Sport Med. 2004;34(13):929-38.

150. Hammami MA, Abderrahmane A Ben, Nebigh A, Le Moal E, Ben Ounis O, Tabka Z, et al. Effects of a soccer season on anthropometric characteristics and physical fitness in elite young soccer players. J Sports Sci. 2013;31(6):589-96.

151. Wong P, Hong Y. Soccer injury in the lower extremities. Br J Sports Med. 2005;39:47382 .

152. Owen AL, Forsyth JJ, Wong DP, Dellal A, Connelly SP, Chamari K. Heart rate-based training intensity and its impact on injury incidence among elite-level professional soccer players. J Strength Cond Res. 2015;29(6):1705-12.

153. Perroni F, Vetrano M, Camolese G, Guidetti L, Baldari C. Anthropometric and 
somatotype characteristics of young soccer players: Differences among categories, subcategories, and playing position. J Strength Cond Res. 2015;29(8,4):2097-104.

154. Hammami A, Chamari K, Slimani M, Shephard RJ, Yousfi N, Tabka Z, et al. Effects of Recreational soccer on physical fitness and health indices in sedentary healthy and unhealthy subjects. Biol Sport. 2016;33(2):127-37.

155. Andersen TE, Tenga A, Engebretsen L, Bahr R. Video analysis of injuries and incidents in Norwegian professional football. Br J Sports Med. 2004;38(5):626-31.

156. Klein C, Henke T, Platen P. Injuries in football ( soccer ) - a systematic review of epidemiology and aetiological aspects. Ger J Exerc Sport Res. 2018;48:309-22.

157. Carling C, Orhant E, LeGall F. Match injuries in professional soccer: Inter-seasonal variation and effects of competition type, match congestion and positional role. Int $\mathrm{J}$ Sports Med. 2010;31(4):271-6.

158. Koulouris G, Connell DA, Brukner P, Schneider-Kolsky M. Magnetic resonance imaging parameters for assessing risk of recurrent hamstring injuries in elite athletes. Am J Sports Med. 2007;35(9):1500-6.

159. Dauty M, Collon S. Incidence of Injuries in French Professional Soccer Players. Int J Sports Med. 2011;32(12):965-9.

160. Ekstrand J, Hägglund M, Waldén M. Epidemiology of Muscle Injuries in Professional Football ( Soccer ). Am J Sports Med. 2011;39(6):1226-32.

161. Arnason A, Andersen TE, Holme I, Engebretsen L, Bahr R. Prevention of hamstring strains in elite soccer: an intervention study. Scand J Med Sci Sport. 2008;18(1):40-8.

162. Eirale C, Tol JL, Farooq A, Smiley F, Chalabi H. Low injury rate strongly correlates with team success in Qatari professional football. Br J Sports Med. 2013;47(12):807-8.

163. Fong DT, Hong Y, Chan L, Yung PS, Chan K. A Systematic Review on Ankle Injury and Ankle Sprain in Sports. Sport Med. 2007;37(1):73-94.

164. Ekstrand J. Keeping your top players on the pitch: the key to football medicine at a professional level. Br J Sports Med. 2013;47(12):3-4.

165. Mueller-Wohlfahrt H-W, Haensel L, Mithoefer K, Ekstrand J, English B, Mcnally S, et al. Terminology and classification of muscle injuries in sport: The Munich consensus statement. Br J Sports Med. 2013;47(6):342-50.

166. Błażkiewicz A, Grygorowicz M, Bialostocki A, Czaprowski D. Characteristics of goalkeeping injuries: a retrospective, self-reported study in adolescent soccer players. J Sports Med Phys Fitness. 2018;58(12):1823-30.

167. van Mechelen W, Hlobil H, Kemper HC. Incidence, Severity, Aetiology and Prevention of Sports Injuries. Sport Med. 1992;14(2):82-99.

168. Eirale C, Hamilton B, Bisciotti G, Grantham J, Chalabi H. Injury epidemiology in a national football team of the Middle East. Scand J Med Sci Sport. 2012;22(3):323-9.

169. Bahr R, Clarsen B, Ekstrand J. Why we should focus on the burden of injuries and illnesses, not just their incidence. Br J Sports Med. 2018;52(16):1018-21.

170. Bahr R, Krosshaug T. Understanding injury mechanisms: A key component of preventing injuries in sport. Br J Sports Med. 2005;39(6):324-9.

171. Finch C. A new framework for research leading to sports injury prevention. J Sci Med Sport. 2006;9(1-2):3-9.

172. Jacobsson J, Timpka T. Classification of Prevention in Sports Medicine and Epidemiology. Sport Med. 2015;45(11):1483-7.

173. Dvorak J, Junge A. Football injuries and physical symptoms. A review of the literature. Am J Sports Med. 2000;28(5):S3-9.

174. Fuller CW, Ekstrand J, Junge A, Andersen TE, Bahr R, Dvorak J, et al. Consensus statement on injury definitions and data collection procedures in studies of football (soccer) injuries. Br J Sports Med. 2006;40(3):193-201.

175. Lundblad M, Waldén M, Magnusson H, Karlsson J, Ekstrand J. The UEFA injury study : 
11-year data concerning $346 \mathrm{MCL}$ injuries and time to return to play. Br J Sports Med. 2013;47:759-62.

176. Waldén M, Hägglund M, Ekstrand J. UEFA Champions League study: A prospective study of injuries in professional football during the 2001-2002 season. Br J Sports Med. 2005;39(8):542-6.

177. Ekstrand J, Waldén M, Hägglund M. Hamstring injuries have increased by $4 \%$ annually in men's professional football, since 2001: A 13-year longitudinal analysis of the UEFA Elite Club injury study. Br J Sports Med. 2016;50(12):731-7.

178. Armfield DR, Kim DH-M, Towers JD, Bradley JP, Robertson DD. Sports-Related Muscle Injury in the Lower Extremity. Clin Sports Med. 2006;25(4):803-42.

179. Hägglund M, Waldén M, Bahr R, Ekstrand J. Methods for epidemiological study of injuries to professional football players: Developing the UEFA model. Br J Sports Med. 2005;39(6):340-6.

180. Weir A, Brukner P, Delahunt E, Ekstrand J, Grif D, Khan KM, et al. Doha agreement meeting on terminology and definitions in groin pain in athletes. Br J Sports Med. 2015;49(12):768-74.

181. Mosler AB, Weir A, Eirale C, Farooq A, Thorborg K, Whiteley RJ, et al. Epidemiology of time loss groin injuries in a men' $\mathrm{s}$ professional football league : a 2-year prospective study of 17 clubs and 606 players. Br J Sports Med. 2018;52(5):292-7.

182. Noya Salces J, Gómez-Carmona PM, Gracia-Marco L, Moliner-Urdiales D, SilleroQuintana M. Epidemiology of injuries in First Division Spanish football. J Sports Sci. 2014;32(13):1263-70.

183. Hägglund M, Waldén M, Ekstrand J. Injury incidence and distribution in elite football - A prospective study of the Danish and the Swedish top divisions. Scand J Med Sci Sport. 2005;15(1):21-8.

184. Waldén M, Hägglund M, Ekstrand J. Injuries in Swedish elite football - A prospective study on injury definitions, risk for injury and injury pattern during 2001. Scand J Med Sci Sport. 2005;15(2):118-25.

185. Ekstrand J, Waldén M, Hägglund M. Risk for injury when playing in a national football team. Scand J Med Sci Sport. 2004;14(1):34-8.

186. Hawkins RD, Fuller CW. A prospective epidemiological study of injuries in four English professional football clubs. Br J Sports Med. 1999;33(3):196-203.

187. Le Gall F, Carling C, Reilly T, Vandewalle H, Church J, Rochcongar P. Incidence of Injuries in Elite French Youth Soccer Players: A 10 seasons study. Am J Sports Med. 2006;34(6):928-38.

188. Hölmich P, Thorborg K, Dehlendorff C, Krogsgaard K, Gluud C. Incidence and clinical presentation of groin injuries in sub-elite male soccer. Br J Sports Med. 2014;48(16):1245-50.

189. Inklaar H, Bol E, Schmikli SL, Mosterd WL. Injuries in male soccer players: Team risk analysis. Int J Sports Med. 1996;17(3):229-34.

190. Inklaar H. Soccer Injuries I: Incidence and Severity. Sport Med Eval Res Exerc Sci Sport Med. 1994;18(1):55-73.

191. Engebretsen AH, Myklebust G, Holme I, Engebretsen L, Bahr R. Prevention of Injuries Among Male Soccer Players: A Prospective, Randomized Intervention Study Targeting Players With Previous Injuries or Reduced Function. Am J Sports Med. 2008;36(6):105260.

192. Drawer S, Fuller C. Evaluating the level of injury in English professional football using a risk based assessment process. Br J Sports Med. 2002;36(6):446-52.

193. Bjørneboe J, Bahr R, Andersen TE. Gradual increase in the risk of match injury in Norwegian male professional football : A 6-year prospective study. Scand J Med Sci Sport. 2014;24(1):189-96. 
194. Ekstrand J, Healy JC, Waldén M, Lee JC, English B, Hägglund M. Hamstring muscle injuries in professional football: The correlation of MRI findings with return to play. Br $\mathrm{J}$ Sports Med. 2012;46(2):112-7.

195. Ueblacker P, Müller-Wohlfahrt H-W, Ekstrand J. Epidemiological and clinical outcome comparison of indirect ('strain') versus direct ('contusion') anterior and posterior thigh muscle injuries in male elite football players: UEFA Elite League study of 2287 thigh injuries (2001 - 2013). Br J Sports Med. 2015;49(22):1461-5.

196. Marom N, Williams RJ. Upper Extremity Injuries in Soccer. Am J Orthop. 2018;47(10,1).

197. Rahnama N, Reilly T, Lees A. Injury risk associated with playing actions during competitive soccer. Br J Sports Med. 2002;36(5):354-9.

198. Keller CS, Noyes FR, Buncher CR. The medical aspects of soccer injury epidemiology. Am J Sports Med. 1987;15(3):230-7.

199. Hawkins RD, Hulse MA, Wilkinson C, Hodson A, Gibson M. The association football medical research programme: an audit of injuries in professional football. Br J Sports Med. 2001;35(1):43-7.

200. Azubuike SO, Okojie OH. An epidemiological study of football (soccer) injuries in Benin City, Nigeria. Br J Sports Med. 2009;43(5):382-6.

201. Junge A, Dvorak J. Influence of definition and data collection on the incidence of injuries in football. Am J Sports Med. 2000;28(5):S40-6.

202. Woods C, Hawkins RD, Maltby S, Hulse M, Thomas A, Hodson A. The Football Association Medical Research Programme : an audit of injuries in professional football analysis of hamstring injuries. Br J Sports Med. 2004;38(1):36-41.

203. Mitchell J, Graham W, Best TM, Collins C, Currie DW, Comstock RD, et al. Epidemiology of meniscal injuries in US high school athletes between 2007 and 2013. Knee Surgery, Sport Traumatol Arthrosc. 2016;24(3):715-22.

204. Poulsen MR, Johnson DL. Meniscal injuries in the young, athletically active patient. Phys Sportsmed. 2011;39(1):123-30.

205. Poehling GG, Ruch DS, Chabon SJ. The landscape of meniscal injuries. Clin Sports Med. 1990;9(3):539-49.

206. Werner J, Hägglund M, Walde M, Ekstrand J. UEFA injury study: a prospective study of hip and groin injuries in professional football over seven consecutive seasons. Br J Sports Med. 2009;43(13):1036-40.

207. Ekstrand J, Hilding J. The incidence and differential diagnosis of acute groin injuries in male soccer players. Scand J Med Sci Sport. 1999;9(2):98-103.

208. Ekstrand J, Hägglund M, Törnqvist H, Kristenson K, Bengtsson H, Magnusson H, et al. Upper extremity injuries in male elite football players. Knee Surgery, Sport Traumatol Arthrosc. 2013;21(7):1626-32.

209. Nielsen AB, Yde J. Epidemiology and traumatology of injuries in soccer. Am J Sports Med. 1989;17(6):803-7.

210. Bahr R. No injuries, but plenty of pain? On the methodology for recording overuse symptoms in sports. Br J Sports Med. 2009;43(13):966-72.

211. Andersen TE, Engebretsen L, Bahr R. Rule Violations as a Cause of Injuries in Male Norwegian Professional Football. Are the referees doing their job? Am J Sports Med. 2004;32(SUPPL 1):62S-68S.

212. Stubbe JH, Van Beijsterveldt AMMC, Van Der Knaap S, Stege J, Verhagen EA, Van Mechelen W, et al. Injuries in professional male soccer players in the Netherlands: A prospective cohort study. J Athl Train. 2015;50(2):211-6.

213. Konopinski M, Graham I, Johnson MI, Jones G. The effect of hypermobility on the incidence of injury in professional football: A multi-site cohort study. Phys Ther Sport. 2016;21:7-13.

214. Brink MS, Visscher C, Arends S, Zwerver J, Post WJ, Lemmink KAPM. Monitoring 
stress and recovery: New insights for the prevention of injuries and illnesses in elite youth soccer players. Br J Sports Med. 2010;44(11):809-15.

215. Morgan BE, Oberlander MA. An Examination of Injuries in Major League Soccer: The inaugural season. Am J Sports Med. 2001;29(4):426-30.

216. Ekstrand J, Waldén M, Hägglund M. A congested football calendar and the wellbeing of players: Correlation between match exposure of European footballers before the World Cup 2002 and their injuries and performers during that World Cup. Br J Sports Med. 2004;38(4):493-7.

217. Hägglund M, Waldén M, Ekstrand J. UEFA injury study - An injury audit of European Championships 2006 to 2008. Br J Sports Med. 2009;43(7):483-9.

218. Cloke D, Moore O, Shab T, Rushton S, Shirley MDF, Deehan DJ. Thigh muscle injuries in youth soccer: Predictors of recovery. Am J Sports Med. 2012;40(2):433-9.

219. Fuller CW, Walker J. Quantifying the functional rehabilitation of injured football players. Br J Sports Med. 2006;40(2):151-7.

220. Aoki H, O'Hata N, Kohno T, Morikawa T, Seki J. A 15-year prospective epidemiological account of acute traumatic injuries during official professional soccer league matches in Japan. Am J Sports Med. 2012;40(5):1006-14.

221. Gonçalves AG, Schmidt LPH, Costa AD, Pedrinelli A, Pagura JR, Cohen M. Orthopaedics injuries in male professional football players in Brazil: a prospective comparison between two divisions. Muscle, Ligaments Tendons J. 2018;7(3):524-31.

222. Waldén M, Krosshaug T, Bjørneboe J, Andersen TE, Faul O, Hägglund M. Three distinct mechanisms predominate in noncontact anterior cruciate ligament injuries in male professional football players: A systematic video analysis of 39 cases. Br J Sports Med. 2015;49(22):1452-60.

223. Brophy RH, Stepan JG, Silvers HJ, Mandelbaum BR. Defending Puts the Anterior Cruciate Ligament at Risk During Soccer: A Gender-Based Analysis. Sports Health. 2015;7(3):244-9.

224. Andersen TE, Larsen Ø, Tenga A, Engebretsen L, Bahr R. Football incident analysis: a new video based method to describe injury mechanisms in professional football. Br J Sports Med. 2003;37(3):226-32.

225. Lindenfeld TN, Schmitt DJ, Hendy MP, Mangine RE, Noyes FR. Incidence of Injury in Indoor Soccer. Am J Sports Med. 1994;22(3):364-71.

226. Serner A, Mosler AB, Tol JL, Bahr R, Weir A. Mechanisms of acute adductor longus injuries in male football players: a systematic visual video analysis. Br J Sports Med. 2019;53(3):158-64.

227. Andersen TE, Floerenes TW, Arnason A, Bahr R. Video Analysis of the Mechanisms for Ankle Injuries in Football. Am J Sports Med. 2004;32(SUPPL. 1):69S-79S.

228. Krosshaug T, Andersen TE, Olsen OEO, Myklebust G, Bahr R. Research approaches to describe the mechanisms of injuries in sport: Limitations and possibilities. Br J Sports Med. 2005;39(6):330-9.

229. McIntosh AS. Risk compensation, motivation, injuries, and biomechanics in competitive sport. Br J Sports Med. 2005;39(1):2-3.

230. Chomiak J, Junge A, Peterson L, Dvorak J. Severe injuries in football players. Influencing factors. Am J Sports Med. 2000;28(5):S58-68.

231. Giza E, Fuller C, Junge A, Dvorak J. Mechanisms of Foot and Ankle Injuries in Soccer. Am J Sports Med. 2003;31(4):550-4.

232. Thacker SB, Stroup DF, Branche CM, Gilchrist J, Goodman RA, Weitman EA. The Prevention of Ankle Sprains in Sports: A Systematic Review of the Literature. Am J Sports Med. 1999;27(6):753-60.

233. Yeung MS, Chan KM, So CH, Yuan WY. An epidemiological survey on ankle sprain. Br J Sports Med. 1994;28(2):112-6. 
234. Yu B, Garrett WE. Mechanisms of non-contact ACL injuries. Br J Sports Med. 2007;41(SUPPL. 1):i47-51.

235. Waldén M, Hägglund M, Orchard J, Kristenson K, Ekstrand J. Regional differences in injury incidence in European professional football. Scand J Med Sci Sport. 2013;23(4):424-30.

236. Markolf KL, Burchfield DM, Shapiro MM, Shepard MF, Finerman GAM, Slauterbeck JL. Combined knee loading states that generate high anterior cruciate ligament forces. $\mathrm{J}$ Orthop Res. 2005;13(6):930-5.

237. Dürselen L, Claes L, Kiefer H. The Influence of Muscle Forces and External Loads on Cruciate Ligament Strain. Am J Sports Med. 1995;23(1):129-36.

238. Yu B, Lin CF, Garrett WE. Lower extremity biomechanics during the landing of a stopjump task. Clin Biomech. 2006;21(3):297-305.

239. Beynnon BD, Fleming BC, Johnson RJ, Nichols CE, Renström PA, Pope MH. Anterior Cruciate Ligament Strain Behavior During Rehabilitation Exercises In Vivo. Am J Sports Med. 1995;23(1):24-34.

240. Li G, Rudy TW, Sakane M, Kanamori A, Ma CB, Woo S.-Y. The importance of quadriceps and hamstring muscle loading on knee kinematics and in-situ forces in the ACL. J Biomech. 1999;32(4):395-400.

241. Pandy MG, Shelburne KB. Dependence of cruciate-ligament loading on muscle forces and external load. J Biomech. 1997;30(10):1015-24.

242. Fleming BC, Renstrom PA, Beynnon BD, Engstrom B, Peura GD, Badger GJ, et al. The effect of weightbearing and external loading on anterior cruciate ligament strain. $\mathrm{J}$ Biomech. 2001;34(2):163-70.

243. Bendjaballah MZ, Shirazi-Adl A, Zukor DJ. Finite element analysis of human knee joint in varus-valgus. Clin Biomech. 1997;12(3):139-48.

244. Matsumoto H, Suda Y, Otani T, Niki Y, Seedhom BB, Fujikawa K. Roles of the anterior cruciate ligament and the medial collateral ligament in preventing valgus instability. $\mathrm{J}$ Orthop Sci. 2001;6(1):28-32.

245. Cross TM, Gibbs N, Houang MT, Cameron M. Acute Quadriceps Muscle Strains: Magnetic resonance imaging features and prognosis. Am J Sports Med. 2004;32(3):710-9.

246. Johnson MA, Polgar J, Weightman D, Appleton D. Data on the distribution of fibre types in thirty-six human muscles. An autopsy study. J Neurol Sci. 1973;18(1):111-29.

247. Glick JM. Muscle strains: Prevention and treatment. Phys Sportsmed. 1980;8(11):73-7.

248. Stanton P, Purdam C. Hamstring lnjuries in Sprinting-The Role of Eccentric Exercise. J Orthop Sports Phys Ther. 1989;10(9):343-9.

249. Speer KP, Lohnes J, Garrett WE. Radiographic imaging of muscle strain injury. Am J Sports Med. 1993;21(1):89-96.

250. Mendiguchia J, Alentorn-Geli E, Idoate F, Myer GD. Rectus femoris muscle injuries in football: A clinically relevant review of mechanisms of injury, risk factors and preventive strategies. Br J Sports Med. 2013;47(6):359-66.

251. Hasselman CT, Best TM, Hughes C, Martinez S, Garrett WE. An Explanation for Various Rectus Femoris Strain Injuries Using Previously Undescribed Muscle Architecture. Am J Sports Med. 1995;23(4):493-9.

252. Schache AG, Dorn TW, Blanch PD, Brown NAT, Pandy MG. Mechanics of the human hamstring muscles during sprinting. Med Sci Sports Exerc. 2012;44(4):647-58.

253. Riley PO, Franz J, Dicharry J, Kerrigan DC. Changes in hip joint muscle-tendon lengths with mode of locomotion. Gait Posture. 2010;31(2):279-83.

254. Hewit J, Cronin J, Button C, Hume P. Understanding Deceleration in Sport. Strength Cond J. 2011;33(1):47-52.

255. Andrews JR, McLeod WD, Ward T, Howard K. The cutting mechanism. Am J Sports Med. 1977;5(3):111-21. 
256. Woods C, Hawkins RD, Hulse M, Hodson A. The Football Association medical research programme: an audit of injuries in professional football - analysis of preseason injuries. $\mathrm{Br}$ J Sports Med. 2002;36(6):436-41.

257. Garrett WE, Safran MR, Seaber A V, Glisson RR, Ribbeck BM. Biomechanical comparison of stimulated and nonstimulated skeletal muscle pulled to failure. Am J Sports Med. 1987;15(5):448-54.

258. Nunome H, Ikegami Y, Kozakai R, Apriantono T, Sano S. Segmental dynamics of soccer instep kicking with the preferred and non-preferred leg. J Sports Sci. 2006;24(5):529-41.

259. Lees A, Nolan L. The biomechanics of soccer: A review. J Sports Sci. 1998;16(3):211-34.

260. Charnock BL, Lewis CL, Garrett WE, Queen RM. Adductor longus mechanics during the maximal effort soccer kick. Sport Biomech. 2009;8(3):223-34.

261. Brophy RH, Backus SI, Pansy BS, Lyman S, Williams RJ. Lower Extremity Muscle Activation and Alignment During the Soccer Instep and Side-foot Kicks. J Orthop Sport Phys Ther. 2007;37(5):260-8.

262. Ahmad CS, Redler LH, Ciccotti MG, Maffulli N, Longo UG, Bradley J. Evaluation and management of hamstring injuries. Am J Sports Med. 2013;41(12):2933-47.

263. Askling CM, Tengvar M, Saartok T, Thorstensson A. Acute First-Time Hamstring Strains during High-Speed Running. Am J Sports Med. 2007;35(2):197-206.

264. Cohen SB, Towers JD, Zoga A, Irrgang JJ, Makda J, Deluca PF, et al. Hamstring Injuries in Professional Football Players: Magnetic Resonance Imaging corelation with Return to Play. Sports Health. 2011;3(5):423-30.

265. Clanton TO, Coupe KJ. Hamstring strains in athletes: diagnosis and treatment. J Am Acad Orthop Surg. 1998;6(4):237-48.

266. Kyröläinen H, Avela J, Komi P V. Changes in muscle activity with increasing running speed. J Sports Sci. 2005;23(10):1101-9.

267. Jönhagen S, Ericson MO, Németh G, Eriksson E. Amplitude and timing of electromyographic activity during sprinting. Scand J Med Sci Sports. 1996;6(1):15-21.

268. Higashihara A, Ono T, Kubota J, Okuwaki T, Fukubayashi T. Functional differences in the activity of the hamstring muscles with increasing running speed. J Sports Sci. 2010;28(10):1085-92.

269. Yu B, Queen RM, Abbey AN, Liu Y, Moorman CT, Garrett WE. Hamstring muscle kinematics and activation during overground sprinting. J Biomech. 2008;41(15):3121-6.

270. Chumanov ES, Heiderscheit BC, Thelen DG. Hamstring musculotendon dynamics during stance and swing phases of high speed running. Med Sci Sports Exerc. 2011;43(3):52532.

271. Chumanov ES, Heiderscheit BC, Thelen DG. The effect of speed and influence of individual muscles on hamstring mechanics during the swing phase of sprinting. $J$ Biomech. 2007;40(16):3555-62.

272. Schache AG, Kim HJ, Morgan DL, Pandy MG. Hamstring muscle forces prior to and immediately following an acute sprinting-related muscle strain injury. Gait Posture. 2010;32(1):136-40.

273. Serner A, Tol JL, Jomaah N, Weir A, Whiteley R, Thorborg K, et al. Diagnosis of Acute Groin Injuries. A prospective study of 110 athletes. Am J Sports Med. 2015;43(8,4):185764.

274. Fridén J, Lieber RL. Structural and mechanical basis of exercise-induced muscle injury. Med Sci Sports Exerc. 1992;24(5):521-9.

275. Fuller C, Drawer S. The Application of Risk Management in sport. Sport Med. 2004;34(6):349-56.

276. Murphy DF, Connolly DAJ, Beynnon BD. Risk factors for lower extremity injury: a review of the literature. Br J Sports Med. 2003;37(1):13-29.

277. Delvaux F, Kaux JF, Croisier JL. Les lésions musculaires des membres inférieurs : 
facteurs de risque et stratégies préventives. Sci Sport. 2017;32(4):179-90.

278. Östenberg A, Roos H. Injury risk factors in female European football. A prospective study of 123 players during one season. Scand J Med Sci Sports. 2000;10(5):279-85.

279. Parkkari J, Kujala UM, Kannus P. Is it Possible to Prevent Sports Injuries? Review of Controlled Clinical Trials and Recommendations for Future Work. Sport Med. 2001;31(14):985-95.

280. Meeuwisse WH, Tyreman H, Hagel B, Emery C. A dynamic model of etiology in sport injury: The recursive nature of risk and causation. Clin J Sport Med. 2007;17(3):215-9.

281. Fuller CW. Managing the risk of injury in sport. Clin J Sport Med. 2007;17(3):182-7.

282. Mccall A, Fanchini M, Coutts AJ. Prediction: The Modern-Day Sport-Science and SportsMedicine "Quest for the Holy Grail ." Int J Sports Physiol Perform. 2017;12(5):704-6.

283. McCall A, Carling C, Davison M, Nedelec M, Le Gall F, Berthoin S, et al. Injury risk factors, screening tests and preventative strategies: A systematic review of the evidence that underpins the perceptions and practices of 44 football (soccer) teams from various premier leagues. Br J Sports Med. 2015;49(9):583-9.

284. Croisier JL. Factors associated with recurrent hamstring injuries. Sport Med. 2004;34(10):681-95.

285. Opar DA, Williams MD, Shield AJ. Hamstring strain injuries: Factors that Lead to injury and re-Injury. Sport Med. 2012;42(3):209-26.

286. Lehance C, Binet J, Bury T, Croisier JL. Muscular strength, functional performances and injury risk in professional and junior elite soccer players. Scand J Med Sci Sport. 2009;19(2):243-51.

287. Junge A. The influence of psychological factors on sports injuries. Review of the literature. Am J Sports Med. 2000;28(5):S10-5.

288. Frisch A, Urhausen A, Seil R, Croisier JL, Windal T, Theisen D. Association between preseason functional tests and injuries in youth football: A prospective follow-up. Scand J Med Sci Sport. 2011;21(6):e468-76.

289. Small K, McNaughton L, Greig M, Lovell R. The effects of multidirectional soccerspecific fatigue on markers of hamstring injury risk. J Sci Med Sport. 2010;13(1):120-5.

290. Reilly T. Energetics of high-intensity exercise (soccer) with particular reference to fatigue. J Sports Sci. 1997;15(3):257-63.

291. Bengtsson H, Ekstrand J, Hägglund M. Muscle injury rates in professional football increase with fixture congestion: An 11-year follow-up of the UEFA Champions League injury study. Br J Sports Med. 2013;47(12):743-7.

292. Fousekis K, Tsepis E, Poulmedis P, Athanasopoulos S, Vagenas G. Intrinsic risk factors of non-contact quadriceps and hamstring strains in soccer: a prospective study of 100 professional players. Br J Sports Med. 2011;45(9):709-14.

293. Konstantinos F, Tsepis E, Vagenas G. Lower limb strength in professional soccer players: Profile, asymmetry, and training age. J Sport Sci Med. 2010;9(3):364-73.

294. Daneshjoo A, Rahnama N, Mokhtar AH, Yusof A. Bilateral and Unilateral Asymmetries of Isokinetic Strength and Flexibility in Male Young Professional Soccer Players. J Hum Kinet. 2013;36(1):45-53.

295. Croisier J, Forthomme B, Namurois M-H, Vanderthommen M, Crielaard J-M. Hamstring Muscle Strain Recurrence and Strength Performance Disorders. Am J Sports Med. 2002;30(2):199-203.

296. Pellicer-Chenoll M, Serra-Añó P, Cabeza-Ruiz R, Pardo A, Aranda R, González LM. Comparación del ratio de fuerza convencional isquiotibial/cuádriceps entre jugadores de fútbol de niveles similares de ambos sexos. Rev Andaluza Med del Deport. 2017;10(1):14-8.

297. O'Toole ML. Prevention and treatment of injuries to runners. Med Sci Sports Exerc. 1992;24(9):S360-3. 
298. Rogalski B, Dawson B, Heasman J, Gabbett TJ. Training and game loads and injury risk in elite Australian footballers. J Sci Med Sport. 2013;16(6):499-503.

299. Cross MJ, Williams S, Trewartha G, Kemp SPT, Stokes KA. The Influence of In-Season Training Loads on Injury Risk in Professional Rugby Union. Int J Sports Physiol Perform. 2016;11(3):350-5.

300. Mccall A, Dupont G, Ekstrand J. Internal workload and non-contact injury: a one- season study of five teams from the UEFA Elite Club Injury Study. Br J Sports Med. 2018;52(23,1):1517-22.

301. Gabbett TJ, Hulin BT, Blanch P, Whiteley R. High training workloads alone do not cause sports injuries: how you get there is the real issue. Br J Sports Med. 2016;50(8):444-5.

302. Soligard T, Schwellnus M, Alonso J-M, Bahr R, Clarsen B, Dijkstra HP, et al. How much is too much? (Part 1) International Olympic Committee consensus statement on load in sport and risk of injury. Br J Sports Med. 2016;50(17):1030-41.

303. Ivarsson A, Johnson U. Psychological factors as predictors of injuries among senior soccer players. A prospective study. J Sport Sci Med. 2010;9(2):347-52.

304. Johnson U, Ekengren J, Andersen MB. Injury Prevention in Sweden: Helping Soccer Players at Risk. J Sport Exerc Psychol. 2005;27(1):32-8.

305. Olmedilla Zafra A, Andreu Álvarez MD, Ortín Montero FJ, Blas Redondo A. Ansiedad competitiva, percepción de éxito y lesiones: Un estudio en futbolistas. Rev Int Med y Ciencias la Act Física y del Deport. 2009;9(33):51-66.

306. Doherty C, Bleakley C, Hertel JAY, Caulfield B, Ryan J, Delahunt E. Dynamic Balance Deficits 6 Months Following First-Time Acute Lateral Ankle Sprain: A Laboratory Analysis. J Orthop Sports Phys Ther. 2015;45(8):626-33.

307. Witchalls J, Blanch P, Waddington G, Adams R. Intrinsic functional deficits associated with increased risk of ankle injuries: A Systematic review with meta-analysis. Br J Sports Med. 2012;46(7):515-23.

308. Barrett JR, Tanji JL, Drake C, Fuller D, Kawasaki RI, Fenton RM. High- versus low-top shoes for the prevention of ankle sprains in basketball players. A prospective randomized study. Am J Sports Med. 1993;21(4):582-5.

309. Baumhauer JF, Alosa DM, Renström PAFH, Trevino S, Beynnon B. A prospective study of ankle injury risk factors. Am J Sports Med. 1995;23(5):564-70.

310. Mchugh MP, Tyler TF, Tetro DT, Mullaney MJ, Nicholas SJ. Risk Factors for Noncontact Ankle Sprains in High School Athletes: The Role of Hip Strength and Balance Ability. Am J Sports Med. 2006;34(3):464-70.

311. Nadler SF, Malanga GA, Feinberg JH, Rubanni M, Moley P, Foye P. Functional performance deficits in athletes with previous lower extremity injury. Clin J Sport Med. 2002;12(2):73-8.

312. Konradsen L, Voigt M. Inversion injury biomechanics in functional ankle instability: A cadaver study of simulated gait. Scand J Med Sci Sport. 2002;12(6):329-36.

313. Hubbard TJ, Kramer LC, Denegar CR, Hertel J. Contributing Factors to Chronic Ankle Instability. Foot Ankle Int. 2007;28(3):343-54.

314. Praz C, Vieira TD, Saithna A, Rosentiel N, Kandhari V, Nogueira H, et al. Risk Factors for Lateral Meniscus Posterior Root Tears in the Anterior Cruciate Ligament-Injured Knee: An Epidemiological Analysis of 3956 Patients From the SANTI Study Group. Am J Sports Med. 2019;47(3):598-605.

315. Orchard JW. Intrinsic and Extrinsic Risk Factors for Muscle Strains in Australian Football. Am J Sports Med. 2001;29(3):300-3.

316. Balagué F, Mannion AF, Pellisé F, Cedraschi C. Non-specific low back pain. Lancet. 2012;379(9814):482-91.

317. Hartvigsen J, Hancock MJ, Kongsted A, Louw Q, Ferreira ML, Genevay S, et al. What low back pain is and why we need to pay attention. Lancet. 2018;391(10137):2356-67. 
318. Miltner O, Wirtz DC, Siebert CH. Strengthening lumbar extensors - therapy of chronic back pain - an overview and meta-analysis. Z Orthop Ihre Grenzgeb. 2001;139(4):28793.

319. Hides JA, Oostenbroek T, Franettovich Smith MM, Mendis MD. The effect of low back pain on trunk muscle size/function and hip strength in elite football (soccer) players. J Sports Sci. 2016;34(24):2303-11.

320. Trompeter K, Fett D, Platen P. Prevalence of Back Pain in Sports: A Systematic Review of the Literature. Sport Med. 2017;47(6):1183-207.

321. Linek P, Noormohammadpour P, Mansournia MA, Wolny T, Sikora D. Morphological changes of the lateral abdominal muscles in adolescent soccer players with low back pain: A prospective cohort study. J Sport Heal Sci. 2018;1-6.

322. Ezechieli M, Siebert CH, Ettinger M, Kieffer O, Weißkopf M, Miltner O. Muscle strength of the lumbar spine in different sports. Technol Heal Care. 2013;21(4):379-86.

323. Wilk KE, Arrigo C. Current concepts in the rehabilitation of the athletic shoulder. J Orthop Sports Phys Ther. 1993;18(1):365-78.

324. Johansen RL, Callis M, Potts J, Shall LM. A modified Internal Rotation Stretching Technique for overhand and throwing athletes. J Orthop Sports Phys Ther. 1995;21(4):216-9.

325. Burkhart SS, Morgan CD, Ben Kibler W. The disabled throwing shoulder: Spectrum of pathology Part I: Pathoanatomy and biomechanics. Arthrosc - J Arthrosc Relat Surg. 2003;19(4):404-20.

326. Maenhout A, van Eessel V, van Dyck L, Vanraes A, Cools A. Quantifying acromiohumeral distance in overhead athletes with glenohumeral internal rotation loss and the influence of a stretching program. Am J Sports Med. 2012;40(9):2105-12.

327. Lintner D, Mayol M, Uzodinma O, Jones R, Labossiere D. Glenohumeral internal rotation deficits in professional pitchers enrolled in an internal rotation stretching program. Am $\mathrm{J}$ Sports Med. 2007;35(4):617-21.

328. Wilk KE, MacRina LC, Fleisig GS, Porterfield R, Simpson CD, Harker P, et al. Correlation of glenohumeral internal rotation deficit and total rotational motion to shoulder injuries in professional baseball pitchers. Am J Sports Med. 2011;39(2):329-35.

329. Shanley E, Rauh MJ, Michener LA, Ellenbecker TS, Garrison JC, Thigpen CA. Shoulder range of motion measures as risk factors for shoulder and elbow injuries in high school softball and baseball players. Am J Sports Med. 2011;39(9):1997-2006.

330. Crockett HC, Gross LB, Wilk KE, Schwartz ML, Reed J, O’Mara J, et al. Osseous adaptation and range of motion at the glenohumeral joint in professional baseball pitchers. Am J Sports Med. 2002;30(1):20-6.

331. Myers JB, Laudner KG, Pasquale MR, Bradley JP, Lephart SM. Glenohumeral range of motion deficits and posterior shoulder tightness in throwers with pathologic internal impingement. Am J Sports Med. 2006;34(3):385-91.

332. Jobe CM. Superior glenoid impingement: Current concepts. Clin Orthop Relat Res. 1996;(330):98-107.

333. Trakis JE, McHugh MP, Caracciolo PA, Busciacco L, Mullaney M, Nicholas SJ. Muscle strength and range of motion in adolescent pitchers with throwing-related pain: Implications for injury prevention. Am J Sports Med. 2008;36(11):2173-8.

334. Clarsen B, Bahr R, Andersson SH, Munk R, Myklebust G. Reduced glenohumeral rotation, external rotation weakness and scapular dyskinesis are risk factors for shoulder injuries among elite male handball players: A prospective cohort study. Br J Sports Med. 2014;48(17):1327-33.

335. Kibler W Ben, McMullen J. Scapular dyskinesis and its relation to shoulder pain. J Am Acad Orthop Surg. 2003;11(2):142-51.

336. Kibler WB, Sciascia AD, Wilkes T. Scapular Dyskinesis and Its Relation to Shoulder 
Injury. J Am Acad Orthop Surg. 2012;20(6):364-72.

337. Pluim BM. Scapular dyskinesis: Practical applications. Br J Sports Med. 2013;47(14):875-6.

338. Kibler W Ben, Sciascia A. Current concepts : scapular dyskinesis. Br J Sports Med. 2010;44(5):300-5.

339. Kennedy DJ, Visco CJ, Press J. Current concepts for shoulder training in the overhead athlete. Curr Sports Med Rep. 2009;8(3):154-60.

340. Cools AMJ, Struyf F, de Mey K, Maenhout A, Castelein B, Cagnie B. Rehabilitation of scapular dyskinesis: from the office worker to the elite overhead athlete. Br J Sports Med. 2014;48(8):692-7.

341. Soto Pérez J, Salazar Lara LV. Clasificación ecográfica de los desgarros musculares. An Radiol México. 2008;2:121-8.

342. Järvinen TAH, Järvinen TLN, Kääriäinen M, Kalimo H, Järvinen M. Muscle injuries: Biology and treatment. Am J Sports Med. 2005;33(5):745-64.

343. Jansen JA, Cormier S, Patel J V. Acute rectus femoris rupture at the distal musculotendinous junction in a football player: A case report and surgical technique. Curr Orthop Pract. 2012;23(4):390-2.

344. García VV, Duhrkop DC, Seijas R, Ares O, Cugat R. Surgical treatment of proximal ruptures of the rectus femoris in professional soccer players. Arch Orthop Trauma Surg. 2012;132(3):329-33.

345. Järvinen TAH, Järvinen TLN, Kääriäinen M, Äärimaa V, Vaittinen S, Kalimo H, et al. Muscle injuries: optimising recovery. Best Pract Res Clin Rheumatol. 2007;21(2):317-31.

346. García López A. Apuntes del Máster Propio en Entrenamiento Personal ( $6{ }^{\mathrm{a}}$ Edición): Entrenamiento de la Musculatura Glútea. 2017.

347. Prieske O, Muehlbauer T, Borde R, Gube M, Bruhn S, Behm DG, et al. Neuromuscular and athletic performance following core strength training in elite youth soccer: Role of instability. Scand J Med Sci Sport. 2016;26(1):48-56.

348. Mauntel TC, Begalle RL, Cram TR, Frank BS, Hirth CJ, Blackburn JT, et al. The effects of lower extremity muscle activation and passive range of motion on single leg squat performance. J Strength Cond Res. 2013;27(7):1813-23.

349. Fransz DP, Huurnink A, Kingma I, de Boode VA, Heyligers IC, van Dieën JH. Performance on a Single-Legged Drop-Jump Landing Test Is Related to Increased Risk of Lateral Ankle Sprains Among Male Elite Soccer Players: A 3-Year Prospective Cohort Study. Am J Sports Med. 2018;46(14,1):3454-62.

350. Petersen J, Thorborg K, Bachmann Nielsen M, Budtz-Jorgensen E, Hölmich P. Preventive Effect of Eccentric Training on Acute Hamstring Injuries in Men' s Soccer: A clusterramdomized controller trial. Am J Sports Med. 2011;39(11):2296-303.

351. van der Horst N, Smits D, Petersen J, Goedhart EA, Backx FJG. The Preventive Effect of the Nordic Hamstring Exercise on Hamstring Injuries in Amateur Soccer Players: A randomized controlled trial. Am J Sports Med. 2015;43(6):1316-23.

352. Bizzini M, Junge A, Dvorak J. Implementation of the FIFA 11+ football warm up program: How to approach and convince the Football associations to invest in prevention. Br J Sports Med. 2013;47(12):803-6.

353. Aman M, Larsén K, Forssblad M, Näsmark A, Waldén M, Hägglund M. A Nationwide Follow-up Survey on the Effectiveness of an Implemented Neuromuscular Training Program to Reduce Acute Knee Injuries in Soccer Players. Orthop J Sport Med. 2018;6(12,1):1-10.

354. Barengo NC, Meneses-Echávez JF, Ramírez-Vélez R, Cohen DD, Tovar G, Correa Bautista JE. The impact of the fifa $11+$ training program on injury prevention in football players: A systematic review. Int J Environ Res Public Health. 2014;11(11):11986-2000.

355. Gomes Neto M, Conceição CS, De Lima Brasileiro AJA, De Sousa CS, Carvalho VO, De 
Jesús FLA. Effects of the FIFA 11 training program on injury prevention and performance in football players: a systematic review and meta-analysis. Clin Rehabil.

2017;31(5,1):651-9.

356. O'Brien J, Donaldson A, Finch CF. It will take more than an existing exercise programme to prevent injury. Br J Sports Med. 2016;50(5):264-5.

357. Söderman K, Werner S, Pietilä T, Engström B, Alfredson H. Balance board training: Prevention of traumatic injuries of the lower extremities in female soccer players? A prospective randomized intervention study. Knee Surgery, Sport Traumatol Arthrosc. 2000;8(6):356-63.

358. Wulf G, Lewthwaite R. Optimizing performance through intrinsic motivation and attention for learning: The OPTIMAL theory of motor learning. Psychon Bull Rev. 2016;23(5):1382-414.

359. LaStayo PC, Woolf JM, Lewek MD, Snyder-Mackler L, Reich T, Lindstedt SL. Eccentric Muscle Contractions: Their Contribution to Injury, Prevention, Rehabilitation, and Sport. J Orthop Sports Phys Ther. 2003;33(10):557-71.

360. Yeung SS, Yeung EW. Shift of Peak Torque Angle After Eccentric Exercise. Int J Sports Med. 2008;29(3):251-6.

361. Iga J, Fruer CS, Deighan M, Croix MDS, James DVB. ' Nordic' Hamstrings Exercise Engagement Characteristics and Training Responses. Int J Sports Med.

2012;33(12):1000-4.

362. Goode AP, Reiman MP, Harris L, Delisa L, Kauffman A, Beltramo D, et al. Eccentric training for prevention of hamstring injuries may depend on intervention compliance : a systematic review and meta-analysis. Br J Sports Med. 2015;49(6):349-56.

363. Brukner P, Nealon A, Morgan C, Burgess D, Dunn A. Recurrent hamstring muscle injury: Applying the limited evidence in the professional football setting with a seven-point programme. Br J Sports Med. 2014;48(11):929-38.

364. Mjolsnes R, Arnason A, Osthagen T, Raastad T, Bahr R. A 10-week randomized trial comparing eccentric vs. concentric hamstring strength training in well-trained soccer players. Scand J Med Sci Sport. 2004;14(5):311-7.

365. Askling C, Karlsson J, Thorstensson A. Hamstring injury occurrence in elite soccer players after preseason strength training with eccentric overload. Scand J Med Sci Sport. 2003; 13(4):244-50.

366. Al Attar WSA, Soomro N, Sinclair PJ, Pappas E, Sanders RH. Effect of Injury Prevention Programs that Include the Nordic Hamstring Exercise on Hamstring Injury Rates in Soccer Players: A Systematic Review and Meta-Analysis. Sport Med. 2017;47(5):907-16.

367. Sharifnezhad A, Marzilger R, Arampatzis A. Effects of load magnitude, muscle length and velocity during eccentric chronic loading on the longitudinal growth of the vastus lateralis muscle. J Exp Biol. 2014;217(15):2726-33.

368. Alonso-Fernandez D, Docampo-Blanco P, Martinez-Fernandez J. Changes in muscle architecture of biceps femoris induced by eccentric strength training with nordic hamstring exercise. Scand J Med Sci Sport. 2018;28(1):88-94.

369. Bourne MN, Duhig SJ, Timmins RG, Williams MD, Opar DA, Al Najjar A, et al. Impact of the Nordic hamstring and hip extension exercises on hamstring architecture and morphology: Implications for injury prevention. Br J Sports Med. 2017;51(5):469-77.

370. Guex K, Millet GP. Conceptual framework for strengthening exercises to prevent hamstring strains. Sport Med. 2013;43(12):1207-15.

371. Hauge Engebretsen A, Myklebust G, Holme I, Engebretsen L, Bahr R. Intrinsic Risk Factors for Hamstring Injuries Among Male Soccer Players: A Prospective Cohort Study. Am J Sports Med. 2010;38(6):1147-53.

372. Brughelli M, Cronin J. Altering the length-tension relationship with eccentric exercise: Implications for performance and injury. Sport Med. 2007;37(9):807-26. 
373. Brughelli M, Mendiguchia J, Nosaka K, Idoate F, Arcos AL, Cronin J. Effects of eccentric exercise on optimum length of the knee flexors and extensors during the preseason in professional soccer players. Phys Ther Sport. 2010;11(2):50-5.

374. Brockett CL, Morgan DL, Proske U. Predicting Hamstring strain Injury in Elite Athletes. Med Sci Sports Exerc. 2004;36(3):379-87.

375. Naczk M, Brzenczek-Owczarzak W, Arlet J, Naczk A, Adach Z. Training effectiveness of the inertial training and measurement system. J Hum Kinet. 2014;44(1):19-28.

376. Norrbrand L, Pozzo M, Tesch PA. Flywheel resistance training calls for greater eccentric muscle activation than weight training. Eur J Appl Physiol. 2010;110(5):997-1005.

377. Norrbrand L, Fluckey JD, Pozzo M, Tesch PA. Resistance training using eccentric overload induces early adaptations in skeletal muscle size. Eur J Appl Physiol. 2008;102(3):271-81.

378. Mosteiro-Muñoz F, Domínguez R. Effects of Inertial Overload Resistance Training on Muscle Function. Rev Int Med y Ciencias la Act Física y del Deport. 2017;17(68):757-73.

379. Prieto-Mondragón LDP, Camargo-Rojas DA, Quinceno CA. Isoinertial technology for rehabilitation and prevention of muscle injuries of soccer players: literature review. Rev la Fac Med. 2017;64(3):543-50.

380. de Hoyo M, Pozzo M, Sañudo B, Carrasco L, Gonzalo-Skok O, Domínguez-Cobo S, et al. Effects of a 10-week in-season eccentric-overload training program on muscle-injury prevention and performance in junior elite soccer players. Int J Sports Physiol Perform. 2015;10(1):46-52.

381. Tous-Fajardo J, Gonzalo-Skok O, Arjol-Serrano JL, Tesch P. Enhancing change-ofdirection speed in soccer players by functional inertial eccentric overload and vibration training. Int J Sports Physiol Perform. 2016;11(1):66-73.

382. de Hoyo M, Sañudo B, Carrasco L, Mateo-Cortes J, Domínguez-Cobo S, Fernandes O, et al. Effects of 10-week eccentric overload training on kinetic parameters during change of direction in football players. J Sports Sci. 2016;34(14):1380-7.

383. de Hoyo M, de la Torre A, Pradas F, Sañudo B, Carrasco L, Mateo-Cortes J, et al. Effects of eccentric overload bout on change of direction and performance in soccer players. Int J Sports Med. 2015;36(4):308-14.

384. Vázquez-Guerrero J, Moras G. Changes in muscular architecture and execution velocity during squats performed using the VersaPulley under stable and unstable conditions in Junior Elite Basketball players. Cuad Psicol del Deport. 2015;15(3):243-52.

385. Tyler TF, Nicholas SJ, Campbell RJ, Donellan S, Mchugh MP. The Effectiveness of a Preseason Exercise Program to Prevent Adductor Muscle Strains in Professional Ice Hockey Players. Am J Sports Med. 2002;30(5):680-3.

386. Lewis CL, Sahrmann SA, Moran DW. Anterior hip joint force increases with hip extension, decreased gluteal force, or decreased iliopsoas force. J Biomech. 2007;40(16):3725-31.

387. Neumann DA. Kinesiology of the Hip: A Focus on Muscular Actions. J Orthop Sports Phys Ther. 2010;40(2):82-94.

388. Hewett TE, Stroupe AL, Nance TA, Noyes FR. Plyometric training in female athletes: Decreased impact forces and increased hamstring torques. Am J Sports Med. 1996;24(6):765-73.

389. Lloyd DG, Buchanan TS. Strategies of muscular support of varus and valgus isometric loads at the human knee. J Biomech. 2001;34(10):1257-67.

390. Mendiguchia J, Ford KR, Quatman CE, Alentorn-geli E, Hewett TE. Sex Differences in Proximal Control of the Knee Joint. Sport Med. 2011;41(7):541-57.

391. Hides JA, Stanton WR. Can motor control training lower the risk of injury for professional football players? Med Sci Sports Exerc. 2014;46(4):762-8.

392. Sherry MA, Best TM. A Comparison of 2 Rehabilitation Programs in the Treatment of 
Acute Hamstring Strains. J Orthop Sports Phys Ther. 2004;34(3):116-25.

393. Hölmich P, Uhrskou P, Ulnits L, Kanstrup I, Bachmann Nielsen M, Bjerg AM.

Effectiveness of active physical training as treatment for long- standing adductor-related groin pain in athletes : randomised trial. Lancet. 1999;353(9151):439-43.

394. McGill SM. Low back stability: From formal description to issues for performance and rehabilitation. Exerc Sport Sci Rev. 2001;29(1):26-31.

395. Vera-Garcia FJ, Elvira JLL, Brown SHM, McGill SM. Effects of abdominal stabilization maneuvers on the control of spine motion and stability against sudden trunk perturbations. J Electromyogr Kinesiol. 2007;17(5):556-67.

396. Tayashiki K, Takai Y, Maeo S, Kanehisa H. Intra-abdominal Pressure and Trunk Muscular Activities during Abdominal Bracing and Hollowing. Int J Sports Med. 2015;37(2):134-43.

397. Grenier SG, McGill SM. Quantification of Lumbar Stability by Using 2 Different Abdominal Activation Strategies. Arch Phys Med Rehabil. 2007;88(1):54-62.

398. Kim D-W, Kim T-H. Effects of abdominal hollowing and abdominal bracing during sidelying hip abduction on the lateral rotation and muscle activity of the pelvis. $J$ Exerc Rehabil. 2018;14(2):226-30.

399. Hewett TE, Ford KR, Myer GD, Wanstrath K, Scheper M. Gender differences in hip adduction motion and torque during a single-leg agility maneuver. J Orthop Res. 2006;24(3):426-31.

400. Hewett TE, Lindenfeld TN, Riccobene J V, Noyes FR. The Effect of Neuromuscular Training on the Incidence of Knee Injury in Female Athletes: A Prospective Study. Am J Sports Med. 1999;27(6):699-706.

401. Mandelbaum BR, Silvers HJ, Watanabe DS, Knarr JF, Thomas SD, Griffin LY, et al. Effectiveness of a neuromuscular and proprioceptive training program in preventing anterior cruciate ligament injuries in female athletes: 2-Year follow-up. Am J Sports Med. 2005;33(7):1003-10.

402. Fowles JR. What I always wanted to know about instability training. Appl Physiol Nutr Metab. 2010;35(1):89-90.

403. Behm DG, Drinkwater EJ, Willardson JM, Cowley PM. The use of instability to train the core musculature. Appl Physiol Nutr Metab. 2010;35(1):91-108.

404. Marshall PW, Murphy BA. Core stability exercises on and off a Swiss ball. Arch Phys Med Rehabil. 2005;86(2):242-9.

405. Wahl MJ, Behm DG. Not all instability training devices enhance muscle activation in highly resistance-trained individuals. J Strength Cond Res. 2008;22(4):1360-70.

406. Cuğ M, Ak E, Özdemir RA, Korkusuz F, Behm DG. The effect of instability training on knee joint proprioception and core strength. J Sport Sci Med. 2012;11(3):468-74.

407. Mok NW, Yeung EW, Cho JC, Hui SC, Liu KC, Pang CH. Core muscle activity during suspension exercises. J Sci Med Sport. 2015;18(2):189-94.

408. Bacarin T de A, Sacco I de CN, Kageyama ERO, Yogi LS. Propriocepção na artroplastia total de joelho em idosos: uma revisão da literatura. Rev Fisioter Univ Säo Paulo. 2004;11(2):96-104.

409. Baltaci G, Kohl HW. Does Proprioceptive Training During Knee and Ankle Rehabilitation Improve Outcome? Phys Ther Rev. 2003;8(1):5-16.

410. Lizardo FB, Ronzani GM, Sousa LR, Silva DC de O, Santos LA dos, Lopes PR, et al. Proprioceptive exercise with bosu maximizes electromyographic activity of the ankle muscles. Biosci J. 2017;33(3):754-62.

411. Caraffa A, Cerulli G, Projetti M, Aisa G, Rizzo A. Prevention of anterior cruciate ligament injuries in soccer: A prospective controlled study of proprioceptive training. Knee Surgery, Sport Traumatol Arthrosc. 1996;4(1):19-21.

412. Patel DR, Stier B, Luckstead EF. Major international sport profiles. Pediatr Clin North 
Am. 2002;49(4):769-92.

413. Tropp H, Askling C, Gillquist J. Prevention of ankle sprains. Am J Sports Med. 1985;13(4):259-62.

414. Tropp H, Ekstrand J, Gillquist J. Stabilometry in functional instability of the ankle and its value in predicting injury. Med Sci Sports Exerc. 1984;16(1):64-6.

415. Mohammadi F. Comparison of 3 Preventive Methods to Reduce the Recurrence of Ankle Inversion Sprains in Male Soccer Players. Am J Sports Med. 2007;35(6):922-6.

416. Malliou P, Gioftsidou A, Pafis G, Beneka A, Godolias G. Proprioceptive training (balance exercises) reduces lower extremity injuries in young soccer players. J Back Musculoskelet Rehabil. 2004;17(3-4):101-4.

417. Engstrom BKO, Renstrom PAFH. How can injuries be prevented in the world cup soccer athlete? Clin Sports Med. 1998;17(4):755-68.

418. Laudner KG, Koschnitzky MM. Ankle muscle activation when using the both sides utilized (BOSU) balance trainer. J Strength Cond Res. 2010;24(1):218-22.

419. Witvrouw E, Danneels L, Asselman P, D'Have T, Cambier D. Muscle flexibility as a risk factor for developing muscle injuries in male professional soccer players: A prospective study. Am J Sports Med. 2003;31(1):41-6.

420. Bazett-Jones DM. Effect of Potentiation and Stretching on Maximal Force, Rate of Force Development, and Range of Motion. J Strength Cond Res. 2005;19(2):421-6.

421. Thacker SB, Gilchrist J, Stroup DF, Kimsey CD. The impact of stretching on sports injury risk: a systematic review of the literature. Med Sci Sports Exerc. 2004;36(3):371-8.

422. Lewis J. A systematic literature review of the relationship between stretching and athletic injury prevention. Orthop Nurs. 2014;33(6):312-20.

423. Sands WA, McNeal JR, Murray SR, Ramsey MW, Sato K, Mizuguchi S, et al. Stretching and its effects on recovery: A review. Strength Cond J. 2013;35(5):30-6.

424. Jemni M, Mkaouer B, Marina M, Asllani A, Sands WA. Acute static vibration-induced stretching enhanced muscle viscoelasticity but did not affect maximal voluntary contractions in footballers. J Strength Cond Res. 2014;28(11):3105-14.

425. Wong P-L, Lau PWC, Mao de W, Wu YY, Behm DG, Ulrik W. Three days of static stretching within a warm-up does not affect repeated-sprint ability in youth soccer players. J Strength Cond Res. 2011;25(3):838-45.

426. Simic L, Sarabon N, Markovic G. Does pre-exercise static stretching inhibit maximal muscular performance? A meta-analytical review. Scand J Med Sci Sport. 2013;23(2):131-48.

427. Sale DG. Postactivation potentiation: Role in performance. Exerc Sport Sci Rev. 2002;30(3):138-43.

428. Kinser AM, Ramsey MW, OBryant HS, Ayres CA, Sands WA, Stone MH. Vibration and stretching effects on flexibility and explosive strength in young gymnasts. Med Sci Sports Exerc. 2008;40(1):133-40.

429. Osawa Y, Oguma Y. Effects of vibration on flexibility: A meta-analysis. J Musculoskelet Neuronal Interact. 2013;13(4):442-53.

430. Rodrigues SA, Rabelo AS, Couto BP, Motta-Santos D, Drummond MDM, Gonçalves R, et al. Acute effects of single bout of stretching exercise and mechanical vibration in hamstring muscle. J Exerc Physiol Online. 2017;20(4):46-57.

431. Chinn L, Peer KS, Miller L. The effects of local vibration on balance, power, and selfreported pain following exercise. J Sport Rehabil. 2017;26(3):193-201.

432. George D, George P, Vasillis M. The effect of four-week interrupted intervention WholeBody Vibration program on hamstring's flexibility. J Phys Educ Sport. 2013;13(4):51721.

433. Szafraniec R, Chromik K, Poborska A, Kawczynski A. Acute effects of contract-relax proprioceptive neuromuscular facilitation stretching of hip abductors and adductors on 
dynamic balance. PeerJ. 2018;2018(12):1-12.

434. Balle SS, Magnusson SP, McHugh MP. Effects of contract-relax vs static stretching on stretch-induced strength loss and length - tension relationship. Scand J Med Sci Sport. 2015;25(6):764-9.

435. Kay AD, Husbands-Beasley J, Blazevich AJ. Effects of Contract-Relax, Static Stretching, and Isometric Contractions on Muscle-Tendon Mechanics. Med Sci Sports Exerc. 2015;47(10):2181-90.

436. Borges MO, Medeiros DM, Minotto BB, Lima CS. Comparison between static stretching and proprioceptive neuromuscular facilitation on hamstring flexibility: systematic review and meta-analysis. Eur J Physiother. 2018;20(1):12-9.

437. Cayco CS, Labro A V., Gorgon EJR. Hold-relax and contract-relax stretching for hamstrings flexibility: A systematic review with meta-analysis. Phys Ther Sport. 2019;35:42-55.

438. Kay AD, Dods S, Blazevich AJ. Acute effects of contract - relax (CR) stretch versus a modified CR technique. Eur J Appl Physiol. 2016;116(3):611-21.

439. Valenza MC, Torres-Sánchez I, Cabrera-Martos I, Valenza-Demet G, Cano-Cappellacci M. Acute effects of contract-relax stretching vs. TENS in young subjects with anterior knee pain: A randomized controlled trial. J Strength Cond Res. 2016;30(8):2271-8.

440. Slysz J, Stultz J, Burr JF. The efficacy of blood flow restricted exercise: A systematic review and meta-analysis. J Sci Med Sport. 2016;19(8):669-75.

441. Hwang PS, Willoughby DS. Mechanisms behind blood flow-restricted training and its effect toward muscle growth. J Strength Cond Res. 2019;33(7):167-79.

442. Loenneke JP, Fahs CA, Rossow LM, Sherk VD, Thiebaud RS, Abe T, et al. Effects of cuff width on arterial occlusion: Implications for blood flow restricted exercise. Eur $\mathbf{J}$ Appl Physiol. 2012;112(8):2903-12.

443. Yasuda T, Fukumura K, Fukuda T, Iida H, Imuta H, Sato Y, et al. Effects of low-intensity, elastic band resistance exercise combined with blood flow restriction on muscle activation. Scand J Med Sci Sport. 2014;24(1):55-61.

444. Scott BR, Loenneke JP, Slattery KM, Dascombe BJ. Blood flow restricted exercise for athletes: A review of available evidence. J Sci Med Sport. 2016;19(5):360-7.

445. Yasuda T, Loenneke JP, Thiebaud RS, Abe T. Effects of blood flow restricted lowintensity concentric or eccentric training on muscle size and strength. PLoS One. 2012;7(12):1-7.

446. Martín-Hernández J, Marín PJ, Menéndez H, Ferrero C, Loenneke JP, Herrero AJ. Muscular adaptations after two different volumes of blood flow-restricted training. Scand J Med Sci Sport. 2013;23(2):114-20.

447. Cook SB, Murphy BG, Labarbera KE. Neuromuscular function after a bout of low-load blood flow-restricted exercise. Med Sci Sports Exerc. 2013;45(1):67-74.

448. Cook SB, Scott BR, Hayes KL, Murphy BG. Neuromuscular adaptations to low-load blood flow restricted resistance training. J Sport Sci Med. 2018;17(1):66-73.

449. Sieljacks P, Degn R, Hollaender K, Wernbom M, Vissing K. Non-failure blood flow restricted exercise induces similar muscle adaptations and less discomfort than failure protocols. Scand J Med Sci Sport. 2019;29(3):336-47.

450. Hodeaux K. The Effect of Floss Bands on Elbow Range of Motion in Tennis Players. Theses Diss. 2017;

451. Driller MW, Overmayer RG. The effects of tissue flossing on ankle range of motion and jump performance. Phys Ther Sport. 2017;25:20-4.

452. Driller M, Mackay K, Mills B, Tavares F. Tissue flossing on ankle range of motion, jump and sprint performance: A follow-up study. Phys Ther Sport. 2017;28:29-33.

453. Mills B, Mayo B, Tavares F, Driller M. The effect of tissue flossing on ankle range of motion, jump and sprinting performance in elite rugby union athletes. J Sport Rehabil. 
2019;1-18.

454. Takarada Y, Nakamura Y, Aruga S, Onda T, Miyazaki S, Ishii N. Rapid increase in plasma growth hormone after low-intensity resistance exercise with vascular occlusion. $\mathrm{J}$ Appl Physiol. 2000;88(1):61-5.

455. Kiefer BN, Lemarr KE, Enriquez CC, Tivener KA. A pilot study: Psychological effects of the voodoo floss band on glenohumeral flexibility. Int J Athl Ther Train. 2017;22(4):2933.

456. Kibler W Ben, Sciascia A, Thomas SJ. Glenohumeral internal rotation deficit: Pathogenesis and response to acute throwing. Sports Med Arthrosc. 2012;20(1):34-8.

457. Laudner KG, Sipes RC, Wilson JT. The acute effects of sleeper stretches on shoulder range of motion. J Athl Train. 2008;43(4):359-63.

458. McClure P, Balaicuis J, Heiland D, Broersma ME, Thorndike CK, Wood A. A randomized controlled comparison of stretching procedures for posterior shoulder tightness. J Orthop Sports Phys Ther. 2007;37(3):108-14.

459. Manske RC, Meschke M, Porter A, Smith B, Reiman M. A randomized controlled singleblinded comparison of stretching versus stretching and joint mobilization for posterior shoulder tightness measured by internal rotation motion loss. Sports Health. 2010;2(2):94-100.

460. Kibler W Ben, Ludewig PM, Mcclure PW, Michener LA, Bak K, Sciascia AD. Clinical implications of scapular dyskinesis in shoulder injury: the 2013 consensus statement from the 'scapular summit.' Br J Sports Med. 2013;47(14):877-85.

461. Gabbett TJ. The training-injury prevention paradox: Should athletes be training smarter and harder? Br J Sports Med. 2016;50(5):273-80.

462. Gabbett TJ, Domrow N. Risk factors for injury in subelite rugby league players. Am J Sports Med. 2005;33(3):428-34.

463. Hulin BT, Gabbett TJ, Lawson DW, Caputi P, Sampson JA. The Acute: Chronic workload ratio predicts injury: High chronic workload may decrease injury risk in elite rugby league players. Br J Sports Med. 2016;50(4):231-6.

464. Bowen L, Gross AS, Gimpel M, Li FX. Accumulated workloads and the acute: Chronic workload ratio relate to injury risk in elite youth football players. Br J Sports Med. 2017;51(5):452-9.

465. Chambers R, Gabbett TJ, Cole MH, Beard A. The Use of Wearable Microsensors to Quantify Sport-Specific Movements. Sport Med. 2015;45(7):1065-81.

466. Borg G, Hassmén P, Lagerström M. Perceived exertion related to heart rate and blood lactate during arm and leg exercise. Eur J Appl Physiol Occup Physiol. 1987;56(6):67985 .

467. Impellizzeri FM, Rampinini E, Coutts AJ, Sassi A, Marcora SM. Use of RPE-based training load in soccer. Med Sci Sports Exerc. 2004;36(6):1042-7.

468. Bourdon PC, Cardinale M, Murray A, Gastin P, Kellmann M, Varley MC, et al. Monitoring athlete training loads: Consensus statement. Int J Sports Physiol Perform. 2017;12(Suppl 2):161-70.

469. Foster C, Florhaug JA, Franklin J, Gottschall L, Hrovatin LA, Parker S, et al. A new approach to monitoring exercise training. J Strength Cond Res. 2001;15(1):109-15.

470. Blanch P, Gabbett TJ. Has the athlete trained enough to return to play safely? The acute:chronic workload ratio permits clinicians to quantify a player's risk of subsequent injury. Br J Sports Med. 2016;50(8):471-5.

471. Marqués-Jiménez D, Calleja-González J, Arratibel I, Delextrat A, Terrados N. Fatigue and Recovery in Soccer: Evidence and Challenges. Open Sports Sci J. 2017;10(1):52-70.

472. Nédélec M, McCall A, Carling C, Legall F, Berthoin S, Dupont G. Recovery in Soccer: Part I-Post-Match fatigue and time course of recovery. Sport Med. 2012;42(12):997-1015.

473. Calleja-González J, Mielgo-Ayuso J, Sampaio J, Delextrat A, Ostojic SM, Marques- 
Jiménez D, et al. Brief ideas about evidence-based recovery in team sports. J Exerc Rehabil. 2018;14(4):545-50.

474. Tomlin DL, Wenger HA. The relationship between aerobic fitness and recovery from high intensity intermittent exercise. Sport Med. 2001;31(1):1-11.

475. Pastre CM, Bastos F do N, Netto Júnior J, Vanderlei LCM, Hoshi RA. Post-exercise recovery methods: A systematic review. Rev Bras Med do Esporte. 2009;15(2):138-44.

476. Cochrane DJ. Alternating hot and cold water immersion for athlete recovery: A review. Phys Ther Sport. 2004;5(1):26-32.

477. Nédélec M, McCall A, Carling C, Legall F, Berthoin S, Dupont G. Recovery in soccer: Part II-Recovery strategies. Sport Med. 2013;43(1):9-22.

478. Poppendieck W, Faude O, Wegmann M, Meyer T. Cooling and performance recovery of trained athletes: A meta-analytical review. Int J Sports Physiol Perform. 2013;8(3):22742.

479. Murray A, Cardinale M. Cold applications for recovery in adolescent athletes: A systematic review and meta analysis. Extrem Physiol Med. 2015;4(1):1-15.

480. Reilly T, Ekblom B. The use of recovery methods post-exercise. J Sports Sci. 2005;23(6):619-27.

481. Herbert RD, de Noronha M, Kamper SJ. Stretching to prevent or reduce muscle soreness after exercise. Cochrane Database Syst Rev. 2011;(7).

482. Calleja-González J. Paradigm for the recovery in team sports. Arch Med del Deport. 2017;34(3):126-7.

483. Mckenney K, Elder AS, Elder C, Hutchins A. Myofascial Release as a Treatment for Orthopaedic Conditions: A Systematic Review. J Athl Train. 2013;48(4):522-7.

484. Beardsley C, Škarabot J. Effects of self-myofascial release: A systematic review. J Bodyw Mov Ther. 2015;19(4):747-58.

485. Schleip R, Jäger H, Klingler W. What is 'fascia'? A review of different nomenclatures. J Bodyw Mov Ther. 2012;16(4):496-502.

486. de Souza A, Sanchotene CG, da Silva Lopes CM, Beck JA, da Silva ACK, Pereira SM, et al. Acute Effect of Two Self-Myofascial Release Protocols on Hip and Ankle Range of Motion. J Sport Rehabil. 2019;28(2):159-64.

487. Macdonald GZ, Penney MDH, Mullaley ME, Cuconato AL, Drake CDJ, Behm DG, et al. An acute bout of self-myofascial release increases range of motion without a subsequent decrease in muscle activation or force. J Strength Cond Res. 2013;27(3):812-21.

488. Schroeder AN, Best TM. Is Self Myofascial Release an Effective Preexercise and Recovery Strategy? A Literature Review. Curr Sports Med Rep. 2015;14(3):200-8.

489. Mohr AR, Long BC, Goad CL. Effect of Foam Rolling and Static Stretching on Passive Hip-Flexion Range of Motion. J Sport Rehabil. 2014;23(4):296-9.

490. Cheatham SW, Stull KR. Comparison of a foam rolling session with active joint motion and without joint motion: A randomized controlled trial. J Bodyw Mov Ther. 2018;22(3):707-12.

491. Macdonald GZ, Button DC, Drinkwater EJ, Behm DG. Foam rolling as a recovery tool after an intense bout of physical activity. Med Sci Sports Exerc. 2014;46(1):131-42.

492. Cheung K, Hume PA, Maxwell L. Delayed onset muscle soreness: Treatment Strategies and Performance Factors. Sport Med. 2003;33(2):145-64.

493. Monteiro ER, Vigotsky A, Śkarabot J, Brown AF, Ferreira de Melo Fiuza AG, Gomes $\mathrm{TM}$, et al. Acute effects of different foam rolling volumes in the interset rest period on maximum repetition performance. Hong Kong Physiother J. 2017;36(1):57-62.

494. Curran PF, Fiore RD, Crisco JJ. A Comparison of the Pressure Exerted on Soft Tissue by 2 Myofascial Rollers. J Sport Rehabil. 2008;17(4):432-42.

495. Behara B, Jacobson BH. The Acute Effects of Deep Tissue Foam Rolling and Dynamic Stretching on Muscular Strength, Power, and Flexibility in Division I Linemen. J Strength 
Cond Res. 2017;31(4):888-92.

496. DeBruyne DM, Dewhurst MM, Fischer KM, Wojtanowski MS, Durall C. Self-

Mobilization Using a Foam Roller Versus a Roller Massager: Which Is More Effective for Increasing Hamstrings Flexibility? J Sport Rehabil. 2017;26(1):94-100.

497. García-Gutiérrez MT, Guillén-Rogel P, Cochrane DJ, Marín PJ. Cross transfer acute effects of foam rolling with vibration on ankle dorsiflexion range of motion. J Musculoskelet Neuronal Interact. 2018;18(2):262-7.

498. Cochrane DJ. Effectiveness of using wearable vibration therapy to alleviate muscle soreness. Eur J Appl Physiol. 2017;117(3):501-9.

499. Rittweger J. Vibration as an exercise modality: How it may work, and what its potential might be. Eur J Appl Physiol. 2010;108(5):877-904.

500. Cheatham SW, Stull KR, Kolber MJ. Comparison of a vibrating foam roller and a nonvibrating foam roller intervention on knee range of motion and pressure pain threshold: A randomized controlled trial. J Sport Rehabil. 2019;28(1):39-45.

501. Lim J-H, Park C-B. The immediate effects of foam roller with vibration on hamstring flexibility and jump performance in healthy adults. J Exerc Rehabil. 2019;15(1):50-4.

502. Nederhof E, Brink MS, Lemmink KAP. Reliability and validity of the Dutch Recovery Stress Questionnaire for athletes. Int J Sport Psychol. 2008;39(4):301-11.

503. Gastin PB, Meyer D, Robinson D. Perceptions of Wellness to monitor adaptative responses to training and competition in elite australian football. J Strength Cond Res. 2013;27(9):2518-26.

504. Mclean BD, Coutts AJ, Kelly V, Mcguigan MR, Cormack SJ. Neuromuscular, Endocrine, and Perceptual Fatigue Responses During Different Length Between-Match Microcycles in Professional Rugby League Players. Int J Sports Physiol Perform. 2010;5(3):367-83.

505. Park CK, Zlomislic V, Du J, Huang BK, Chang EY, Chang DG. Nonoperative Management of a Severe Proximal Rectus Femoris Musculotendinous Injury in a Recreational Athlete: A Case Report. PM R. 2018;10(12):1417-21.

506. Orchard J, Best TM, Verrall GM. Return to play following muscle strains. Clin J Sport Med. 2005;15(6):436-41.

507. Blackburn TA, W.D M, White B. Electromyographic analysis of posterior rotator cuff exercises. J Athl Train. 1990;25:40-5.

508. Seo SH, Jeon IH, Cho YH, Lee HG, Hwang YT, Jang JH. Surface EMG during the pushup plus exercise on a stable support or Swiss ball: Scapular stabilizer muscle exercise. J Phys Ther Sci. 2013;25(7):833-7.

509. Yoo WG. Effect of the dual-wall pushup plus exercise in patients with scapular dyskinesis with a winged or tipped scapula. J Phys Ther Sci. 2015;27(8):2661-2.

510. Tarantino F. Entrenamiento Propioceptivo. Principios en el diseño de ejercicios y guías prácticas. Panamericana EM, editor. Madrid; 2017. p. 178.

511. Conde J. Apuntes del Máster Propio en Entrenamiento Personal (6 $6^{\mathrm{a}}$ Edición): El control neuromuscular. El entrenamiento del sistema sensoriomotor. 2017.

512. Kavcic N, Grenier S, McGill SM. Determining the stabilizing role of individual torso muscles during rehabilitation exercises. Spine (Phila Pa 1976). 2004;29(11):1254-65.

513. Dębski P, Białas E, Gnat R. The parameters of foam rolling, self-myofascial release treatment: A review of the literature. Biomed Hum Kinet. 2019;11(1):36-46.

514. Kreutzer R, Stechmann K, Eggers H, Kolster BC. Flossing. Técnicas de aplicación de las bandas compresivas. Paidotribo. Badalona; 2018. 104 p.

515. Bennassar I. Apuntes del Máster Propio en Entrenamiento Personal ( $6^{\mathrm{a}}$ Edición): Prevención de Disfunciones de Movimiento en la región Coxolumbopélvica. Paradigmas y Modelos. 2017.

516. Selkowitz DM, Beneck GJ, Powers CM. Which exercises target the gluteal muscles while minimizing activation of the tensor fascia lata? Electromyographic assessment using fine- 
wire electrodes. J Orthop Sports Phys Ther. 2013;43(2):54-64.

517. Fernandez-Gonzalo R, Lundberg TR, Alvarez-Alvarez L, De Paz JA. Muscle damage responses and adaptations to eccentric-overload resistance exercise in men and women. Eur J Appl Physiol. 2014;114(5):1075-84.

518. Seirul-lo Vargas F, Tous Fajardo J, Moras Feliu G, Jorge Vizuete J, Sole i Fortó J, Serrés Lara R, et al. El entrenamiento en los deportes de equipo. Autor Edit. Barcelona; 2017. $435 \mathrm{p}$.

519. Moras Feliu G. Apuntes del Máster Propio en Entrenamiento Personal ( $6^{\mathrm{a}}$ Edición): Planificación y diseño de programas de entrenamiento a través de los niveles de aproximación. 2017.

520. Makris EA, Hadidi P, Athanasiou KA. The knee meniscus: structure-function, pathophysiology, current repair techniques, and prospects for regeneration. Biomaterials. 2011;32(30):7411-31.

521. Astur DC, Xerez M, Rozas J, Debieux PV, Franciozi EC, Cohen M. Lesões do ligamento cruzado anterior e do menisco no esporte : incidência, tempo de prática até a lesão e limitações causadas pelo trauma. Rev Bras Ortop. 2016;51(6,1):652-6.

522. Greis PE, Bardana DD, Holmstrom MC, Burks RT. Meniscal injury : I . Basic science and evaluation. J Am Acad Orthop Surg. 2002;10(3):168-76.

523. Kvist J. Rehabilitation following anterior cruciate ligament injury. Current recommendations for sports participation. Sport Med. 2004;34(4):269-80.

524. van Dyk N, Bahr R, Whiteley R, Tol JL, Kumar BD, Hamilton B, et al. Hamstring and Quadriceps Isokinetic Strength Deficits Are Weak Risk Factors for Hamstring Strain Injuries: A 4-Year Cohort Study. Am J Sports Med. 2016;44(7,1):1789-95.

525. Bakken A, Targett S, Bere T, Eirale C, Farooq A, Mosler AB, et al. Muscle Strength Is a Poor Screening Test for Predicting Lower Extremity Injuries in Professional Male Soccer Players: A 2-Year Prospective Cohort Study. Am J Sports Med. 2018;46(6):1481-91.

526. Bennell K, Wajswelner H, Lew P, Schall-Riaucour A, Leslie S, Plant D, et al. Isokinetic strength testing does not predict hamstring injury in Australian Rules footballers. Br J Sports Med. 1998;32(4):309-14.

527. Graham-Smith P, Jones PA, Comfort P, Munro AG. Assessment of knee flexor and extensor muscle balance. Int J Athl Ther Train. 2013;18(5):1-5.

528. Lee J, Mok K, Chan H, Yung P, Chan K. Eccentric hamstring strength deficit and poor hamstring-to-quadriceps ratio are risk factors for hamstring strain injury in football: A prospective study of 146 professional players. J Sci Med Sport. 2018;21(8):789-93.

529. Pincivero DM, Lephart SM, Karunakara RA. Reliability and precision of isokinetic strength and muscular endurance for the quadriceps and hamstrings. Int J Sports Med. 1997;18(2):113-7.

530. Gonzalo-Skok O, Tous-Fajardo J, Valero-Campo C, Berzosa C, Bataller AV, ArjolSerrano JL, et al. Eccentric-overload training in team-sport functional performance: Constant bilateral vertical versus variable unilateral multidirectional movements. Int J Sports Physiol Perform. 2017;12(7):951-8. 